\title{
Artealización y Ecología: Un Cronograma de Paisajes Productivos Sostenibles
}

Tesis Doctoral 


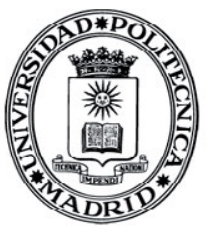

UNIVERSIDAD POLITÉCNICA DE MADRID

Tribunal nombrado por el Magfco. y Excmo. Sr. Rector de la Universidad Politécnica de Madrid el día de de 2018

Presidente:

Secretario:

Vocal:

Vocal:

Vocal:

Suplente:

Suplente:

Realizada la defensa y lectura de Tesis el día de de 2018 en la Escuela Técnica Superior de Arquitectura de Madrid

EL PRESIDENTE

LOS VOCALES

EL SECRETARIO 


\section{INDICE}

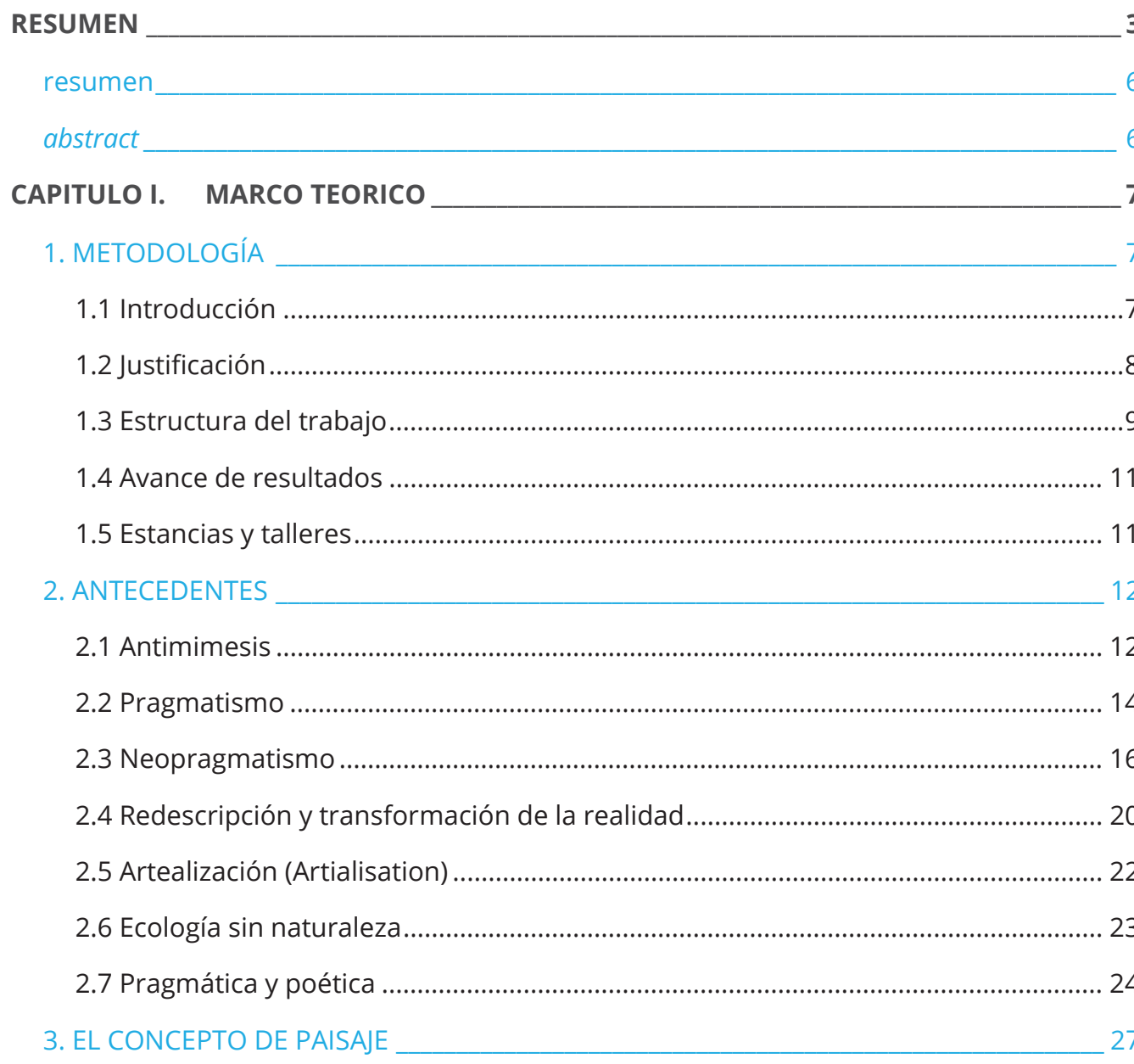

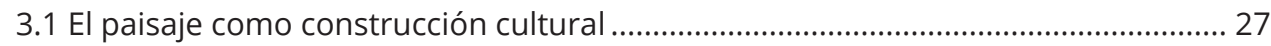

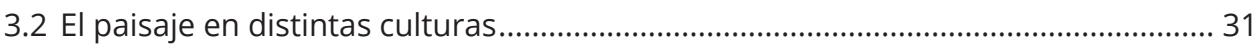

4. REDESCRIPCIONES Y ARTEALIZACIONES __ 34

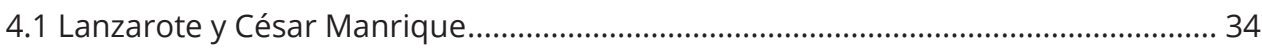

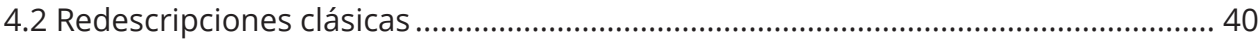

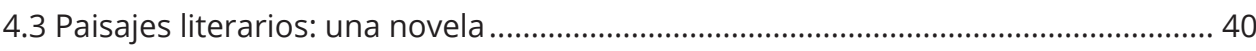

CAPITULO II. HACIA UNA ECOLOGIA__ 43

1. INTRODUCCION _ 43

2. FASES $\quad 44$

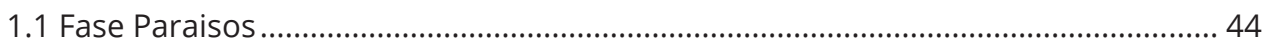

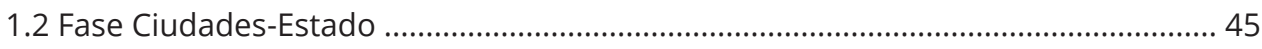

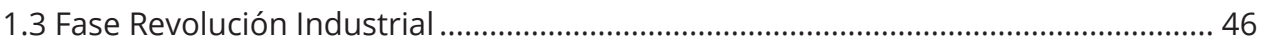

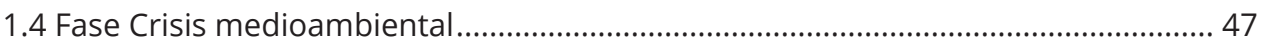

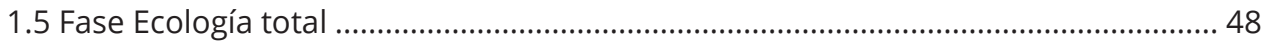


1. Ecosistemas Gestionados / Managed Ecosystems ___ 49

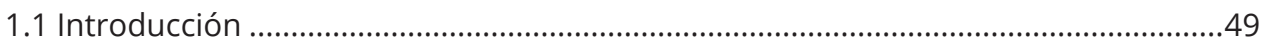

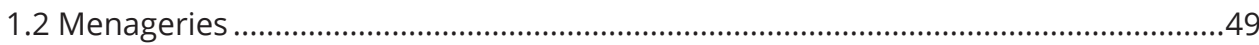

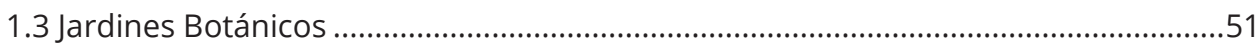

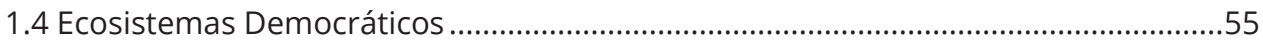

2. Jardinería Productiva / Productive Gardening ___ 60

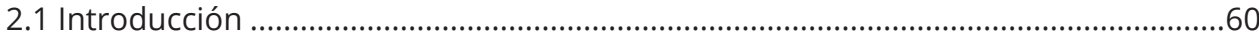

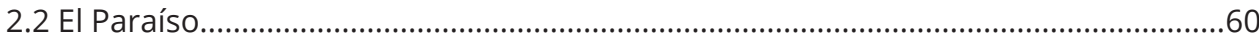

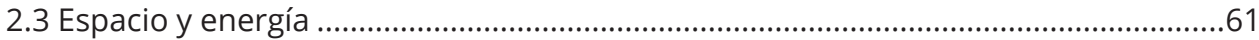

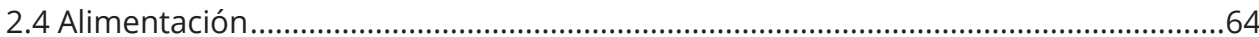

3. Escalas de la Agricultura y Territorio/ Rescaling Agriculture and Land___ 66

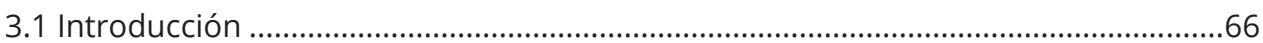

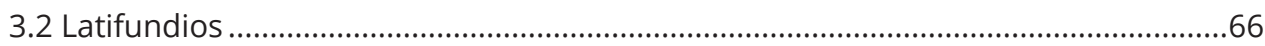

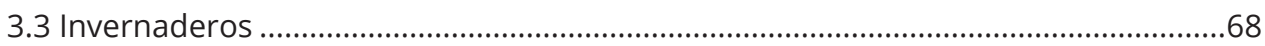

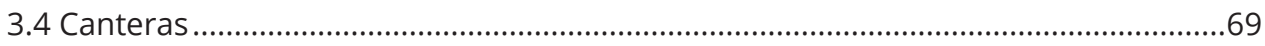

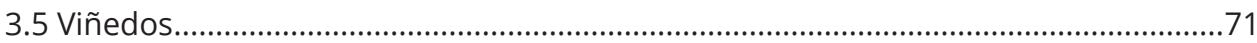

4. Digestiones Pesadas / Heavy Digestions __ 73

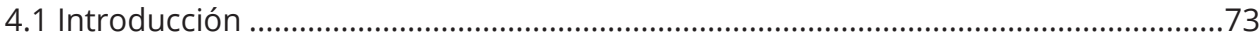

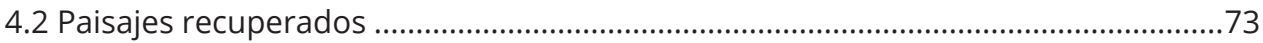

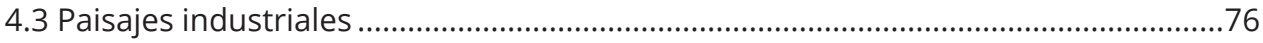

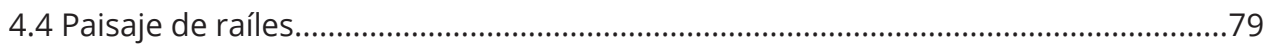

5. Gestión de Residuos / Waste Management ___ 82

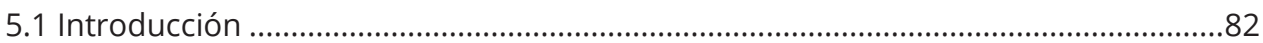

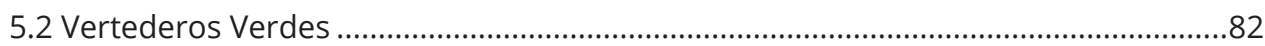

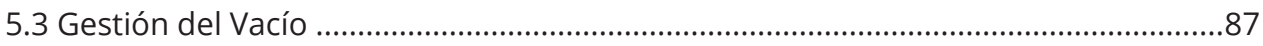

6. Residuos Inertes / Waste Mining ___ 88

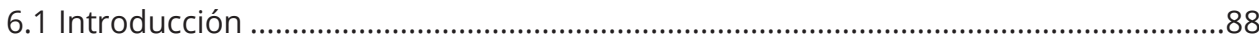

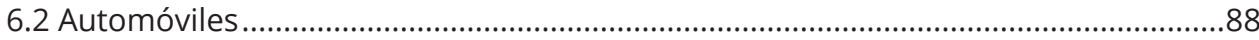

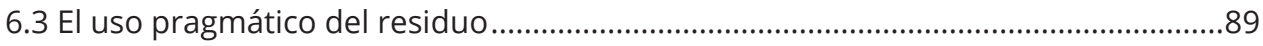

7. Limpieza de Agua / Water Filtration __ 92

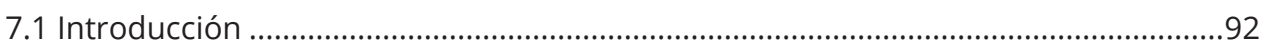

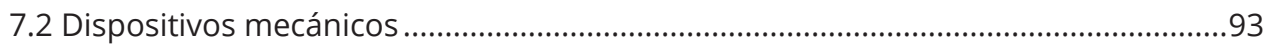

7.3 Humedales y purificación natural ...........................................................................94

8. Captación de Agua / Water Harvesting___ 99 


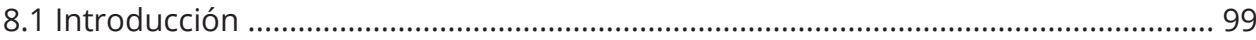

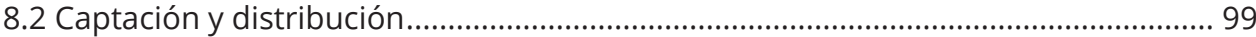

8.3 La arquitectura de los depósitos de agua............................................................... 101

9. Paisajes, Mécanica y Energía / Mechanics, Landscape and Energy___ 104

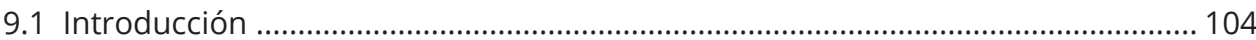

9.2 Los Paisajes del Viento ......................................................................................... 111

10. Infraestructuras / Infrastructures ___ 118

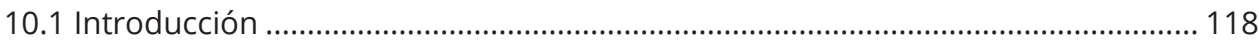

10.2 Infraestructuras milenarias .................................................................................... 118

10.3 Revolución Industrial.............................................................................................. 119

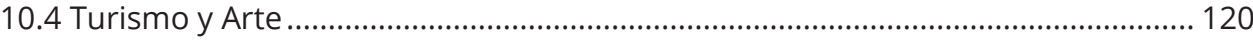

11. Almacenamiento y barreras de energía / Storage and Energy Barriers___ 128

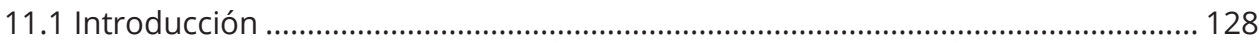

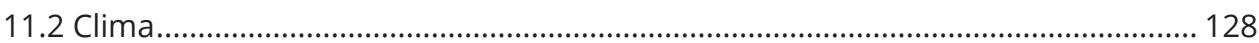

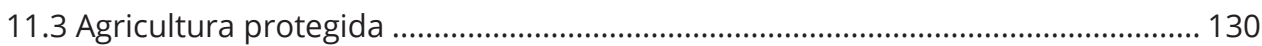

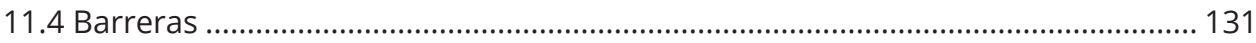

CAPÍTULO IV. CONCLUSIONES__ 136

1. Conclusiones__ 136

2. Consideraciones finales ___ 138

Conclusions _ 138

Final considerations __ 140

BIBLIOGRAFÍA _ 141

BIBLIOGRAFÍA BÁSICA _ 141

BIBLIOGRAFÍA CONSULTADA _ _ 142

DATOS DE CONTACTO 


\section{resumen}

Con el objetivo último de conseguir que el paisaje de la producción sostenible sea deseable, la primera parte de este trabajo estudia las teorías que explican el surgimiento de la idea de paisaje, la construcción cultural de la idea de belleza, y las herramientas para aplicar visiones poéticas a territorios de lo pragmático.

Los procesos de artealización in visu y artealización in situ descritos por Alain Roger para entender la idea de paisaje según su definición clásica, pueden extrapolarse a otros contextos para propiciar el surgimiento de nuevos paisajes deseables.

El cuerpo principal de este trabajo es catalogación de los paisajes productivos contemporáneos y de los paisajes necesarios ante la triple crisis actual (ambiental, energética, financiera), en un estudio en forma de cronograma de las correspondientes intervenciones de artealización. Un recorrido a lo largo y a través de este cronograma nos permite aceptarlos como algo necesario, preexistente $y$, finalmente, deseable.

\section{abstract}

With the ultimate goal of ensuring that the landscape of sustainable production is considered beautiful, the first part of this thesis studies the theories that explain the emergence of the idea of landscape, the cultural construction of the idea of beauty, and the tools to implement poetic visions onto territories of the pragmatic.

Artealization processes, as described by Alain Roger to understand the emergence of the idea of landscape according to its classical definition, can be extrapolated to other contexts and actively implemented to foster the emergence of new desirable landscapes.

The main body of this work is a catalogue of artealisations of productive landscapes, as made necessary by the the current triple crisis (environment, energy, finance), in the form of a chronological time-field study. Reading through and across this chronogram will help us accept them as necessary, precedented and, ultimately, desirable. 


\section{CAPITULO I. MARCO TEORICO}

\section{METODOLOGÍA}

\subsection{Introducción}

Queremos explorar el potencial de los paisajes productivos sostenibles para construir una nueva cultura de la sostenibilidad y proporcionar las herramientas de implementación en proyectos concretos,

Esa nueva cultura necesita

-un lenguaje, que articule en paisaje los dispositivos y campos productivos -una red de prácticas, que asegure el uso cotidiano de ese lenguaje -una identidad comunicable, que posicione al observador ante el paisaje creado Nuestro objetivo estrategico es conseguir que el paisaje de la producción sostenible sea hermoso a través de una redescripción; que pueda identificarse como paisaje deseable.

Consideramos importante partir de un análisis de los elementos prestigiadores de un paisaje, que lo convierten en algo percibido como bello por la sociedad. Nuestro trabajo describiría procesos que permitan un transvase de elementos prestigiadores hacia los paisajes productivos provocando una transformación del fenómeno NIMBY (not in my back yard) en un fenómeno PIMFY (please in my front yard).

Los cronogramas que constituyen el cuerpo principal de esta investigación, junto con las fichas que describen cada item incluido en los mismos, nos permitiran contemplar los paisajes productivos sostenibles como parte de un paisaje cultural ya establecido.

Además de valorarse por sus positivas consecuencias ecológicas, económicas y culturales, los paisajes productivos serían un instrumento de empuje para la región donde se promuevan estas intervenciones; es decir una herramienta clave para la creación de la identidad social y nacional, como señala Mitchell en Landscape and Power ${ }^{1}$.

${ }^{1}$ MITCHELL, W.J.T. (2004) Landscape and Power. ISBN 0-226-53207-0 


\subsection{Justificación}

En la etapa post-industrial iniciada en los años ochenta ya se había desarrollado un debate político y cultural sobre el paisaje, incitado por agentes con intereses tan dispares como los de los movimientos ecologistas en un extremo, y los artistas y teóricos del llamado Land Art en otro. La crisis en que terminó aquella década modificó las agendas políticas dejando el debate sin resolver, pero ya había emergido la conciencia de un paisaje alterado, así como la posibilidad de intervenir activamente en su transformación como objeto cultural.

En el momento actual, un conjunto de factores igualmente diversos nos urgen a adoptar una estrategia innovadora que sea capaz de dar sentido a esos paisajes alterados, que en el último ciclo económico han sufrido una de las mayores transformaciones de su historia, hasta llegar a la definición del Antropoceno como la actual Era Geológica. ${ }^{2}$

La triple crisis de nuestros días obliga a repensar nuestra relación con la producción. La crisis medioambiental obliga a introducir nuevos elementos en el paisaje cotidiano, desde los dispositivos para la generación de energía de fuentes renovables hasta los de producción en cercanía para reducir la huella ecológica de los transportes, pasando por la actualización e integración de los protocolos de procesado de residuos y tratamiento de aguas. Las sucesivas crisis del petróleo inciden también en la creciente presencia de las energías renovables en el paisaje y la transformación de los criterios de transporte. Las crisis financieras y los vaivenes de los mercados internacionales se traducen en un número de procesos interrumpidos de transformación del territorio en distintos puntos del planeta, lo cual es quizá tan grave como la situación de la mayoría de los procesos que sí consiguieron salir adelante en la última década, guiados por agendas mercantiles de corto plazo.

Todos estos factores definen un importante cambio en las agendas ambiental, política y económica, pero es importante añadir que hemos detectado cambios equivalentes en la agenda sociocultural, relacionados íntimamente con aquellos. Tanto en la sociedad en general como en los distintos colectivos de creadores se observa un creciente compromiso con la construcción de una cultura de la sostenibilidad.

${ }^{2}$ CRUTZEN, P. J. y STOERMER, E. F. (2000). The 'Anthropocene'. Global Change Newsletter 
En este contexto abrimos la presente investigación bajo el nombre inicial de Paisajes Productivos, que propone una teoría de paisaje que deshaga la separación entre "pragmática y poética" de la que nos habla Anne Whiston Spirn. ${ }^{3}$

Asumimos la exigente agenda ecológica que es urgente adoptar, orientada hacia el control de las emisiones y la huella ecológica, el consumo responsable de recursos, el reciclaje y la reutilización. Sin embargo, entendems que la conciencia moral es insuficiente para conseguir el grado de movilización necesario para implementar esta agenda, por lo que queremos dar un paso más y conseguir que los paisajes productivos de nuestra época sean hermosos. Buscamos que los molinos, las huertas solares, los vertederos de escombros (que ya no están fuera de los márgenes de la ciudad porque la ciudad ha dejado de tener límites) sean bellos, históricos, deseables.

\subsection{Estructura del trabajo}

En el primer capítulo y como marco teórico estudiaremos las teorías que explican el surgimiento de la idea de paisaje, la construcción cultural de la idea de belleza, y las herramientas para aplicar visiones poéticas a territorios de lo pragmático. Entender esos mecanismos es esencial para lograr nuestro objetivo último, conseguir que el paisaje de la producción sostenible sea considerado hermoso.

Especialmente útiles son los procesos de artealización in visu y artealización in situ descritos por Roger para entender el surgimiento de la idea de paisaje según su definición clásica, que pueden extrapolarse a otros contextos y aplicarse activamente para propiciar el surgimiento de nuevos paisajes deseables.

Estudiaremos también ejemplos en los que los mecanismos enunciados se hayan aplicado exitosamente, tanto en el propio campo del paisaje como en otros contextos, en los que la construcción de un aparato estético haya supuesto una transformación cultural.

El segundo capítulo se presenta como una lectura del marco teórico y una propuesta de futuro sobre la que se apoya el resto del trabajo..

En el tercer capítulo y como cuerpo principal de la investigación procedemos a la catalogación de los paisajes productivos contemporáneos y de los paisajes necesarios ante la triple crisis actual (ambiental, energética, financiera).

${ }^{3}$ WHISTON SPIRN, A. (1998) The Language of Landscape. Yale University Press. ISBN:0300077459 
Cada paisaje necesario se presenta un estudio cronológico, una línea de tiempo, que nos ayude a construir un aparato estético que lo constituya como entidad cultural. Para ello identificaremos:

1. Primeras llamadas de atención sobre la existencia de una cuestión

2. Intervenciones de artealización in visu o visualizaciones de la cuestión

3. Toma de conciencia generalizada, o momento "portada de la revista Time"

4. Intervenciones de proyecto o de artealización in situ.

5. Ejemplos paradigmáticos y casos tipológicos.

El catálogo así construido es en si mismo un imaginario de paisajes productivos potenciales. 


\subsection{Avance de resultados}

Una primera formulación de este trabajo, muy incipiente, fue nominada al Premio de Investigación de la Bienal de VIII Arquitectura Iberoamericana, según se refleja en el Acta http://www.bienaliberoamericana.org/images/viii_cadiz2012/viii\%20biau\%202012\%20invest igacion\%20espaa.pdf (Paisajes Productivos, Carlos Arroyo 2011)

Capítulo Farming en el libro: Europan 10 Results, Paris, Abril 2010, Europan, ISBN: 2-91429618-5 - Texto (pp. 188-191) y selección de trabajos relevantes.

Capítulo Catalogando los Paisajes Productivos Sostenibles en el libro: Pasaia Produktiboak / Paisajes Productivos. Bilbao, Febrero 2013, COAVN ISBN-10: 84-695-9700-0 - ISBN-13: 978 84-695-9700-2 - Texto en pp. 35-45

Capítulo: Productive urban landscape. Unveiling latent resources through artialisation, del libro Ressources urbaines latentes: Pour un renouveau écologique des territoires. MetisPresses, Genève 2016 ISBN: 978-2-940563-03-6 - Texto e ilustraciones pp.243-255 Artículo: Artealización y Ecología: Paisajes Productivos Sostenibles, en Dearq. Revista de Arquitectura. Universidad de los Andes, Bogotá 2018 ISSN 2011-3188 | elSSN 2215-969X Numero en preparación. (Paisaje)

\subsection{Estancias y talleres}

Desde 2010 venimos desarrollando una serie de talleres que exploran estrategias para descubrir, enfatizar o construir el valor cultural de los paisajes productivos sostenibles, con especial atención a los no agrícolas.

$\begin{array}{llll}2015 & \text { Milan } & \text { Productive Landscapes (MIAW) - Politecnico di Milano } & 9 \text { meses } \\ 2014 & \text { Kigali } & \text { Productive Landscapes - University of Rwanda - KIST } & 2 \text { sem } \\ 2014 & \text { Edimburgo Productive Landscapes - Royal College of Edinburgh } & 2 \text { sem } \\ 2013 & \text { Dessau } & \text { After Speculation - Bauhaus Lab, Bauhaus } & 3 \text { meses } \\ 2013 & \text { Madrid } & \text { Monte Villa - Universidad Europea de Madrid } & 3 \text { meses } \\ 2013 & \text { Bogotá } & \text { Paisajes Productivos - U.Javeriana + EEDM + SAP Harvard GSD } & 2 \text { sem } \\ 2012 & \text { Bilbao } & \text { Paisajes Productivos - COAVN } & 3 \text { dias } \\ 2010 & \text { Murcia } & \text { Productive Golf - Observatorio de la Sostenibilidad Murcia } & 9 \text { meses }\end{array}$




\section{ANTECEDENTES}

\subsection{Antimimesis}

Para entender esta propuesta es necesario detenerse inicialmente en la idea de antimimesis, definida por Oscar Wilde en 1891: La vida imita al arte mucho más que el arte imita a la vida (Life imitates Art far more than Art imitates Life). ${ }^{4}$

Según Wilde, el arte puede ofrecer modelos hacia los que la vida puede dirigirse; en aparente contradicción con la mimesis aristoteliana, Wilde se hace la misma pregunta que Aristofanes cuando éste interpela al comediógrafo Menandro, "Oh Menandro, oh Vida! ¿Quién de ustedes tomó al otro como su modelo?" (O Menander and life, which of thou has imitated the other?) ${ }^{5}$

Paisajes y retratos, dos formatos de representacion pictorica de la realidad (mimesis), construyen un aparato estético que sirve de guía para la interpretación y transformación de la realidad en una generación posterior (antimimesis).

Un retrato ofrece un ideal de belleza que puede ser seguido por otros. Barbas, peinados, maquillaje, o incluso la cirugía, son herramientas útiles para la posterior transformación. Los jóvenes ensayan sonrisas en el espejo para conseguir la forma ideal de cara siguiendo el ejemplo de un retrato.

En los primeros días del cine, con película de relativamente poca sensibilidad para los breves tiempos de exposición, el bajo contraste resultante hacía que las expresiones faciales fuesen difíciles de capturar; como consecuencia, los actores reforzaban el contraste visual de sus labios superiores con finos bigotes y las actrices se aplicaban lápiz labial muy contrastado, casi negro, y marcaban la forma de sus ojos con sombras muy oscuras sobre sus párpados. Estos rasgos fueron divulgados través del cine y las revistas, y posteriormente imitados por el público hasta el punto de convertirse en una moda omnipresente, incluso si los aspectos técnicos de la fotografía no eran relevantes en la vida real; se trata de un caso de la vida imitando al arte.

\footnotetext{
${ }^{4}$ WILDE, Oscar The Decay of Lying -1889 : "Life imitates Art far more than Art imitates Life" Edición en español: La decadencia de la mentira, Siruela, Madrid 2004
}

${ }^{5}$ HALLIWELL, Stephen - The Aesthetics of Mimesis: Ancient Texts and Modern Problems - Princeton 2002: "O Menander and Life! Which of you took the other as your model?" 
Cuando el problema técnico fue superado, se desarrollaron nuevos modelos, convirtiendo la sombra de ojos oscura en un rasgo absurdo y hasta macabro, o simplemente feo - hasta que fue recuperado por una segunda antimimesis, ya en la era de cine en color.

Con este ejemplo, el mecanismo de la antimimesis se revela claramente ante nosotros. No es una cuestión de embellecimiento, o de descubrimiento de la belleza; es un proceso por el cual establecemos qué es la belleza.

El texto de Wilde está cargado de ironía, tanto en el sentido literal como en el que establecerá Rorty más adelante y que estudiaremos en el capítulo dedicado a la redescripción. Dice Wilde:

“... esa luz blanca trepidante que ahora vemos en Francia, con sus singulares manchas malvas y sus móviles sombras violetas, es la úlima fantasía del arte, que la naturaleza, hay que reconocerlo, reproduce de maravilla. Donde antes componía corots y dauvignys, ahora nos ofrece adorables monets y encantadores pissarros"6

El tono conversacional de Wilde en este texto, escrito al modo de un dialogo platónico en un contexto mundano, transmite de manera muy sugerente lo que Roger llamará más tarde el "giro copernicano de la estética", la idea de que la realidad es "cada vez" una función de la cultura.

${ }^{6}$ WILDE, Oscar Ibid. 


\subsection{Pragmatismo}

La primera corriente filosófica desarrollada de forma independiente en Estados Unidos surge en el siglo XIX alrededor del Metaphysical Club de Cambridge (Massachussets), con el nombre de pragmatismo; es consecuencia del incipiente pero poderoso desarrollo tecnológico del país que resultaría en su etapa expansionista y nuevo estatus de potencia mundial. ${ }^{7}$

Considerado como el padre del pragmatismo ${ }^{8}$ (aunque posteriormente se distanciase de ese término), Charles Sanders Peirce (1839-1814), desarrolla una serie de teorías en torno a los efectos prácticos o función que tiene lo que se quiere describir o representar. Este conocimiento de las consecuencias, es decir la experiencia, es lo que ayuda a entender el concepto de las cosas y evaluar la verdad de las mismas.

Por otro lado, William James aplicará el pragmatismo en otras disciplinas como la psicología, a la cual exige un empirismo radical, defendiendo la obligación de experimentación científica de toda dimensión de la realidad que sea susceptible de ello. También desarrolló un método pragmático en torno a las relaciones, entendiendo que si las consecuencias de los objetos pueden ser experimentadas, también pueden serlo sus relaciones. Así buscó clarificar conceptos e hipótesis, y estableció la siguiente técnica para resolver cualquier disputa trivial:

"Hace algunos años, estando de campamento en las montañas, volví de un paseo solitario para encontrar a todos involucrados en una feroz disputa metafísica. El corpus de la disputa era una ardilla, una ardilla viva supuestamente aferrada a un lado del tronco de un árbol; mientras que en el lado opuesto del árbol se encontraría un ser humano. Este testigo humano intenta ver a la ardilla moviéndose rápidamente alrededor del árbol, pero no por más veloz que sea, la ardilla se mueve igual de rápido en la dirección opuesta, y siempre mantiene el árbol entre si y el hombre, de modo que éste nunca consigue vislumbrar la ardilla. El problema metafísico resultante es este: ¿EL HOMBRE RODEA A LA ARDILLA O NO? Él va alrededor del árbol, efectivamente, y la ardilla está en el árbol; pero ¿rodea a la ardilla?"

${ }^{7}$ RODRIGUEZ GENOVÉS. F (2013): El origen del pragmatismo. (Consultado el 14 de Julio de 2016). Ver en http://www.lanacion.com.ar/503533-el-origen-del-pragmatismo

${ }^{8}$ NET INDUSTRIES, EDUCATION, KNOWLEDGE AND INFORMATION (2016): Pragmatism- Charles Sanders Peirce, William James, John Dewey. Other Figures in the History of Pragmatism. (Consultado el 14 de Julio de 2016). Ver en http://science.jrank.org/pages/7995/Pragmatism.html 
(Some years ago, being with a camping party in the mountains, I returned from a solitary ramble to find everyone engaged in a ferocious metaphysical dispute. The corpus of the dispute was a squirrel - a live squirrel supposed to be clinging to one side of a tree-trunk; while over against the tree's opposite side a human being was imagined to stand. This human witness tries to get sight of the squirrel by moving rapidly round the tree, but no matter how fast he goes, the squirrel moves as fast in the opposite direction, and always keeps the tree between himself and the man, so that never a glimpse of him is caught. The resultant metaphysical problem now is this: DOES THE MAN GO ROUND THE SQUIRREL OR NOT? He goes round the tree, sure enough, and the squirrel is on the tree; but does he go round the squirrel?).

James señala lo siguiente para resolver el problema. La respuesta correcta depende de lo que quieras decir "en la práctica" cuando dices dar vueltas:

"Si te refieres a pasar del norte al este, luego al sur, luego al oeste, y luego al norte otra vez, obviamente el hombre la rodea, porque ocupa estas posiciones sucesivas. Pero si, por el contrario, te refieres a estar primero frente a la ardilla, luego a su derecha, luego detrás, luego a su izquierda, y finalmente al frente otra vez, es igualmente obvio que el hombre no consigue rodearla, porque mediante los movimientos de compensación que hace la ardilla, mantiene su barriga hacia el hombre todo el tiempo, y la espalda siempre oculta al hombre. Si se hace esta distinción, ya no hay ocasión para disputas. Ambos tienen razón y ambos están equivocados según conciban el verbo rodear en uno u otro sentido práctico."

(If you mean passing from the north of him to the east, then to the south, then to the west, and then to the north of him again, obviously the man does go round him, for he occupies these successive positions. But if on the contrary you mean being first in front of him, then on the right of him, then behind him, then on his left, and finally in front again, it is quite as obvious that the man fails to go round him, for by the compensating movements the squirrel makes, he keeps his belly turned towards the man all the time, and his back turned away. Make the distinction, and there is no occasion for any farther dispute. You are both right and both wrong according as you conceive the verb 'to go round' in one practical fashion or the other).

De esta forma, aún a riesgo de parecer una evasiva, el pragmatismo afirma poder solventar cualquier tipo de disputa interminable, analizando las consecuencias prácticas de cada alternativa. Si no se puede encontrar diferencias entre ellas, es que ambas son la misma cosa y no hay disputa. Si la diferencia es radical entre las alternativas, se deben demostrar las implicaciones prácticas de cada una, y así se llegará a una concepción de verdad.

"El hecho tangible en la raíz de todas nuestras distinciones de pensamiento, aunque sea sutil, es que no hay ninguna tan fina que no pueda llegar a consistir en una diferencia práctica. Para alcanzar la claridad perfecta en nuestros pensamientos sobre un 
objeto, entonces, solo tenemos que considerar qué efectos concebibles de un tipo práctico puede implicar el objeto, qué sensaciones debemos esperar de él y qué reacciones debemos preparar. “

(The tangible fact at the root of all our thought-distinctions, however subtle, is that there is no one of them so fine as to consist in anything but a possible difference of practice. To attain perfect clearness in our thoughts of an object, then, we need only consider what conceivable effects of a practical kind the object may involve-what sensations we are to expect from it, and what reactions we must prepare $)^{9}$

Estas doctrinas se desarrollarían también desde nuevas perspectivas. Así el filósofo y pensador John Dewey, con obras como "The Quest for Certaninty" o "The School and Society", se acerca al pragmatismo desde la teoría y práctica educativas, produciendo activos cambios en la pedagogía estadounidense durante el siglo XX, basados en la experimentación y la actividad como método de aprendizaje. El uso de "proposiciones y términos" sustituirá a "frases y palabras".

Como bien indica James en el subtítulo de su ensayo sobre el pragmatismo, se trata de una nueva forma de ver algunas maneras antiguas de pensamiento empírico, pues este método para acercarse a la verdad ya existía: desde Aristóteles, pasando por Locke, Berkeley y Hume. Lo que es novedoso es la implantación de un método tan radical de forma generalizada y consciente, convirtiendo las teorías filosóficas en instrumentos para construir la verdad, no para hallarla.

Es precisamente éste el punto donde Richard Rorty tomaría el testigo de los pragmatistas americanos en el camino del neo-pragmatismo. Aquí se apoya el concepto de redescripción, antecedente fundamental para entender la extrapolación del concepto de artealización a todos los procesos de construcción cultural procesos.

\subsection{Neopragmatismo}

Richard Rorty, desarrolla en su ensayo "Contingencia, Ironía y Solidaridad" (1989) ${ }^{10}$ un acercamiento a la verdad basándose en el legado de los pragmatistas. Para entender la realidad y los procesos de creación de la misma, se desarrollan los tres conceptos enunciados en el título. Por un lado, entender el progreso del mundo como el resultado de

${ }^{9}$ WILLIAM, J (1907): Pragmatism, a new name for some old ways of thinking. Harvard University (Pág. 29)

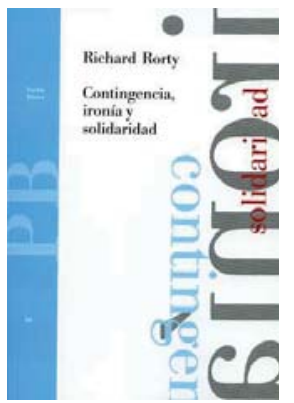
(Consultado el 14 de Julio de 2016). Ver en https://archive.org/details/157unkngoog (Digitalizado, recurso electrónico, dominio público)

${ }^{10}$ RORTY, R (1989) Contingencia, Ironía y Solidaridad. Paidos Iberica. 
la contingencia; la ironía como el conocimiento extendido entre la gente del concepto anterior -contingencia- que llevará a usar un nuevo léxico generado a través de la metáfora; y por último, la solidaridad como la compatibilidad entre el individualismo con la vida en sociedad. ${ }^{11}$

El neopragmatismo nos conmina a aceptar un mundo sin esencias, a renunciar a la búsqueda de conocimientos o verdades preexistentes y a aceptar que la complejidad y la multiculturalidad hacen imposible encontrar universales. Simultáneamente, nos permite entender cómo nuestros enunciados y proposiciones pueden construir un mundo que, siendo de naturaleza sígnica, puede tener la coherencia de lo verdadero, aun cuando resulte inconmensurable e incomprensible para los individuos de otro marco cultural.

Partiendo de la premisa pragmatista de que la verdad es algo que se construye y no que se halla, Rorty establece el punto de partida del entendimiento contemporáneo del mundo en el final de la revolución francesa, cuando los intelectuales románticos comienzan a confiar en el poder de la imaginación humana, y cuando quedó establecido que el arte no es una imitación sino una creación del artista, tal y como reivindicaron Schiller y Shelley. Así el arte pasó a ocupar el lugar de la religión, de la filosofía y la ciencia, llegando a tener un papel crucial en los movimientos sociales.

Así evolucionamos desde los posicionamientos de la llustración: la ciencia vs la religión, la razón vs la sinrazón; "La verdad está ahí fuera”. Hacia un posicionamiento que colocaba a la cultura junto a las artes y la política, versus la ciencia o tecnología. Sería entonces "El mundo está ahí fuera"; las descripciones del mundo pueden ser múltiples, asume que no existe la representación exacta de cómo es el mundo en sí mismo y la idea de una verdad autónoma está fuera de lugar. Así, tal y como enunciábamos en el capítulo anterior: "La verdad se construye, no se halla".

"Lo que se vislumbraba a finales del siglo XVIII era la posibilidad de hacer que cualquier cosa resultara buena o mala, importante o insignificante, útil o inútil, describiéndola." 12

Así, los románticos introdujeron la ecuación imaginación versus razón. La imaginación se convirtió en la facultad humana fundamental, donde radica el talento de hablar de forma diferente, frente al talento de argumentar. Al hablar de forma diferente,

${ }^{11}$ TRUCHERO CUEVAS, J (2008) Rorty y la solidaridad. Universidad Autónoma de Madrid.

${ }^{12}$ RORTY, R (1989) Contingency, Irony and Solidarity. Cambridge University Press, 1989 - Version española: Contingencia, Ironía y Solidaridad, Paidos Iberica. (pag 10) 
aparecen nuevos tipos de seres humanos. Así reconocemos a los idealistas alemanes, los revolucionarios franceses y los poetas románticos.

"La filosofía no es el análisis de los pros y contras de una tesis, sino una disputa entre un léxico establecido que se ha convertido en un estorbo y un léxico nuevo, inacabado y a menudo formal, que promete grandes cosas" ${ }^{13}$. Así aparecerá un nuevo método filosófico, que trata de volver a describir las cosas de una manera nueva, para construir una nueva verdad.

Aquí entra en juego la ironía, que Rorty detecta en tres situaciones:

1. Cuando duda del vocabulario final que usa, ya que éste está tomado de otros vocabularios finales de otras personas, libros...

2. Cuando se da cuenta que el vocabulario actual no puede resolver esas dudas y es necesario crear uno nuevo.

3. Cuando reflexiona acerca de esta situación, y se da cuenta que su vocabulario no se encuentra más cercano a la realidad que otros.

Donald Davidson, pensador de referencia para el neopragmatismo, explica ${ }^{14}$ que cuando somos capaces de hablar el mismo lenguaje es porque coincidimos en teorías momentáneas que se van estableciendo de una expresión a otra. Sin embargo, un uso metafórico del léxico hace que nos dediquemos a desarrollar una nueva teoría. Introducir metáforas es como utilizar ilustraciones, puntaciones o diagramas inusuales. Esto produce efectos en el interlocutor o el lector, sin que podamos hablar de transmisión por un lenguaje.

Así, para los positivistas y platónicos la metáfora es inservible para el propósito serio del lenguaje, el cuál es representar la realidad, una realidad oculta que está fuera de nosotros. Mientras, para los románticos, la metáfora es la imaginación. Todo lo literal es irrelevante, pues se trata de enunciar una realidad potencial que puede llegar a estar dentro de nosotros. Es decir, poniendo a Galileo como ejemplo, para los primeros sería "alguien que realizó un descubrimiento", mientras que para los segundos sería "alguien que enunció una herramienta que para ciertos propósitos puede funcionar mejor que cualquier otra herramienta precedente."

${ }^{13}$ Ibid.

${ }^{14}$ DAVIDSON, Donald, 1978, What Metaphors Mean. Critical Inquiry, 5(1) : 31-47. Reprinted in Inquiries into Truth and Interpretation, Oxford and New York: Oxford University Press, 1984, 
La verdad acontece; acontece cuando alguien propone nuevas herramientas para ver el mundo. Ese alguien, poeta, quien hace nuevos lenguajes, es la vanguardia de la especie. Ese alguien, poeta, sufre de "la angustia de las influencias" que según H. Bloom es el horror al descubrir que ha creado una copia o una réplica. ${ }^{15}$

La novedad ocurre a partir de las contingencias. Freud, Nietzsche o Bloom hablarán de la contingencia de la consciencia, mientras que Wittgenstein o Davidson, hablarán de la contingencia del lenguaje. La contingencia genera ruptura con lo anterior, y por tanto, novedad; siendo lo literal el viejo lenguaje y lo metafórico el nuevo lenguaje. Nietzsche hace de ese "poeta vigoroso, del hacedor" -del artista- el héroe de la humanidad, en vez del científico o inventor. Es la persona que emplea las palabras nunca antes empleadas, y la más capacitada para apreciar su propia contingencia. Así el artista puede ser un ironista, alguien que participa de las condiciones de la ironía arriba descrita.

Freud defiende la necesidad de orientarnos en las contingencias personales de nuestro pasado individual, y apartarnos de lo universal, para dirigirnos hacia lo concreto en vez de hallar verdades universales. "Freud democratizó el genio dándole a cada uno un consciente creativo." 16

La imaginación para los románticos es la facultad de expresión, el vínculo con algo distinto de nosotros, para Freud es la facultad para crear metáforas a partir de obsesiones de la etapa temprana de la vida. Davidson puntualizará que "no expresa algo que existía previamente, aunque si es causada por algo que si existía previamente"17

En definitiva, la imaginación según Freud es una obsesión privada que da lugar a una metáfora para la cual podemos hallar una aplicación. Es la diferencia entre la genialidad y la fantasía. Ambas son individualidades, pero "la genialidad es comprendida por otras personas, y esto es así debido a las contingencias de una situación histórica, de una necesidad particular que una comunidad determinada resulta tener en un momento determinado".

Dicho en palabras simples, la diferencia entre vanguardia y locura no está en las acciones propias, sino en el número de seguidores.

\footnotetext{
${ }^{15}$ BLOOM, Harold - The Anxiety of Influence: A Theory of Poetry 1973. Versión en español: La Angustia de las Influencias - Monte Avila Editores 1991.

${ }^{16}$ RORTY, op cit.

${ }^{17}$ RORTY, op cit.
} 
O en palabras de Rorty, "Resumiendo: el progreso poético, artístico, filosófico, científico o político, deriva de la coincidencia accidental de una obsesión privada con una necesidad pública." ${ }^{18}$ Esto es lo que Rorty desarrolla como Solidaridad, tercer y último parámetro de acercamiento a la realidad.

Más información en:

Contingency, Irony, and Solidarity by Richard Rorty pdf univ Oregon

Contingencia, ironía y solidaridad por Richard Rorty pdf en castellano

\subsection{Redescripción y transformación de la realidad}

El filósofo del lenguaje, la lógica y las matemáticas, Saul Kripke, desarrolla paralelamente una teoría de la verdad según la cual el mundo no es algo cierto que se descubre, sino algo que se estipula mediante descripciones:

"Generalmente, las cosas sobre una situación contrafáctica no se descubren, se estipulan; los mundos posibles no se dan necesariamente de manera puramente cualitativa, como si los estuviéramos mirando a través de un telescopio." (Generally, things aren't 'found out' about a counterfactual situation, they are stipulated; possible worlds need not be given purely qualitatively, as if we were looking at them through a telescope) ${ }^{19}$

Este concepto de verdad resuena en la proposición de Rorty, la redescripción como herramienta de creación:

"... el método es redescribir las cosas de nuevas formas, hasta que hayas creado un patrón de comportamiento lingüístico que tentará a la nueva generación a adoptarlo ... Este tipo de filosofía no funciona pieza por pieza, analizando concepto tras concepto, o demostrando tesis tras tesis, más bien funciona de manera holística y pragmática. Dice cosas como "intente pensar de esta manera" o, más específicamente, "trate de ignorar las preguntas tradicionales aparentemente fútiles, sustituyéndolas con las siguientes preguntas nuevas, quizá interesantes". No pretende tener un mejor candidato para hacer las mismas cosas viejas, aquellas de que hablábamos a la vieja usanza ... En conformidad con mis propios preceptos, no voy a ofrecer argumentos en contra del vocabulario que quiero reemplazar; en cambio, voy a tratar de hacer

\footnotetext{
${ }^{18}$ RORTY, op cit.
}

${ }^{19}$ KRIPKE. S (1980): Naming and Necessity. Cambridge: Harvard University Press. (Pg 5) 
que el vocabulario que prefiero se vea más atractivo al mostrar cómo se puede usar para describir una variedad de temas"

(...the method is to rediscribe [...] things in new ways, until you have created a pattern of linguistic behaviour which will tempt the rising generation to adopt it... This sort of philosophy does not work piece-by-piece, analyzing concept after concept, or testing thesis after thesis, rather it works holistically and pragmatically. It says things like "try thinking of it this way" or, more specifically, "try to ignore the apparently futile traditional questions by substituting the following new and possible interesting questions". It does not pretend to have a better candidate for doing the same old things, which we did when we spoke in the old way... Conforming to my own precepts, I am not going to offer arguments against vocabulary I want to replace, instead, I am going to try to make the vocabulary I favour look more attractive by showing how it may be used to describe a variety of topics) ${ }^{20}$

El lenguaje es, pues, una herramienta poética capaz de crear mundos, que son de naturaleza contingente e histórica.

Esta lectura positiva y pragmática es una de las bases del presente trabajo. En cambio, dejaremos de lado la ironía, que según la definición de Rorty es un efecto resultante de la redescripción:

"'El ironismo, como lo he definido, es el resultado del reconocimiento del poder de la redescripción. Pero la mayoría de la gente no quiere ser redescrita. Quieren ser tomados en sus propios términos, tomados en serio tal como son y según hablan. El ironista les dice que el lenguaje que hablan está en cuestión para ciertas personas. Hay algo potencialmente muy cruel sobre esa aserción. La mejor manera de causar dolor duradero a las personas es humillarlas haciendo que las cosas que les parecían más importantes se vean inútiles, obsoletas e impotentes.

(Ironism, as I have defined it, results from awareness of the power of redescription. But most people do not want to be redescribed. They want to be taken on their own terms - taken seriously just as they are and just they talk. The ironist tells them that language they speak is up for grabs by her and her kind. There is something potentially very cruel about that claim. For the best way to cause people long-lasting pain is to humiliate them by making the things that seemed most important to them look futile, obsolete, and powerless" 21

\footnotetext{
${ }^{20}$ RORTY, op cit. p. 9

${ }^{21}$ RORTY, op cit. p. 89
} 


\subsection{Artealización (Artialisation)}

Alain Roger, filosofo francés nacido en 1936, Profesor de Estética, es autor de algunos de los más influyentes textos de teoría del paisaje. En 1978 enunció por primera vez su teoría de la artealización, según la cual todo paisaje es un producto del arte, teoría que desarrolla y explica muy didacticamente en su celebrado texto Court traité du paysage (1997), traducido al castellano como "Breve tratado del paisaje".

Roger acuñó las expresiones artialisation in visu y artialisation in situ para describir el mecanismo detrás de la construcción de la idea de paisaje en la cultura occidental. En la primera etapa, el arte ofrece una lectura del territorio, creando una construcción cultural y un ideal a seguir. En una segunda etapa, la construcción cultural determina las intervenciones sobre el territorio en sí.

Esos dos pasos se corresponden con la evolución del propio término paisaje, que aparece a final del sXV como denominación de la representación gráfica de un territorio, denotando exclusivamente un género pictórico, una representación artística de una porción de terreno, el país. La realidad es el país; su representación es el paisaje.

Si en el siglo XVI alguien dijese "iqué hermoso paisaje!", sólo podía referirse a una representación gráfica. Nadie utilizaría esa expresión para señalar una montaña verdadera, así como nadie diría «iqué hermoso retrato!» señalando a una persona real.

Hoy, paisaje denota tanto el territorio como su representación; este es el resultado de un segundo proceso, durante el siglo XVIII, cuando el aparato estético construido por el arte transformando la visión del territorio (artealización in visu) conduce a la intervención sobre el mismo (artealización in situ).

Aparecen los arquitectos del paisaje, que explican cómo intervenir en el territorio para obtener una escena que, si se representase gráficamente, sería agradable y satisfactoria - es decir, estaría de acuerdo con el aparato estético creado por los pintores paisajistas.

La evolución del término coincide con los procesos de formación de los estados modernos en Europa, desde la fragmentación feudal y las ciudades-estado hacia un control integral del territorio. La relación entre campo y ciudad se transforma, las propiedades campestres amplían el escenario de la vida social para las clases dominantes, las fincas productivas se convierten en símbolo de riqueza y las arquitecturas que en ellas se construyen se abren al territorio que dominan, transformándolo según un ideal construido culturalmente. 
El trabajo de Roger es estrictamente un tratado del paisaje, pero el mecanismo de la artealización quizá pueda extrapolarse a cualquier forma de construcción cultural.

Recordemos a Oscar Wilde, y su fijación con el retrato, ese otro género de representación gráfica. Hemos visto como unas fotografías en blanco y negro en las que se subrayan determinados rasgos se hacen populares, y a partir de ese momento la gente comienza a intervenir en su propio "territorio" para integrarse en el aparato estético construido por las fotografías. ¿Es esto aplicable a toda nuestra cultura?

“Se podría objetar que se trata de una estética elitista, que supone una cultura reservada a algunos aficionados (la gente con clase) lo bastante ricos y ociosos como para frecuentarlas galerías de arte? No lo creo. Nuestra mirada, aunque la creamos pobre, es rica y está saturada de una profusión de modelos, latentes, arraigados y, por tanto, insospechados: pictóricos, literarios, cinematográficos, televisivos, publicitarios, etc., que actúan en silencio para, en cada momento, modelar nuestra experiencia, perceptiva o no. Por nuestra parte, nosotros somos un montaje artístico y nos quedaríamos estupefactos si se nos revelara todo lo que, en nosotros, procede del arte. Lo mismo sucede con el paisaje, uno de los lugares privilegiados donde se puede verificar y medir este poder estético."22

\subsection{Ecología sin naturaleza}

El libro "Ecología sin naturaleza" de Timothy Morton se presenta con un subtítulo

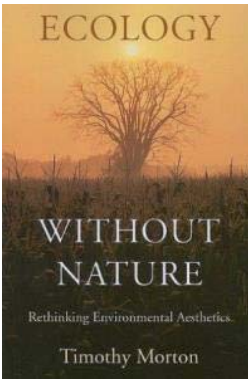
esclarecedor: "Repensando la estética de la sostenibilidad". ${ }^{23}$

Su punto de partida es un elocuente discurso que plantea un paralelismo con las tesis feministas de Simone de Beauvoir en los siguientes términos: dice Simone de Beauvoir: "la mujer es desposeída de su capacidad operativa en el terreno a través de la idealización"24. En determinados momentos de la historia, el hombre (masculino) pone a la mujer en un altar, idealizada, separada del terreno no doméstico, e incapaz entonces de manejar los recursos del poder real. Del mismo modo, la naturaleza idealizada como un territorio supuestamente virgen que necesita protección y respeto, confinada a una reserva que está separada de lo urbano, nos impide hacer frente a la ecología real, el día a día de los recursos, la energía y el clima en este planeta.

\footnotetext{
${ }^{22}$ ROGER, ibid

${ }^{23}$ MORTON, Timothy - Ecology without Nature: Rethinking Environmental Aesthetics (2007)

${ }^{24}$ BEAUVOIR, Simone de - El segundo sexo (1949)
} 
Un caso de estudio en nuestra investigación sirve como ilustración para la tesis de Morton. La ciudad de Amberes ha estado debatiendo si completar una autovía de circunvalación con un viaducto en superficie o bajo tierra mediante un túnel. En 2009 hubo un referéndum público; el Partido Verde y las asociaciones vecinales abogaron por la opción subterránea, argumentando que permitirá la continuidad del paisaje y de la biosfera; ${ }^{25}$ sin embargo, el estudio de impacto ambiental favorece al viaducto elevado. ${ }^{26}$ Este es un caso típico en que la idealización de la naturaleza lleva a criterios opuestos a la ecología. Una autopista subterránea tiene una enorme huella de carbono, desplazando kilómetros cúbicos de tierra en camiones diésel, mordiéndolo de la tierra con gigantescas máquinas perforadoras de túneles; requiere hectáreas cúbicas de hormigón, enterradas en el delicado sistema de agua subterránea de los países bajos; durante su vida útil consume energía para ventilación forzada y bombeo de aguas; es un desastre ecológico, invisible en la superficie, pero cuantificable. La ficción de un paisaje rural construido encima, la continuidad de los campos verdes, es decir, la idealización de la naturaleza, puede conducir a una catástrofe ecológica.

Esto arroja una luz específica sobre la palabra ecofeminismo, poniendo las dos idealizaciones en el mismo plano, y que conduce a una forma diferente de gestión de las decisiones en la vida cotidiana, como una red de pares. En un sentido aún más relevante para nuestros propósitos, también da un nuevo matiz a las palabras paisaje, urbano, verde, producción y sostenibilidad.

\subsection{Pragmática y poética}

"Puede ser cierto que uno tenga que elegir entre ética y estética, pero cualquiera que se elija, uno siempre se encontrará con la otra al final del camino. (It may be true that one has to choose between ethics and aesthetics, but whichever one chooses, one will always find the other at the end of the road". Jean-Luc Godard"27

La pragmática de la producción, los recursos y la sostenibilidad puede llegar a ser deseable, si establecemos las condiciones para que los diferentes agentes humanos luchen

\footnotetext{
${ }^{25}$ Gazet van Antwerpen. http://www.gva.be (14/11/2016). Groen positief over nota intendant:"Overkapping is noodzaklijk". --- De Morgen. http://www.demorgen.be (09/06/08). Groen! trekt ten strijde tegen Lange Wapperbrug.
}

${ }^{26}$ VV.AA. Vervaet, C., Putzeys, G., Dermaux, D., Pauwels, G., Goemaere, K., Arts, P., \& Bauwens, M. (2015). Project MER Oosterweelverbnding (Mileu Effecten Rapport) (p. 124). Antea Group.

${ }^{27}$ SONTAG, S (1969): Styles of Radical Will. Farrar, Straus and Giroux. New York. 
por su aplicación en su entorno cercano, es decir, si construimos un aparato estético en torno a la noción de paisajes productivos.

"La distinción es, tal vez, expresada por los términos técnica y poética, en la medida en que diferencian entre, por un lado, lo objetivo y lo cuantitativo y, por otro, lo subjetivo o cualitativo. Esto no significa que ambas categorías sean mutuamente excluyentes, sino que el entorno arquitectónico es mucho más que una cuestión de prescripción pragmática y realización técnica, por útiles que puedan ser [...] En" Studies in Tectonic Culture ", Kenneth Frampton aclara la distinción entre espacialidad y tectónica en la arquitectura y desarrolla un poderoso argumento para el restablecimiento del significado de la tectónica en relación con la posición dominante del espacio en gran parte de la teoría del siglo XX. Así, la tectónica se representa como algo más que un mero instrumento de construcción, rechazando la noción de que ésta sea un fin en sí mismo. La preocupación es con la poética de la construcción: "El potencial tectónico completo de cualquier edificio se deriva de su capacidad para articular los aspectos tanto poéticos como cognitivos de su sustancia". El argumento de Frampton presenta un desafío implícito para los historiadores y teóricos del entorno arquitectónico a desarrollar una narrativa paralela de su evolución "."28.

"The distinction is, perhaps, expressed by the terms technics and poetics, insofar as these differentiate between, on the one hand, the objective and quantitative and, on the other the subjective or qualitative. This is not to propose that these are mutually exclusive categories, but to make the point that the architectural environment is much more than a matter of pragmatic prescription and technical realisation, however useful that might be..."29. "In "Studies in Tectonic Culture", Kenneth Frampton clarifies the distinction between spatiality and tectonics in architecture and develops a powerful argument for the re-establishment of the significance of the tectonic in relation to the dominant position of space in much of twentieth-century theory. In this, the tectonic is represented as more than a mere instrument of construction, resisting the notion that it is an end in itself. The concern is with the poetics of construction: "The full tectonic potential of any building stems from its capacity to articulate both the poetic and the cognitive aspects of its substance" 30 Frampton's argument presents an implicit challenge to the historians and theoreticians of the architectural environment to develop a parallel account of its evolution."

${ }^{28}$ HAWKES, D (2008): The Environmental Imagination. Technics and poetics of the architectural environment. Routledge. New York.

${ }^{29}$ HAWKES, D (2008): The Environmental Imagination. Technics and poetics of the architectural environment. Routledge. New York.

${ }^{30}$ FRAMPTON, K (1995): Studies in Tectonic Culture. Poetics of Construction in Nineteenth and Twentieth Century. MIT Press. Cambridge. 
Los casos estudiados pueden llegar a establecer una metodología analizando sistemáticamente otros procesos de transformación de la idea de la belleza en nuestros paisajes habitados. La lista de ejemplos paradigmáticos puede darnos algunas pistas sobre cómo activar procesos de artealización como parte de un proyecto.

Podemos estudiar los siguientes parámetros:

- Grado de conciencia. ¿Es el proceso de artealización un esfuerzo consciente para transformar nuestros puntos de vista? Podemos establecer un gradiente desde -1 (el artista estaba tratando de denunciar algo, pero sus esfuerzos lo hicieron deseable) a 1 (el artista es una pieza en un esfuerzo orquestado para cambiar la percepción).

- Esfuerzo vs influencia. ¿Qué proporciones qué encontramos entre las artialisations en visu e in situ? Los extremos pueden ir de los casos en que una pequeña pieza permite una transformación a gran escala del territorio, hasta los casos en que es necesario desgranar toda una serie de ejemplos implementados para conseguir un efecto transformador.

- Medios de comunicación. ¿Cómo puede una artealización convertirse en corriente principal? ¿Es suficiente el boca a boca, o ha de asociarse a otras formas de arte como el cine de la música? ¿Es parte de una campaña publicitaria?

- Entrada vs salida. ¿Cuál es el contexto en términos de recursos e insumos? Para cada conjunto de entradas, ¿cuáles son las posibles salidas de acuerdo con el conjunto de ejemplos?

Podemos estudiar la posible evolución de tales artealizaciones existentes, evaluando su capacidad de transformación cultural, la cobertura mediática que hayan tenido y en qué medida son capaces de transformar la visión pública de su objeto.

Y, por último, planteamos una pregunta: ¿Puede este proceso ser diseñado? 


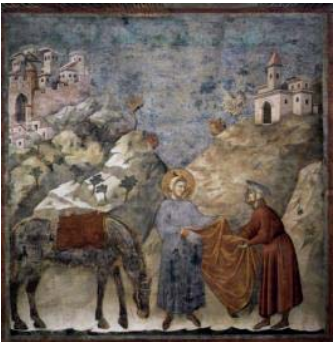

1290 San Francisco entregando su manto a un pobre. Giotto

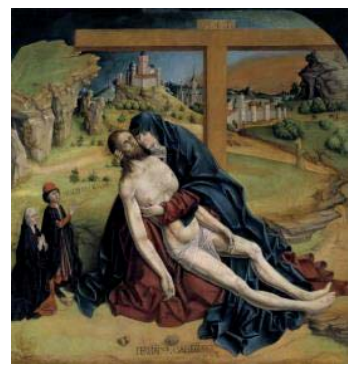

1465-70 Piedad. Fernando Gallego

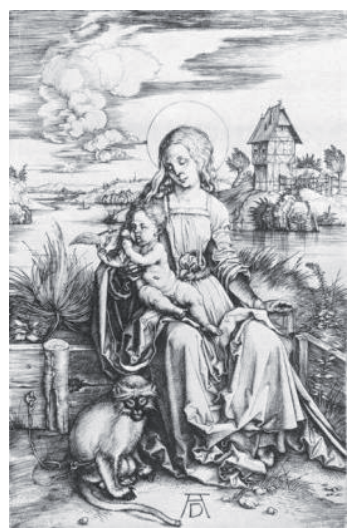

1498 Virgen del mono de rabo largo. Alberto Durero

\section{EL CONCEPTO DE PAISAJE}

\subsection{El paisaje como construcción cultural}

"El paisaje es un constructo, una elaboración mental que los hombres realizamos a través de los fenómenos de la cultura, y como tal, varía de una cultura a otra. (...) El término se ha extendido innecesariamente, para designar fenómenos en épocas (o lugares) en las que no existía ni el concepto ni la palabra. ${ }^{31}$

Un territorio no constituye paisaje en si mismo; el paisaje es una cultura de la mirada y la experiencia.

El concepto de paisaje en Europa tiene un origen remoto en la cultura romana que, desde el siglo I, se acercó a la creación de un sentido de paisaje mediante pinturas decorativas de vistas y villas con jardines de recreo. Sin embargo, estas primeras pinturas no construyen una imagen del territorio. Tampoco las escenas de caza presentes en mosaicos y pinturas, que representarían igualente un lugar exterior, pero generalmente a través de elementos simbólicos aislados como árboles o rios.

Es en el periodo prerenacentista cuando se comienza a realizar pinturas de escenas en exteriores con representación del territorio, como San Francisco entregando su manto a un pobre de Giotto (1290). Aquí se mostrarán algunos elementos paisajisticos, siguiendo todavía los modos de representación medival sin poder reconocerse el paraje ilustrado en la realidad, Estos, necesitaban evitar referencias a tiempos o espacios concretos, siendo todavía metáforas religiosas y morales: rosa-perfección, loto-vida, crisantemos-muerte....

Ya en el siglo XV encontramos obras en que el territorio adquiere entidad propia, aunque todavía como fondo para una escena principal de otra índole, normalmente religiosa. Es el caso de la Piedad (1465-70) de Fernando Gallego o Virgen del Mono de rabo largo (1498) por Alberto Durero, que basaría su fondo en un dibujo anterior realizado por el mismo artista dos años antes. Joachim Patinir (1480-1524) lleva al extremo esta dualidad escena-fondo.

La inseguridad que durante un milenio producirían los eventos acaecidos durante Edad Media poco a poco iría remitiendo, volviendo a considerar el territorio como un lugar de estancia susceptible de ser descrito. La mirada temerosa desaparecerá ante todo aquello que se encontraba extra-muros y comenzará la apreciación del medio rural desde

${ }^{31}$ MADERUelo, J (2005): El Paisaje. Génesis de un concepto. Abada Editores. Madrid. 
un punto de vista poético. La vuelta a la consideración de las villas como lugares de placer visual, potenciaría el desarrollo de una sensibilidad y apreciación del entorno que estaría a punto de conceptualizarse.

Sin embargo, los viajes registrados aún omitían descripciones de los espectaculares lugares que visitaban. Michel de Montaigne (1581) no dejaría ni la menor constancia de su travesía por los Alpes, más que un somero "paseo agradable sin excesiva emoción" seguramente referido a ausencia de encuentros con maleantes u otras incidencias logísticas. Montaigne realizaría este trayecto en dos ocasiones más, con el objeto declarado de conocer los paises, pero su descripción se centraría en la comparación pragmática de tierras y costumbres, lo que denota en palabras de Javier Maderuelo, la falta de una "cultura paisajista".

Los territorios podian llegar a ser nombrados como locus horridus ${ }^{32}$, llenos de peligro, la selva, el mar el desierto y la montaña; precisamente aquellos que más adelante se identificarán con la característica estética de Lo Sublime. Tan sólo el arquetipo locus amoenus -lugar agradable, gracias a su vegetación- procedente de la poesía pastoril, hacía intuir la aparición de un gusto por la naturaleza recuperada y domesticada desarrollada en ejemplos de villas italianas como Villa Médici di Castello (1447) y los jardines monacales ${ }^{33}$.

"Aquello que impide que el paisaje haya surgido antes en la cultura occidental es la ausencia de un soporte coneptual y no un asunto meramente técnico de la práctica de la pintura, como lo demuestra el hecho de que paralelamente a la consolidación de estos logros plásticos, casi en las mismas fechas, se está produciendo un fenómeno similar en la literatura, cuando está empezando a cuajar la novela como género literario" 34.

El paisaje de dunas que Hendrick Goltzius dibuja en el año 1603 - pintura hoy conocida como Paisaje de dunas cerca de Haarlem, aunque anteriormente las obras de este genero se nombraban como vistas, países o marinas - , supone la primera vista autónoma considerada como paisaje.

Paralelamente, Carel van Mander, inventa el término holandes "landschap" para designar la actividad de su compañero pintor Gillos Van Coninxloo en 1604, en el tratado de pintura Het Schilder-Boek que escribiría imitando al de Vasari. Los paisajes de Coninxloo, son panorámicas de territorios inventados, pero a diferencia de muchos de sus coetáneos,

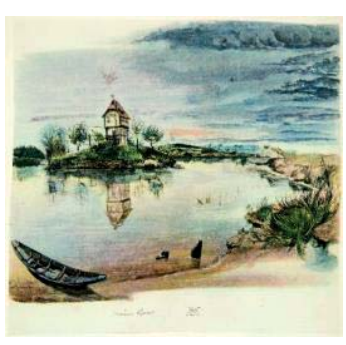

1496 House by a Pond. Alberto Durero

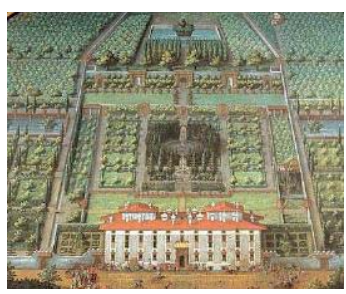

1600 Villa Médici di Castello Giusto Utens

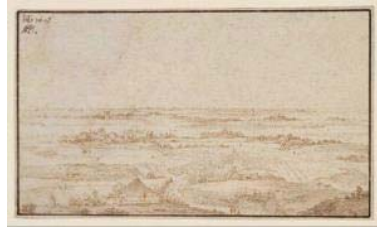

1498 Paisaje de dunas cerca de Haarlem Hendrick Goltzius.

\footnotetext{
32 MADERUELO, J (2005): El Paisaje. Génesis de un concepto. Abada Editores. Madrid.

${ }^{33}$ MADERUELO, J (2005): Ibid

${ }^{34}$ MADERUELO, J (2005): Ibid
} 
son creibles. No obstante no tienen intencionalidad autónoma, ya que servirían perfectamente como fondos acompañantes de otras escenas.

Rápidamente, artistas de todos los paises europeos comienzan a pintar paisajes sin escena, y el término se traduce a todas las lenguas. Se trataba de pinturas con tendencias realistas, realizadas sin encargo y disponible para su adquisición por cualquiera. Su popularización llenó los interiores de las casas holandesas burguesas con este tipo de objeto artístico doméstico. Holanda se convierte por tanto, en el lugar propicio para la aparición del género paisajistico en Occidente, debido a razones religiosas -vetos de temáticas-, y técnicas -activa actividad cartográfica-; así como el aprecio del territorio por sus gentes, y la topografía plana que permite la observación del horizonte.

El término alemán Landschaft, se encuentra documentado desde el siglo VIII, pero no significará "paisaje" hasta el Renacimiento. Hasta entonces se refería a región o provincia, nombrando a la tierra que se halla situada alrededor de un pueblo, término por tanto ligado a la idea de propiedad del suelo, zona, país o reino. Sin embargo, tal y como veremos más adelante, existen culturas que ya disponían de este término con anterioridad como es el caso de China, ya desde el siglo V.

En el siglo XVII se produce el punto de inflexión en el que del paisaje como representación surge el paisaje como concepto.

"El simbolismo en el paisaje es una característica permanente, común, tanto en el periodo pre-romántico como en el romántico, mostrándose el movimiento paisajístico inglés como su expresión más depurada. Pero la difrerencia profunda está en el hecho de que, en el primer caso, la selva, la planta singular, las flores, los animales, las rocas, las fuentes, son asumidas esencialmente como símbolos de calidad, o como condiciones racionalmente valiosas, como manifestaciones tangibles de la divinidad. En el segundo caso, son símbolos de sentimientos individuales, como el miedo, la melancolía, el amor, la fidelidad y algunos paisajestipo como la marina, el brezal, el paisaje rocoso, se convierten en símbolos de sentimientos e ideales colectivos" 35 .

Para la crítica de arte de finales del siglo XIX - desde el romanticismo hasta el impresionismo, incluso arraigada durante todo el siglo XX- el paisaje reúne unas determinadas condiciones de calidad, así términos como refinamiento, lujo y gracia, imágenes estereotipadas como las que ofrecen los árboles agrupados en ramilletes, ondulaciones suaves del terreno o el verde del césped, han aportado un aura de calidad al término paisaje, relegando al resto de los "escenarios" que carecen de estas cualidades a una condición no paisajista. Encontrándose

${ }^{35}$ CALZOLARI, V (2012): Paisaje / Paesistica. Instituto Universitario de Urbanística. Universidad de Valladolid. 
entonces la idea más generalizada de paisaje unida a la sensación de disfrute en la apreciación de la imagen de un territorio. ${ }^{36}$

A lo largo del siglo XX la pintura deja de interesarse por el paisaje como género, por lo que desaparece la confusión entre representación y concepto. Otras disciplinas reclaman parcelas de conocimiento sobre el territorio, tanto entre las artísticas como en las ciencias políticas, económicas y sociales.

"Cuando en la actualidad el término y el concepto paisaje vuelven a cobrar un enorme interés nos encontramos con que, al menos en el campo de las artes, los estudios sobre él, realizados durante el siglo XX, se encuentran lastrados por los prejuicios fraguados durante la "modernidad vanguardista" y no han sabido profundizar en muchos de los aspectos que hacen que el paisaje en la posmodernidad sea un tema rabiosamente actual. Piénsese en el interés que desde finales de los años 60 han tenido algunas manifestaciones artísticas relacionadas con el paisaje, como el Land Art o los Earthworks, y la dificultad de encontrar un acomodo en las antiguas categorías con que se dividiían las artes o los géneros." 37

"Los valores que han conformado nuestra cultura consumista nos han conducido a una "cosificación" del paisaje; sin embargo, el paisaje no es una cosa, no es un objeto grande ni un conjunto de objetos configurados por la naturaleza o transformados por la acción humana". ${ }^{38}$

"El paisaje y los valores que se encuentran asociados a él se han redescubierto en estos últimos años por vías muy diferentes en un abanico que se abre desde el dilentantismo artístico hasta el activismo ecologista, pasando por la práctica urbanística, las actividades turísticas o el positivismo biológico. Esta diversidad de intereses demuestra que el concepto paisaje se ha extendido pero, a cambio, el término que lo designa ha diluido su capacidad de referirse a algo concreto y preciso. Su contenido se ha dilatado de tal manera que corremos el riesgo de no saber muy bien a qué nos referimos exactamente cuando pronunciamos la palabra paisaje." 39

\footnotetext{
${ }^{36}$ MADERUELO, J (2005): El Paisaje. Génesis de un concepto. Abada Editores. Madrid.

37 IBID.

${ }^{38}$ IBID.

${ }^{39}$ IBID.
} 


\subsection{El paisaje en distintas culturas}

Según Agustin Berque ${ }^{40}$, la noción de paisaje no ha existido siempre ni esta presente en todas las culturas; para que se pueda hablar con propiedad de que una civilización posee una cultura paisajista es necesario que se cumplan cuatro condiciones...

1. Que se reconozca el uso de una o más palabras para decir paisaje.

2. Que exista literatura, oral o escrita describiendo su belleza

3. Que existan representaciones pictóricas capaces de establecer criterios estéticos

4. Que existan lugares organizados según esos criterios

Visto así, muchas culturas no reunen apenas ninguna de estas condiciones. El que una cultura no llegue a necesitar inventar una palabra es algo más que una mera cuestión lingüística que ataña al vocabulario, es algo que afecta a su concepción del mundo.

“Podemos apreciar en las lenguas europeas un fenómeno curioso en la formación del término paisaje, cual es que se ha generado una ambigüedad que origina la polisemia que hoy posee, ya que la palabra paisaje sirve tanto para designar un entorno real (país) como una representación de ese entorno (lejos), al contrario de lo que sucede en los idiomas chino o japonés, en los que existen palabras de raíces diferentes para estos conceptos. Por ejemplo, en japonés se utiliza la raíz keikan para nombrar el entorno y fukiega para referirse a la representación, que ponen en evidencia no sólo dos orígenes diferenciados, sino dos conceptos distintos, mientras que en la cultura europea no existe la necesidad de esta diferenciación, ya que ambos conceptos han surgido y se han desarrollado juntos". ${ }^{41}$

La primera cultura que parece disponer de un término específico para nombrar al paisaje, en la que hay poetas que lo describen, artistas que lo pintan y en que se cultivan jardines por placer es China desde el siglo V. Durante la dinastía china Han (206 a.C. -220 d.C.), periódo casi contemporáneo al Imperio Romano, hubo un complicado contexto repleto de cambios que llevarían a la práctica del retiro en la naturaleza por parte de los ilustrados que querían manifestar el desacuerdo con el nuevo régimen, dando lugar al descubrimiento del paisaje como tal. Estos eremitas abandonaron en confucianismo para considerar la belleza de la naturaleza en sí misma. ${ }^{42}$

${ }^{40}$ BERQUE, A (1994): Paysage, milieu, histoire, Cinq propositions pour une théorie du paysage. Champ Vallon. Seyssel.

${ }^{41}$ MADERUELO, J (2005): El Paisaje. Génesis de un concepto. Abada Editores. Madrid.

${ }^{42}$ ROGER, A 1997 (2007): Breve tratado del paisaje. Editorial Biblioteca Nueva. Madrid. (pág. 67 y sigs.) 
"Al contrario de lo que sucedió en China, en los orígenes de nuestra cultura occidental, tanto en Mesopotamia, Egipto o Grecia Clásica, no se despertó un interés poético por el territorio, o la naturaleza. En Occidente la conciencia del lugar cobrará unos tintes claramente pragmáticos y utilitarios". Los únicos relatos que podrían llevar a confusión serían los mitos, pero la razón de ser de estos es puramente pragmática, uniendo dioses a elementos naturales, sin atender a ningún tipo de intención poética ${ }^{43}$. Así los griegos, que tomaban especial cuidado en ubicarse en el lugar idóneo, a partir de ritos con transfondo utilitario, buscaban los parajes "sanos"; es decir aquellos con una buena orientación, terreno y recursos. En ningún momento hablaron de las vistas o la construcción de un bello skyline. Del mismo modo, los romanos tampoco lo dejaron registrado a la hora de decidir las localizaciones de sus villas. A pesar de cumplir una de las ideas de Berque, el cultivo de jardines para el deleite en los espacios públicos, no tienen inclinaciones hacia el resto de puntos del concepto de paisaje; y es que jardín y paisaje no es lo mismo. Tampoco la estructura de Roma pudo proporcionar las condiciones para el desarrollo del paisaje. El Mundo Antiguo hubiese terminado por conceptualizarlo, si no se hubiese terminado abruptamente con la aparición del cristianismo, lo que supondría un parón de un milenio. La religión, impondría nuevas reglas morales que evitarian el disfrute del placer mundano, de manera que sería imposible continuar con la tradición romana de las villas y jardines; así como de la representación del territorio y la cartografía. La ciencia sería también relegada junto con la idea de paisaje al Renacimiento ${ }^{44}$.

"En Inglaterra el paisaje siempre ha sido considerado un argumento de interés común, no sintiéndose la necesidad de convertirlo en objeto de especializazción autónoma, lo que ha favorecido por otra parte, la evolución actual del landscape architecture hacia el landscape planning, concebido como parte itnegrante de la planificaicón territorial" 45.

"En la época medieval, los habitantes de las aldeas inglesas se manifestaban tomando las plazas, si el derecho al "bien verde" era amenazado. "Esta reacción se debe al convencimiento de que la posesión de un trozo de naturaleza libre es un sarosanto derecho de la comunidad, que ésta tiene el deber de defender". Desde 1900, se constituirán asociaciones ciudadanas con el objetivo de crear nuevos mediante leyes de control del crecimiento de los centros urbanos ${ }^{46}$.

“En Italia no sólo en esta primera fase sino tambén durante la posguerra, la disciplina del paisaje no encuentra espacio en las facultades, confiado a los cursos de "arte de los jardines". En la segunda fase, iniciada, como decimos en la posguerra, confluirán la cultura y la didáctica paisajística con problemas de tipo funcional y urbanístico. Todos los países implicados

\footnotetext{
43 MADERUELO, J (2005): El Paisaje. Génesis de un concepto. Abada Editores. Madrid.

44 IBID.

${ }^{45}$ CALZOLARI, V (2012): Paisaje / Paesistica. Instituto Universitario de Urbanística. Universidad de Valladolid.

46 IBID.
} 
en la guerra se encontraron frente a problemas comunes que incidían en la conservación y la utilización del territorio. Las grandes tareas, en estos campos, eran por entonces reconstruir ciudades con más espacios verdes; reforestar las zonas abandonadas por la agruicultura; crear nuevos espacios para el tiempo libre de las masas urbanizadas; insertar en el paisaje las autopistas, grandes complejos residenciales....etc". Como consecuencia de ello, en cada país ha aumentado el campo de los intereses de los especialistas del paisaje, y una homgeneización en los intentos seguidos por el sistema educativo. Pero de ello no se ha derivado dada la necesidad de introducir, en la educación paisajista, una diversidad de conocimientos de carácter histórico, socio-económico, arquitectónico... ${ }^{47}$.

Para los habitantes de buena parte de África y algunas zonas rurales de América el concepto de paisaje es aún hoy inexistente o muy débil, aunque existe una gran presión eurocéntrica impuesta a través de los medios ${ }^{48}$.

${ }^{47}$ CALzoLARI, V (2012): Paisaje / Paesistica. Instituto Universitario de Urbanística. Universidad de Valladolid.

${ }^{48}$ IBID. 


\section{REDESCRIPCIONES Y ARTEALIZACIONES}

\subsection{Lanzarote y César Manrique}

En la isla de Lanzarote encontramos un ejemplo que nos permite entender los mecanismos que consiguen la construcción de un paisaje como proceso de doble artealización, resultado de los esfuerzos del artista César Manrique (1919 - 1992); podemos decir que el paisaje de Lanzarote es la obra más relevante de Manrique. ${ }^{49}$

Antes de su intervención, la isla de Lanzarote era una pesadilla de hambruna y sequía, que sufría sucesivos episodios de crisis. Sus propios habitantes -tal y como Manrique pudo comprobar durante su formación en la Universidad de La Laguna en Tenerife-, la describían como isla de tierra infértil y excrementos de cabras ${ }^{50}$. Sin embargo, tras su regreso de una estancia en Estados Unidos (1964) Manrique puso en marcha un conjunto de operaciones artísticas que transformarían las difíciles condiciones de vida en la isla en un sello identidad.

Estas condiciones se podrían resumir en seis puntos que cambiarían la percepción de la isla -tanto vernácula como turística- para siempre.

\section{EL VIENTO: De azote y molestia, a la magia de los "juguetes del viento"}

La isla de Lanzarote es afectada por una corriente de vientos constantes, los Alisios, que arrastran polvo y arena -calima- procedente del Sahara en el cercano continente africano, con alto potencial erosivo, y que tiñe el aire de un color rojizo impidiendo la visibilidad.

El viento, por tanto, es una identidad negativa de la isla. Es también uno de los mayores condicionantes para el desarrollo de las labores económicas, de la resistente vegetación -escasa y baja-, y de la arquitectura. Siendo así típicos los molinos de viento, que aprovechaban estas corrientes para triturar el cereal -principal fuente de sustento y exportación de la isla, hasta que las erupciones volcánicas destruyeran la mayoría de los campos. La consecuente y progresiva desaparición de los molinos es una imagen del pasado de la isla que Manrique se esmeró en recuperar, en forma de "referencias

\footnotetext{
${ }^{49}$ MARTIN HORMIGA, A.F. y Perdomo M.A (1995): Una isla como tema. Cabildo de Lanzarote y Universidad de Las Palmas de Gran Canaria.
}

${ }^{50}$ SARDÁ, J, ZAMORA, A (2014): Aproximación a los paisajes culturales del regadío. La Geria de Lanzarote. Universidad Politécnica de Cataluña. Consultado el 24 de mayo de 2016 en http://ocs.editorial.upv.es/index.php/ISL/ISL2014/paper/viewFile/197/156 


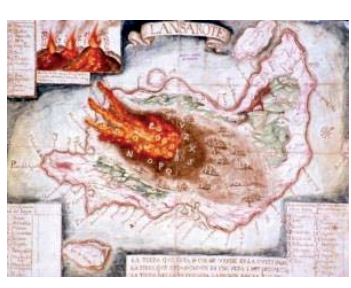

1730 Mapa de la Erupción del Timanfaya. Archivo de Simancas

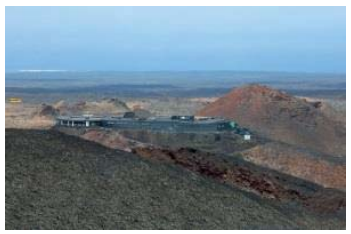

1974 Mirador El Diablo. Timanfaya. César Manrique. Foto: Luis Miguel Bugallo Sánchez

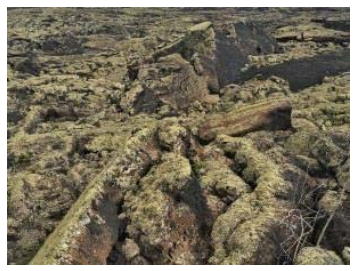

2015. Malpaís. Lanzarote (foto 2015)

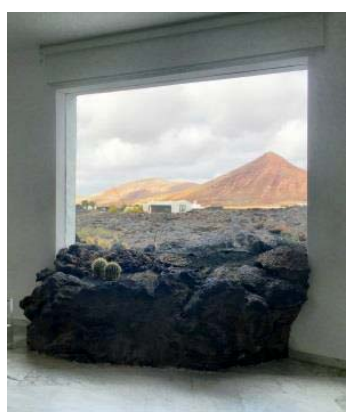

1968. Malpaís en la Casa de Manrique. Lanzarote (foto 2015) sustitutorias" 51 de carácter más lúdico. Esto se realizará a partir de la instalación de los llamados Juguetes de viento, artealizaciones in situ, que suponían una suerte de evolución de la veleta tradicional, ubicados en distintos puntos repartidos a lo largo del territorio de la isla; como eventos en el paisaje /difusores de memoria /. Desde 1990 y de forma póstuma se han emplazado más de media docena, realizados por artesanos del hierro de la isla.

EI MALPAÍs: De la dureza infértil a la belleza muda

Son los páramos producidos por las coladas de lava y el ambiente árido, traducidas en la infertilidad de las tierras, inservibles para la agricultura. Revelan los recorridos de la lava que durante más de seis años emanó de uno de los volcanes de la isla -aún activo- El Timanfaya. La erupción principal tuvo lugar el 1 de septiembre de 1730, cubriendo un cuarto del territorio, sepultando valiosos terrenos agrícolas y asentamientos, produciendo la emigración masiva de su población, y cambiando así el paisaje de forma irreversible. Los popularmente denominados "días del fuego" dejarían un paisaje volcánico cuya puesta en valor tendría que pasar por ese proceso de artealización del lugar. Las tareas de acondicionamiento de la zona comenzarían en 1968 creando la ruta de los volcanes, cuya intervención mínima permite recorrer coladas de lava perfectamente conservadas. Es allí también donde realizaría un mirador - restaurante que aprovecha el calor que emana del subsuelo como barbacoa natural -El Diablo-. Desde entonces y tras su conversión en Parque Nacional en 1974, es el segundo más visitado de España ${ }^{52}$. La puesta en valor del Malpaís, con la fuerza estética de la topografía producida por la lava y los volcanes será uno de los aspectos a los que Manrique atenderá, convirtiéndola en una herramienta de diseño, como veremos más adelante.

El malpaís es un ejemplo perfecto de doble artealización. Manrique inicia su trabajo de artista con una abundante y exitosa obra pictórica abstracta de una gran fuerza matérica, integrada en las corrientes internacionales, que podríamos describir como "malpaís sobre lienzo" Es una artealización in visu. A continuación, enmarca el malpaís real incluso en las ventanas de su propia casa, que construye dentro y alrededor de las coladas de lava. Es una artealización in situ.

51 SARDÁ, J, ZAMORA, A (2014): Aproximación a los paisajes culturales del regadío. La Geria de Lanzarote. Universidad Politécnica de Cataluña. Consultado el 24 de Mayo de 2016 en http://ocs.editorial.upv.es/index.php/ISL/ISL2014/paper/viewFile/197/156

52 CENTRO DE ARTE, CULTURA Y TURISMO DEL CABILDO DE LANZAROTE. Las Montañas del Fuego. Consultado el 27 de Mayo de 2016 en http://www.centrosturisticos.com/centros/CENTROS/published es/DEFAULT/node 2032.html 
BLANCO HUESO: De la muerte bajo el sol a la luz entre las rocas

De estas condiciones adversas que imponen los dos primeros puntos citados anteriormente -el malpaís, y su clima subdesértico con los vientos alisios-; deriva el desarrollo dificultoso tanto de la vegetación, como el del resto de seres vivos.

Precisamente los huesos pelados por la intemperie son una de las imágenes más representativas y popularmente extendidas de las tierras inhóspitas, baldías, en general -badlands para zonas no volcánicas-; y del malpaís -volcánicos- en particular. Ese color blanco de los esqueletos perfectamente conservados que descansan sobre los tonos oscuros de la lava y las cenizas solidificadas, remiten al mismo contraste que produce la obra pictórica y, posteriormente, la arquitectura de César Manrique.

LA TOPOGRAFÍA: De accidentes a oportunidades

El nuevo relieve de la isla tras la erupción del siglo XVIII supuso una catástrofe de gran envergadura para los habitantes que tuvieron, sino que huir, adaptarse a un nuevo medio natural. Uno de esos ejemplos es el aprovechamiento de la ceniza en las gerias para el cultivo de la vid, reconvertido en un icono de la isla.

La intención de los espacios de Manrique es similar a esta intervención de las gerias, un encuentro totalmente integrado e inmerso en el relieve del paisaje, estableciendo un juego con la topografía. Es así como consiguió una unión satisfactoria entre pragmática y poética con la serie de miradores que realizó para habitar algunos parajes naturales en busca de un turismo de calidad. Encontramos el ejemplo paradigmático del Mirador del Río (1973), al borde de un acantilado sobre el que se puede observar la isla de la Graciosa. Una construcción casi imperceptible desde el exterior, ya que se encuentra integrado en una "piel" de roca volcánica. Manrique se apropió de una antigua posición estratégica de artillería en desuso las "Baterías del Río".

Los espacios abovedados del interior, de color blanco, se encuentran abiertos a través de grandes ventanales circulares para la observación del paisaje. El mirador, que permite abarcar la crudeza del territorio, crea el paisaje para nosotros.

Además de este realizaría otros miradores en la misma línea en Lanzarote, y en otras islas cercanas como el de La Peña en la isla del Hierro, o el del Palmarejo, en la isla de la Gomera; así como otros diseños que todavía no han sido materializados.

En Guatifa (Lanzarote), Manrique plantea un proyecto de recuperación de una antigua cantera, donde el terreno se había convertido en un vertedero. Propone al Cabildo que se haga con el terreno, restaure el molino, y cree un ecosistema vegetal de referencia a nivel internacional, conformando un ejemplo de proyecto paradigmático en cuanto a la unión conseguida entre productividad y belleza. Aquí se encuentra además el mayor cultivo de cochinilla -usado como tinte natural- de toda Canarias. Los recorridos a

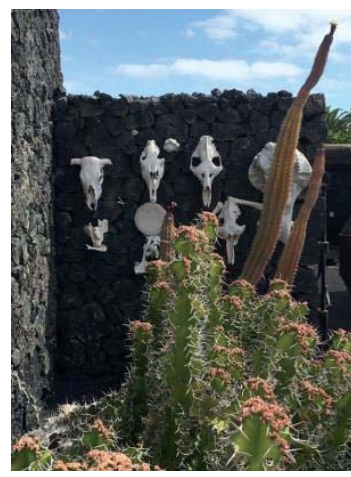

1968. Huesos sobre lava en la casa de Manrique. Lanzarote. (foto 2015)

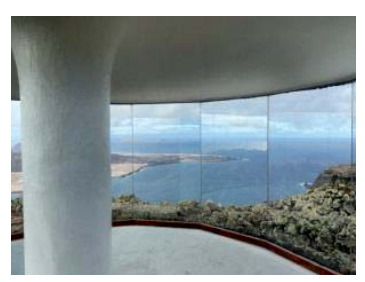

1973* Mirador del Río hacia Graciosa. Lanzarote. (foto 2015)

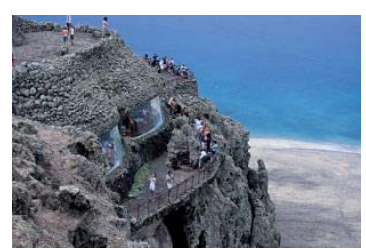

1973. Mirador del Río Lanzarote. (foto 2015)

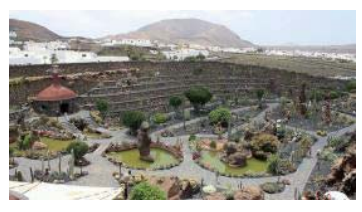

1990. Jardín de Cactus César Manrique 


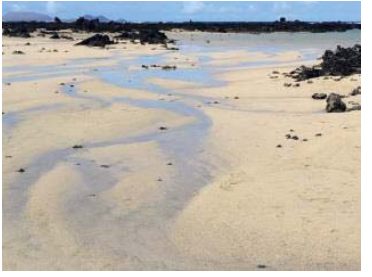

2016- Agua. Lanzarote. (foto 2015)

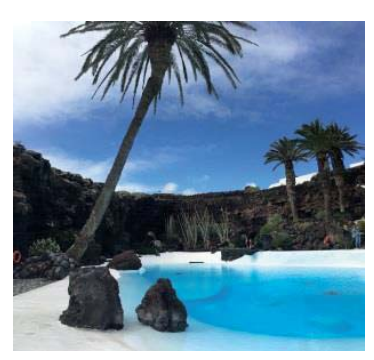

1977. Jameos del Agua. Lanzarote. Cesar Manrique. (foto 2015)

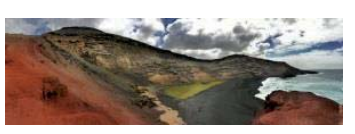

2016. Lago Verde. Lanzarote

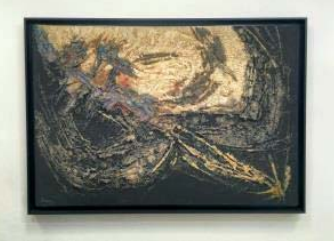

1954. Pinturas.

César Manrique

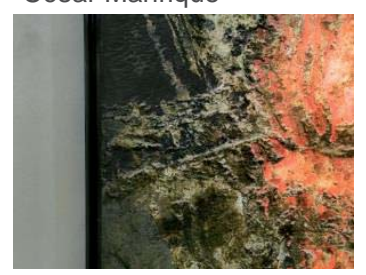

1949. Tierras Rojas y Negras. César Manrique través de cactus, lagunas, nenúfares y peces terminan de dar nombre al Jardín de Cactus, finalizado en 1990.

\section{EL AGUA: De la corrosión salina al gran azul}

Una de las primeras obras proyectadas para el Cabildo de Lanzarote, Jameos del Agua terminado entre 1966 -1977. Consta de una serie de espacios - jameos y túneles volcánicos- conformados a partir de ciertas condiciones naturales, rescatados de un territorio en abandono y deterioro que se adentra en el mar. Manrique aprecia el malpaís y su topografía para integrar este paisaje natural con el artificial, rescatando además una imagen característica de las playas de la isla: los charcos y estelas de agua en la arena que las olas producen. Las tres aberturas o "jameos" tienen diferentes características, y es precisamente en el jameo grande, donde se evoca esa imagen del agua sobre la arena blanca. Estos espacios, donde cabe destacar el espectacular auditorio natural, llevarían a crear especiales morfologías que conservan en su interior pequeños ecosistemas acuíferos con animales y vegetales iconos de la isla, como es el caso cangrejo ciego o Jameíto.

EL COLOR: De minerales tóxicos a pinturas en el paisaje

Los colores predominantes de la obra de Manrique son los del propio paisaje lanzaroteño: rojo de la lava ardiente, negro basáltico y marrones del malpaís; el verde metálico de óxido venenoso del lago verde; el azul de la corrosiva agua salina; y el blanco del hueso seco y de la arquitectura vernácula. Su arte matérico transforma la percepción de estos colores, construyendo un relato épico que nos hace ver el hostil paisaje de la isla como una obra de arte natural.

El aprecio de Manrique por el paisaje, junto a la cultura y arquitectura populares, se reflejan inicialmente en sus pinturas de 1942. En sus propias palabras se consideraba un pintor antes que cualquier otra $\operatorname{cosa}^{53}$. Tras estas primeras artealizaciones in visu, de textura abstracta y matérica, pero naturaleza figurativa, Manrique comenzaría a decantarse por la pintura puramente abstracta (1954) lo que le llevaría a descontextualizar estos mismos elementos buscando otras formas de interpretarlos. Para lograr la apariencia de ceniza de volcán o arenas, no usa esos elementos naturales, sino que realiza mezclas artificiales con serrín o cola.

${ }^{53}$ CESAR MANRIQUE. Pintura. Consultado el 30 de mayo de 2016 en http://www.cesarmanrique.com/pintura e.htm 
Es singular la fijación con el color de la arquitectura popular, que respondía fundamentalmente al marcado clima de la isla; así el color blanco es el predominante, reflejando la luz del sol e impidiendo el aumento de la temperatura interior. Manrique se declaraba fascinado con estas construcciones vernáculas, defendiendo la conservación y la recuperación del estilo resultante, que se propuso artealizar con su pintura. A continuación, promovió estrategias de restauración de lo existente, lo que le llevaría a publicar en 1972 un libro de fotografías Ilamado "Lanzarote, arquitectura inédita."

\section{Intervenciones in situ}

Manrique trató de conjugar y poner en valor la visión volcánica del malpaís con el blanco del hueso y del paisaje construido por el hombre. Esto daría forma a un nuevo paisaje contrastado, que además de aglutinante de las influencias coloniales de su pasado desarrollaría una fuerte identidad propia, considerada desde este momento un estilo típicamente lanzaroteño, pudiendo ser visto en algunos ejemplos como la Casa y Monumento al Campesino (1968) -homenaje a las tradiciones vernáculas e historia de la isla; siendo este último construido a partir de tanques de agua de barcos reutilizados y otros objetos ensamblados-; el lago natural de Jameos del Agua (1977), su vivienda en Taro de Tahiche (1968), o en la Residencia Taller de la Fundación César Manrique de 1999 -póstuma-.

Un ejemplo de artealización in situ, que a pequeña escala reúne todos los recursos anteriormente citados, se puede encontrar en la obra de su propia casa en el Taro de Tahiche (1968), actualmente reconvertida en la sede de la Fundación César Manrique. Los recursos empleados en la realización de esta obra son prácticamente todos los elementos anteriormente citados. Como sucede en los miradores, la intervención también se encuentra integrada en una colada de lava, con la clara intención de habitar un oasis en medio de la ¿terrible? naturaleza volcánica ${ }^{54}$. El color blanco, aplicado en los pasillos distribuidores hacia habitaciones subterráneas, salones en burbujas de lava, juguetes de viento, un lago similar a un jameo en el patio, pinturas inspiradas en el paisaje lanzaroteño...

Actualmente el turismo se ha convertido en la principal actividad económica, cuyo modelo territorial ha tratado de ser desarrollado bajo las reglas establecidas por el trabajo conjunto de Manrique y el presidente del Cabildo, José Ramírez entre los años

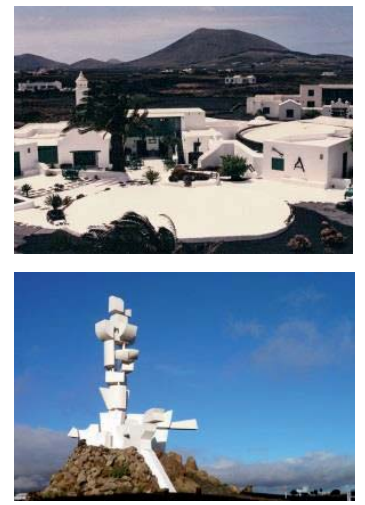

1968. Monumento al Campesino

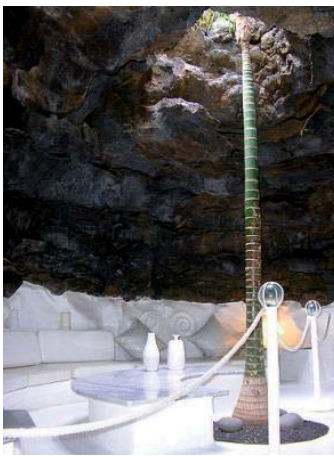

1968. Casa en Tahiche César Manrique

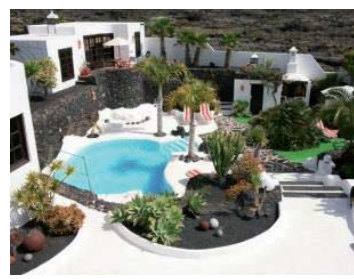

1968. Casa en TahicheCésar Manrique

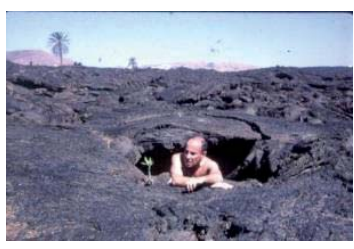

c.1960. César Manrique en un una Burbuja Volcánica. Autor: Francisco Ontañón

${ }^{54}$ SARDÁ, J, ZAMORA, A (2014): Aproximación a los paisajes culturales del regadío. La Geria de Lanzarote. Universidad Politécnica de Cataluña. Consultado el 24 de mayo de 2016 en http://ocs.editorial.upv.es/index.php/ISL/ISL2014/paper/viewFile/197/156 


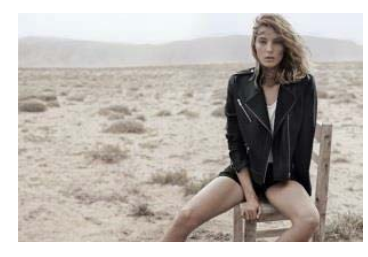

2014. Campaña de Mango. Lanzarote.

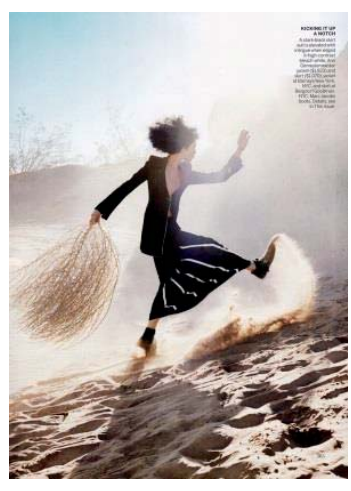

2014. American Gothic. Vogue USA. Lanzarote.
1960 y 1974. Ambos entendieron que una propuesta global, que mezclara arte y turismo (poética y pragmática), aprovechando el especial potencial del paisaje artealizado por Manrique, era el enfoque que la isla necesitaba para diferenciarse de las otras y así conseguir su expansión económica. Su modelo era categóricamente contrario a los otros planes turísticos de la época, que optaban por el desarrollo y disfrute de la rentabilidad rápida en entornos de sol y playa ${ }^{55}$. Las intervenciones en el territorio lanzaroteño se caracterizaban por un absoluto respeto al programa estético creado por Manrique.

Como resumen de lo anterior, y realizando un pequeño recorrido en el proceso de artealización de la isla de Lanzarote, podemos establecer un primer momento de generación de imaginarios y representaciones de lo existente, son las artealizaciones in visu, en forma de pinturas o fotografías que Manrique realizó entre los años 1942 y 1972 y que también popularizaría y llevaría más allá de sus fronteras. Esta atención a ciertos aspectos del territorio comenzaría a ponerse en práctica tras su regreso de Estados Unidos en 1964, actividad desarrollada conjuntamente con los medios políticos. Estas son las artealizaciones in situ, descritas con anterioridad: juguetes de viento en sustitución de las vallas publicitarias y turísticas en el paisaje, Casa - Monumento del Campesino, Jardín de Cactus, Miradores, Jameos del Agua...Un recorrido de arte público, que termina en la visualización general del conjunto del plan de intervenciones de pequeña escala repartidas por el territorio. Finalmente, estas han producido la consideración de la isla de Lanzarote como un paisaje reconocible, y un ejemplo paradigmático y deseable de gestión del paisaje.

${ }^{55}$ CRUZ, J (2012): EL PAís: César Manrique en la guerra y en la paz. Consultado el 30 de mayo de 2016 en http://cultura.elpais.com/cultura/2012/09/25/actualidad/1348574980_832486.html 


\subsection{Redescripciones clásicas}

En la disciplina arquitectónica hay una serie de redescripciones bien conocidas y prestigiadas: “Los Ángeles: La arquitectura de las cuatro ecologías” de Reyner Banham (1971), que por un año se adelanta al trabajo de Venturi, Izenour y Scott-Brown (que también estaban trabajando sobre Los Ángeles) "Aprendiendo de Las Vegas" (1972) y “Delirious New York", de Rem Koolhaas (1978). Los presentamos aquí como ejemplo de cómo un libro puede cambiar radicalmente la percepción de un contexto, y condicionar las posteriores intervenciones.

Los Ángeles era, hasta la aparición de este libro, inconcebible como objeto de estudio desde la Academia. El territorio de la costa oeste no constituía un paisaje sino un error del sistema, una abominación. Este libro redescribe esa costa y su forma de vida dispersa; y hace pensar que allí ha aparecido, en realidad, algo nuevo, una cultura nueva, que tiene interés, y que puede ser estudiada.

Con "Aprendiendo de Las Vegas" ocurre algo semejante. Las Vegas era considerado in infierno del mal gusto. Nadie en su sano juicio, dentro de un sistema académico, podía ni siquiera considerar dedicar una palabra a Las Vegas. Sin embargo, el lugar se redescribe en este libro, que explica cómo funciona, hablándonos de cómo es nuestra sociedad actual y de cómo puede llegar a ser si la controlamos.

"Delirious New York", que no llega a ser una década posterior, hace algo semejante con el denso contexto de la isla de Manhattan.

Los tres libros dan entidad a sus respectivos territorios constituyéndolos en paisaje - artealización in visu - y a continuación se erigen en referencia para otros tantos capítulos en la historia de la arquitectura - artealización in situ.

\subsection{Paisajes literarios: una novela}

El arte conforma la imagen detrás del espejo en que nos queremos reflejar, el ideal que buscamos alcanzar. Un nuevo arte crea un nuevo ideal y nuestra realidad se transforma hacia la nueva referencia. El proceso es suficientemente lento como para que nos sea difícil percibir el cambio cultural.

Más arriba hemos utilizado el ejemplo del retrato para entender la génesis del concepto de paisaje, así como para apoyar el estudio de la antimímesis y la artealización. Es interesante visitar otros aspectos de nuestra cultura para entender las profundas implicaciones que estos procesos pueden tener en nuestra vida cotidiana. 


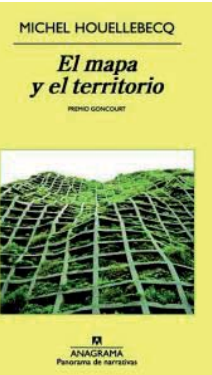

Supongamos que cambiamos paisaje por "amor". Según el ensayista Alain de Botton ${ }^{56}$, el arte, especialmente la literatura, ha determinado la forma en la que vivimos las relaciones personales. Aprendemos qué es enamorarse en las narrativas de cada cultura y cada momento, desde los cuentos populares de transmisión oral a cine de nuestros días.

Por ejemplo, en la obra de 1774 "Las Cuitas del Joven Werther" de Goethe, el protagonista es capaz de dejar de lado todas ocupaciones mundanas entrando en una espiral de sufrimiento por un amor que no puede materializarse. Las crónicas de la época reflejan un incremento de fugas, duelos y suicidios, entre un público lector que se ha alistado a esa idea de lo sublime.

Sin embargo, en la novela postromántica, representada por Madame Bovary (Gustave Flaubert, 1856); Emma sufre un golpe de realidad cuando la idea de amor romántico que había leído en las novelas no se corresponde con la realidad, y los problemas económicos y familiares acaban minando su vida. Tal y como Ortega y Gasset afirma, ésta se convierte en víctima de los ideales burgueses de la Europa de la época, protagonista de un romanticismo positivista ${ }^{57}$.

Esta será la transición al siglo XIX, en el que el realismo será lo que prime; se considerará la realidad en su faceta más cruda, sin dejar espacio de ningún tipo para la idealización. No habrá ni libertad ni originalidad; entendiendo que ésta última nace del espacio de incertidumbre que fomentan ${ }^{58}$. En general, este esquema se repetirá de forma cíclica en el tiempo, encajando evolución y rupturas con lo anterior establecido.

"El mapa y el territorio" (Michel Houellebecq, La Carte et le Territoire 2010) dice desde su título que habla de la relación íntima entre dos cosas muy diferentes, el territorio y nuestra lectura del mismo, que se retroalimentan e influencian mutuamente en un baile infinito.

El protagonista es un artista que redescribe el mundo. Primero con una serie de fotografías de objetos industriales, que hace deseables, artealizando los objetos cotidianos. Segundo con una serie de fotografías de mapas (los del título) con los que evidencia la belleza de los filtros de información sobre el territorio. Y finalmente con una serie de retratos de profesionales en una especie de paisaje humano de fin de siglo, artealizando comportamientos y situaciones que hasta ese momento sólo tenían lectura pragmática.

\footnotetext{
${ }^{56}$ BOTTON, A. (2016). Love, actually. 24 de Abril de 2016. Financial Times

57 ORTEGA Y GASSET, J 1983 (1914) : Flaubert, Cervantes, Darwin, en Obras completas, (Meditaciones del Quijote, Meditación primera, 20), Madrid: Alianza Editorial, 1983 (1914), pp. 399-400

${ }^{58}$ ORTEGA Y GASSET, J. Op cit
} 
A lo largo de la novela, y de la vida del artista, cambia la relación con el territorio, en el sentido literal: vive en el campo, en la que fue la casa de su padre, que poco a poco ha sido absorbida por las periferias urbanas, hasta llegar a un curioso epílogo ambientado en el año 2040 en que el campo francés es un paisaje mantenido para el turismo asiático. Un epilogo de "ciencia-ficción" en la tradición de las anti-utopías

El protagonista de la novela se levanta y descubre una mañana que toda Francia, todo el paisaje de una gran parte Europa, es en realidad un jardín agrícola conservado para el turismo de otro continente. Esto enlaza con las Directivas Europeas y la Política Agrícola Común que desde los años ochenta convierte a los agricultores y ganaderos franceses en jardineros del paisaje, subvencionados para dar continuidad a sus actividades productivas no viables, cuidando el paisaje para que visualmente, como espectáculo, sea bello. 


\section{CAPITULO II. HACIA UNA ECOLOGIA}

\section{INTRODUCCION}

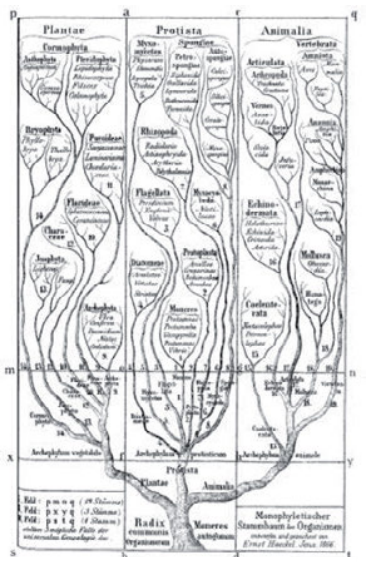

1866. "Generelle Morphologie der Organismen". Ernst Haeckel
El término ecología, acuñado en el año 1866 -Ökologie- por el filósofo alemán Ernst Haeckel ${ }^{59}$ en el trabajo "Generelle Morphologie der Organismen", está compuesto por los elementos griegos oikos (casa) y logos (estudio o tratado). Significa, por tanto, “Estudio del hogar". Sin embargo, Haeckel -influenciado por las teorías de Charles Darwinestablece una relación entre la ecología y la economía, denominando a la ecología como la "Economía de la naturaleza". Más concretamente: "la ecología es la ciencia de la economía, modo de vida y relaciones externas entre organismos," 60 y en su opinión, debe buscarse un modo para gestionarla.

La ecología se ocupa de las relaciones, no de las cosas; es decir, un objeto no puede ser ecológico; sin embargo, la relación de este con el resto de cosas sí puede serlo. La economía de las relaciones entre organismos se puede cuantificar en otros organismos, en los efectos en su ambiente, y en los intercambios y consumos de recursos en el mismo.

No cabe distinguir categorías que sitúen las economías de ciertos organismos en un plano diferente de los de otros organismos, es decir, no tiene sentido la diferenciación romántica entre "natural" y "artificial", abarcando todas las asociaciones posibles entre cualquier tipo de organismo, ${ }^{61}$ y entendiendo el término naturaleza como las características del universo material.

Si consideramos que el universo material en el que las relaciones entre organismos pueden ser gestionadas se circunscribe, de momento, al planeta Tierra, definiremos la ecología como la economía de la Tierra.

Para visualizar las implicaciones de esta afirmación para nuestra cultura, hemos preparado la siguiente secuencia de esquemas, que reflejan la evolución del concepto de "hogar" desde el punto de vista humano.

${ }^{59}$ CORTÉS GABAUDAN. F (2011): Ecología, la economía de la naturaleza según Ernst Haeckel. Universidad de Salamanca.

${ }^{60}$ ASCOT, P; MÜLLER, G (1998): "The Birth of Scientific Ecology" en The European Origins of Scientific Ecology, 1800-1901. Ámsterdam: Gordon \& Breach

${ }^{61}$ HOSEY, L (2012) The Shape of Green. Aesthetics, Ecology and Design. Island Press. Washington. 


\section{FASES}

\subsection{Fase Paraisos}

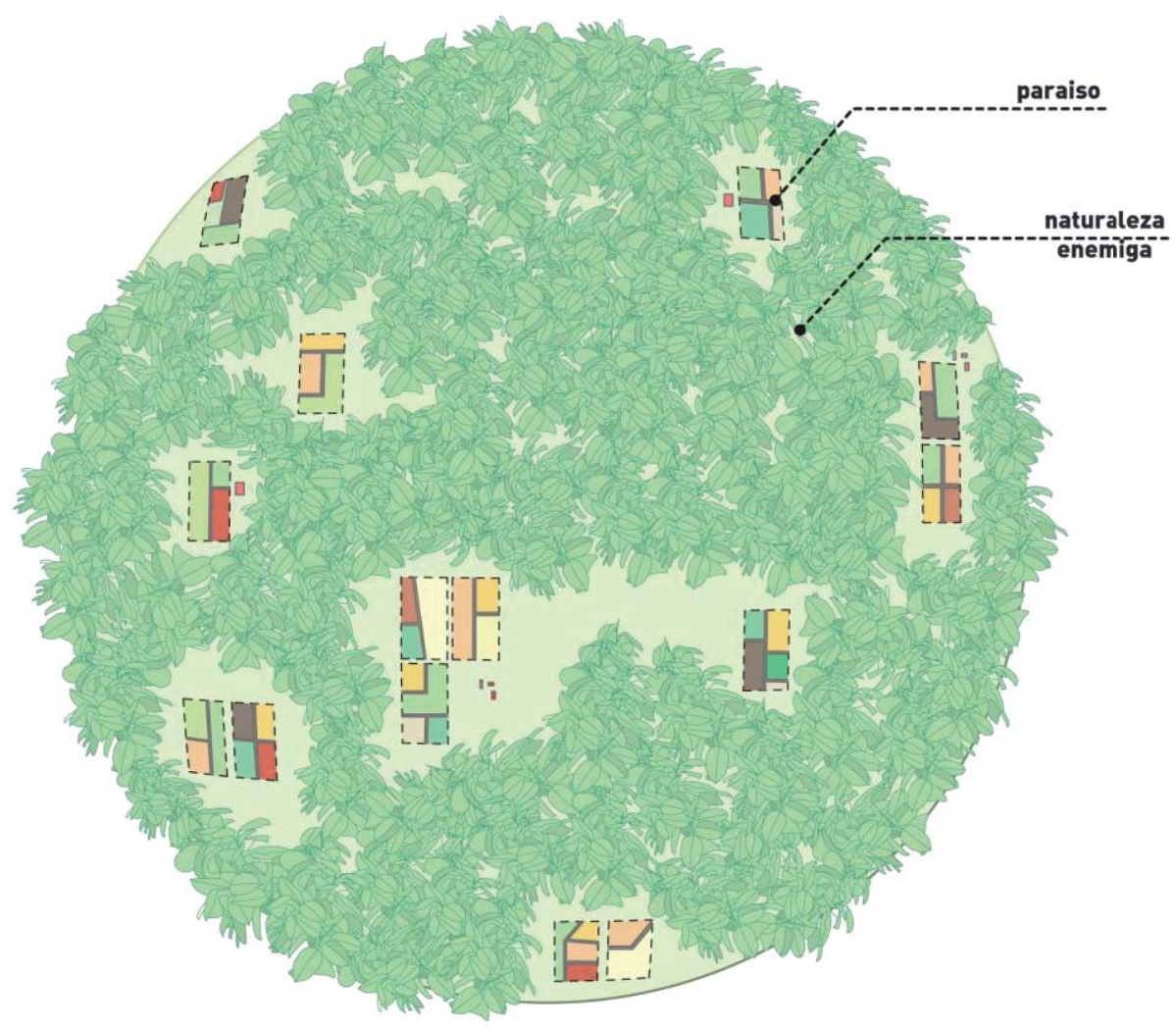

El paraíso primigenio es un recinto tapiado, un artificio de geometría abstracta, un cultivo productivo con árboles de fruto y especies comestibles, separado y protegido del territorio de lo salvaje y lo mortal. Dentro del muro hay orden y alimento. Fuera del muro hay fieras salvajes, frutos venenosos y peligros inesperados.

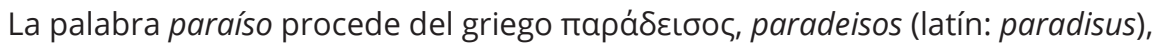
que se utiliza en la Biblia griega para referirse al Jardín del Edén. A su vez, el término griego procede del persa برديسpaerdís, 'cercado', que es un compuesto de paer-, 'alrededor' (relacionado con el prefijo griego peri-) y -dis, 'crear'.

En esta fase, el limite deseable es el muro del jardín productivo.

Es interesante observar que hoy en día la palabra paraíso desencadena en Google una colección de imágenes de naturaleza salvaje. La idea de paraíso ha evolucionado desde una cosa hasta su contraria; ¿podemos reconducirla en una tercera dirección? 


\subsection{Fase Ciudades-Estado}

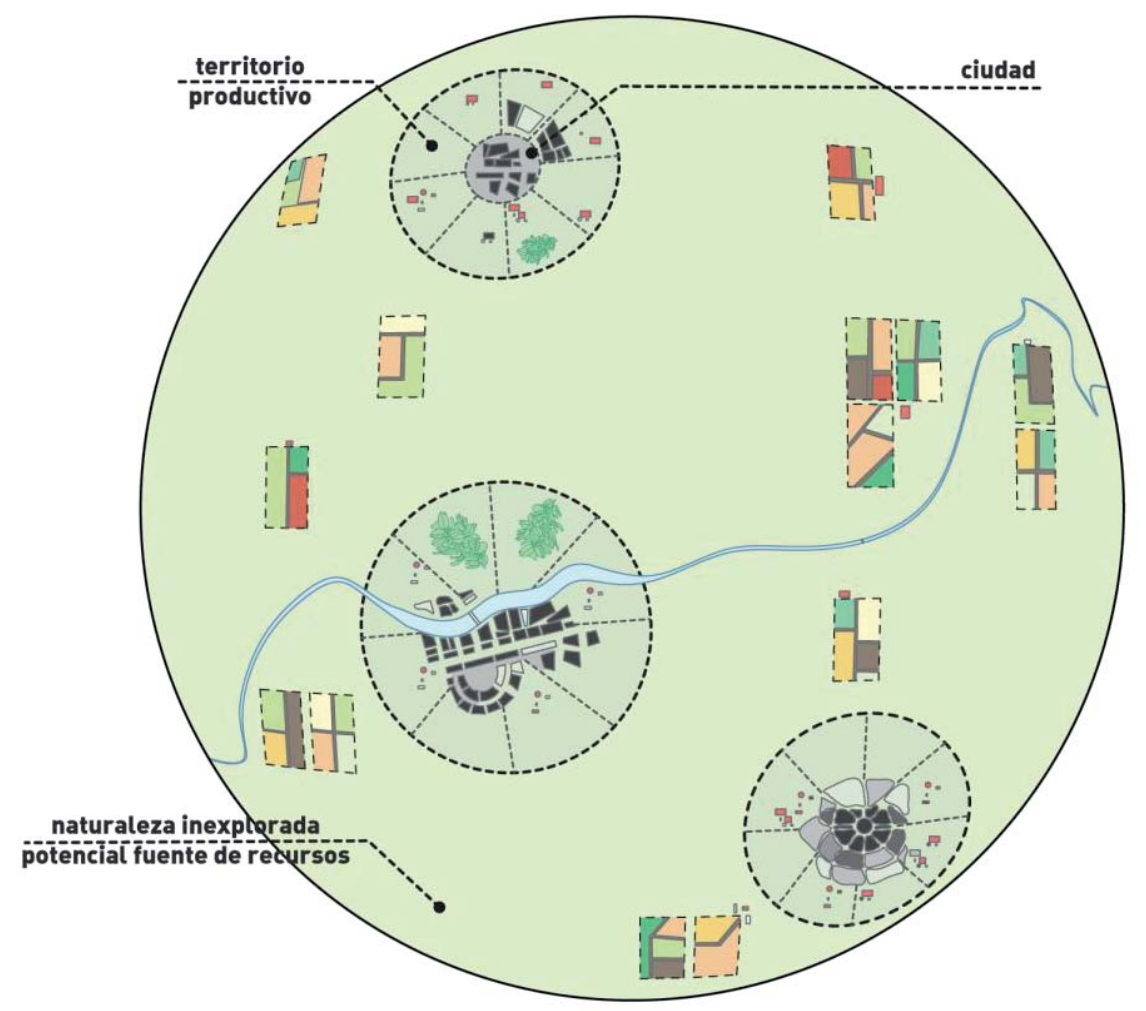

La ciudad-estado emerge como ampliación de ese "cercado" en el territorio, un recinto de orden en un territorio hostil.

El muro del paraíso protege ahora la civilización. La etimología de civilización, como las de ciudad, civil, polis o política, es compleja. Nos limitaremos a observar que el hogar es la ciudad, y el territorio es un lugar peligroso pero valioso como fuente de recursos que alimente la ciudad desde fuera.

A medida que la ciudad aumenta su control sobre el territorio este va adquiriendo carácter de hogar, en el proceso de formación de los estados modernos. Emerge en concepto de paisaje. 


\subsection{Fase Revolución Industrial}

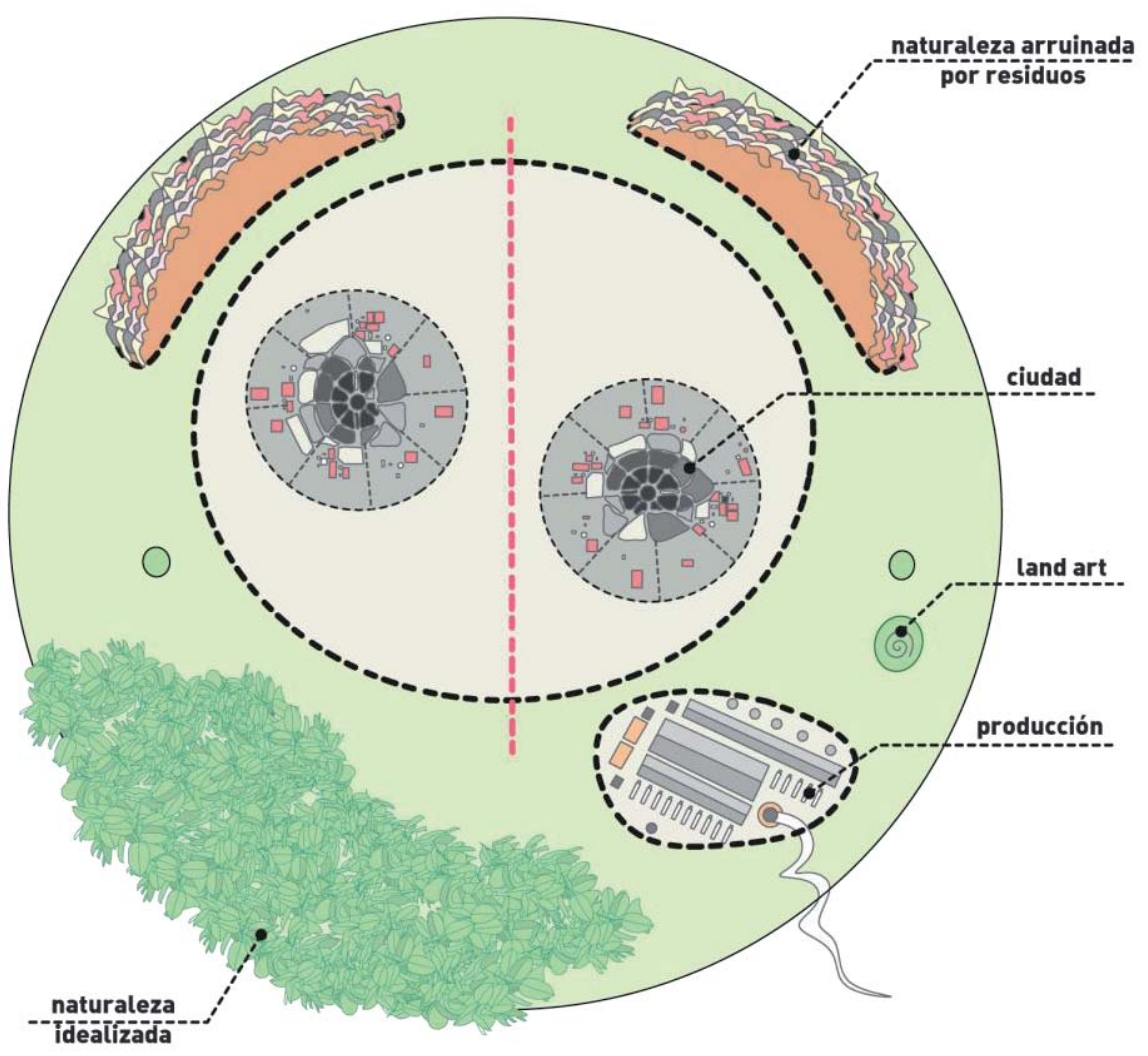

Controlado el territorio, el hogar se amplía para incluir espacios circundantes a las ciudades, a la vez que se fijan territorios "exteriores" en los que cabe la contaminación por residuos, ruidos y humos resultado de la actividad industrial

Aparece un nuevo ideal de naturaleza: el reducto de lo salvaje adquiere las connotaciones de lo sublime. El concepto de paisaje queda establecido. 


\subsection{Fase Crisis medioambiental}

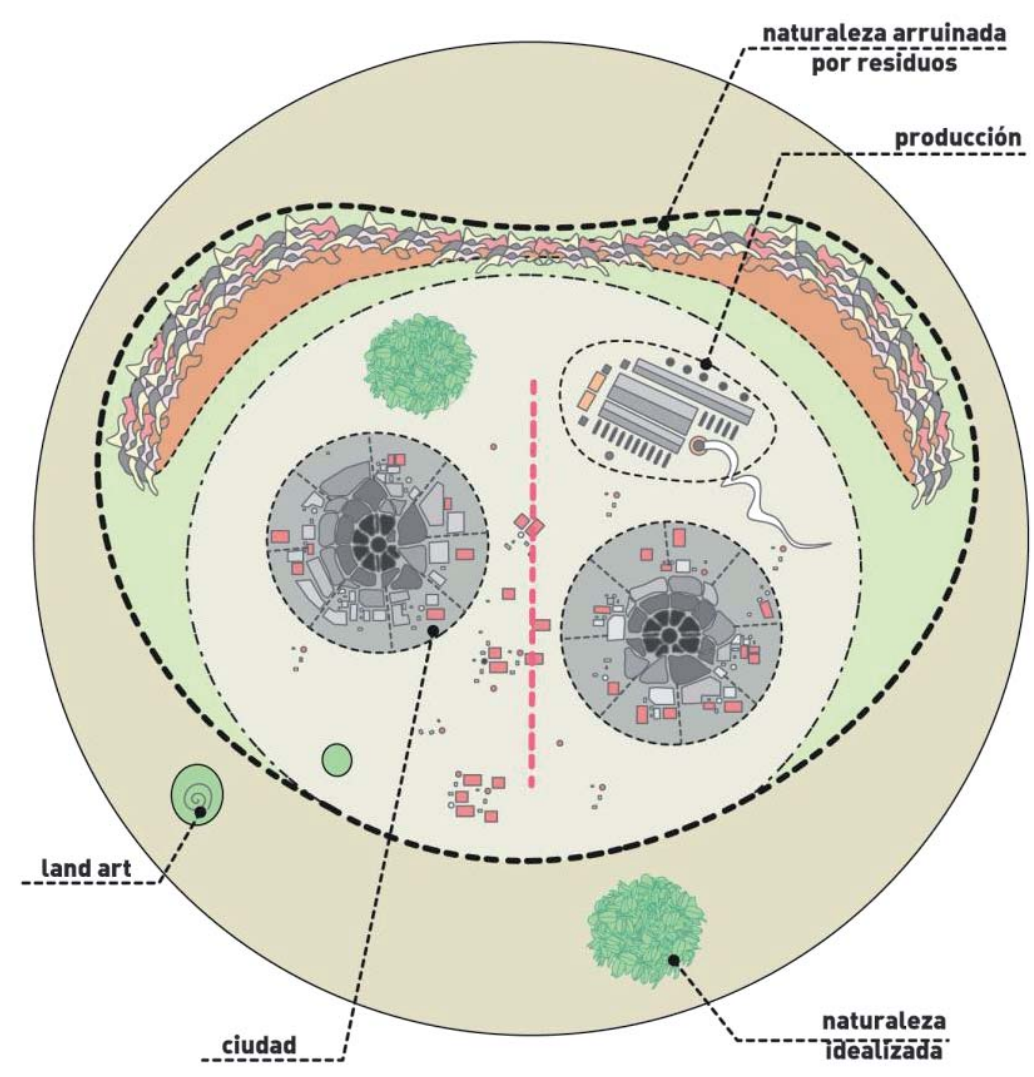

La conciencia de la crisis medioambiental lleva a la inclusión en el perímetro del hogar de los territorios de lo productivo y sus residuos. Ya no hay un "fuera" en el que sea lícito verter contaminantes.

Persiste el concepto de naturaleza idealizada, reducida a una pequeña fracción del territorio. Simultáneamente, se incorporan elementos de naturaleza idealizada en el interior del recinto hogar.

El concepto de paisaje continúa asociándose al territorio exterior. 


\subsection{Fase Ecología total}

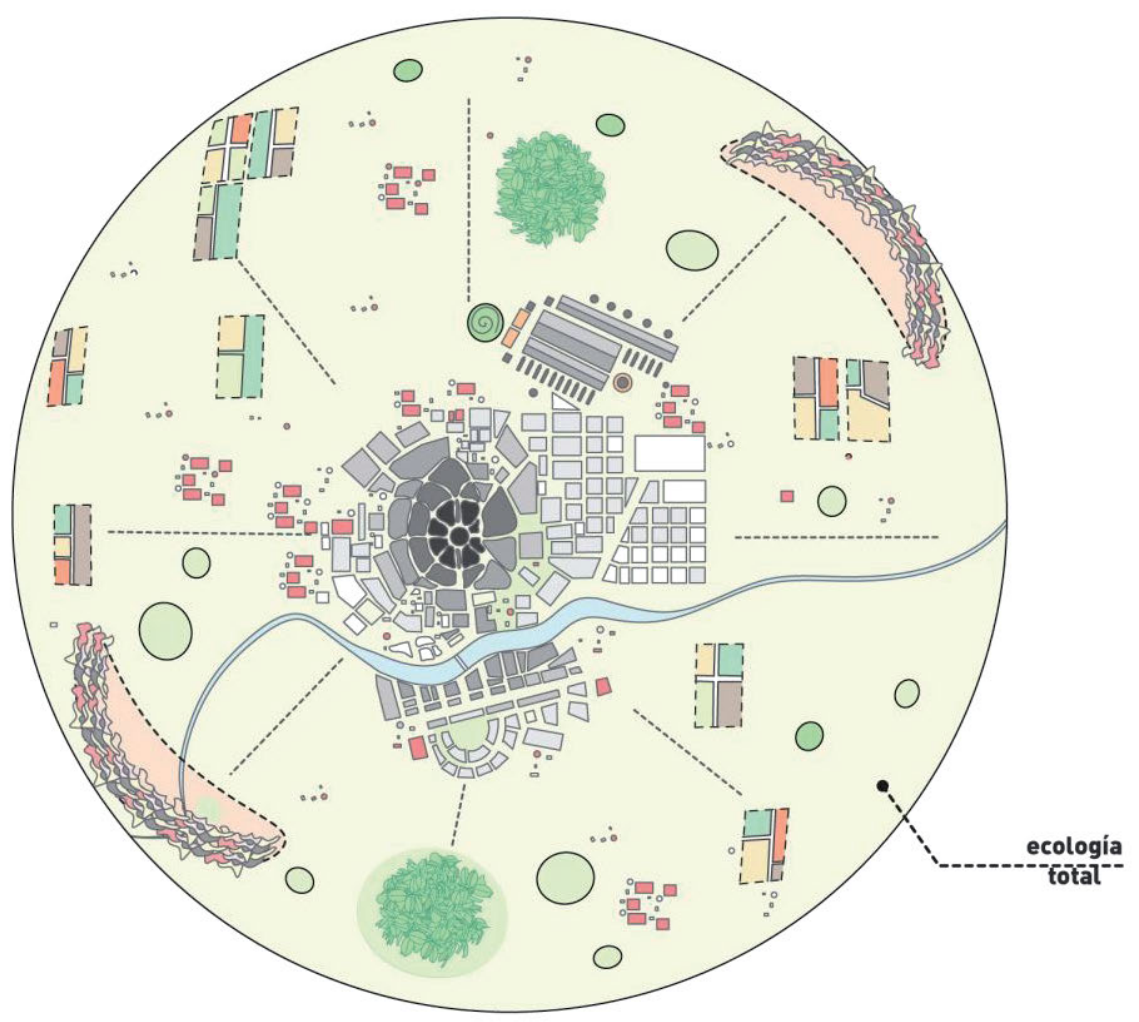

Hipótesis de futuro. Todo el planeta es hogar, y se gestiona su economía con la ecología total. El concepto de paisaje se aplica a todo el territorio. El Paisaje Productivo es el más deseable, en una nueva lectura de la idea de paraíso (da capo). 


\section{CAPITULO III. CATÁLOGO DE PAISAJES PRODUCTIVOS}

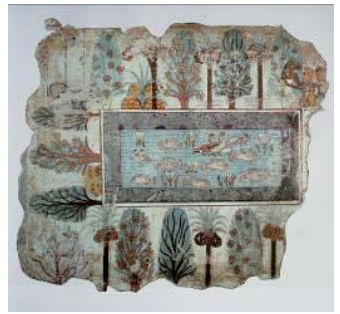

3500 B.C., Fresco from the tomb Nebamun.

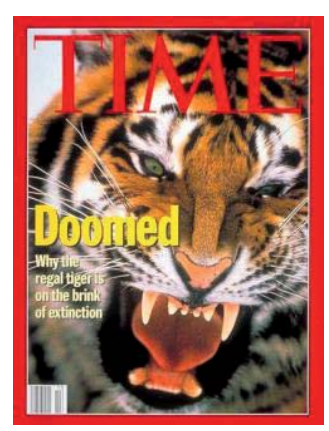

1994, TIMES MAGAZINE: Doomed

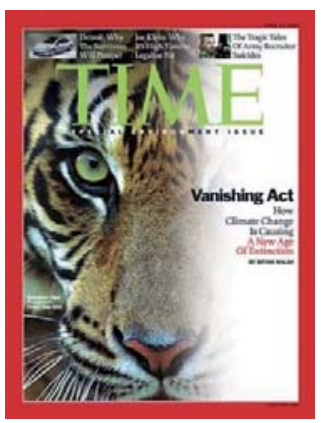

2009, TIMES MAGAZINE: Vanishing Act. How climate change is causing a new age of extinction.

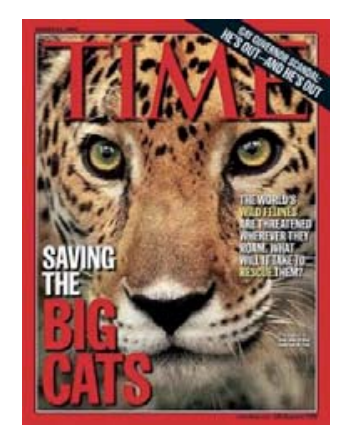

2004, TIMES MAGAZINE: Saving the big cats

\section{Ecosistemas Gestionados / Managed Ecosystems}

\subsection{Introducción}

El origen del concepto de ecosistema es relativamente reciente: en el año 1935 aparece descrito en los textos del botánico británico A.G. Tansley, donde ya se consideraban fundamentales la atención tanto a los factores inorgánicos como los orgánicos. De su definición podríamos extraer que los ecosistemas se definen por "una red de interacciones entre organismos y entre los organismos y su ambiente"62, y "pueden tener diferentes escalas, pero normalmente se trata de espacios de tamaño limitado y específico ${ }^{63}$. En los últimos años, el término ha pasado a relacionarse directamente con la ecología, definiendo conceptos muy ligados a la misma: flujos de energía, ciclos materiales y conservación de recursos. No obstante, los estudios indican un cambio desde la consideración del concepto como una condición descriptiva, hacia el énfasis en una perspectiva predictiva. En estos términos, la noción ecosistema "proporciona una base productiva para el entendimiento de sistemas naturales que poseen un alto grado de organización" 64 .

\subsection{Menageries}

Hasta el momento en el que los ecosistemas fueron considerados susceptibles de ser conservados, y por tanto, dando importancia a relaciones democráticas o de beneficio común, estos se describían según relaciones jerárquicas, donde el ser humano se situaba en la parte más alta de la pirámide. El primer indicio de la existencia de un microecosistema gestionado por el ser humano data de 3500 a.C. a partir de una artealización in visu, de lo que posteriormente se llamaría menagerie, representado en un fresco de la tumba de Nebamun, Tebas (18 ${ }^{a}$ Dinastía) en Egipto. Una menagerie es un término francés que designa una colección de animales salvajes-en su mayoría exóticos-, así como domésticos, que lleva a la coexistencia con humanos en el mismo lugar, pero participando en relaciones de cautividad: sólo son mostrados. En 1204, el Rey Juan I de

62 VVAA. (2005) Plant Ecology. Berlin, Springer. ISBN 3-540-20833-X.

${ }^{63}$ VVAA. (2002) Principles of Terrestrial Ecosystem Ecology. New York, Springer. ISBN 0-387-95443-0.

${ }^{64}$ WILLIS, A.J. (1997) Funcional Ecology 11. British Ecological Society. (pág 268-271). 
Inglaterra usaba la Torre de Londres como menagerie real, donde guardaba distintas especies procedentes de regalos. Las menageries solían pertenecer a aristócratas cuyas intenciones primarias no eran científicas ni educacionales, sino para ilustrar su poder y riquezas, mediante animales procedentes de sus colonias y agasajos futo de sus relaciones con la aristocracia. Eran las instituciones predecesoras de lo que nosotros conocemos por los actuales zoos. De hecho, la menagerie del Palacio del Buen Retiro, fundada en 1774 por Carlos II en España y configurada de manera similar a la del Palacio de Versalles (1664) en Francia, se encontraba formada por animales traídos de las colonias españolas y cuyos descendientes formarían siglos después el zoo de Madrid.

El diseño de estos espacios, y de los zoos modernos, como el Berlin Zoological Garden o el de Nueva York, se encuentran claramente influenciados por los primeros dioramas. El Museo de Historia Natural de Nueva York creó en 1869 esta artealización in visu, como modo de representación en perspectiva de hábitats y ecosistemas, mediante una escenografía realista, cercana a la taxidermia y un fondo ilustrado. Escenografías, que más adelante comenzarían a albergar animales vivos y plantas en los contextos de los zoos, conformando de alguna manera artealizaciones in situ.

Con el paso de los años, las tipologías de estos espacios han seguido evolucionando independientemente, siempre en una búsqueda por evitar o camuflar virtualmente -y visualmente- las barreras que protegen a sus visitantes humanos. Un ejemplo paradigmático es el Aviario del Zoo de Londres (1964) de Cedric Price, cuyos visitantes pueden introducirse en el hábitat de las especies de pájaros que alberga.

En esta línea y durante los años noventa, la configuración diorama llegó a su radicalización en Disney Animal Kingdom en 1998. A caballo entre parque de atracciones, museo y zoo, su formalización era un gigantesco diorama que perdía su bidimensionalidad en favor de accidentes geográficos en tres dimensiones a escala 1:1.

En ejemplos posteriores se suaviza el contexto y el diseño del paisaje para intentar recrear con mayor realismo los lugares de procedencia de cada especie -evitando las representaciones tipo diorama- en un acercamiento hacia la línea del tiempo coetánea más democrática y al realismo artificial, es el ejemplo del zoológico de Paris por Bernard Tschumi (2009). 


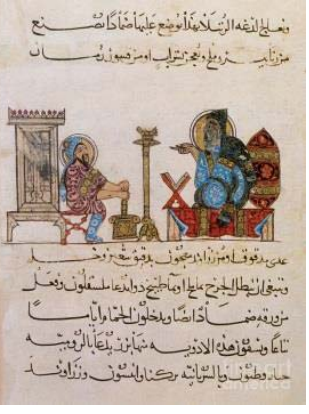

$50 \mathrm{dC}$,"De Materia Médica"- Dioscórides

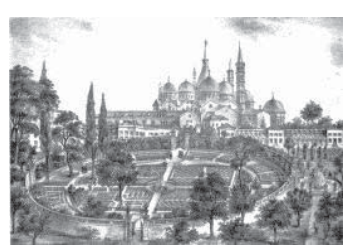

1545, Botanic Garden in Padova

\subsection{Jardines Botánicos}

En este apartado se desarrollarán los ecosistemas vegetales gestionados, o una tipología de microecosistema cuyo fin es la conservación y muestra de agentes no-humanos en relación con humanos. Estos mantienen estrechas relaciones con los paisajes fruto de la jardinería productiva -que desarrollaremos en otro apartado- compartiendo un origen similar hasta su popularización y creación de una identidad propia.

Los primeros jardines botánicos, comenzaron con el impulso del conocimiento de las plantas medicinales. La publicación del libro De Materia Médica (50 d.C.) del médico, farmacólogo y botánico griego Dioscórides, fue clave para el desarrollo. La obra fue ampliamente difundida durante el imperio romano y también traducida al árabe, teniendo vigencia hasta el siglo XVII ${ }^{65}$. Las hierbas y remedios referidos en el tratado comenzaron a ser cultivados en jardines para su uso. Estos jardines eran prácticamente exclusivos - como el Jardín del Edén- , ya que su carácter era privado y requerían una mano especializada para su conservación; por eso durante la Edad Media se encontraban principalmente gestionados en los monasterios.

"Así muchos jardines monásticos se compusieron según una división en cuatro partes alrededor de un fontín y cobraron un sentido simbólico, de manera que el fontín representa la fe, de la que mana la vida y los cuatro parterres simbolizan los evangelios. Algunos desarrollaron hasta laberintos en símbolo de penitencia, en ningún caso con afán de sensualidad paisajista." 66.

Es precisamente en Italia en 1545, en un monasterio de Padua, donde se funda el primer jardín botánico de la historia -aún conservado- y origen de todos los demás jardines según la UNESCO. Por decisión del Senado italiano, en él se buscaba cultivar simples "variedades vegetales con virtudes medicinales, cultivadas en jardines urbanos"67 -para la realización de medicamentos, que como hemos visto, era principal propósito de esta tipología de ecosistema.

Durante el Renacimiento, su gestión seguía siendo especializada, pero pasó a vincularse a las universidades: por un lado, los monasterios se convirtieron en lugares académicos y por otro, el descubrimiento de nuevas especies de plantas produjo la

${ }^{65}$ ELÍA. R.H. (2009) Dioscórides Rescatado por los árabes. (Consultado el 15 de Julio de 2015) Ver en: http://www.scielo.cl/pdf/byzantion/n28/art02.pdf

${ }^{66}$ MADERUELO, J (2005): El Paisaje. Génesis de un concepto. Abada Editores. Madrid.

${ }^{67}$ WIKIPEDIA . Jardín de los Simples de Florencia. (Consultado el 18 de abril de 2016) Ver en: https://es.wikipedia.org/wiki/Jard\%C3\%ADn_de_los_Simples_de_Florencia 
aparición de un género literario de análisis y conocimiento del medio. Estas publicaciones se acompañaban de cuidadas ilustraciones que, aun teniendo un carácter científico, se eran auténticas artealizaciones in visu; convirtiendo esas plantas en elementos de colección y deseo. Así proliferaron los Ilamados jardines académicos, que integraban lecciones de la facultad y que incluían especies "desconocidas" traídas de otros lugares del mundo.

Justamente, ya en el siglo XIX, es cuando la búsqueda de lo exótico, el conocimiento, la investigación y la observación, convierte a estos ecosistemas vegetales en una herramienta educativa para las generaciones posteriores y una fuente de producción cultural e inspiración. Este período -localizado en la anterior línea del tiempo como el momento en el que Yellowstone se convertía en parque Nacional en 1872- es también el que consideramos como introducción para hablar de los ecosistemas gestionados vegetales, como una tipología de la preservación y display de paisajes abiertos al público.

Tomamos como inicio la muestra etnológica de Robert Latham en el Crystal Palace de 1854. Por entonces, la etnología era una nueva disciplina, y Latham fue el comisario de un circuito de historia natural, en el que se mostraba material de trece grupos humanos de origen exótico - incluso había seres humanos vivos de esos grupos- junto con su entorno, principalmente mostrado mediante displays botánicos. Esta artealización in situ, mostraba la obsesión con los rankings característica de esta disciplina, hablando de características de unas culturas por encima de las otras; y también la obsesión del propio comisario, que buscaba enfatizar todo aquello que no se podía mostrar, como el lenguaje o sus religiones ${ }^{68}$.

Décadas más tarde, con el inicio de la carrera espacial y la búsqueda de posibles escenarios con los que averiguar cómo funciona nuestro planeta, comenzaron exhaustivas investigaciones sobre el desarrollo de ecosistemas en entornos espaciales. Tanto es así, que se reprodujeron las características de estos entornos en condiciones terrestres, para poder validarlas antes de llevarlas al espacio. Uno de estos espacios es BIOS-3 (1965), ubicado en Krasnoyarsk, Rusia; que además incluía una tripulación humana. De hecho, el módulo de vivienda cumplió así una satisfactoria simulación, habitándose durante más de un año.

La biosfera de Montreal, realizada por Buckminster Fuller, fue el primer museo del agua de Canadá, y también un ejemplo tipológico de cómo mostrar al público general un paisaje encapsulado con fin educacional. Fue el pabellón de Estados Unidos en la Expo '67 en Montreal, que posteriormente se donó a la misma ciudad, y en su interior albergaba un

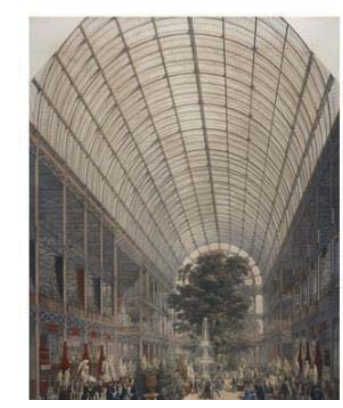

1851, Crystal Palace"Paxton

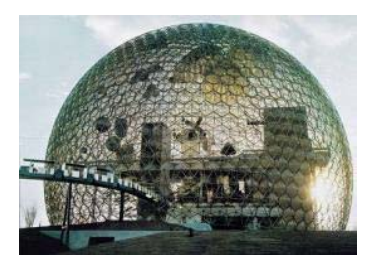

1967, Biosfera. Buckminster Fuller

${ }^{68}$ VV.AA. (2013) 1854: Natural History Department of the Crystal Palace Described. Euston Grove Press. Facsimile of 1854 Edition. 


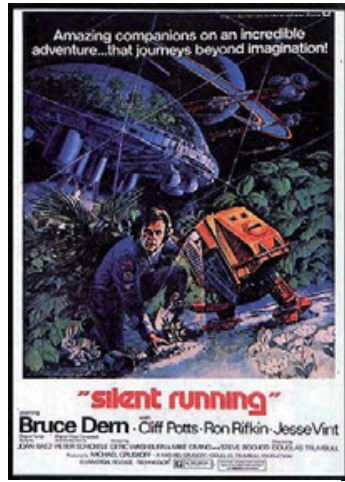

1965, "Silent Running"-

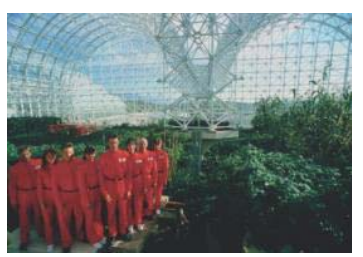

1984, Biosphere 2

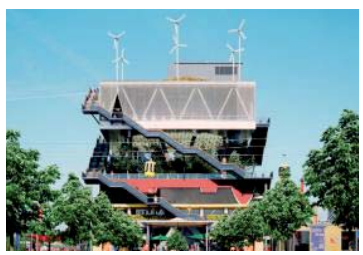

2000, Holland Pavillion EXPO 2000, MVRDV. pequeño ecosistema dedicado a los paisajes de los Great Lakes - St. Laurence. El cine comenzó por entonces a reflejar estos escenarios, como en la cinta posapocalíptica, Silent Running (1972), generando toda una estética de ciencia ficción en torno a este tipo de espacios.

Pero el ejemplo más extremo de cómo experimentar con ecosistemas encapsulados fue - pensado para al menos cien años- con el fin de recabar información para investigación y educación acerca de cómo funciona nuestro mundo. Ubicado en el desierto de Arizona, esta artealización in situ, se compone de siete ecosistemas completos que son reflejo de los existentes en la tierra. El sistema incluye un océano con una barrera de coral, un desierto, una sabana, un bosque tropical, un humedal, un área de agricultura intensiva, un hábitat humano y una estructura subterránea. Los biospherians, ocho seres humanos, hombres y mujeres convivieron en los ecosistemas durante períodos de dos años.

El experimento fracasó en 1993, en la segunda ronda, haciendo visibles algunos problemas que tienen que ver con nuestro presente: en algunos ecosistemas hubo incidencias en el control de plagas y la extinción de ciertos animales y plantas, la falta de organización en el grupo de biospherians provocó la incapacidad para producir los cultivos necesarios para su supervivencia, la compacidad en el diseño del complejo produjo un déficit de oxígeno; y finalmente, el descontento de los participantes les llevó a contar su experiencia delante de las cámaras de televisión, arruinando toda credibilidad científica del proyecto. Actualmente, pendiente de ser recuperado, es un espacio educacional visitable perteneciente a la Universidad de Columbia.

Años más tarde, se establecen los objetivos de Exposición universal de Hannover del año ecosistémicos entre los seres humanos, la naturaleza y la tecnología, así como proponer soluciones para esta coexistencia. Para ello, los arquitectos MVRDV, en representación de Holanda, crearon un microecosistema, pero con las características de un monumental parque por niveles. Se trata de un ejemplo de artealización in situ, sobre el que se testeaban soluciones para la falta de luz y de espacio terrestre, funcionando como un laboratorio. El pabellón se encontraba formado por la apilación de seis ecosistemas holandeses, que iban desde el paisaje dunar, hasta el paisaje invernadero, coronados por un pequeño lago rodeado de molinos de viento, que proporcionaban la energía al conjunto. En sus propias palabras, un "kit de supervivencia"69, en el que hacían visible a los visitantes, las energías renovables, la cultura del reciclaje y el respeto por la naturaleza.

${ }^{69}$ MVRDV.Expo 2000. Ver en http://www.mvrdv.nl/en/projects/expo\#/archive (Consultado 11 de diciembre de 2015) 
Por el contexto en el que se han mostrado, pocas de las artealizaciones in situ antes descritas han tenido un uso real pragmático -ya sea fuera del ámbito de las muestras universales o como ejemplos de experimentación-, sino que se desafortunadamente la mayoría de ellas han tenido un destino de propuestas temporales y abandonadas.

De nuevo en el marco de una Exposición Universal, encontramos al arquitecto inglés Thomas Heatherwick, encargado de representar a Inglaterra en Shanghai 2010. Inglaterra fue uno de los primeros países en fundar una institución de bótanica, pero en ellas jamás suelen mostrarse las semillas, para ello, la firma propone Seed Cathedral, un semillero para el que toma como referencia la película Jurassic Park y un juguete infantil para su formalización.

El proyecto se basa en la acumulación de finos "cabellos" de fibra óptica que traslada la luz del exterior al interior. Embebidos en cada uno de esos cabellos, se encuentran las semillas como el mosquito paleolítico en el ámbar del Dr.Hammond, creando así un microecosistema que mantiene un control de la temperatura en su interior ${ }^{70}$.

Para finalizar, y ya cercano a nuestra contemporaneidad, nos encontramos con el ejemplo de "Gardens by the bay “(2012). Esta propuesta, nació como una estrategia para convertir la ciudad de Singapur "de una ciudad con jardines, a ser una ciudad en un jardín"71. Realizado por los arquitectos Wilkinson Eyre and Grant Associates se encuentra compuesto por dieciocho árboles-torre de más de 50 metros de altura, con especies de plantas creciendo de sus troncos, todos conectados por puentes por encima de los 20 metros de altura; y dos invernaderos. Cada árbol posee un tanque colector de agua de lluvia que sirve para refrigerar los propios árboles y los invernaderos.

Estos últimos poseen una gran infraestructura que albergan todas aquellas plantas procedentes del resto del mundo que no pueden crecer normalmente en Singapur, convirtiéndose en una herramienta educativa. El proyecto no contiene, por tanto, un sólo espacio controlado donde se conservan ecosistemas, sino que el propio Gardens by the Bay se configura como un microecosistema en sí mismo. Desde su finalización en 2012, este jardín se ha convertido en un polo de atracción de turistas, capaz de ser el protagonista de la artealización in visu generada por las campañas de publicidad de aerolíneas como Qatar Airlines, siendo un paisaje sinónimo de modernidad.

${ }^{70}$ HEATHERWICK, T (2011) Construyendo la catedral de semillas. TED Talks. Ver en: https://www.ted.com/talks/thomas heatherwick?language=es (Consultado el 22 de octubre de 2015).

${ }^{71}$ GRANT ASSOCIATES (2012) Gardens by the Bay. Ver en: http://www.grantassociates.uk.com/projects/gardens-by-the-bay/ (Consultado el 01 de junio de 2015). 


\subsection{Ecosistemas Democráticos}

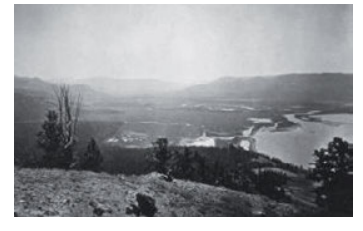

1871, "Yellowstone" William Henry Jackson.

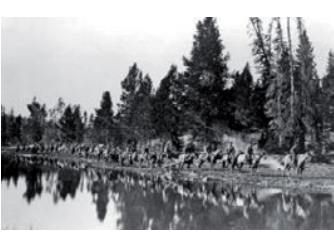

1871, "Yellowstone Expedition" William Henry Jackson.

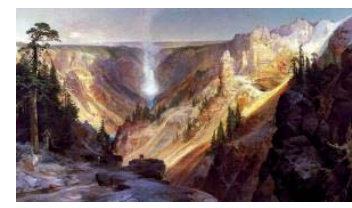

1871, "Yellowstone Expedition" William Henry Jackson.

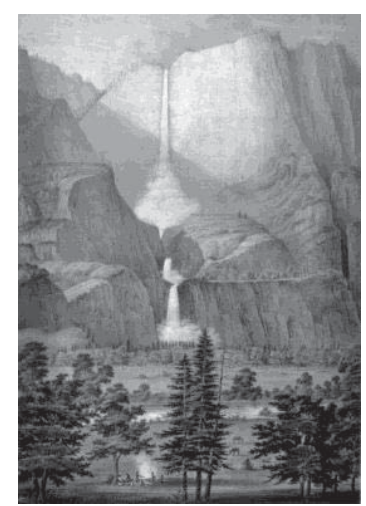

1855, "Yosemite"-

Thomas Ayres
En 1872 ocurre por primera vez que un ecosistema sea apreciado como espacio a preservar: el Congreso de los Estados Unidos establece Yellowstone como Parque Nacional para proteger sus hábitats, gracias a la obra del pintor Thomas Moran. El primer contacto de Moran con Yellowstone nace de unas pinturas que realizó para ilustrar un artículo sobre as maravillas del parque, el cual jamás había visitado físicamente ${ }^{72}$. Su interés hizo que, en 1871, fuera invitado a participar en la expedición del Dr. Ferdinand Hayden, financiada por a Northern Pacific Railroad para explorar la desconocida región. Durante cuarenta días, Moran documentó a través de dibujos en su diario, más de treinta lugares de la zona. A su vuelta, materializaría los bocetos en impresionantes pinturas (1871-1872) como "The Grand Canyon on the Yellowstone", en consonancia con las corrientes contemporáneas que categorizaban a la naturaleza como salvaje y "sublime". En muchas de ellas aparecen retratados sus compañeros de expedición observando el entorno en forma de lejanas figuras que contextualizaban la escala de paisaje en la que se encontraban inmersos. Junto a Moran, se encontraba también el fotógrafo William Henry Jackson ${ }^{73}$. Las obras circularon por el Congreso de los Estados Unidos, donde se puso en perspectiva el papel del paisaje, asumiendo que estos también forman parte de la identidad e historia americanas. Ambas obras conformaron claros ejemplos de artealización in visu, haciendo posible mostrar al mundo esa atractiva visión de una exótica y salvaje América, lista para ser explorada y preservada.

El mismo camino siguió Yosemite Park, aunque no fue parcialmente nombrado Parque Nacional hasta 1890. Los esfuerzos por contemplar la protección de sus paisajes habían comenzado incluso antes que Yellowstone, sin embargo, su proceso legal duraría más de treinta años. En 1855, los primeros visitantes -el empresario James Hutchings, y el artista Thomas Ayres- escribieron a su regreso un artículo en una revista de tirada nacional, junto con una litografía de la cascada de Yosemite realizado por Ayres. A partir de entonces, Hutchings volvió en reiteradas ocasiones a explorar la zona, siempre acompañado de artistas o fotógrafos que registraban el paisaje para después exponer al público sus obras,

\footnotetext{
${ }^{72}$ National Park Service: Thomas Moran. Painter of Yellowstone, NP. (Consultado el 18 Apr. 2016). Ver en https://www.nps.gov/museum/exhibits/moran/yellow.htm
}

${ }^{73}$ JACKSON, W.H: Hayden survey expedition in the Yellowstone region, 1871. Encyclopædia Britannica Online. Web. (Consultado el 18 Apr. 2016).

Ver en http://www.britannica.com/biography/William-Henry-Jackson/images-videos/Members-of-theHayden-survey-expedition-in-the-Yellowstone-region/169471 
llegando incluso a manos de Abraham Lincoln. Es el caso del pintor Alfred Bierstadt (1863), o el fotógrafo Carleton Watkins (1863), cuyas obras convirtieron este paisaje en "un símbolo de la conexión entre Yosemite, América y el Edén"744. Estas artealizaciones in visu, resultaron una publicidad muy efectiva: en menos de medio siglo, la destrucción causada por el turismo comenzó a hacerse visible. El Senado de los Estados Unidos -asustado por la degradación del paisaje- contempló la posibilidad de protegerlo de dicha explotación; y mediante su nombramiento como Parque Nacional en 1890, se estableció un control del paisaje y una gestión de todo lo que ocurría en él.

Junto con este evento, la introducción del “Mutualismo"- por el antropólogo Pier-Joseph van Beneden tan sólo cuatro años después- que designa al tipo de relaciones que existen entre dos organismos que pertenecen a distintas especies y cada individuo es beneficiado por las mismas; estableció un nuevo tipo de relaciones más democráticas entre humanos, animales no-humanos, agentes no-humanos y su entorno. Un primer ejemplo de proyecto que aplica este concepto sería la torre de murciélagos de Charles Campbell, construida en 1911 en Texas. Los murciélagos -depredadores naturales de mosquitos - eran atraídos por las torres-refugio, y servían como control natural de plagas como la malaria, a la vez que se obtenían beneficios por la venta del guano depositado en la torre. El diseño, rápidamente fue extendiéndose hasta llegar a Europa. Con el descenso de la malaria, las torres de murciélagos entraron en desuso, a excepción de asentamientos cerca de lagos y zonas acuosas, donde eran útiles para el control de la población de mosquitos.

En 1942, se estrena la artealización in visu de Walt Disney, Bambi; basada en la novela "Bambi: historia de una vida en el bosque", del escritor austríaco Felix Salten en 1923. Por primera vez, la naturaleza es recreada en un medio artístico de manera fiel. Uno de los aspectos fundamentales de la película es el punto de vista desde el cuál se cuenta la historia; el del propio animal -el ciervo Bambi-. De esta manera, la humanización del mismo trataba de establecer una relación más democrática a la entonces acostumbrada, además de constituir una denuncia ante las acciones humanas en la naturaleza. Es interesante observar cómo el rostro de los humanos no aparece en ningún momento a lo largo del largometraje, restándoles todo protagonismo y otorgándoselo al ciervo; sugiriendo además la facilidad que poseen las intervenciones humanas para desencadenar situaciones negativas. La relevancia de este film se encontraría reforzada por la fiel representación

${ }^{74}$ ÁBALOS, I (2008) Atlas Pintoresco, Vol II: Los viajes. Barcelona, Editorial Gustavo Gili. ISBN10: 8425221188 


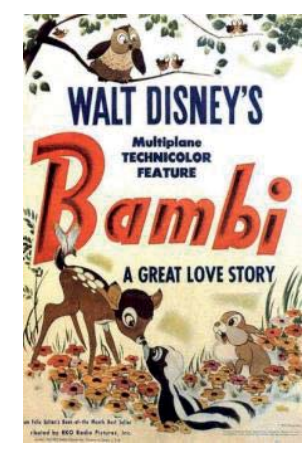

1942, "Bambi" Walt Disney

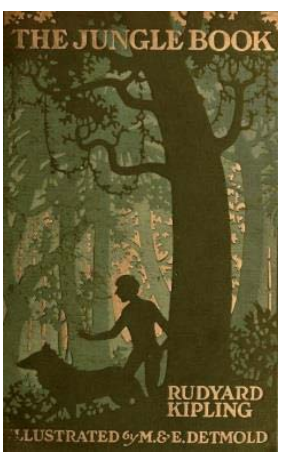

1894, "The Jungle Book"Rudyard Kipling

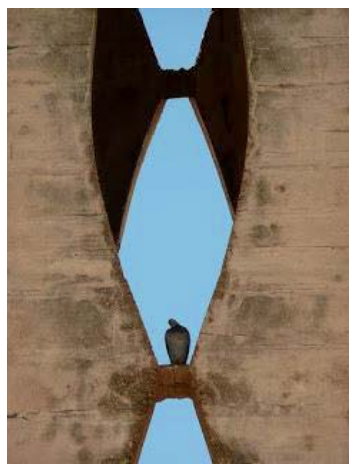

1961, Pombal Sculpture, Oscar Niemeyer. anatómica y por la crudeza de la ficción llegando a emocionar y traspasar la barrera de la ficción durante generaciones ${ }^{75}$.

Un paso más en esta línea, que gozaría también de gran éxito, lo encontraríamos en la película El libro de la selva (1967) -Walt Disney-. También una adaptación de una novela, en este caso The Jungle Book del escritor indobritánico, Rudyard Kipling en 1894. La artealización, se basa en la historia de Mowgli, un niño humano que debe sobrevivir en la selva, donde establece relaciones de carácter horizontal con los animales, como si todos pertenecieran a la misma especie -aunque estos últimos se encuentran antropomorfizados.

En cualquier caso, la antropomorfización de los animales no es algo que Disney inventara; ya Jean de la Fontaine usaba este recurso para el desarrollo de sus fábulas a finales del siglo XIX. Es posible que Disney intuyera que dotar de sentimientos a los animales sería un éxito ${ }^{76}$, aunque lo que seguramente no sabría es que la convivencia entre humanos y animales; y la interacción entre ellos a un mismo nivel, estaba cargado de significado -de una posibilidad utópica de que eso llegara a ser posible- un tema que poco a poco iba a ganar fuerza a lo largo del siglo XX. La humanización también se puede observar en los vegetales, flores, hierbas...y especialmente la figura del árbol; extendiéndose así a muchos agentes no-humanos. Hubo un momento que el estudio Disney, se convirtió casi en un museo de historia natural, una institución que enseñaba a los dibujantes a copiar el movimiento de los animales con realismo ${ }^{77}$.

Durante la segunda mitad de siglo, encontramos ejemplos puntuales de artealizaciones in situ, como la escultura Pombal de Oscar Niemeyer en Brasilia (1961) convertida en palomar; o las instalaciones para el trabajo con el ganado consecuente con el bienestar animal por la Temple Grandin (1985). No obstante, estas propuestas aisladas, no tuvieron realmente impacto en el ámbito arquitectónico, hasta que fueran contempladas a través de la sociología, y específicamente a través de los ensayos del sociólogo francés Bruno Latour -Politics of Nature: How to bring science into democracy (2004)- acerca de cómo puede la sociedad reconciliarse con la naturaleza a través de la ciencia, y la ecología política, que han influido directamente sobre la práctica arquitectónica reciente. Así, las citadas torres para murciélagos y dispositivos semejantes han proliferado para visibilizar este tipo de cuestiones en modo artealización in situ (Bat Tower, Joyce Hwang. 2010), evolucionando su

75 COLT, S (2015) American Experience: Walt Disney [VIDEO]. PBS. Estados Unidos.

${ }^{76}$ DOUX,S (2006) Il etait un Fois Walt Disney [EXPOSICIÓN]. Paris.

77 IBID 
diseño hasta incorporarse a una valla publicitaria, y disponer de un interfaz interactivo que dialoga con ella, conformando un ejemplo tipológico (Bat Billboard, Chris Woebken, 2012).

Una década antes de Politics of Nature (2004) Bruno Latour, había publicado su ensayo We have never been modern (1993) también haciendo hincapié en la ecología. En esos años la revista Time mostraba en sus portadas (1990, sobe los equilibrios en los bosques; 1992, Earth Summit '92, sobre la Diversidad Biológica; y 1993 -¿Pueden pensar los animales?) la preocupación general acerca de estas cuestiones. Mientras que el mundo del arte no se quedaba atrás: Damien Hirst realiza en 1991 una artealización in visu en su instalación In and Out of Love: Butterfly Room 1. La obra se encontraba formada por una habitación mariposario con unas condiciones de temperatura y ventilación determinadas, sobre las paredes descansaban lienzos en blanco, fortuitamente pintados por las mariposas que volaban libres en la sala. Durante unos minutos, el visitante podía compartir su hábitat, enmarcado a su vez dentro del espacio de una galería.

Dentro de la misma línea, y tras la irrupción en el ámbito arquitectónico, nos encontramos un proyecto de 2002 del estudio Amid 09, "Roses, Insects and Butterflies Amalgam". Un ejemplo que transforma una central eléctrica abandonada en lowa, USA, en una montaña artificial, que proporciona un lugar de descanso para ciertas especies de pájaros migratorios, junto con un ecosistema en equilibrio para ciertos tipos de rosas, insectos y mariposas, como alternativa a bosques y humedales desaparecidos.

Hospedero y Nectarifero para Mariposas de Cali, Colombia (2007), de la Plataforma HUSOS. Tras un análisis de la región, se observó que poseía la máxima diversidad de mariposas en el mundo. El proyecto, derivado de un encargo privado, sirvió también para contribuir a la preservación del ecosistema del barrio, a través de un jardín vertical que alberga especies de plantas nectaríferas que atraen a las mariposas locales; y que a su vez sirven como indicadores biológicos de la calidad del ecosistema local ${ }^{78}$. Recientemente, no sólo continúan proliferado las torres de murciélagos y los mariposarios, sino también toda una serie de dispositivos y estrategias diseñadas para el pensamiento ecosistémico.

Hablamos de proyectos como "Mosquito Bottleneck" (2003) del arquitecto francés François Roche, o intervenciones en el territorio como el ejemplo tipológico "Cancer City" del estudio estadounidense Visiondivision; artealizaciones in situ como "Farm Fountain" de Amy Young (2007), las obras de Natalie Jeremijenko, como el "Butterfly Bridge", o "Salamander Superhighway" (ambas 2010), también "Oyster-tecture" (2010) de ScapeStudio, presentado por primera vez en el marco de la exposición "Rising Currents Exhibition" del MOMA de

78 PLATAFORMA HUSOS (2007): Edificio Jardín Hospedero y Nectarífero para Mariposas de Cali. Ver en: http://Www. husos.info/EN EJHNMC text.html (Consultado el 13 de Julio de 2015).

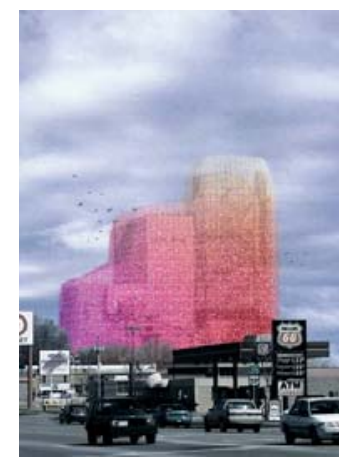

2002, Roses, Insects and Butterflies Amalgam Amid 09.

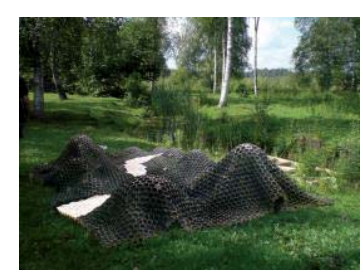

2010, Cancer City, Visiondivision. 


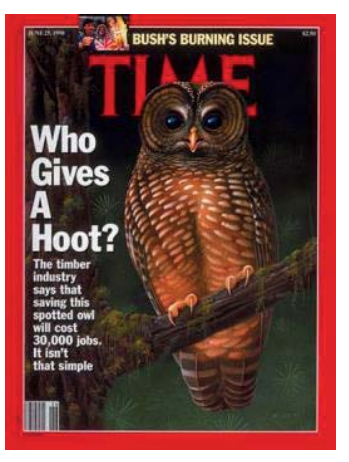

1990, TIMES MAGAZINE: Who gives a hoot? - The timber industry says that saving this spotted owl will cost 30000 jobs. It isnt' that simple.

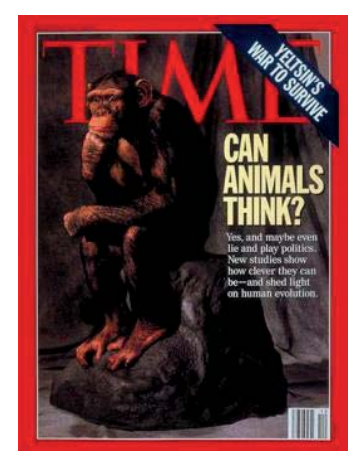

1993, TIMES MAGAZINE: Can Animals Think? Yes, and maybe even lie and play politics. New studies show how clever they can be- and shed light on human evolution.
Nueva York. Y un largo etcétera de actuaciones a nivel urbanístico entre las que destaca el temprano proyecto "SNACKLOKET IJburg" (1999) de Mattonoffice, un fast food para pájaros diseñado en el marco de un suburbio holandés, que usa la pirámide alimenticia como herramienta de diseño. Debido al clima favorable de IJburg, muchos pájaros lo consideran como el lugar idóneo para parar a comer y descansar; de manera que el espacio urbano atiende a estas necesidades, creando espacios diseñados especialmente para ello: conchas en los tejados, árboles especiales... ${ }^{79}$.

También más recientemente, “New York Rising” (2013) un proyecto derivado de la exposición antes descrita "Rising Currents Exhibition", que plantea relaciones beneficiosas entre agentes en ecosistemas resilientes, a la hora de reconstruir comunidades que fueron dañadas durante el huracán Sandy.

${ }^{79}$ VV.AA. (1999): The Artificial Landscape. Hans Ibelings Ed. NAi Publishers. 


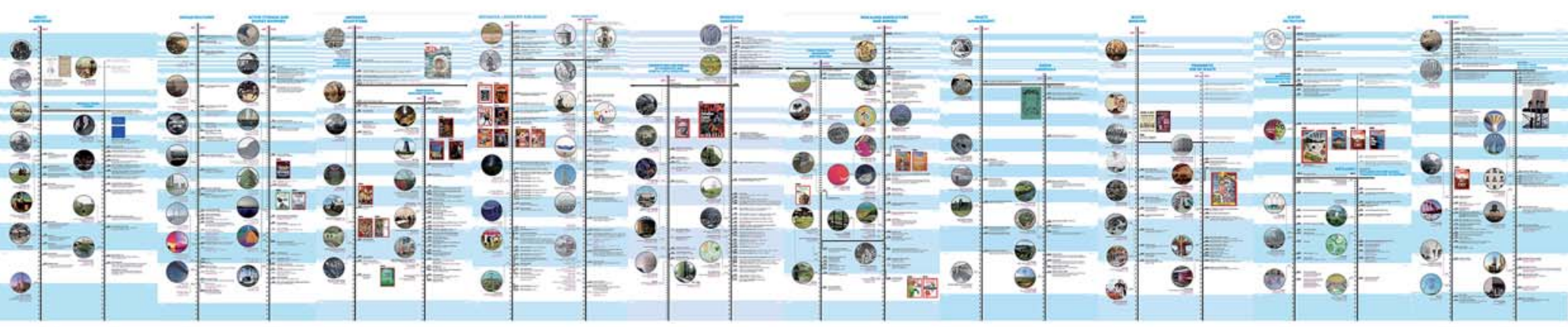



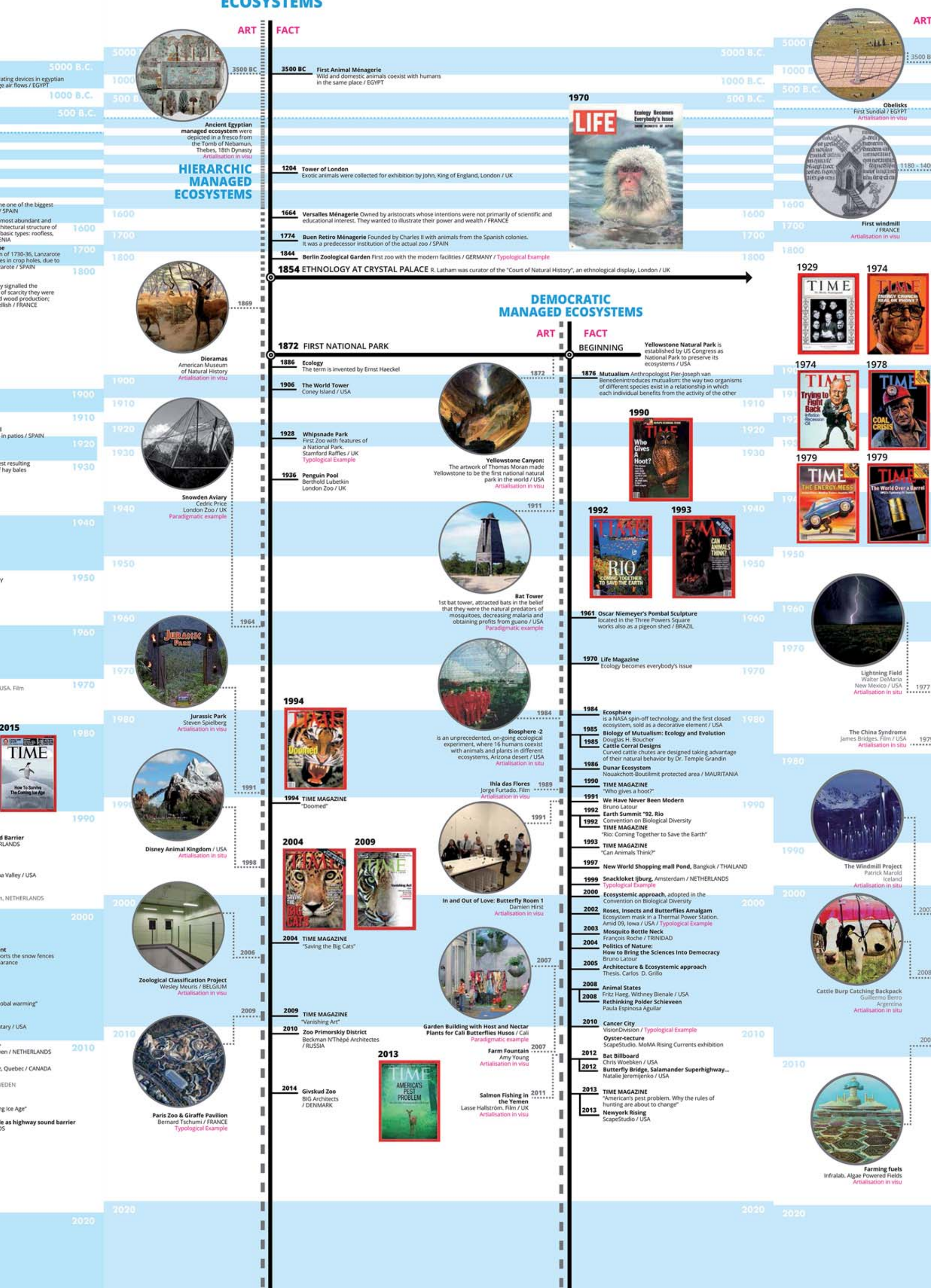


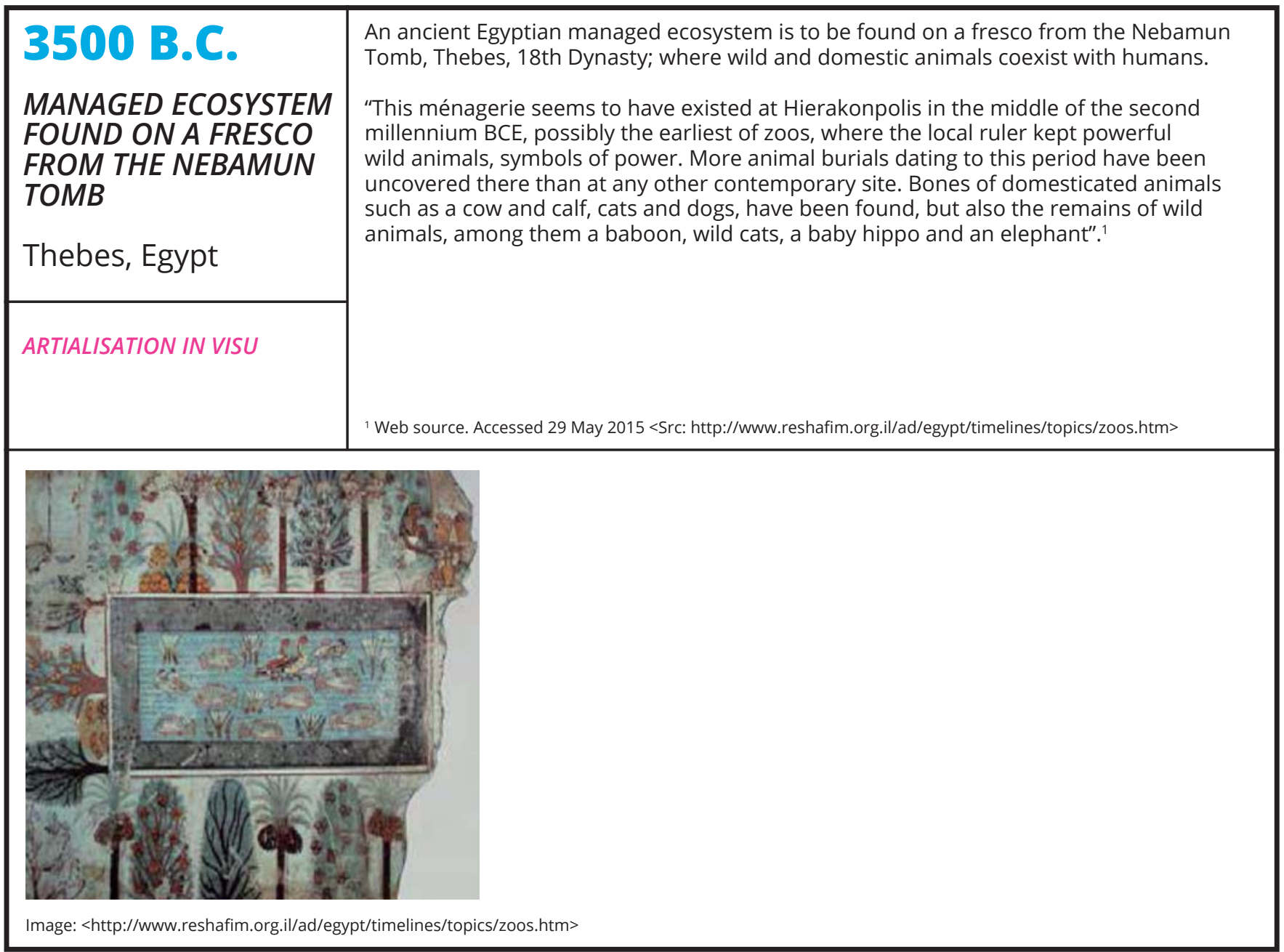

\begin{tabular}{|l|l|}
\hline 1869 & $\begin{array}{l}\text { Dioramas are illusionist reproductions of natural environments generally incorporating } \\
\text { a curved painted backdrop behind three-dimensional figures. The influence of these } \\
\text { reproductions is visible in the design of actual zoos, especially in the 'scenography' that } \\
\text { surrounds most of animal environments. }\end{array}$ \\
DIORAMAS: AMERICAN \\
MUSEUM OF NATURAL \\
HISTORY Individual dioramas often took years to complete, as scientists and artists physically \\
travelled to each place to take photographs, render sketches and collect zoological and \\
biological specimens, sometimes staying for months at a time. Each plant and animal \\
then had to be shipped back to New York City and artificially recreated for display. \\
Following the trip, a massive arts and crafts endeavour began back at the museum, \\
where the flora and fauna were brought to life".'
\end{tabular}




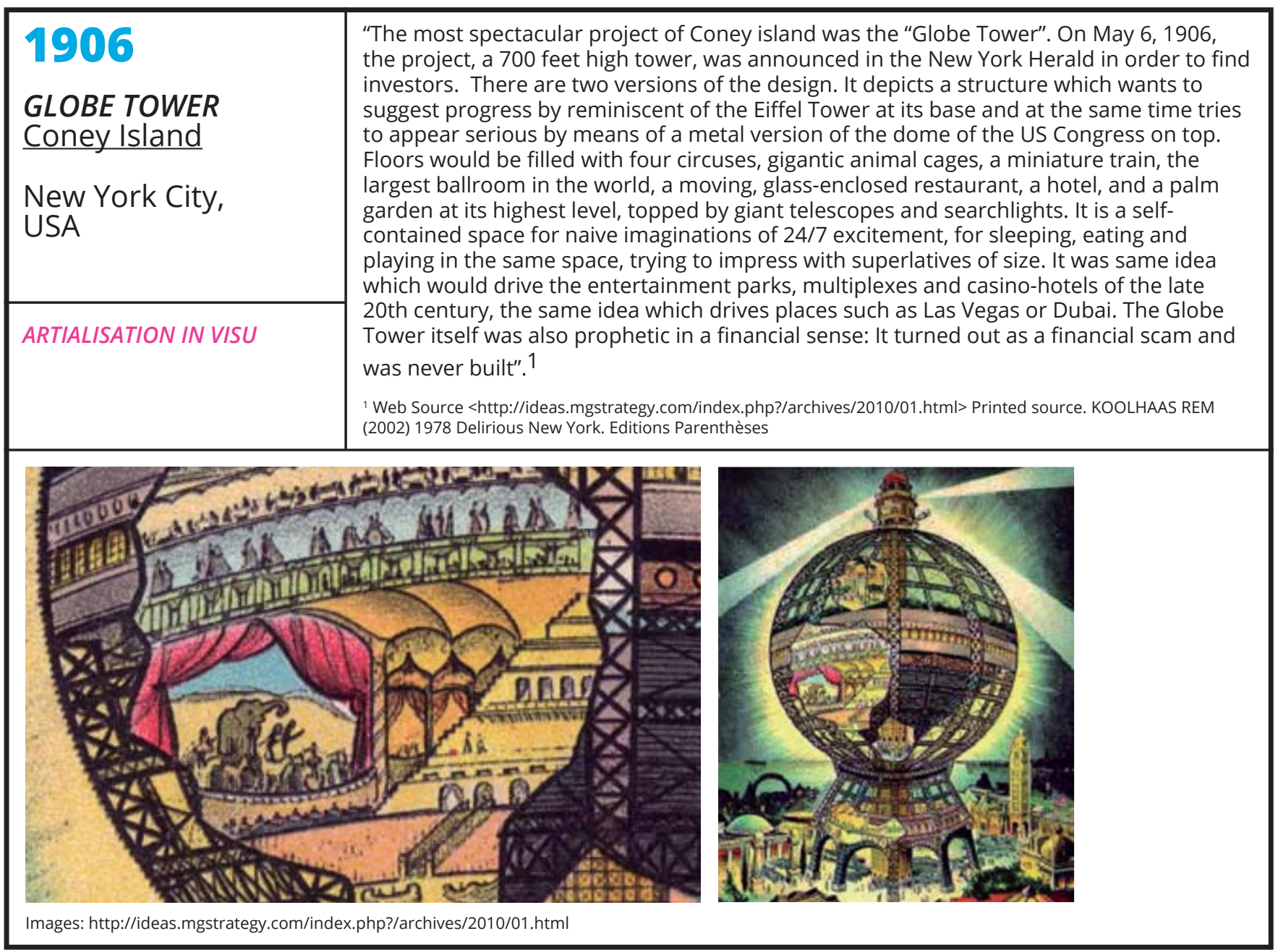

\begin{tabular}{|l|l|}
\hline 1964 & $\begin{array}{l}\text { "Lord Snowdon, Cedric Price and Frank Newby's extraordinary aviary at the same zoo, } \\
\text { built } 30 \text { years later, also attempted to be aesthetically pleasing to humans and acceptable } \\
\text { to birds, and was designed so that both humans and birds could at times occupy the } \\
\text { same space. Unfortunately, as with the Lubetkin's penguin's slide, the aviary was both } \\
\text { difficult to construct and proved a challenge to maintain".' }\end{array}$ \\
$\begin{array}{l}\text { SNOWDON AVIARY } \\
\text { Cedric Price }\end{array}$ & \\
\hline UK &
\end{tabular}




\begin{tabular}{|c|c|}
\hline $\begin{array}{l}2009 \\
\text { PARIS ZOO \& } \\
\text { GIRAFFE PAVILION } \\
\text { Bernard TSChumi } \\
\text { Paris, } \\
\text { France }\end{array}$ & $\begin{array}{l}\text { "Towards the end of the twentieth century, zoos became increasingly immersive. The } \\
\text { visible construction of animal houses took a back seat to the re-creation and presentation } \\
\text { of faux-natural habitats. In contrast to Lubetkin's or Price's stark forms, zoo buildings } \\
\text { became increasingly camouflaged and integrated with animals, visitors and landscape } \\
\text { alike. Bernard Tschumi's Giraffe Pavilion in the Paris Zoo (part of his } 2009 \text { redesign of } \\
\text { the entire site), for example, blends environment, fencing and structure into one habitat, } \\
\text { creating a statement of synthesis and mutualism without being phoney"." }\end{array}$ \\
\hline TYPOLOGICAL EXAMPLE & $\begin{array}{l}\text { 1Web source. Ned Dodington. Beastly Designs. Accessed } 17 \text { June 2015 <Src: http://mwww.uncubemagazine.com/sixcms/ } \\
\text { detail.php?id=15044811 \&articleid=art-1420471282122-c58b1824-2e6d-4d1 b-83a7-e17334dc1 ab7\#t!/page30> }\end{array}$ \\
\hline (1) & 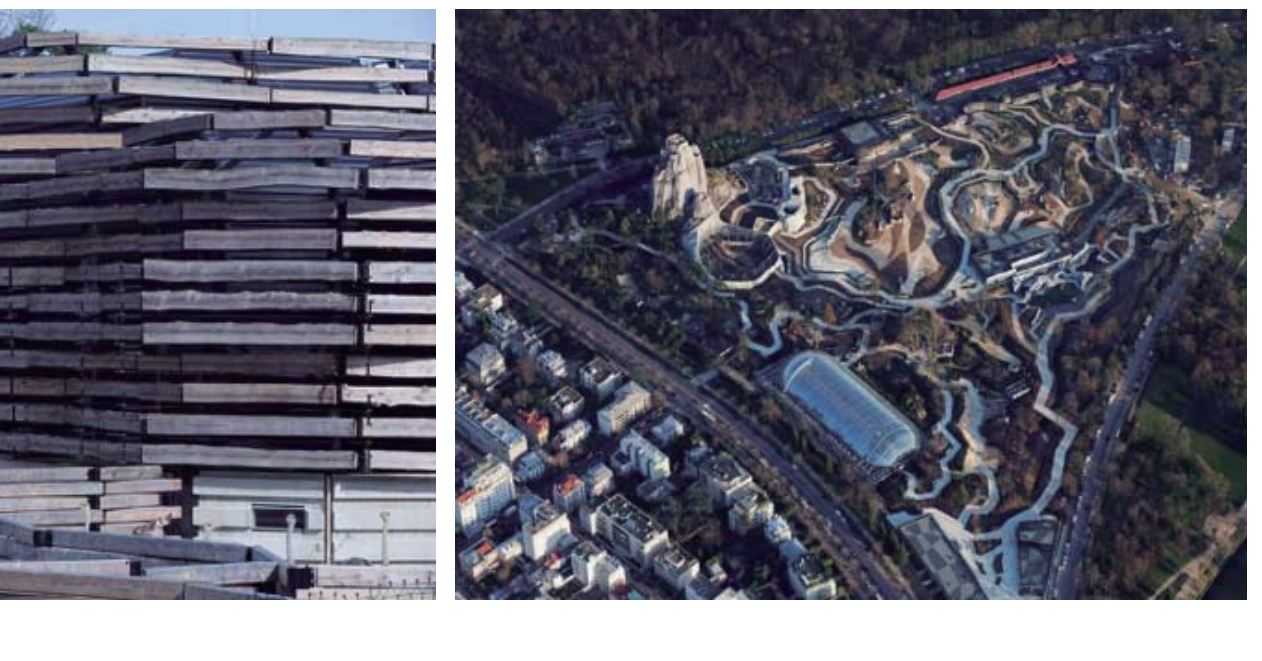 \\
\hline
\end{tabular}

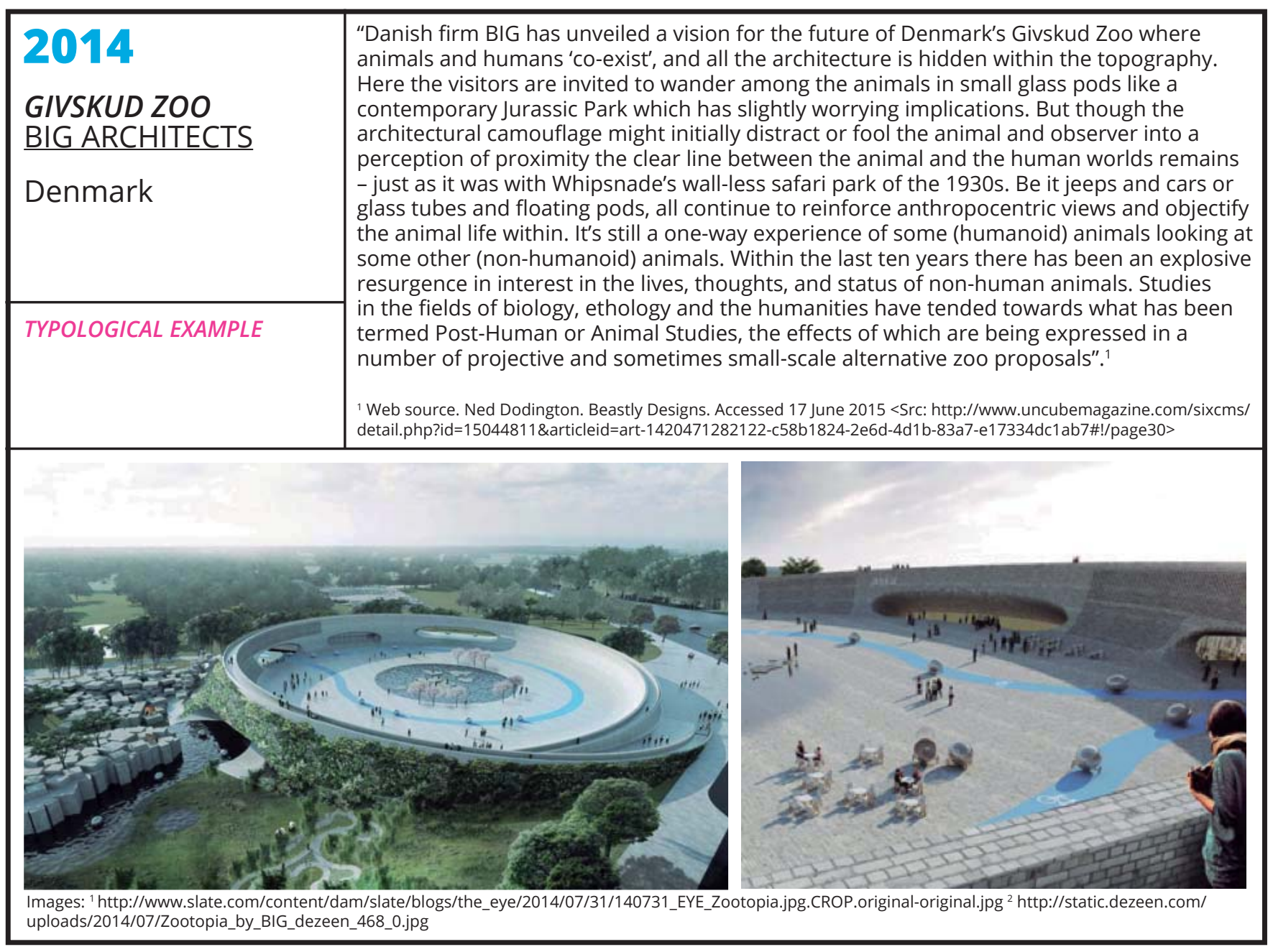




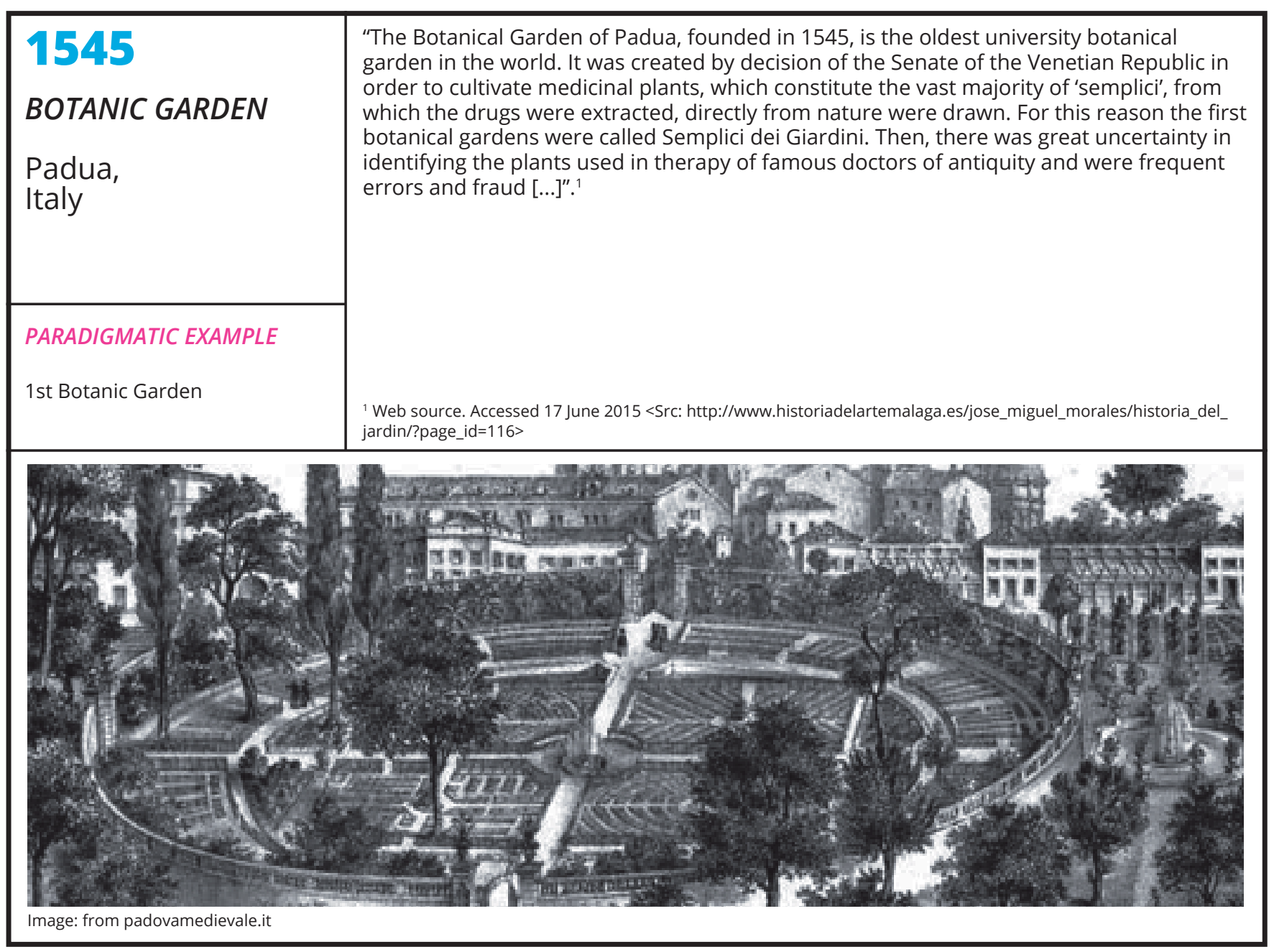

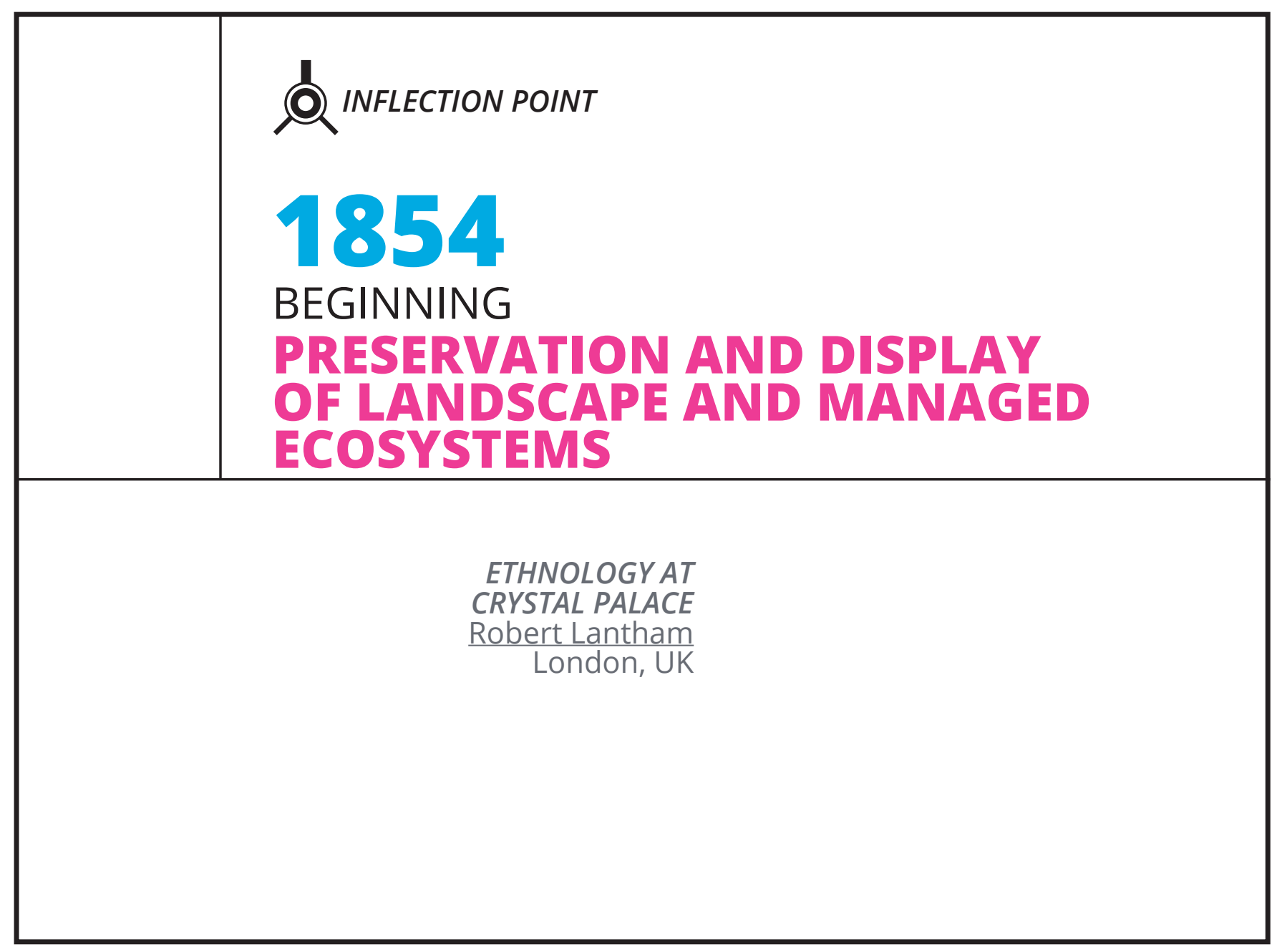




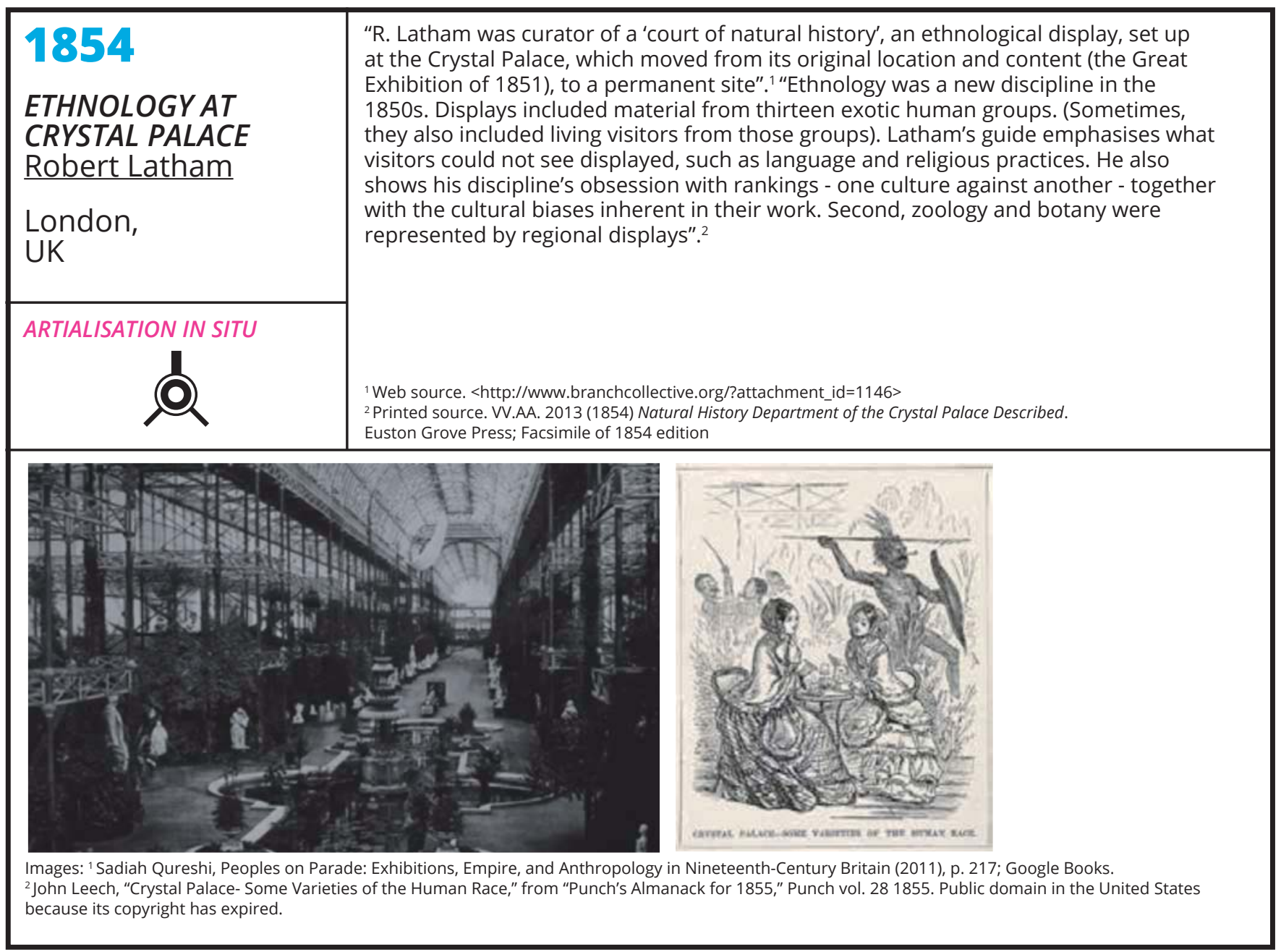

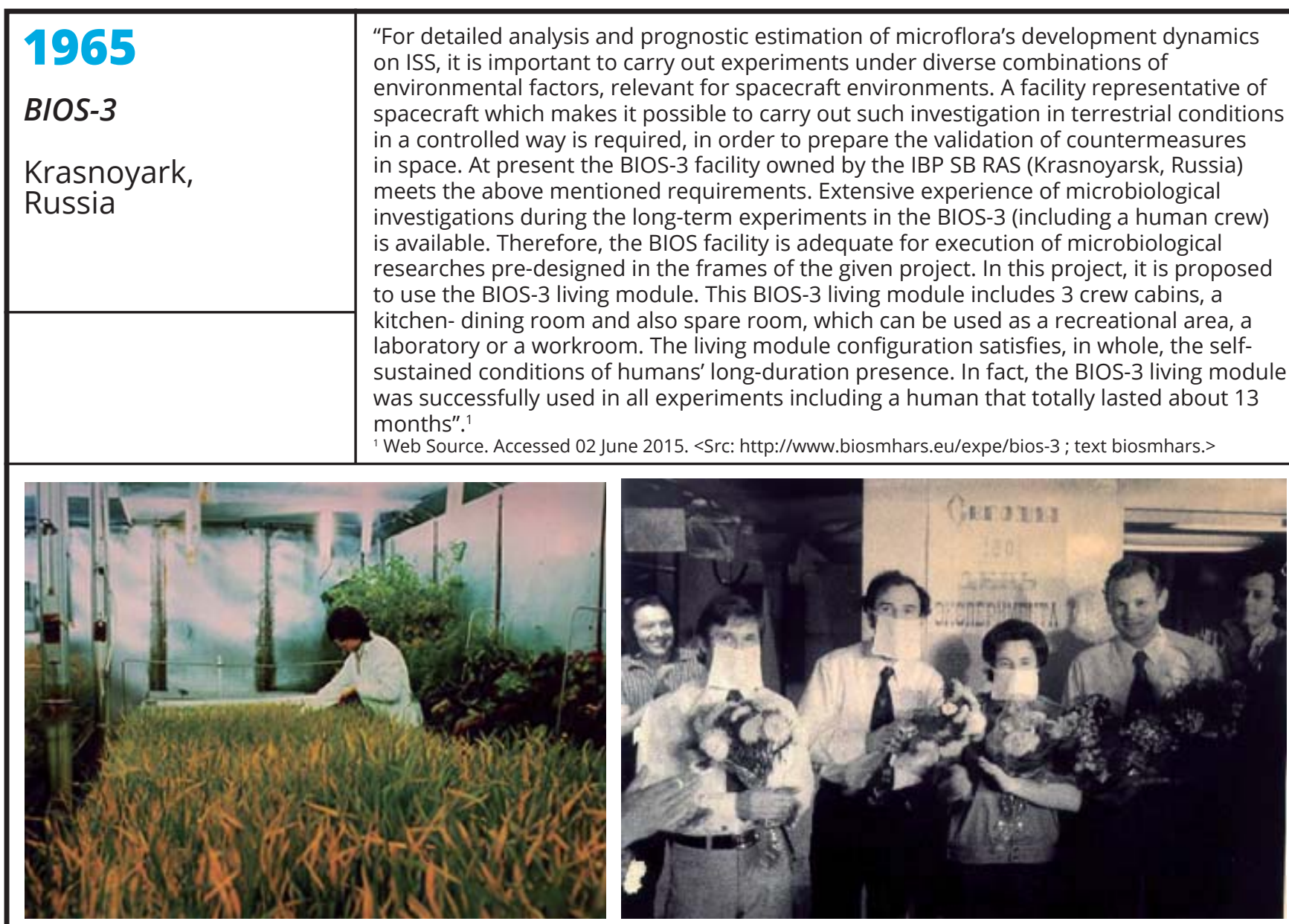

Images: http://www.ibp.ru/history/info01_eng.php; Institute of Biophysics of The Siberian Branch 


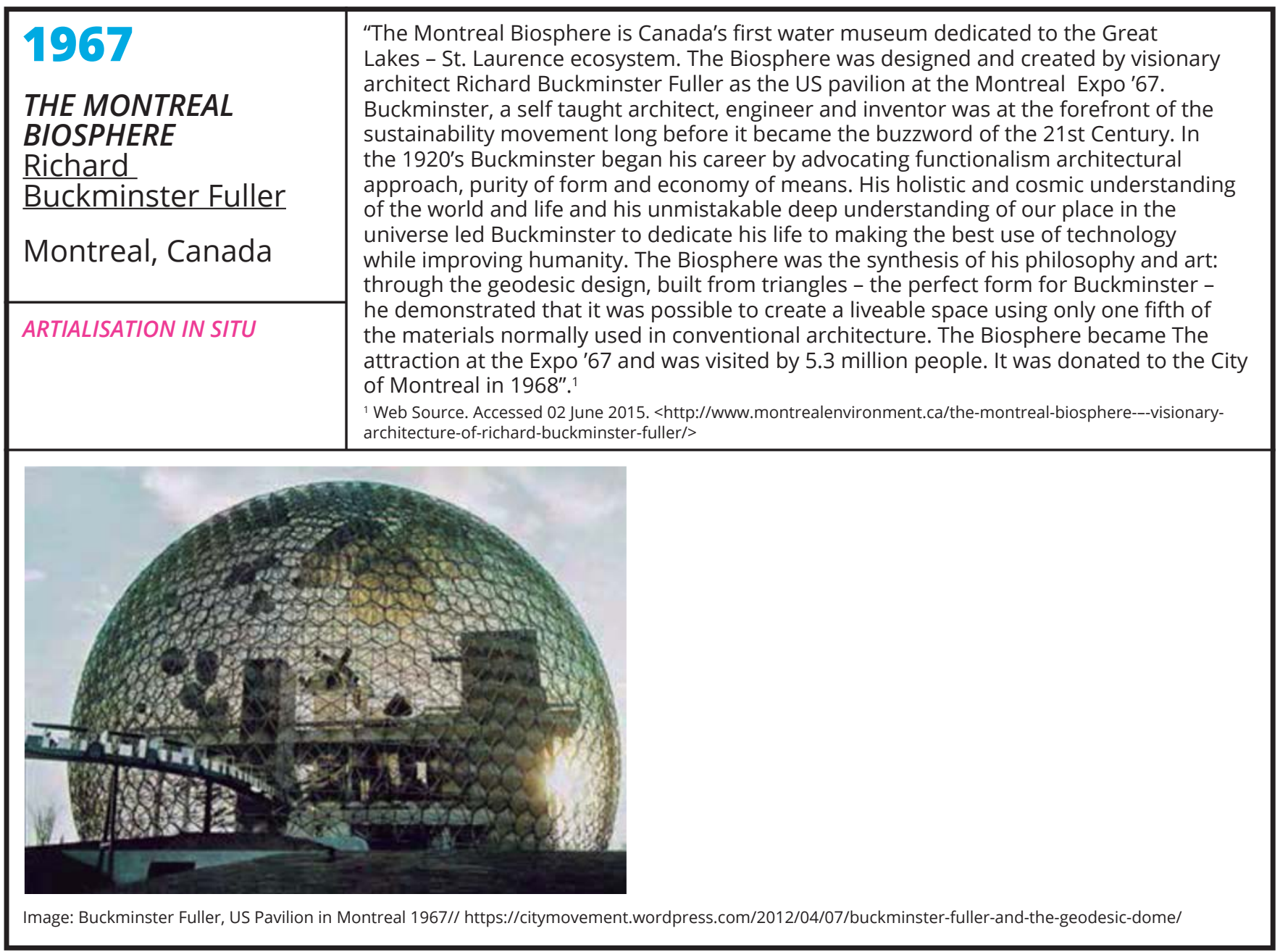

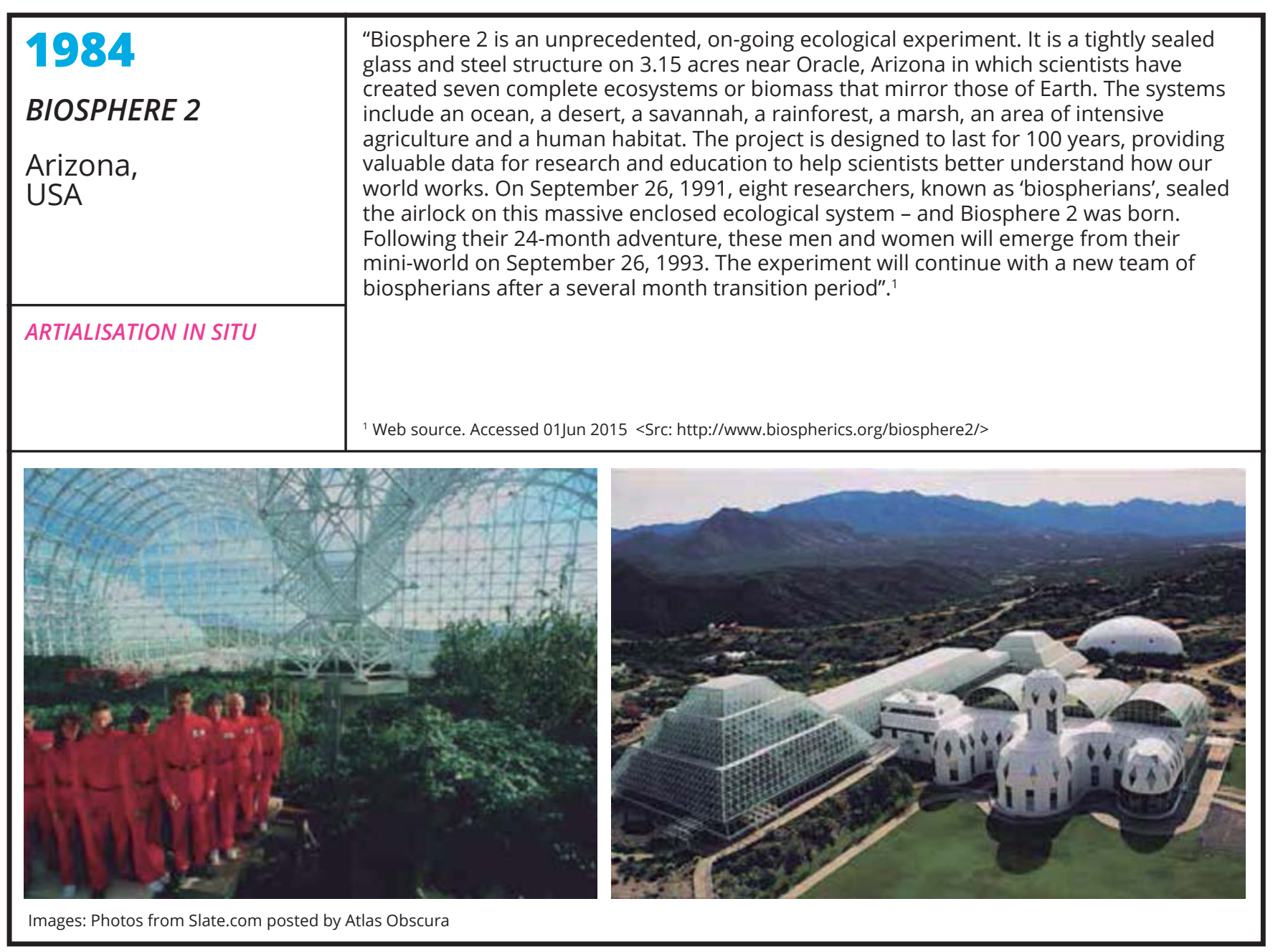




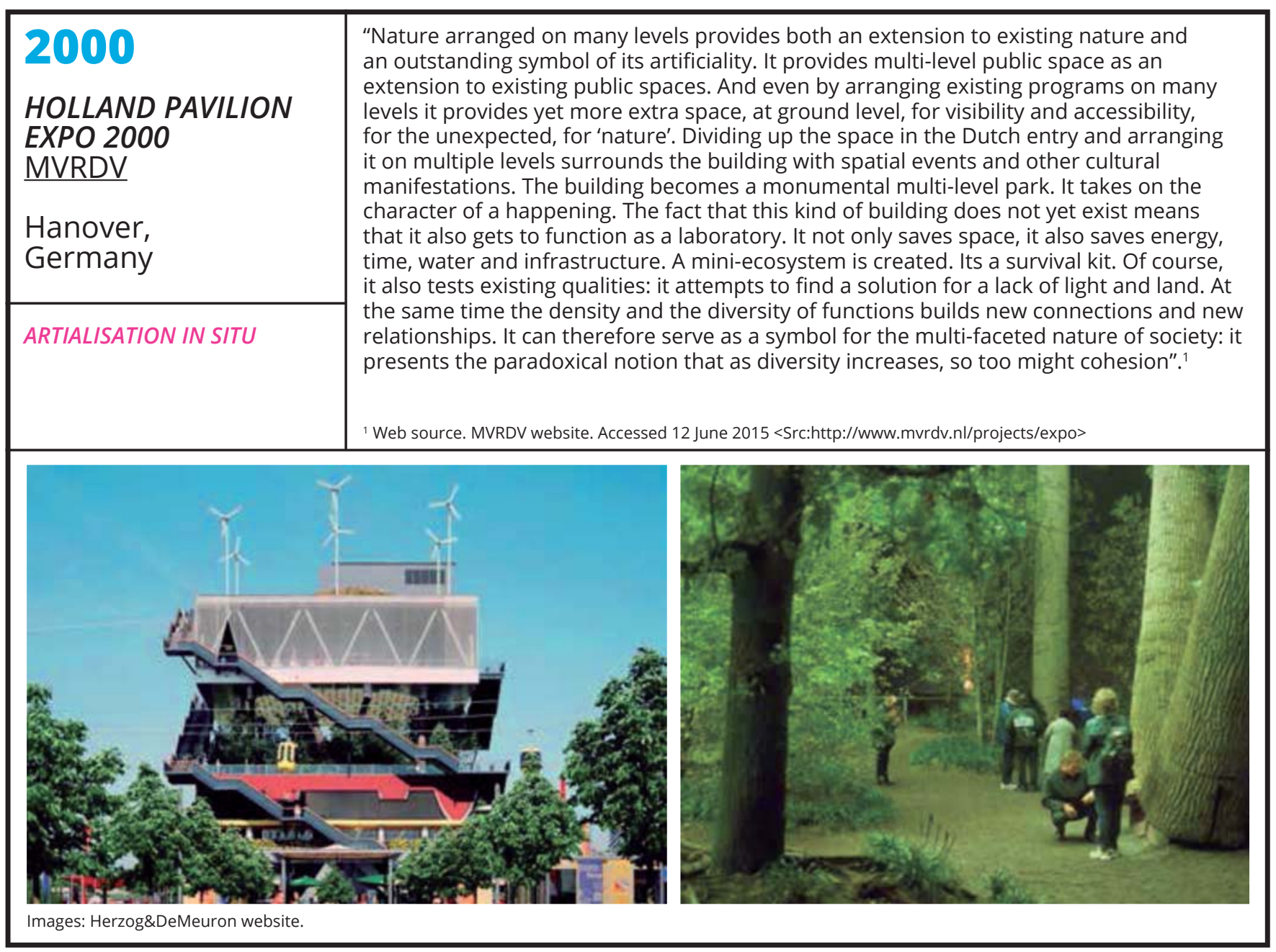

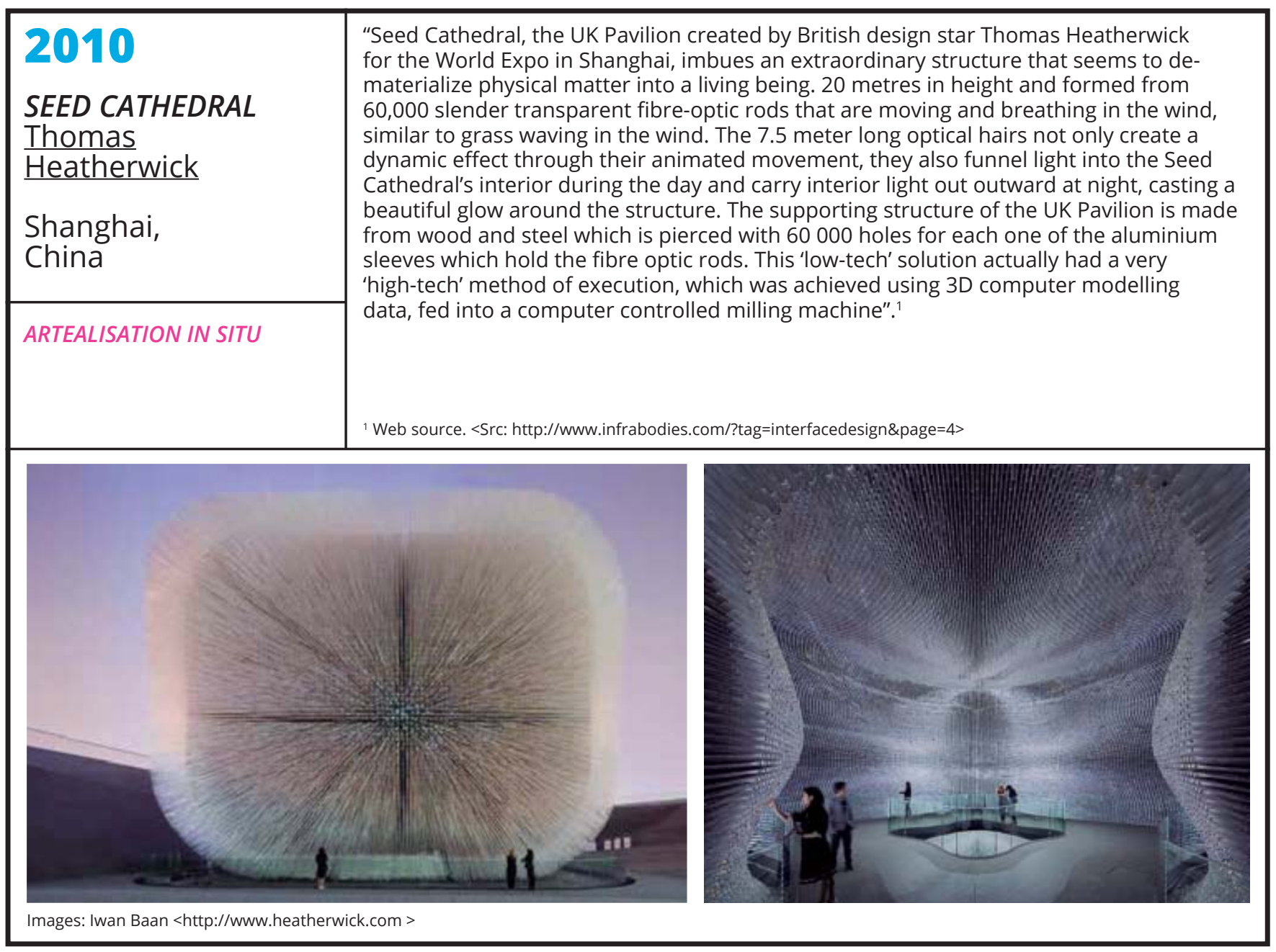




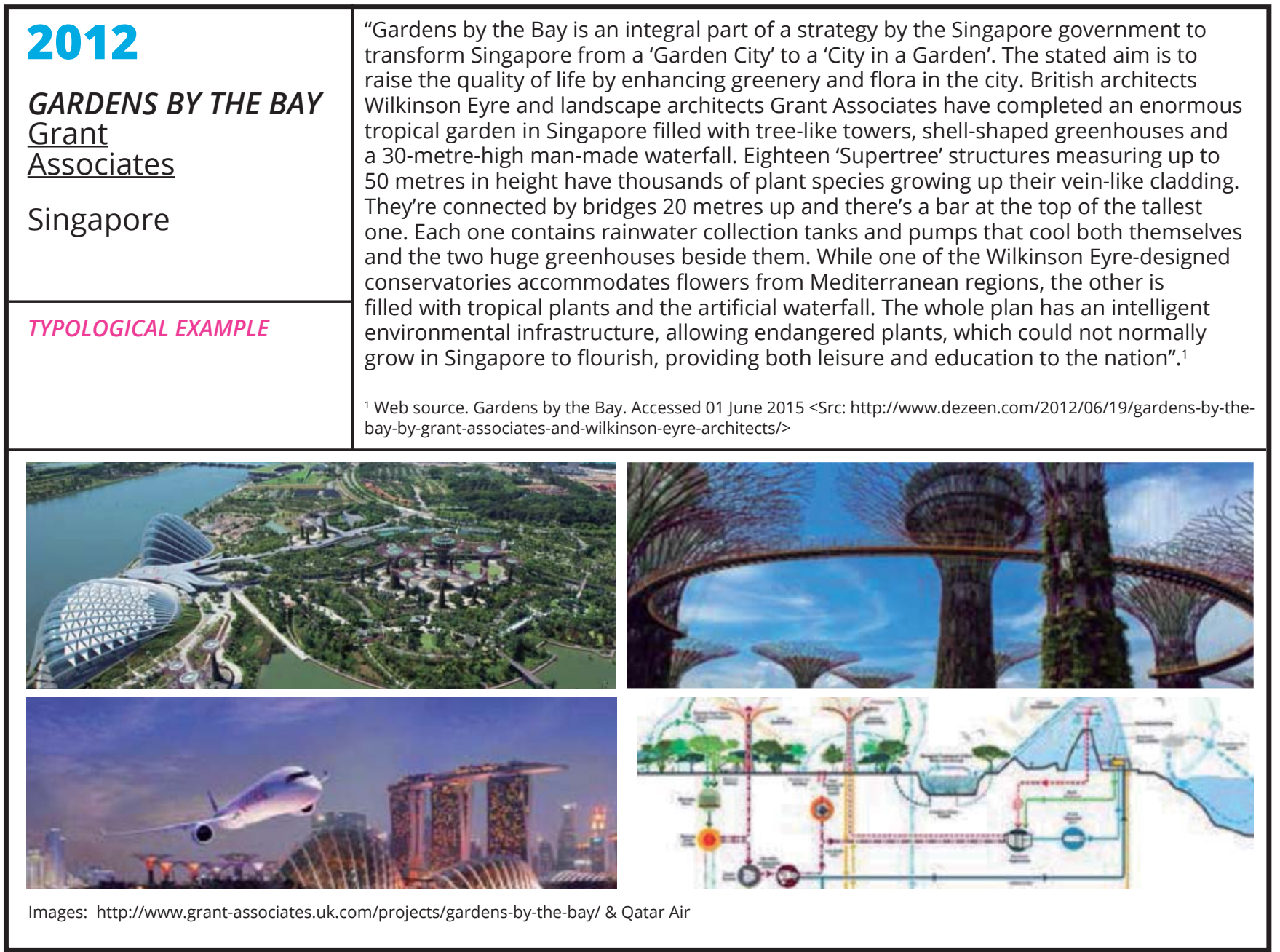

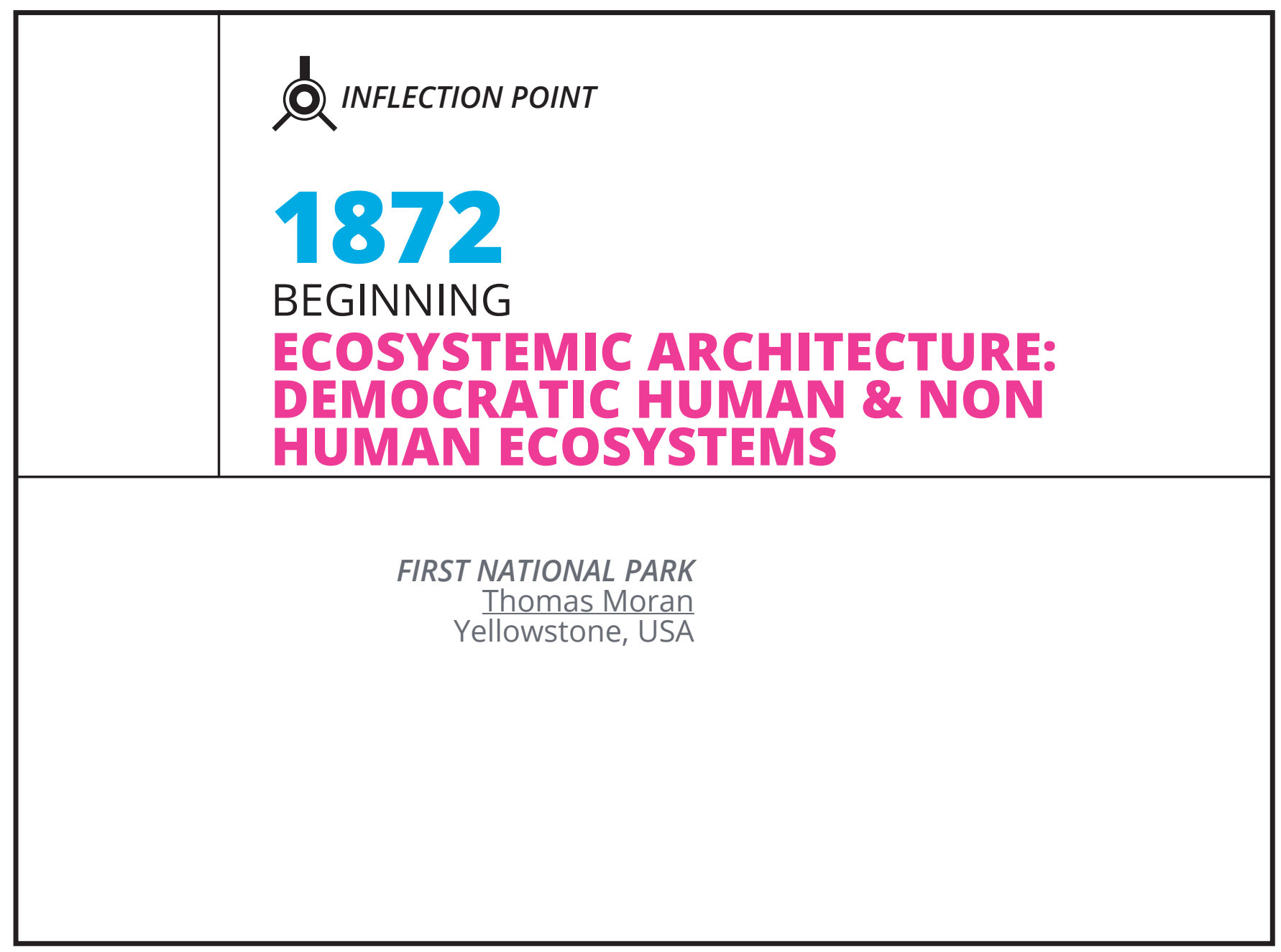




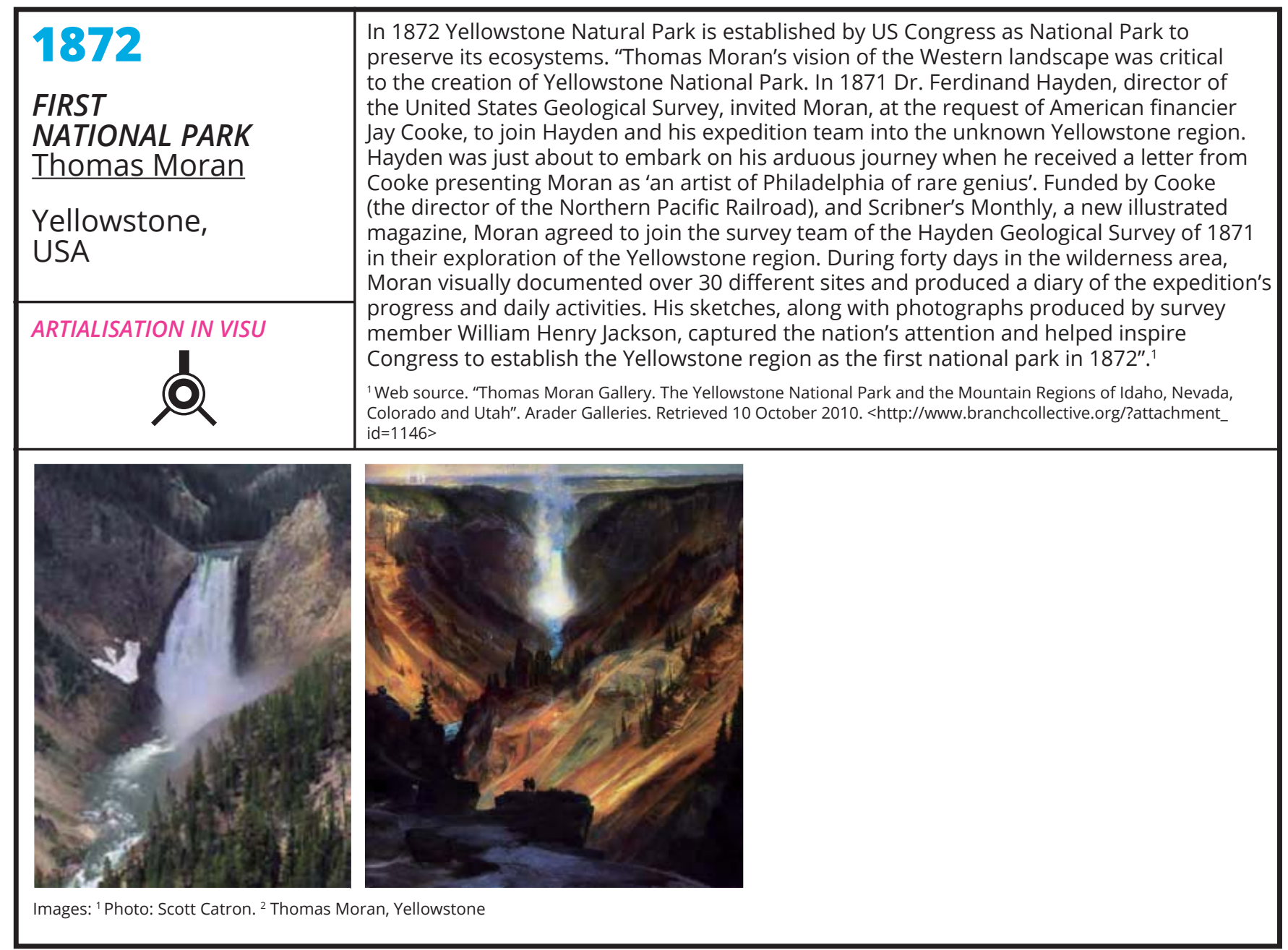

\begin{tabular}{|l|l|}
\hline 1911 & $\begin{array}{l}\text { The first bat tower, attracted bats as the natural predators of mosquitoes, decreasing } \\
\text { malaria and obtaining profits from guano. "His new tower, claimed as the world's first } \\
\text { successful intentional artificial bat roost, was built next to Mitchell's Lake, ten miles south } \\
\text { of San Antonio, in spring 1911. Malaria cases in the neighbourhood decreased, Campbell } \\
\text { cleared hundreds of dollars in guano sales, and the Mitchell's Lake tower was soon } \\
\text { followed by more than a dozen more built to the same design, one as far afield as Italy. } \\
\text { Perky obtained the roost plans from Campbell in 1929, and constructed his own tower at a } \\
\text { cost of } \$ 10,000 \text {. More than thirty feet tall, and sturdy enough to have weathered dozens of } \\
\text { hurricanes over the past eighty years, the tower still features a louvre bat entrance facing } \\
\text { the prevailing wind, a central guano removal chute, and a dense, honeycombed walls of } \\
\text { cypress wood bat corrugation that function as roosting shelves".' }\end{array}$ \\
\hline $\begin{array}{l}\text { San Antonio, } \\
\text { USA }\end{array}$ & $\begin{array}{l}\text { 'Web source. Accessed 08 june 2015. <http://www.theatlantic.com/technology/archive/2012/11/the-bat-tower-the-30- } \\
\text { foot-monument-to-biological-pest-control-and-cross-species-design/265465/> }\end{array}$ \\
\hline PARADIGMATIC EXAMPLE &
\end{tabular}




\begin{tabular}{|c|c|}
\hline $\begin{array}{l}1961 \\
\text { POMBAL SCULPTURE } \\
\text { Oscar Niemeyer } \\
\text { Three Powers Square, } \\
\text { Brasilia, Brazil }\end{array}$ & 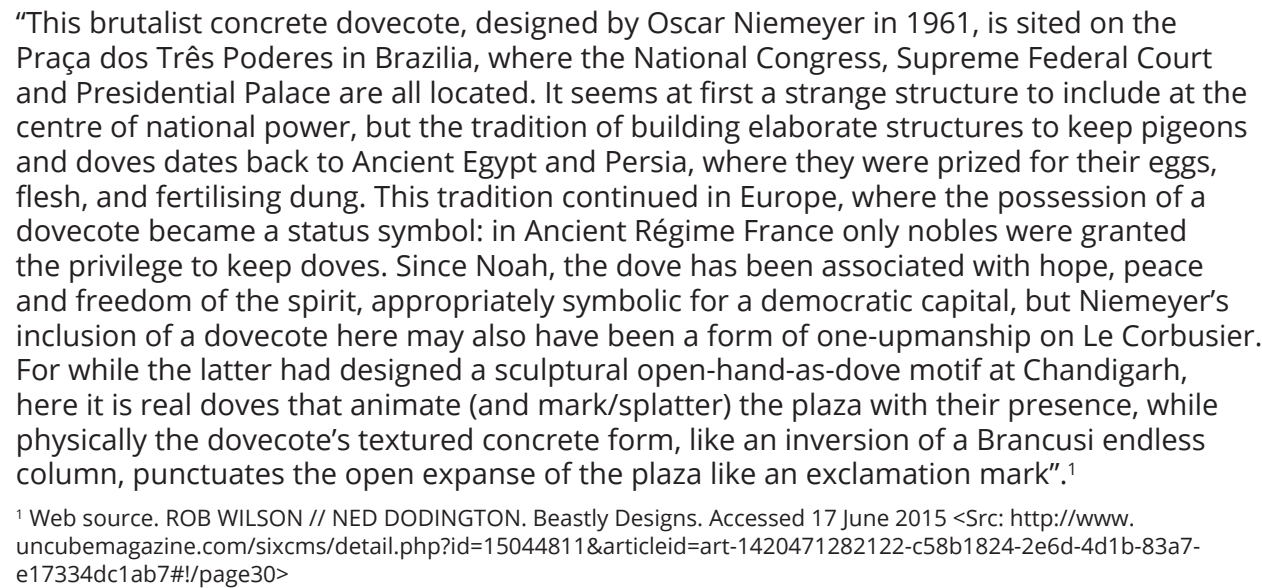 \\
\hline & 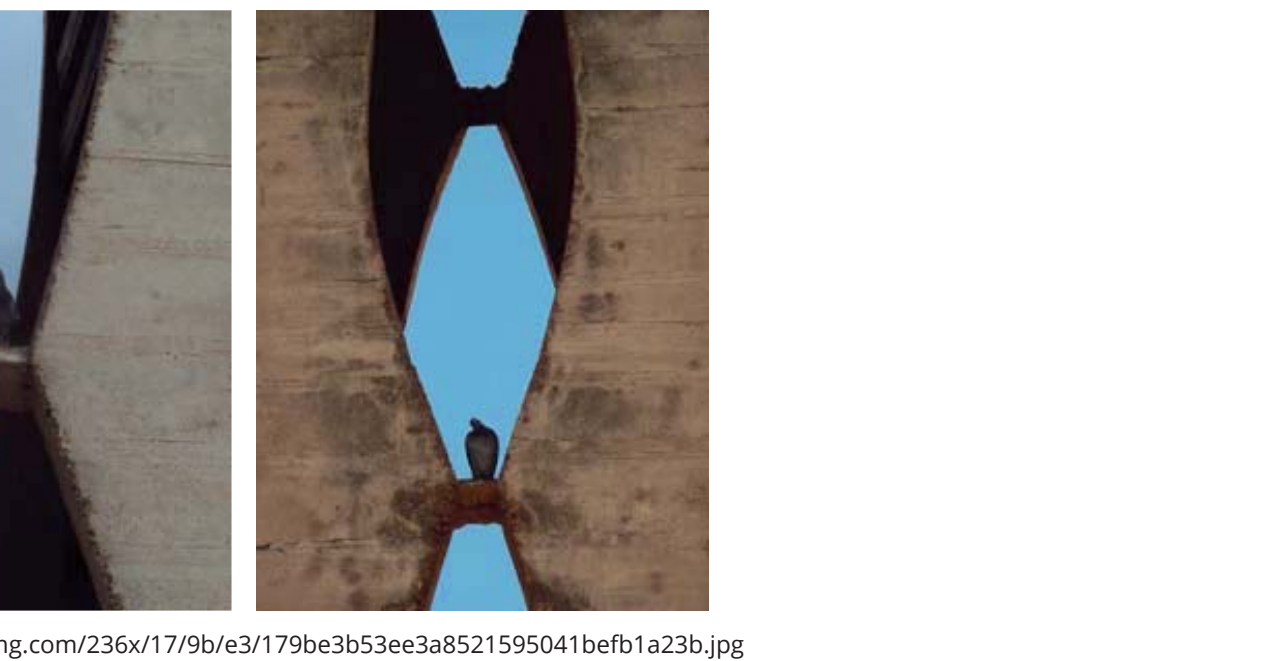 \\
\hline
\end{tabular}

\begin{tabular}{|l|l|}
1985 & $\begin{array}{l}\text { Cattle corral designs with curved chutes: "Curved cattle chutes are more efficient for } \\
\text { handling cattle because they take advantage of the natural behaviour of cattle. Cattle } \\
\text { move through curved races more easily because they have a natural tendency to go } \\
\text { back to where they came from. In the computer aided drawing section there are layout } \\
\text { drawings of cattle yard designs for both large and small ranches and feedlots. There } \\
\text { are also drawings of a cattle loading ramp for trucks, diagonal stockyard pens for cattle, } \\
\text { and detail drawings of a single file race and cattle dip vat. If you are planning to build } \\
\text { new corrals or other cattle handling facilities you can download blueprints of cattle pen } \\
\text { layouts that will reduce stress on cattle and improve handling efficiency". }\end{array}$ \\
$\begin{array}{l}\text { DESIGNS } \\
\text { Gra. Temple }\end{array}$ & $\begin{array}{ll}\text { Grandin } \\
\text { Colorado, USA }\end{array}$
\end{tabular}




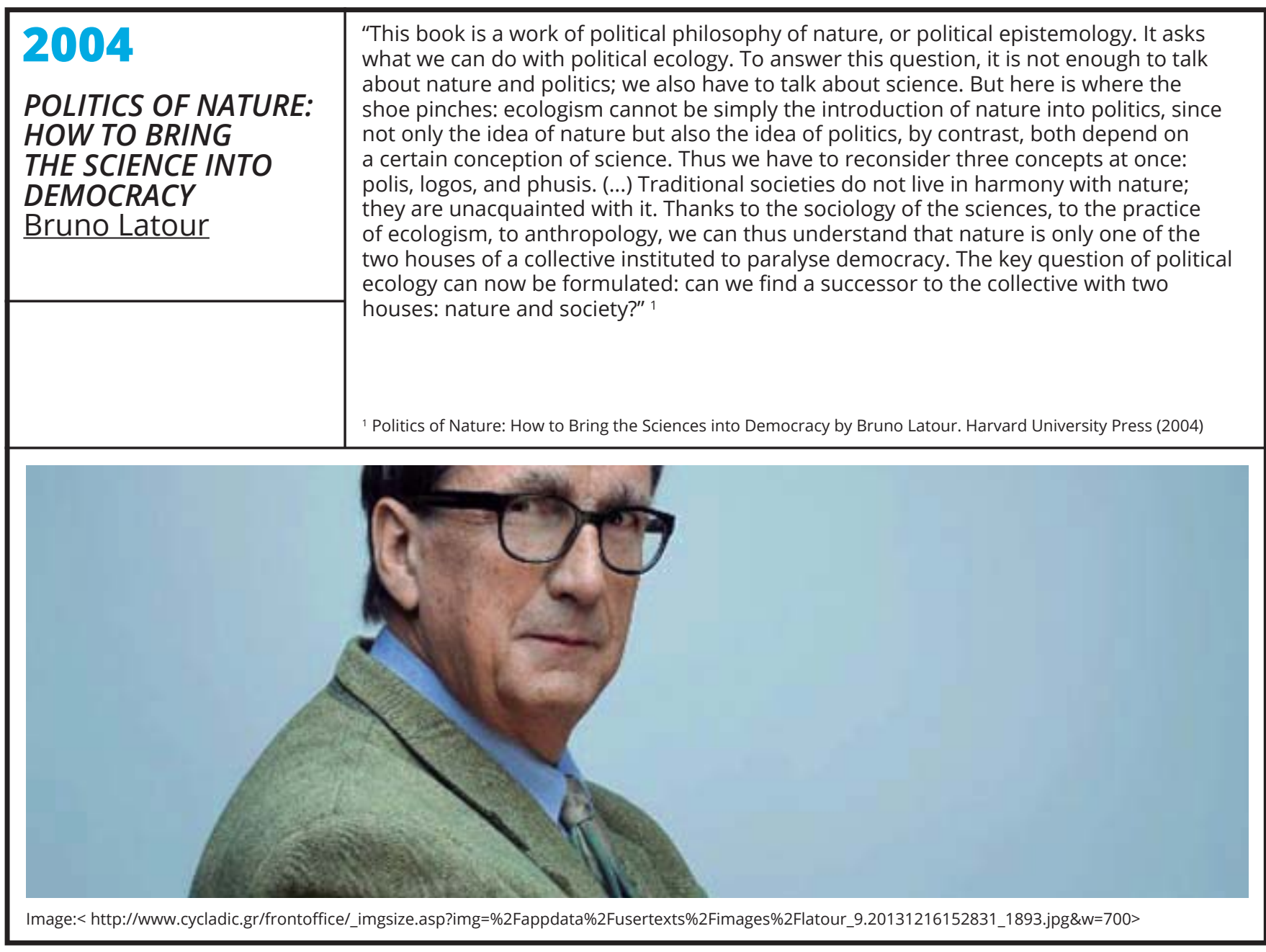

\begin{tabular}{|l|l|}
\hline 2010 & $\begin{array}{l}\text { "BAT TOWER is the first built prototype in a series of bat habitation projects which } \\
\text { explore strategies for increasing public awareness of bats as a critical component of our } \\
\text { ecosystem. Bats are effective as natural pesticides, pollinators, and mosquito abatement. } \\
\text { Yet they are often considered as a kind of urban pest, and are frequently exterminated } \\
\text { by human-run 'pest control' services. Their very survival is also being challenged by } \\
\text { White Nose Syndrome, a disease which has inexplicably been wiping out large bat } \\
\text { populations in north-eastern United States. In an attempt to bring visibility to bats, BAT } \\
\text { TOWER challenges notions of the typical off-the-shelf bat house. Rather than innocuously } \\
\text { fading into the background, the tower stands as a prominently visible outdoor sculpture. } \\
\text { Drawing from the idea of a vertical cave, the installation has a heavy and intense } \\
\text { presence, contrasting the lightness and invisibility associated with do-it-yourself bat } \\
\text { house constructions"." }\end{array}$ \\
\hline TYPOLOGICAL EXAMPLE & $\begin{array}{l}\text { New York, USA } \\
\text { Images: } \text { OAnts of the Prairie }\end{array}$ \\
\hline
\end{tabular}




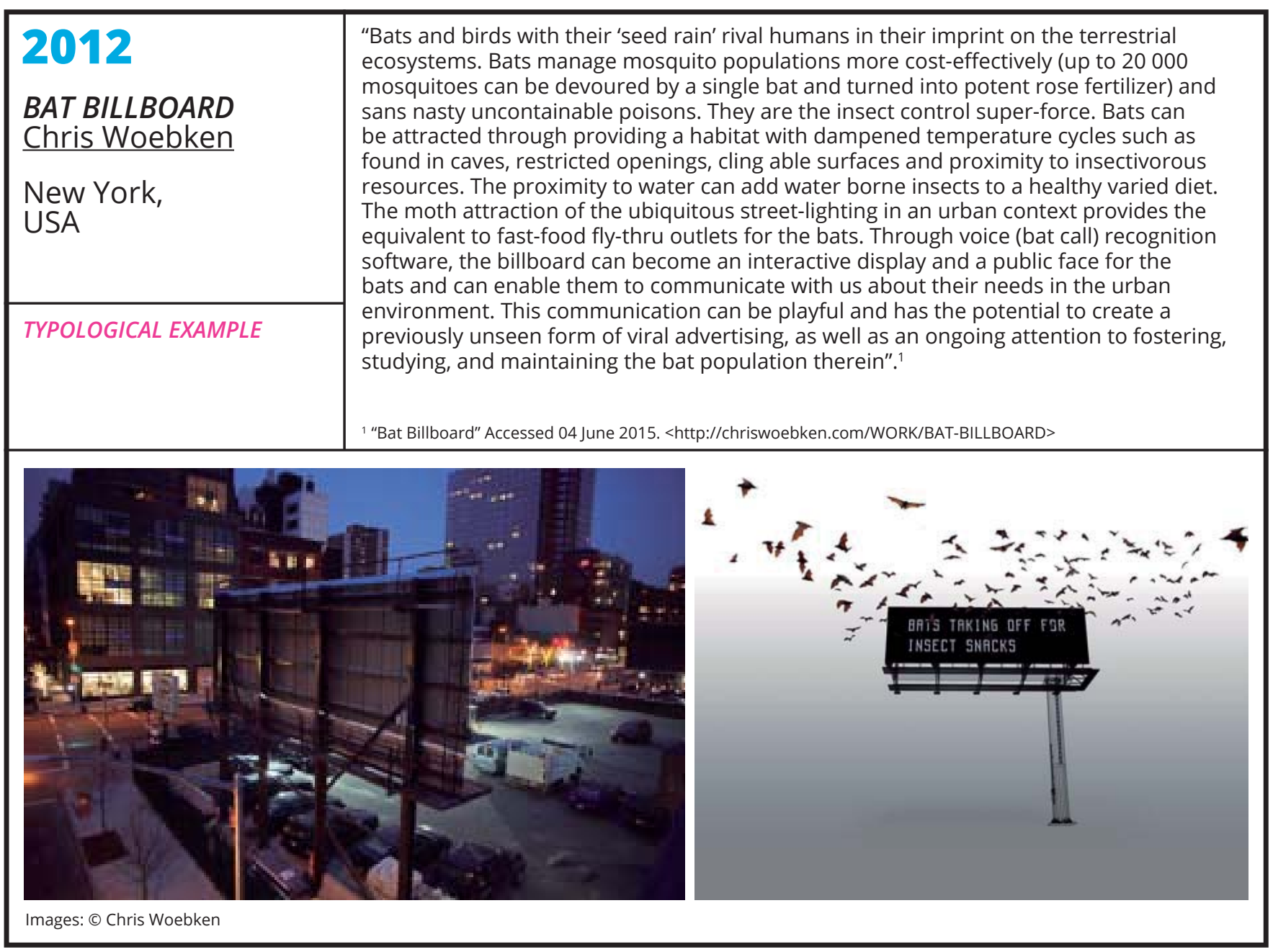

\begin{tabular}{|c|c|}
\hline $\begin{array}{l}1991 \\
\text { IN AND OUT OF LOVE: } \\
\text { BUTTERFLY ROOM } 1 \\
\text { Damien Hirst } \\
\text { London, UK } \\
\text { ARTIALISATION IN VISU }\end{array}$ & 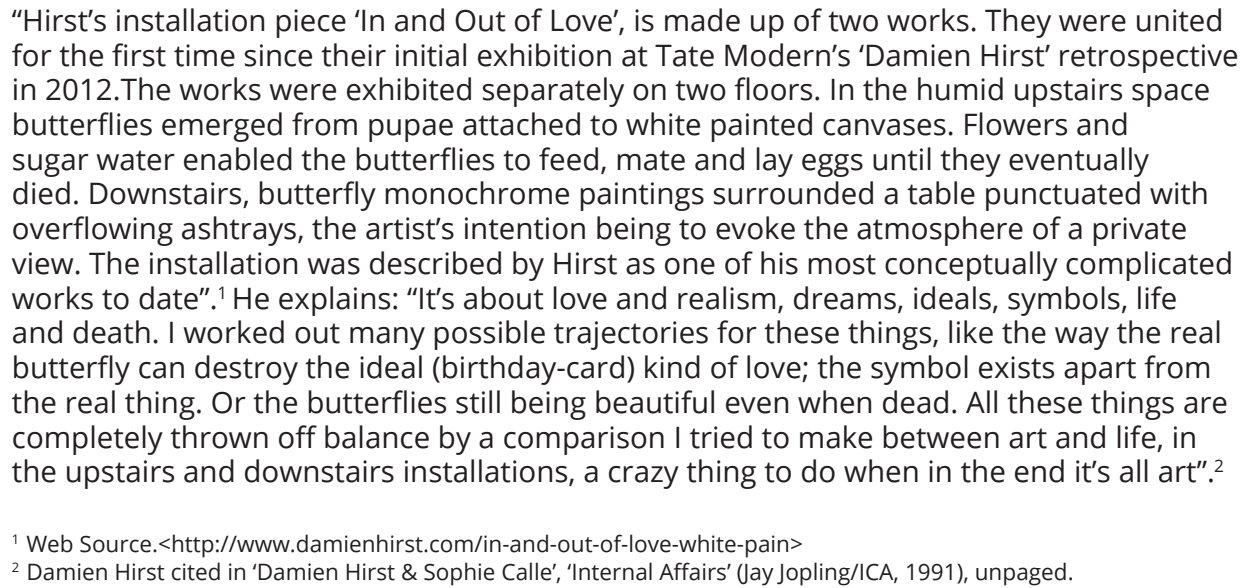 \\
\hline & ind \\
\hline
\end{tabular}




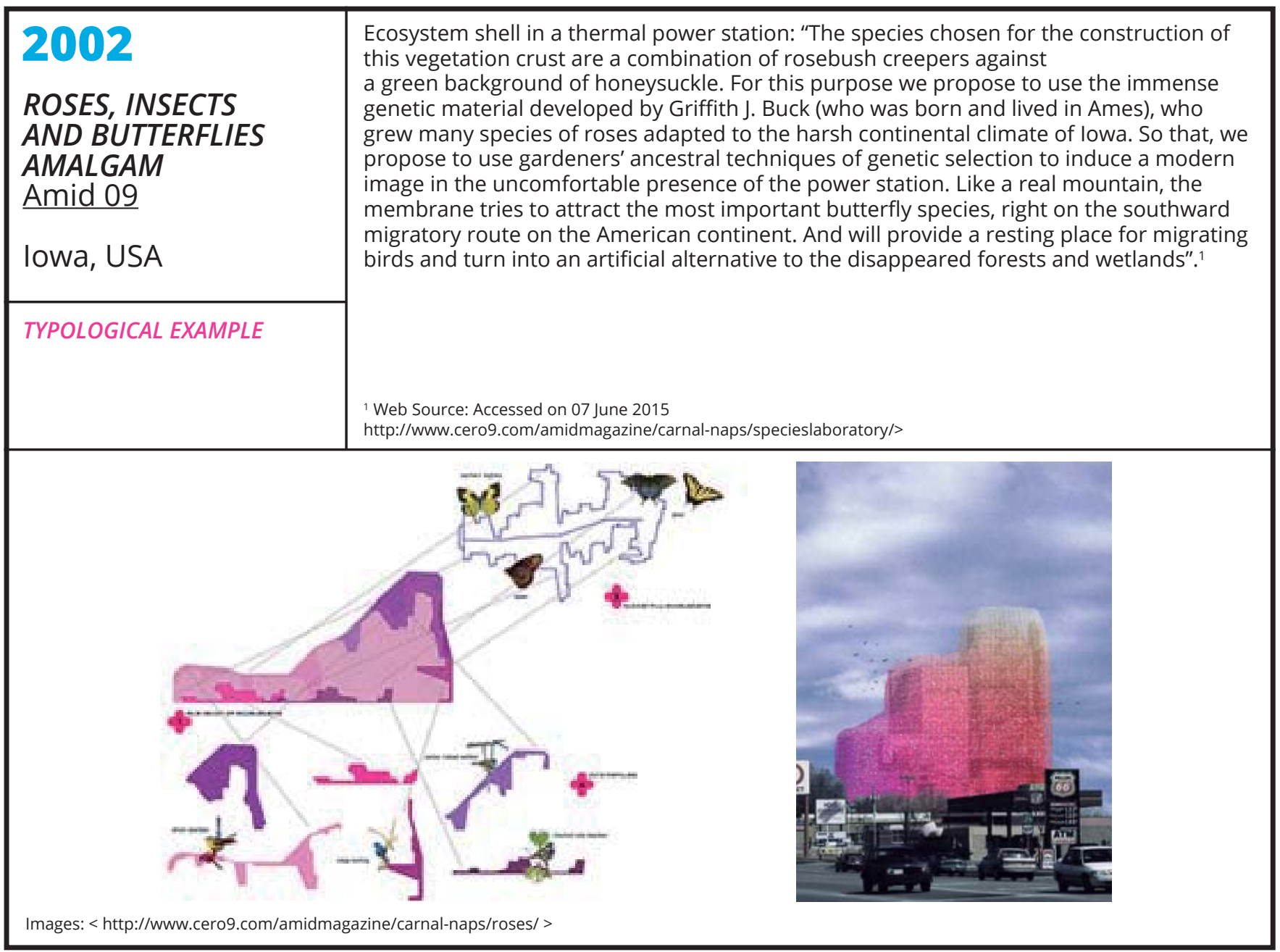

\begin{tabular}{|l|l|}
2007 & $\begin{array}{l}\text { "This project begins as a private commission to design a building for a fashion workshop } \\
\text { (Taller Croquis) in the city of Cali. It became also a plan of different actions aimed to } \\
\text { contribute to the preservation of the natural ecosystem in the neighbourhood, by } \\
\text { facilitating environmentally responsible small gardening initiatives among neighbours, } \\
\text { clients and other regular visitors of the shop. The main action is the GBHNPCB a } \\
\text { prototype for a vertical garden building with host and nectar plants that attracts local } \\
\text { butterflies, which are effective bioindicators of the environmental quality and biodiversity } \\
\text { of the ecosystem and particularly important in this region that has the highest diversity } \\
\text { of butterflies in the world. At the same time the building houses living and production } \\
\text { spaces for the shop".1 }\end{array}$ \\
$\begin{array}{l}\text { WITH HOST AND } \\
\text { CALI BUTTERFLIES } \\
\text { Plataforma HUSOS }\end{array}$ & $\begin{array}{l}\text { Cali, Colombia } \\
\text { PARADIGMATIC EXAMPLE }\end{array}$
\end{tabular}




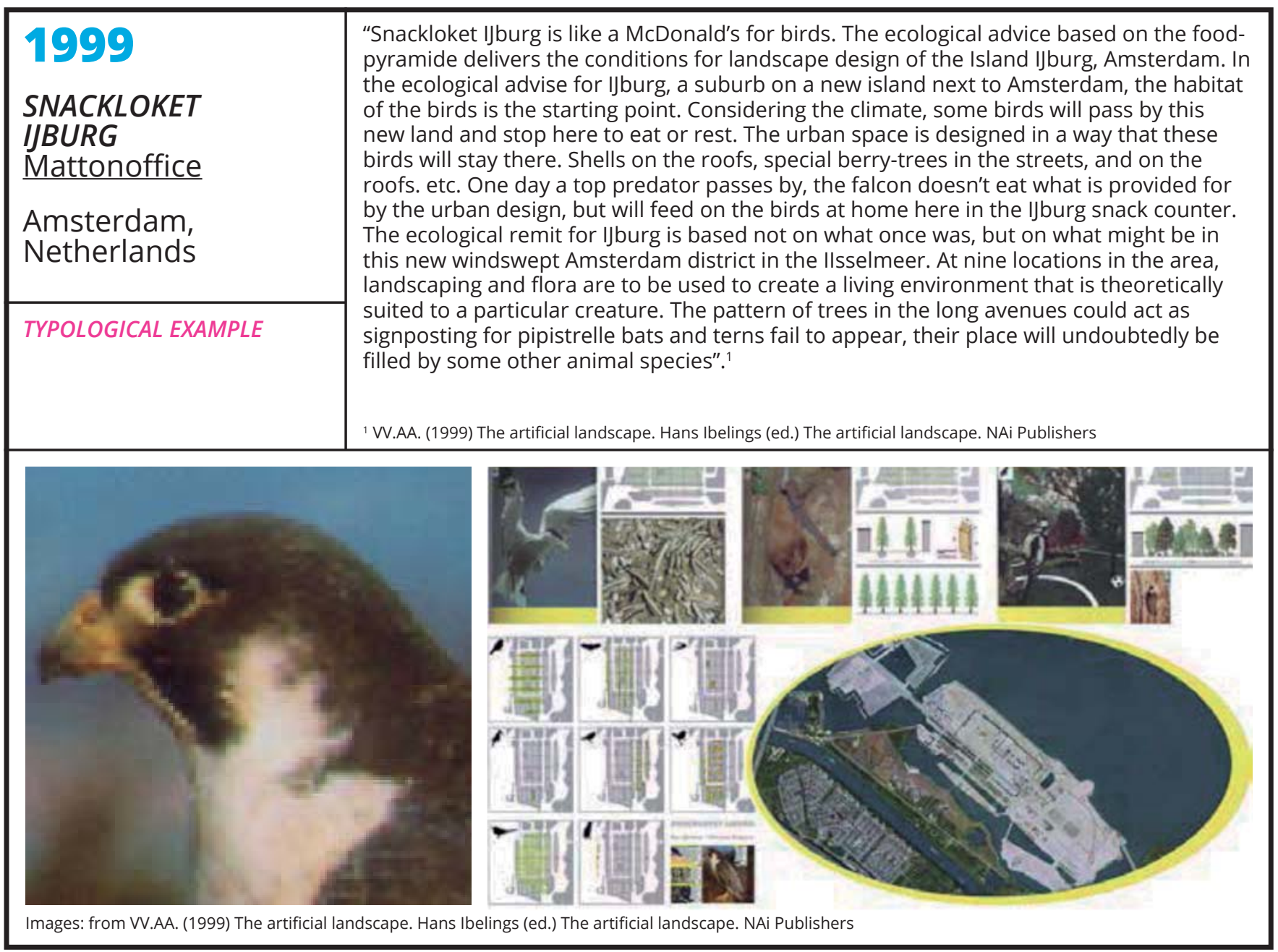

\begin{tabular}{|c|c|}
\hline $\begin{array}{l}2007 \\
\text { FARM FOUNTAIN } \\
\text { Amy Young, } \\
\text { Ken Rinaldo } \\
\text { New York, } \\
\text { USA } \\
\text { ARTIALISATION IN SITU }\end{array}$ & $\begin{array}{l}\text { "Farm Fountain is a system for growing edible and ornamental fish and plants in a } \\
\text { constructed, indoor ecosystem. Based on the concept of aquaponics, this hanging garden } \\
\text { fountain uses a simple pond pump, along with gravity to flow the nutrients from fish } \\
\text { waste through the plant roots. The plants and bacteria in the system serve to cleanse and } \\
\text { purify the water for the fish. This project is an experiment in local, sustainable agriculture } \\
\text { and recycling. It utilizes 2-liter plastic soda bottles as planters and continuously recycles } \\
\text { the water in the system to create a symbiotic relationship between edible plants, fish and } \\
\text { humans. The work creates an indoor healthy environment that also provides oxygen and } \\
\text { light to the humans working and moving through the space. The sound of water trickling } \\
\text { through the plant containers creates a peaceful, relaxing waterfall. The Koi and Tilapia } \\
\text { fish that are part of this project also provide a focus for relaxed viewing. The plants we } \\
\text { are currently growing include lettuces, cilantro, mint, basil, tomatoes, chives, parsley, } \\
\text { mizuna, watercress and tatsoi. The Tilapia fish in this work are also edible and are a } \\
\text { variety that have been farmed for thousands of years in the Nile delta. Farm Fountain is a } \\
\text { collaborative project by artists Ken Rinaldo and Amy Youngs"." } \\
\text { 'Web source. Accessed } 13 \text { jul } 2015 \text { <http://www.farmfountain.com/s }\end{array}$ \\
\hline & 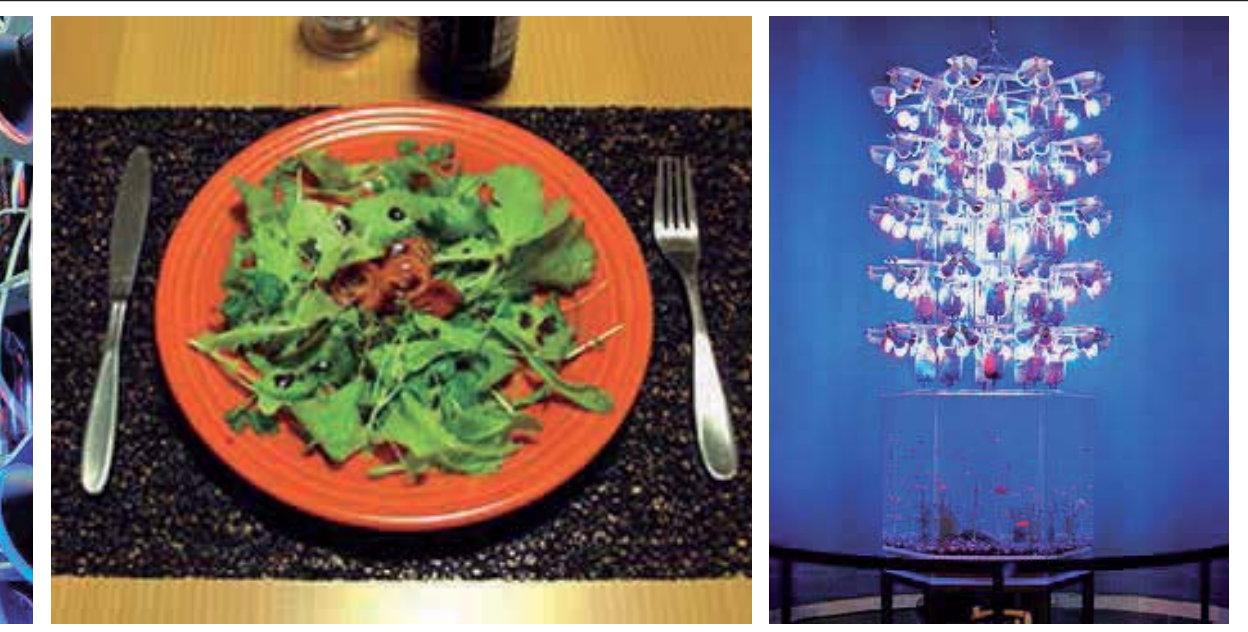 \\
\hline
\end{tabular}




\begin{tabular}{|c|c|}
\hline $\begin{array}{l}2010 \\
\text { CANCER CITY } \\
\text { Visiondivision } \\
\text { USA }\end{array}$ & $\begin{array}{l}\text { "The design for 'cancer city' is an undulated concrete landscape in which crayfish live } \\
\text { inside the structures hills. These hills are equipped with lids which allow the gentleman } \\
\text { to walk on top of the landscape so that he can capture his yearly crayfish quota. a white } \\
\text { path runs on the construction so that the hunter can hunt during the night when crayfish } \\
\text { are most active. waterproof LED lights are attached inside the hills, attracting the crayfish, } \\
\text { making them visible to the hunter. the man-made hills have several escape holes and } \\
\text { underground safe zones, just to make sure that hunting won't be too easy. Up close look } \\
\text { at the undulating landscape made of butong (a lightweight, slightly transparent concrete } \\
\text { called 'butong' was chosen for the construction because of its properties which allow the } \\
\text { structure to be water resistant, transportable and is strong enough to carry full grown } \\
\text { persons or animals walking along it, providing shelter to the crayfishes. Butong also }\end{array}$ \\
\hline TYPOLOGICAL EXAMPLE & $\begin{array}{l}\text { 'Web source: Accessed 02 June 2015. <http://www.designboom.com/architecture/visiondivision-cancer-city/ posted } \\
\text { on AUG 28, } 2010 \text { on designboom.com> }\end{array}$ \\
\hline & 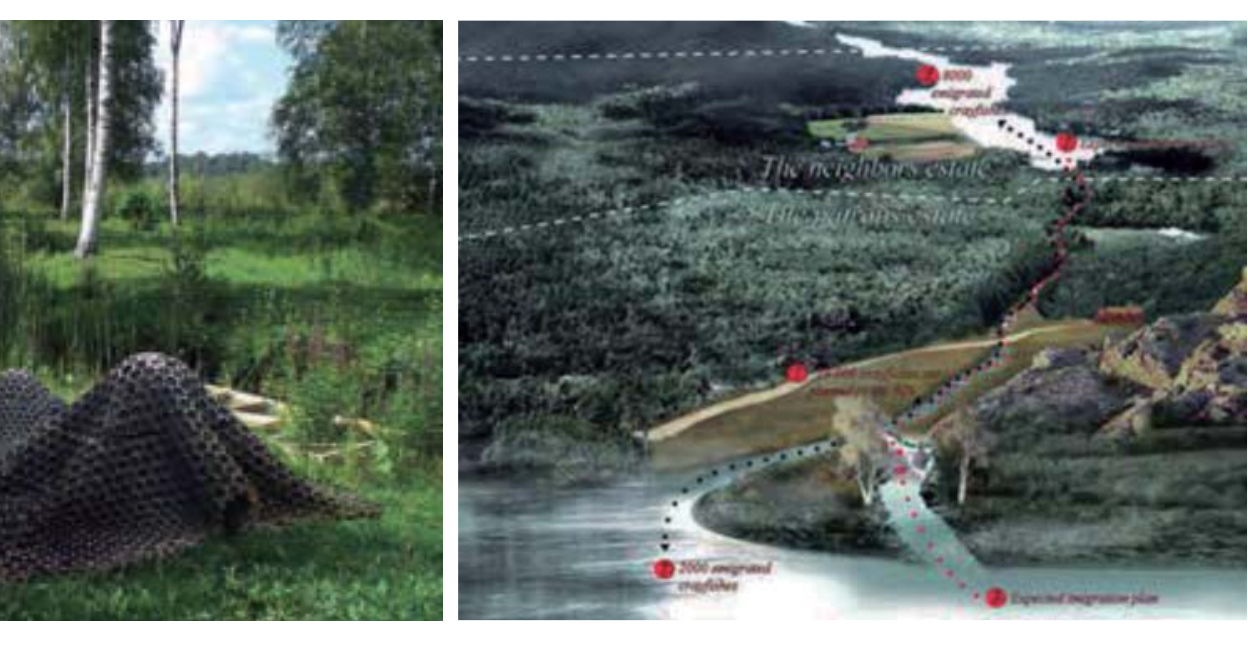 \\
\hline
\end{tabular}

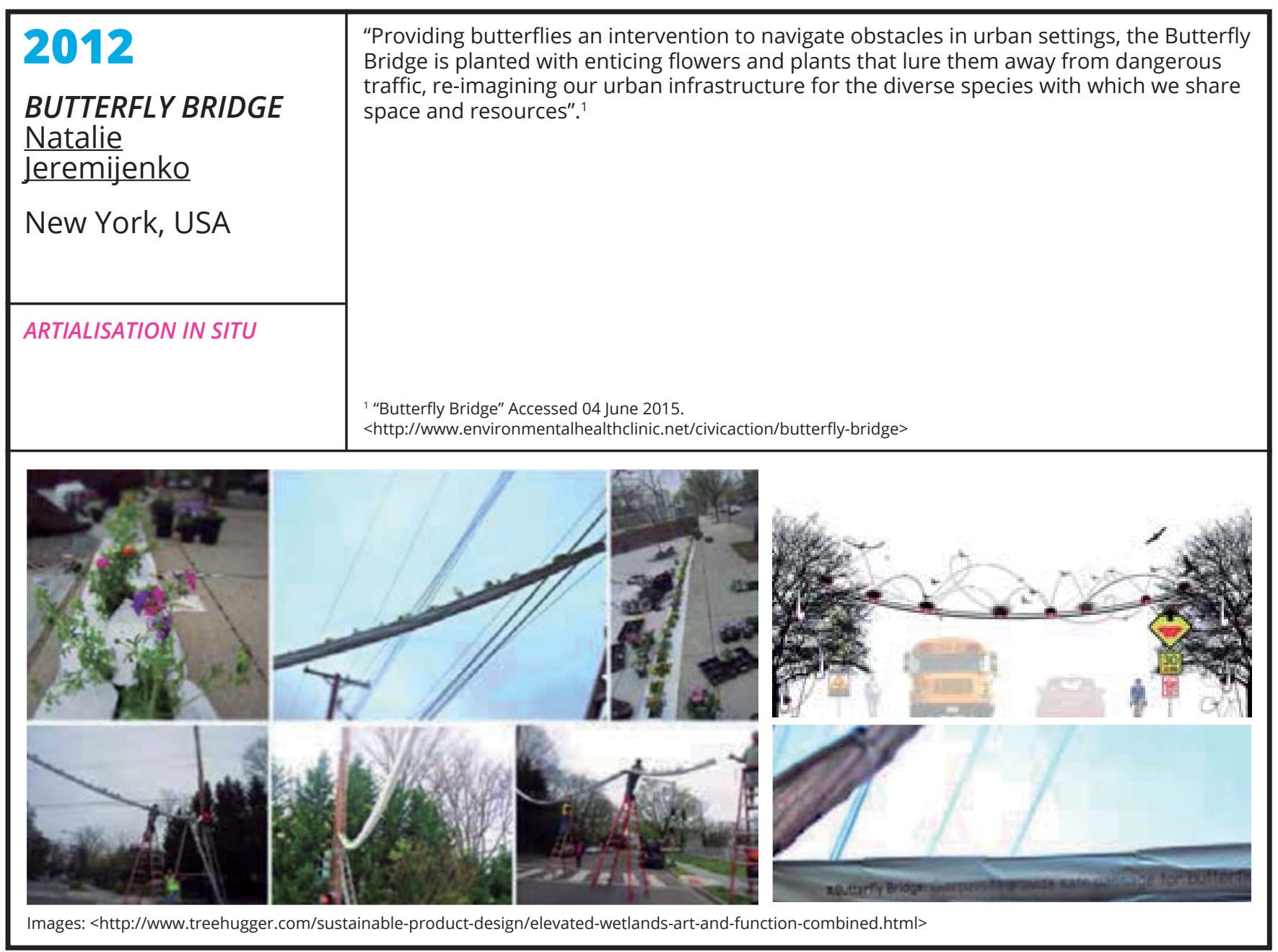




\begin{tabular}{|l|l|}
\hline 2013 & $\begin{array}{l}\text { "As part of a New York state initiative to respond to storm damage from Hurricane } \\
\text { Sandy, SCAPE, with HR\&A and Parsons Brinckerhoff, developed a series of strategies } \\
\text { for rebuilding resilient communities in the Howard Beach and Broad Channel, Queens } \\
\text { neighbourhoods. The community reconstruction plans included cost and feasibility } \\
\text { studies for a pair of tide gates and a berm at Howard Beach, and salt marsh restoration, } \\
\text { berm construction, and oyster reefs at Broad Channel/Sunset Cove. The tide gates and } \\
\text { the berm would connect with protection features in the New York State Department } \\
\text { of Environmental Conservation's (NYS DEC) lower Spring Creek project and U.S. Army } \\
\text { Corps of Engineers' (USACE) Hawtree Point project. Through fieldwork and community } \\
\text { meetings, the study, coupled with the NYS DEC and USACE projects, would create a } \\
\text { comprehensive flood protection strategy that would include the placement of berms } \\
\text { in the upland perimeter to provide shoreline protection, ensuring greater resiliency to } \\
\text { coastal flooding, and the effects of climate change"." }\end{array}$ \\
\hline TYPOLOGICAL EXAMPLE & $\begin{array}{l}\text { New York, USA } \\
\text { Web source. Accessed 07 June 2015 <http://www.scapestudio.com/projects/new-york-rising/s }\end{array}$ \\
\hline Images: O ScapeStudio &
\end{tabular}




\section{Jardinería Productiva / Productive Gardening}

\subsection{Introducción}

La jardinería productiva se entiende enmarcada en un sistema urbano, o una escala en relación con el asentamiento y la vivienda, con origen en el autoabastecimiento y el acceso a la alimentación evolucionando desde los huertos ${ }^{80}$, y en relación con el cultivo de plantas medicinales y flores que derivaría en la aparición de los jardines botánicos y de recreo, hasta su evolución en una tipología contemporánea.

\subsection{El Paraíso}

La idea de un paraíso terrenal se encuentra ampliamente extendida a través de la literatura de numerosas culturas, por ejemplo, los persas usan el término "pairidaeza" -del antiguo persa relacionada con la idea de recinto o muro. La palabra designa inicialmente un jardín productivo protegido por una valla o muro.

En el libro del Génesis (5000 a.C.) -basado en tradiciones orales mesopotámicas sobre el origen del mundo- el Jardín del Edén aparece descrito como un jardín poseedor de toda suerte de árboles que complacían a la vista y además proporcionaban buenos alimentos. Esta artealización in visu, se relaciona directamente con la visión antropocentrista de la dominación del ser humano sobre la naturaleza, la cual únicamente serviría para proporcionarle víveres y armonía. Este es el primer jardín conocido; "el término "edén", en sumerio significaba "campo fértil", este mismo término toma en hebreo el significado de "delicia", así, el jardín del Edén es entendido como un paraíso de vegetación creado para el deleite y los placeres" 81 .

Desde entonces el ser humano busca replicar, tanto in visu, como sucede en la representación pictórica del Bosco "El Jardín de las Delicias" (1500), en la que grupos de personas aparecen comiendo frutos gigantes; como in situ, esas características de fertilidad y belleza. Estas réplicas in situ las podemos ver a lo largo del tiempo en los jardines funerarios egipcios (1989 a.C.) donde se cultivaban vegetales, plantas o hierbas consideradas especiales, en recintos cerrados para el culto a ciertas deidades; en la

${ }^{80}$ RAMIREZ, J.E. (2011): Jardines Productivos. Historia, herramientas y metodologías I. Ver en: https://es.scribd.com/doc/53347802/JARDINES-PRODUCTIVOS-historia-herramientas-y-metodologias-1 (Consultado el 18 de Abril de 2016).

${ }^{81}$ MADERUELO, J (2005): El Paisaje. Génesis de un concepto. Abada Editores. Madrid.

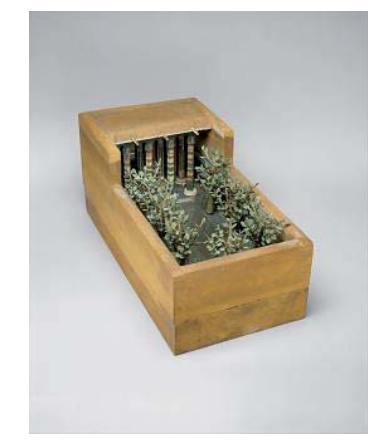

1989 B.C., Funerary Gardens. Ancient Egypt

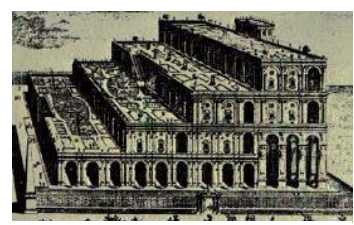

600 a.C., "Jardines Colgantes de Babilonia" Artealisation in Visu

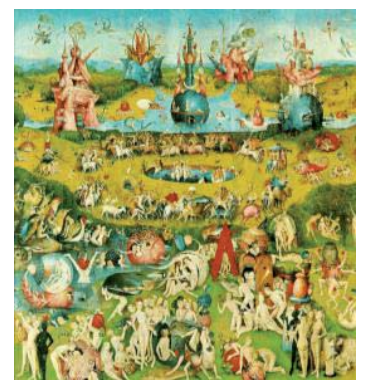

1500, The Gardens of the Earthly Delights. Hieronymus Bosch 


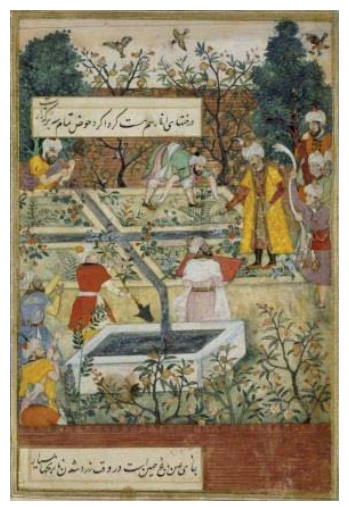

711-1492, "Al Andalus Gardens"

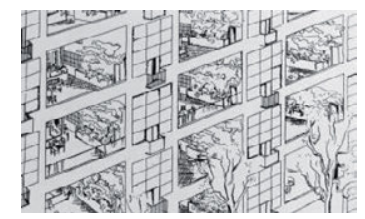

1922., "Fachada Jardin. Le Corbusier

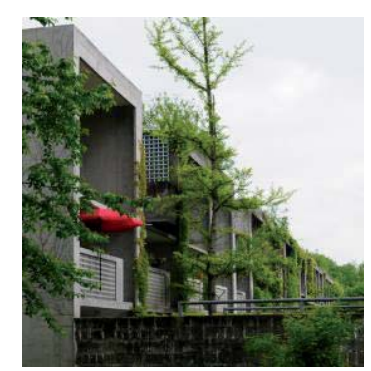

1961, Siedlung Halen, Atelier 5. leyenda de los Jardines Colgantes de Babilonia (600 a.C.), o en los jardines de las villas romanas -Villas Pompeyanas y Villa Adriana (100 a.C. La evolución tipológica de las villas italianas -Villa y Jardín Medici de Michelozzo (1492), se convertirán en un reflejo del cambio de actitud y mirada con respecto a la naturaleza, que volverá a verse a través de un filtro poético como un lugar de descanso, refugio y hedonismo. Así en un fragmento del Decamerón (1351) de Bocaccio se mencionan villas "con Francesco Colonna que describe los jardines en los que tiene lugar la acción con tal minuciosidad, que ha sido considerado uno de los primeros tratados de jardinería de la historia o "arsenal de ideas que inspirará la construcción de los jardines occidentales" 82 . Con anterioridad, también en los jardines japoneses -Jardín del Valle Dorado (803)- encontramos algunos ejemplos.

En la cultura indoeuropea, los llamados jardines del paraíso designan a toda una tipología en sí, con características reconocibles. Excluyen todo tipo de naturaleza salvaje, poseen un perímetro definido y se apoyan en el uso del agua en forma de canales, estanques o riachuelos -incluso en regiones áridas- que proporcionan un orden y una geometría claramente diferenciada del caos reinante en el territorio. Los jardines persas fueron los precursores, extendiéndose rápidamente a la cultura india o a la musulmana como se ve reflejado en los jardines del Al-Andalus (711 -1492). La influencia es visible incluso en los jardines de Versalles (1661-1709).

\subsection{Espacio y energía}

Durante los últimos sesenta años, investigaciones en el campo de la jardinería productiva han impulsado su desarrollo, no solamente para obtener alimentos, sino también para constituirse como estrategia espacial y en relación con la energía. Esto podría poner fin a la tradicional división entre la ciudad y el territorio, en términos de sostenibilidad, mediante estrategias pasivas de control climático y espacios de reunión y compromiso social.

Un ejemplo paradigmático de esta cuestión lo encontramos en 1961, en el proyecto de Atelier 5 Siedlung Halen (1961) ubicado en Suiza. Esta propuesta de viviendas se convirtió en el primer edificio de la historia en poseer una cubierta vegetal, tal y como la entendemos hoy en día. Inmersas en la naturaleza, su diseño responde a la relación con su entorno, la luz, las visuales y la ventilación natural. Al intervenir en este espacio natural, se tuvo en cuenta que la vegetación original del lugar, que fue reemplazada por los edificios, se incorporara en los mismos. Esto se consiguió mediante unas terrazas formadas por dicha vegetación.

${ }^{82}$ OP CIT.: MADERUELO 
Esta estrategia fue también empleada por Friedensreich Hundertwasser, que se convirtió durante las siguientes décadas en un pionero de las cubiertas ajardinadas modernas, creando algunos de los edificios poseedores de los más espectaculares ejemplos, como la GreenHaus ó Hundertwasserhaus.

Es en 1996 cuando nos encontramos con otro ejemplo de proyecto paradigmático: La biblioteca de la Universidad de Delft de los arquitectos Mecanoo. Una de las cosas interesantes de este proyecto y que lo hace ser considerado pionero, es el diseño de su cubierta vegetal. La división entre el paisaje circundante, el edificio de la biblioteca y el auditorio es prácticamente inexistente, así su cubierta se conforma como una extensión del paisaje, siendo el espacio preferido de los estudiantes para descansar y reunirse. ${ }^{83}$ Esta configuración también se puede ver en diseños más recientes como la Ewha Women University (2008) del arquitecto francés Dominique Perrault en Seul.

Dos años más tarde, en 1998, el botánico francés Patrick Blanc, instala en la Fundación Cartier de París una artialización in situ, que buscaba visibilizar preocupaciones de ecología y cambio climático. Esa instalación, se acabó convirtiendo en una de las estrategias pasivas bioclimáticas más exitosas de las últimas décadas: los muros vegetales o jardines verticales.

En los últimos quince años, proyectos de "Digestiones Pesadas" -cuestión más adelante desarrollada- como The Highline (2002) de los arquitectos americanos Diller, Scofidio \& Renfro en Nueva York, el Centro de Tratamiento de Residuos (2012) de Battle i Roig Architectes en España, e incluso la revista TIME, se hacen eco de estos "Sueños Verdes" (2006).

Es precisamente en 2005 cuando encontramos en Madrid un ejemplo paradigmático de proyecto: el Ecobulevar de Ecosistema Urbano. Se trata de unos artefactos que hacen lo mismo que hacen los árboles. Son construcciones artificiales que replican las funciones de un árbol, son monumentales, como buen árbol, dan sombra, como buen árbol; evaporan agua dando frescor, como un buen árbol; también aprovechan la energía del sol, aunque no mediante la fotosíntesis: están coronados por paneles fotovoltaicos que recogen la energía del sol. En proyecto, esos paneles podían resultar un beneficio de 6000 euros al año para el ayuntamiento, con lo que se podía pagar el mantenimiento del Bulevar, la limpieza, etc. Desgraciadamente, aunque los paneles están en su lugar, no se produce la energía fotovoltaica, no están conectados a la red. La razón es que no hay un agente del

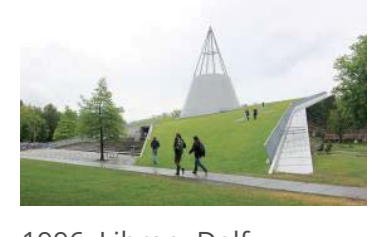

1996, Library Delf University, Mecanoo.

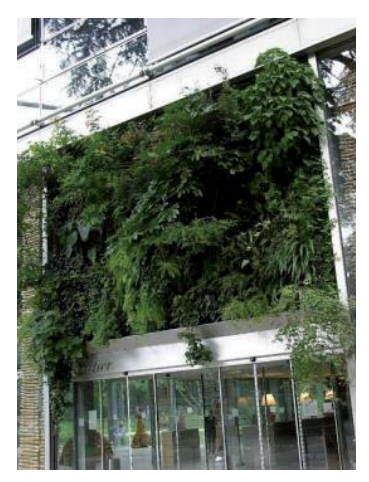

1988, Cartier Foundation, Patrick Blanc.

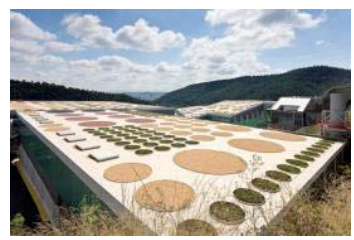

2012, Centro de tratamiento de residuos, Batlle i Roig arquitectes..

\footnotetext{
${ }^{83}$ MECANOO. Library Delft University of Technology. Ver en: http://www.mecanoo.nl/Projects/project/27/Library-Delft-University-of-Technology?t=0 (Consultado el 11 de Diciembre de 2015)
} 


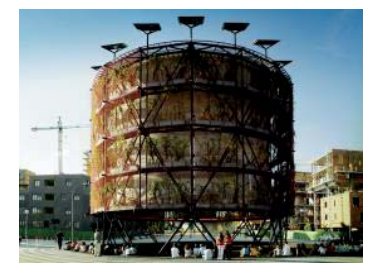

2005, Ecobulevar, Ecosistema Urbano.

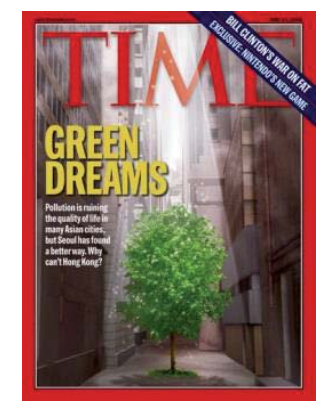

2006, "TIME MAGAZINE. Green Dreams

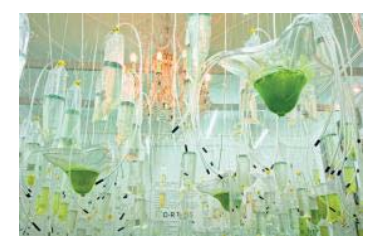

2012, H.O.R.T.U.S., Ecologic Studio. ayuntamiento que se pueda encargar de gestionar la electricidad producida. Ese aspecto no está “construido"; de nuevo, la construcción es algo más que el hormigón o el acero.

Desde la creación de esos muros vegetales o jardines verticales, hemos visto como su función bioclimática o decorativa ha evolucionado también para formar parte de algunos de los proyectos que hemos visto en la línea del tiempo de los ecosistemas gestionados. El pensamiento ecosistémico se traduce en una característica más de estos jardines productivos. Por ejemplo, el barrio de Queens en Nueva York sustituyó una parte infrautilizada de sus aceras para instalar un pequeño jardín de tormentas en 2013. El proyecto Butterfly Bioswale de Studio_Scape, absorbe el exceso de agua producido en las tormentas para evitar inundaciones, a la vez que crea un hábitat especialmente pensado para mariposas, insectos y pájaros.

Recientemente, se ha podido percibir un avance en el uso de la jardinería productiva como herramienta de proyecto, reflejo del desarrollo de estrategias innovadoras, como el cultivo de algas para la generación de energía. Así se puede ver en la artealizacion in visu consistente en una instalación de un nuevo prototipo de jardín a base de micro-macro organismos de alga, y bacterias bioluminiscentes de Ecologic Studio para la Architectural Association de Londres (H.O.R.T.U.S, 2012). La instalación busca estimular la necesidad de creación de nuevas prácticas que relacionen las energías renovables, agricultura y las interfaces virtuales.

Sólo un año más tarde es desarrollada por ARUP, la primera fachada que genera energía En 2015 Urban Algae Follie, de nuevo por Ecologic Studio, propone una artealización in situ recinto, que demuestra que una serie de especies de microalgas crean un control más efectivo de la atmósfera urbana -en términos de absorción de CO2 y confort- que incluso los propios árboles. 


\subsection{Alimentación}

La jardinería productiva no llegó a contextos que podamos llamar generalistas hasta el siglo XIV, a través del libro de recetas medieval para amas de casa "Le Ménagier de Paris" (1393), que contiene desde nociones de jardinería básica hasta consejos maritales. Si bien es cierto, que los huertos son considerados jardinería productiva, eran más comunes en las zonas rurales donde se podría hablar simplemente de una escala menor de la agricultura. Por entonces, los monasterios aún poseían la exclusividad de los jardines medicinales. Pero en cuanto a la aparición de un jardín que atienda tanto a la contemplación como a la productividad de alimentos para consumo nos encontramos con un ejemplo paradigmático con los jardines del castillo de Villandry (1536, jardines reconstruidos c.1906) en Loira, Francia. Aquí, los cultivos pasan a formar parte de la belleza de los jardines franceses, siendo diseñado atendiendo tanto a las necesidades productivas como a la experiencia de su disfrute cotidiano.

No obstante, su diseño actual corresponde a 1906, cuando la propiedad fue comprada y recuperada por Joachim Carvallo y Ann Coleman en base a textos antiguos sobre el jardín del siglo XIV84. Otros de los muchos jardines franceses de la época como L'Orangerie du Versailles (1613), o posteriormente los ingleses como Chiswick House (1724); incluían una parte de jardín productivo integrado en el conjunto.

Cuando parecía que el ejemplo paradigmático de los jardines del castillo de Villandry no iba a tener una réplica de carácter más público y en un contexto más urbano, aparece en 2004, la Shenyang Architectural University de Turenscape en China. El campus se encuentra inmerso en un entorno creado a partir de campos de cultivo y puntual ganadería. Este proyecto supone un ejemplo tipológico, resultado del progresivo acercamiento entre dos de los cronogramas de este trabajo, Escalando la agricultura y Jardinería productiva, enfocada a la alimentación. La estrategia nace de la demanda de la población china por una mayor producción de comida, que el territorio, actualmente sobreexplotado, a duras penas puede abastecer.

Ese mismo año, la astroculture, investigación promovida por la NASA, consigue por primera vez cultivar plantas satisfactoriamente en el espacio; un paso más de lo conseguido en la simulación del proyecto espacial ruso de BIOS-3 (1965), referenciado en la línea de microecosistemas vegetales. Si existe entonces la tecnología para cultivar fuera de la tierra, las herramientas para hacerlo en cualquier sitio dentro de ella, se multiplican.

\footnotetext{
${ }^{84}$ WIKIPEDIA. Chateau de Villandry. (Consultado el 29 de Mayo de 2015) Ver en: https://es.wikipedia.org/wiki/Castillo_de_Villandry
}

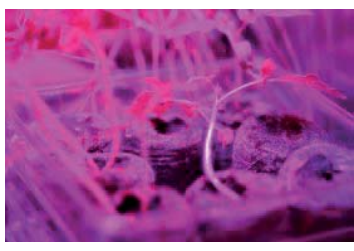

2004, Astroculture: NASA LED Wheat.

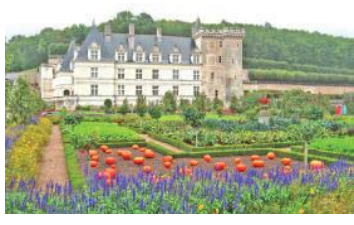

1536, Villandry Gardens

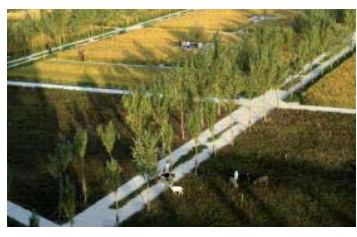

2004, Shenyang Architectural University, Turenscape 


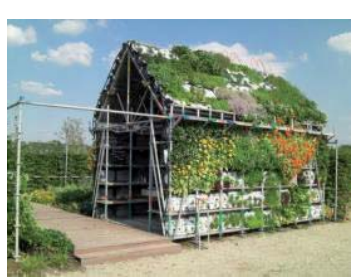

2010, Eat House, Pasona Group.

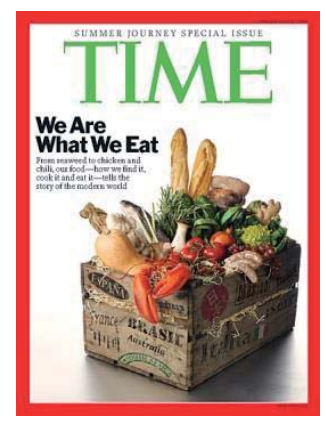

2007, "TIME MAGAZINE: We are what we eat.

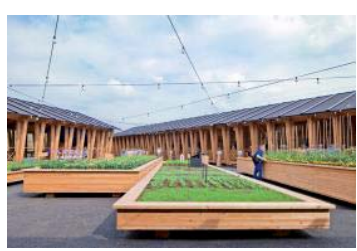

2015, Slow Food Pavilion, Herzog \& DeMeuron.
Pronto, restaurantes americanos comienzan a cultivar su propia comida (2006); reflejo de ello, la revista TIME dedica una portada un tema transversal a todos estos proyectos que reflejan el renovado impulso de la producción de alimentos propia: "We are what we eat" Somos lo que comemos- (2007). Los riesgos a la salud provocados por pesticidas, plaguicidas, alimentos transgénicos y reflejados en los medios de comunicación, nos lleva a la necesidad de la creación de nuevos estilos de vida, que monitorizan los procesos de lo que ingerimos. Es esta preocupación es el motivo por la que los restaurantes americanos comienzan a cultivar su propia comida. El arte se hace eco de estas necesidades y ejemplos como la artealización in visu para el MOMA PS1 de ese año, Public Farm 1 del estudio WORK Architecture Company; el aprovechamiento de una cámara acorazada de un banco en desuso para convertirlo en un cultivo urbano en Tokio -Pasona 02; o la creación del huerto vecinal Esta es una plaza (2008) como pionero en la conversión de solares en desuso de Madrid en jardines productivos autogestionados, así lo reflejan.

En los últimos años, continúa esta intención con el ejemplo extremo de artealización in situ Eat House (2010) de Atelier Gras, que literalmente crea un espacio aprovechando los propios cultivos como material de construcción.

También con la propuesta de los arquitectos Herzog \& DeMeuron para la EXPO de Milán de 2015. Slow Food Pavillion, es el nombre que recibe el espacio creado para mostrar a los visitantes el significado de la biodiversidad agroalimentaria y promover nuevos hábitos de consumo, así como mostrar el masterplan que el estudio creó en 2011 y que pretendía incluir estos conceptos en el propio diseño de una exposición universal. Su radical intervención a escala urbana no fue posible, en parte debido a la visibilización de los cuestionables intereses de las grandes compañías agrarias, pero en cambio fue posible la formalización de un pabellón en el que mostrarlo ${ }^{85}$.

${ }^{85}$ (Traducida) HERZOG \& DEMEURON. Slow Food Pavillion, en http://www.herzogdemeuron.com/index/projects/complete-works/426-450/446-expo-milan-2015-slowfood-pavilion.html (Consultada el 26 de Octubre de 2015) 
PRODUCTIVE

GARDENING

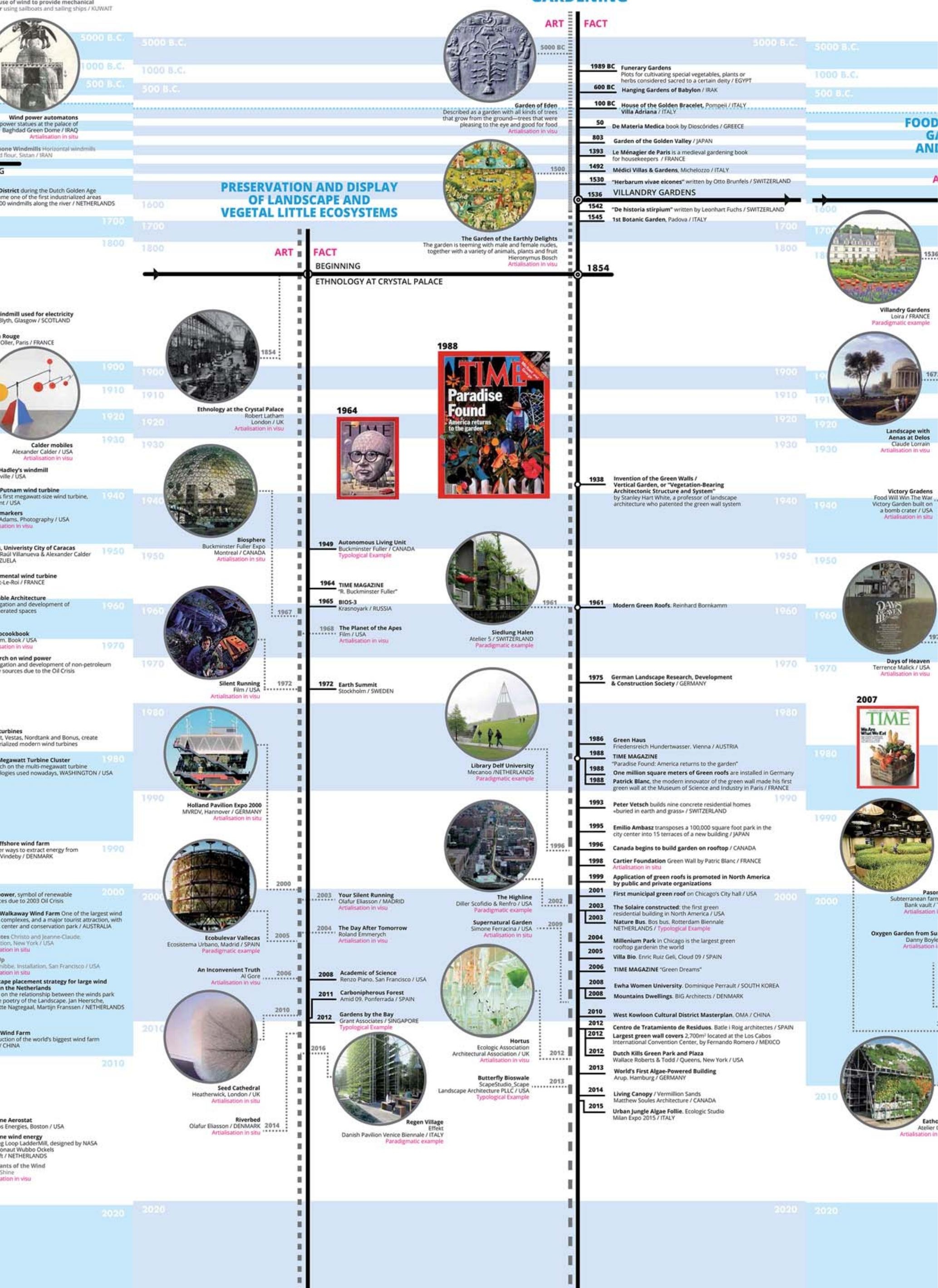




$\begin{array}{ll}5000 \text { B.C. } & \begin{array}{l}\text { Described as a garden with all kinds of trees that grow from the ground-trees that were } \\ \text { pleasing to the eye and good for food. "All in all the Garden Eden's foods were delicious, } \\ \text { comforting, and naturally sweet".' The Tree of Life will be in heaven, it has twelve kinds } \\ \text { of fruits that yield each month and whose leaves have healing powers. It seems like the } \\ \text { Tree of Life is the only fruit that God created for humans to eat. "And God said, Behold, I } \\ \text { have given you every plant yielding seed that is on the face of all the earth, and every tree } \\ \text { with seed in its fruit. You shall have them for food".' }\end{array} \\ \text { OF EDEN } & \end{array}$

\begin{tabular}{|l|l|}
\hline 1989 BC & $\begin{array}{l}\text { "Temple gardens had plots for cultivating special vegetables, plants or herbs considered } \\
\text { sacred to a certain deity and which were required in rituals and offerings like lettuce } \\
\text { to Min. Sacred groves and ornamental trees were planted in front of or near both cult } \\
\text { temples and mortuary temples. As temples were representations of heaven and built } \\
\text { as the actual home of the god, gardens were laid out according to the same principle. } \\
\text { Avenues leading up to the entrance could be lined with trees, courtyards could hold small } \\
\text { gardens and between temple buildings gardens with trees, vineyards, flowers and ponds } \\
\text { were maintained"." }\end{array}$ \\
$\begin{array}{l}\text { GARDENS } \\
\text { Thebes, }\end{array}$ & $\begin{array}{l}\text { 'Web source. Accessed 29 May 2015 <http://ancientpeoples.tumblr.com/post/52795182428/wooden-model- } \\
\text { of-a-garden-this-model-would-be-taken> }\end{array}$ \\
\hline ARTIALISATION IN SITU & \\
\hline
\end{tabular}




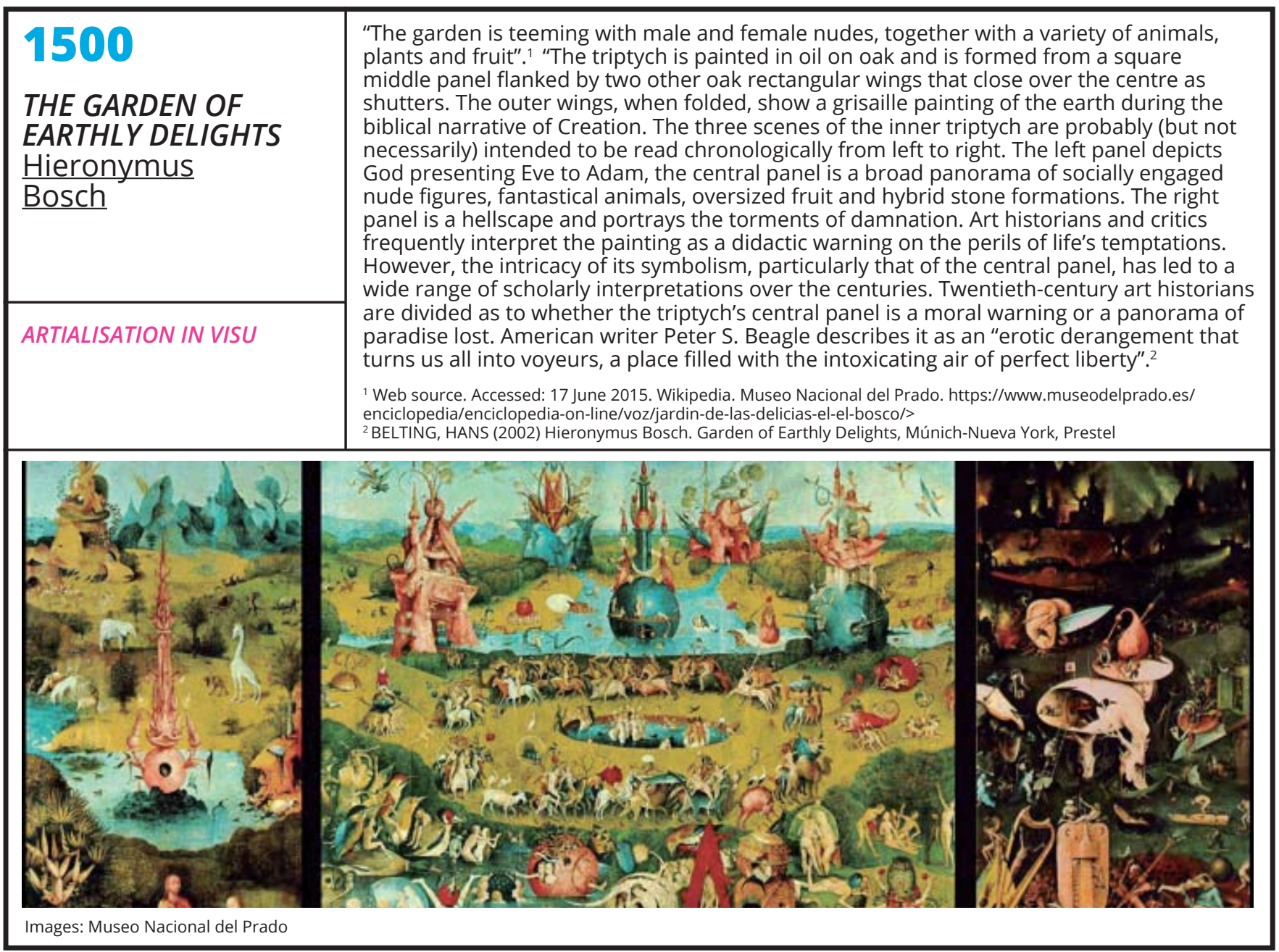

\begin{tabular}{|l|l|}
\hline 1961 & $\begin{array}{l}\text { "Siedlung Halen could be presented as an artefact of housing immersed in nature. Inserted } \\
\text { in the middle of a forest hillside. Its design responds to the environment, light and natural } \\
\text { ventilation, the visuals, the relationship of housing with green space; but completely } \\
\text { isolated from the urban environment (one of the goals of Atelier } 5 \text { was to 'protect' } \\
\text { interior private space as an exterior, and achieve acoustic insulation of each housing } \\
\text { unit). However, despite this intervention in the green space, a sort of replacement of the } \\
\text { original vegetation is proposed by using landscaped terraces, which although it is not equal } \\
\text { to the original trees, at least introduce the vegetation in the house and create a green } \\
\text { environment not only in the outdoor gardens but practically all over the deck area. On the } \\
\text { other hand, consideration of the slopes results in an optimal adaptation of the architecture } \\
\text { to the hillside, by taking advantage of the underground parts of the terraces for the least } \\
\text { permeable functions, while the decks and higher levels take advantage of sunlight and } \\
\text { visuals...." }\end{array}$ \\
\hline Switzerland & $\begin{array}{l}\text { Web source. http://laboratoriovivienda21.com/magazine/?p=159; Text from laboratorio vivienda 21.com Barcelona. } \\
\text { Posted by Cristina Soler, Ana Maria Unterladstaetter }\end{array}$ \\
\hline FARADIGMATIC EXAMPLE green terrace building &
\end{tabular}




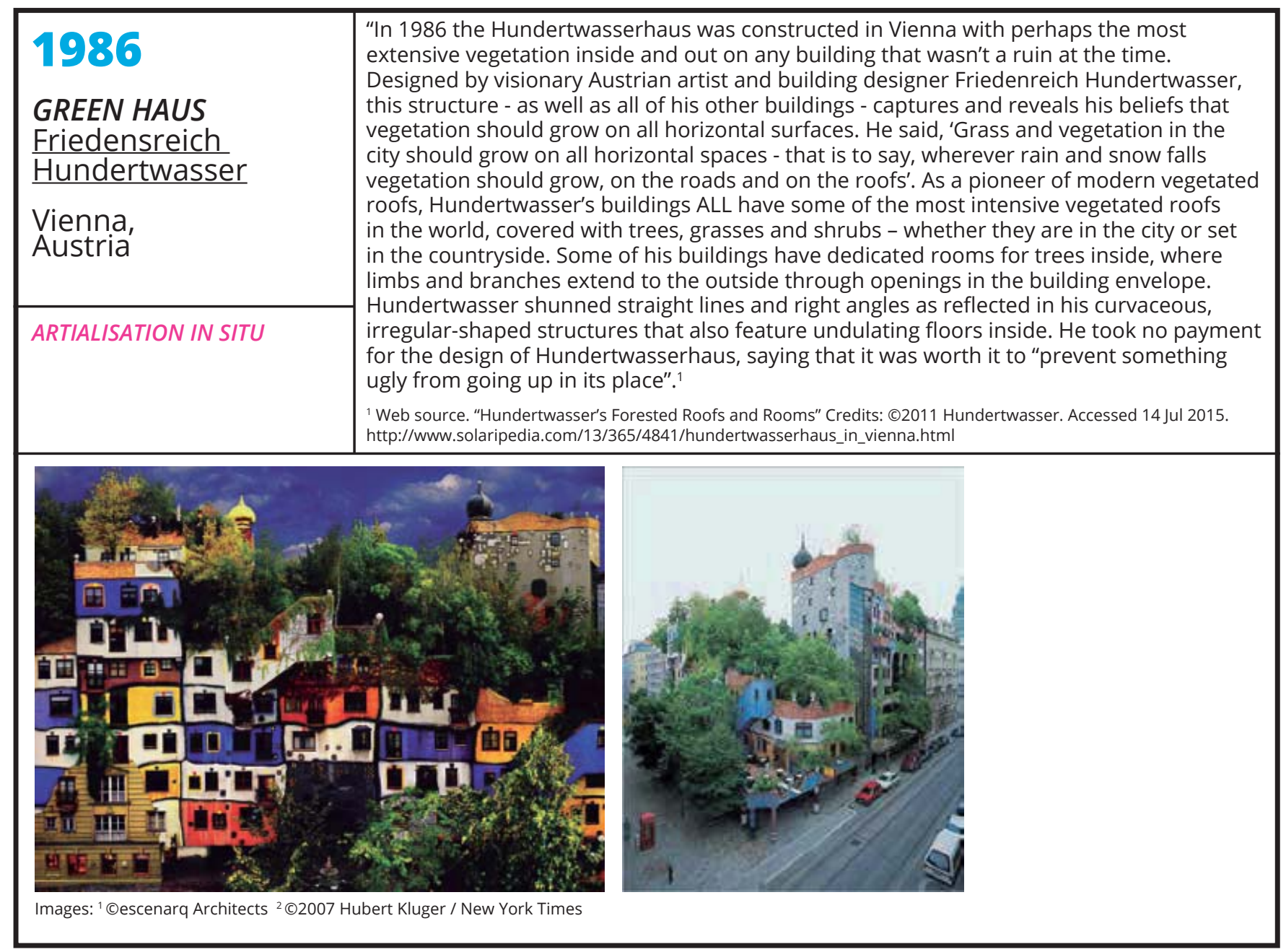

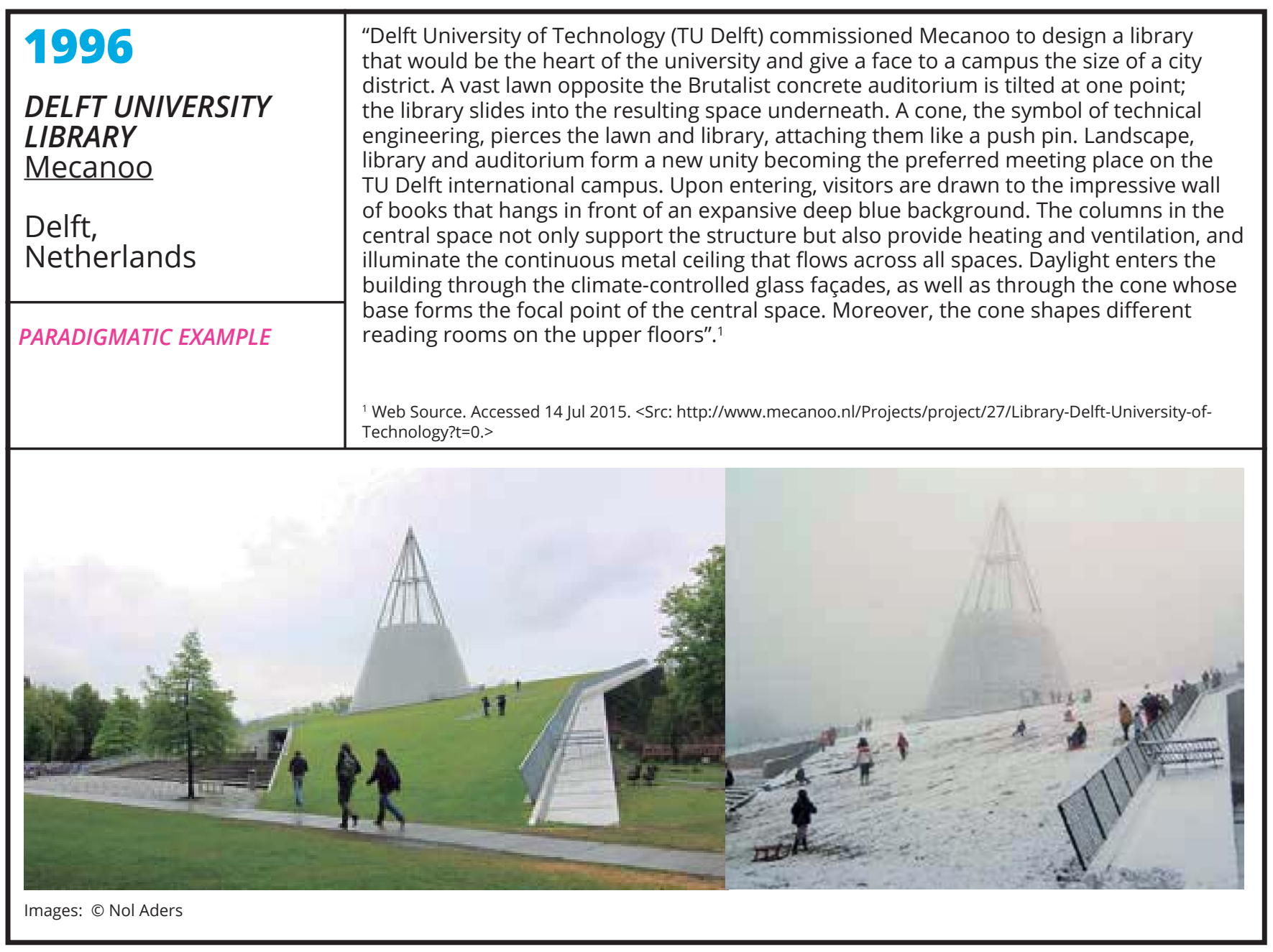




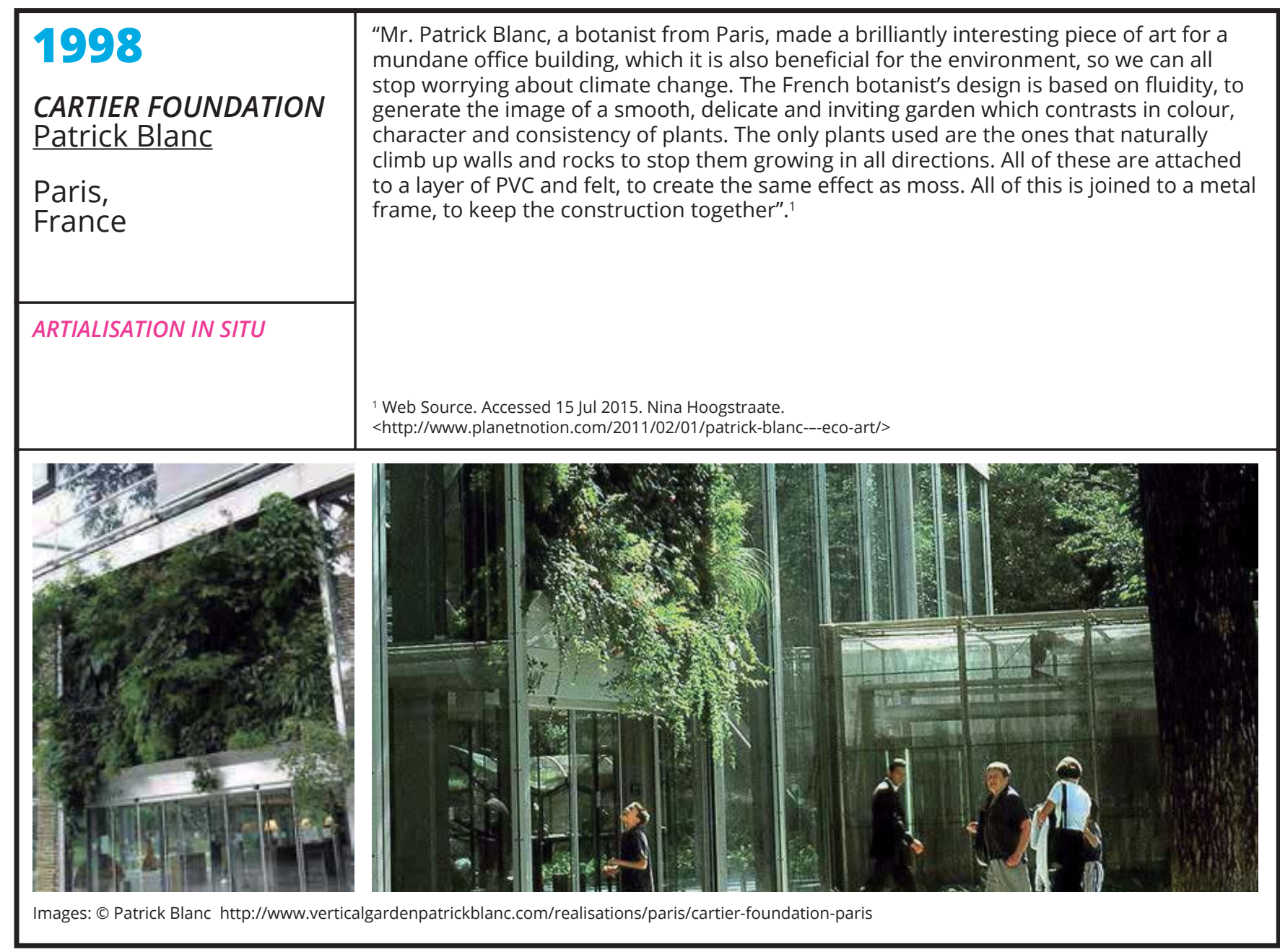

\begin{tabular}{|l|l|}
\hline 2002 & $\begin{array}{l}\text { "Agri-tecture is inspired by the melancholic found beauty of the High Line, where nature } \\
\text { has reclaimed a once-vital piece of urban infrastructure. The design team aims to re-fit } \\
\text { this industrial conveyance into a post-industrial instrument of leisure. By changing the } \\
\text { rules of engagement between plant life and pedestrians, our strategy of agri-tecture } \\
\text { combines organic and building materials into a blend of changing proportions that } \\
\text { accommodates the wild, the cultivated, the intimate, and the hyper-social"." }\end{array}$ \\
$\begin{array}{l}\text { Diller SCOfidio } \\
\text { \& Renfro }\end{array}$ &
\end{tabular}




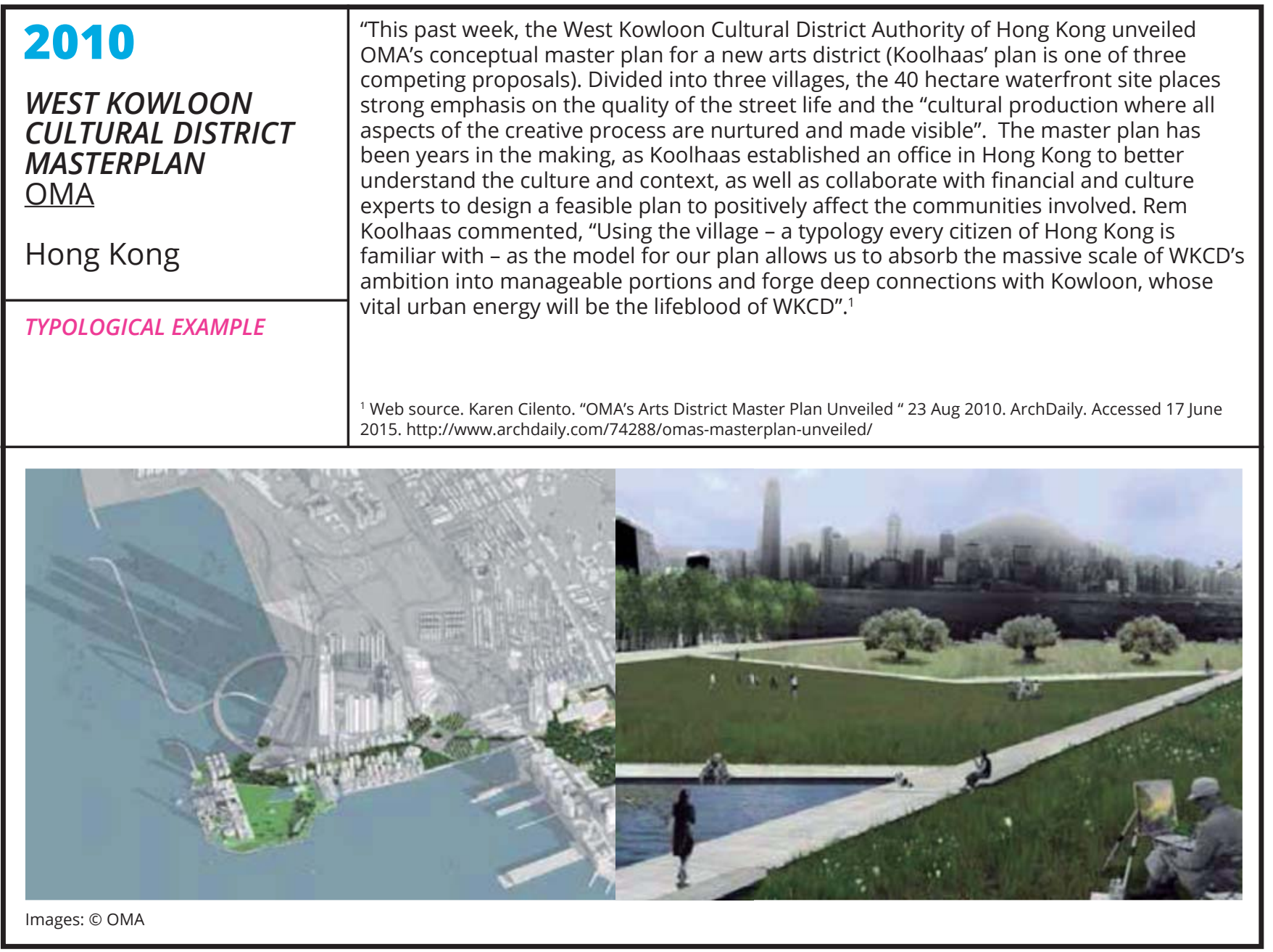

\begin{tabular}{|l|l|}
\hline 2012 & $\begin{array}{l}\text { “The Waste Treatment Centre (CTR) is situated on a slope of the mountain in } \\
\text { the municipality of Vacarisses. The activity of the existing landfill had not been respectful } \\
\text { of their immediate surroundings, had caused alterations of the natural environment and } \\
\text { modifications to the existing topography. For this reason, was decided to implement the } \\
\text { facilities in areas where the activity of the landfill where the natural environment had } \\
\text { been already damaged. Despite the magnitude of the facilities of the Centre, the project } \\
\text { aims to achieve maximum integration with the surrounding landscape. Therefore it } \\
\text { seeks a maximum topographical adaptation, where the impact of the roofs and façades } \\
\text { is minimized by subsequent revegetation landscape. The different circles contain earth, } \\
\text { gravel and typical species, that eventually balance out the impact of installations without } \\
\text { falling in camouflage or imitation". }\end{array}$ \\
$\begin{array}{l}\text { BE RESIDUOS } \\
\text { Battle i rOig }\end{array}$ & $\begin{array}{l}\text { architectes } \\
\text { Spain }\end{array}$ \\
\hline TYPOLOGICAL EXAMPLE & Woot-monument-to-biological-pest-control-and-cross-species-design/265465/>
\end{tabular}




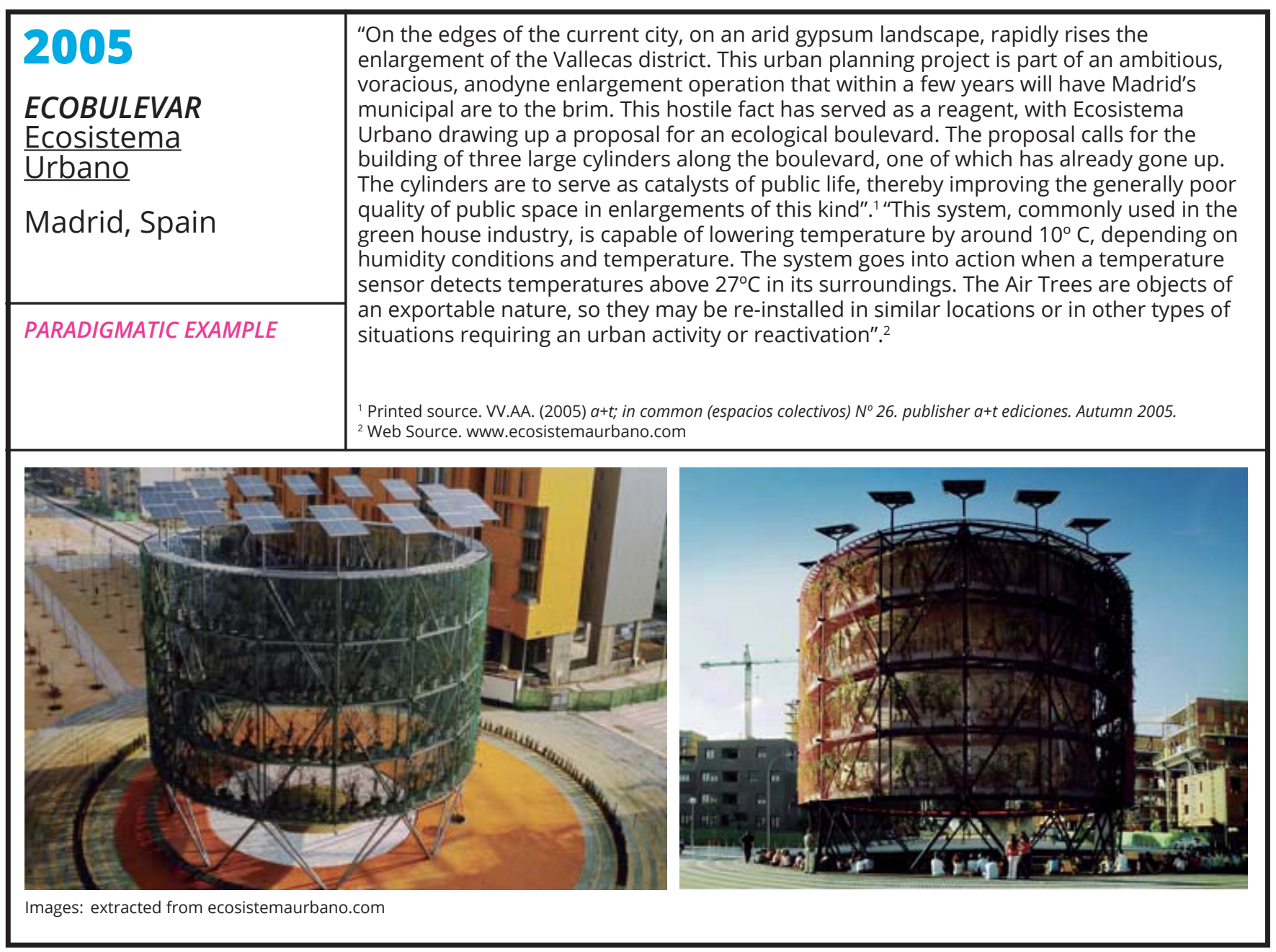

\begin{tabular}{|c|c|}
\hline $\begin{array}{l}2013 \\
\text { BUTTERFLY BIOSWALE } \\
\text { ScapeStudio Scape / } \\
\text { Landscape } \\
\text { Architecture PLLC } \\
\text { New York, USA }\end{array}$ & $\begin{array}{l}\text { "This landscape removed } 300 \text { square feet of impervious surface to create a storm water } \\
\text { capture garden and butterfly / insect habitat strip. A slight swale was graded to hold } \\
\text { water and robust plantings replaced underutilized sidewalk area. This project resulted in } \\
\text { fewer gallons of storm water runoff collecting in the Tier } 1 \text { sewer shed, helping to reduce } \\
\text { incidence of CSO (combined sewer overflow) events. In addition, a } 100 \text { gallon rain cistern } \\
\text { helps to catch and reduce the 'first flush' of storm water into the system. The garden } \\
\text { serves as a natural habitat for insects and forage for birds".' }\end{array}$ \\
\hline ARTIALISATION IN SITU & 'Web source. Accessed 02 June 2015 <http://www.scapestudio.com> \\
\hline & D AFTER \\
\hline
\end{tabular}




\begin{tabular}{|c|c|}
\hline $\begin{array}{l}2009 \\
\text { SUPERNATURAL } \\
\text { GARDEN } \\
\text { Simone } \\
\text { Ferracina } \\
\text { New York, USA }\end{array}$ & $\begin{array}{l}\text { "Super-Natural Garden is an on-going project aimed at the digital extension of the } \\
\text { Brooklyn Botanic Garden in New York City. Visitors looking at the Garden through the } \\
\text { technological lens of smart phones and headset devices will discover it expanded by } \\
\text { electronic ecologies, augmented by scattered digital performances: cybernetic dances, } \\
\text { transformations and emergences. Electronic weeds will insinuate themselves into the } \\
\text { life of the Garden, establishing varying degrees of dependence on real-world plants and } \\
\text { on each other, from competition and parasitism to coupling and symbiosis. They will } \\
\text { broaden and diffuse the boundaries of the Garden into a sort of cyborgian 'extended } \\
\text { phenotype,' an augmented geography of interconnectedness and interaction. Their } \\
\text { invasive character, rather than symbolizing the instinctual power of a holistic 'Nature' } \\
\text { as in the weeds described by architect Louis Sullivan1, will present visitors with the }\end{array}$ \\
\hline ARTIALISATION IN SITU & $\begin{array}{l}\text { 'Web source. KERB } 19 \text { / Paradigms of Nature: Postnatural Futures published in Archdaily by Ethel Baraona Pohl } 20 \\
\text { Oct } 2011<\text { : http://www.archdaily.Com/177905//erb-19-paradigms-of-nature-postnatural-futures/\#more-177905 > }\end{array}$ \\
\hline & POUEN DONuT \\
\hline
\end{tabular}

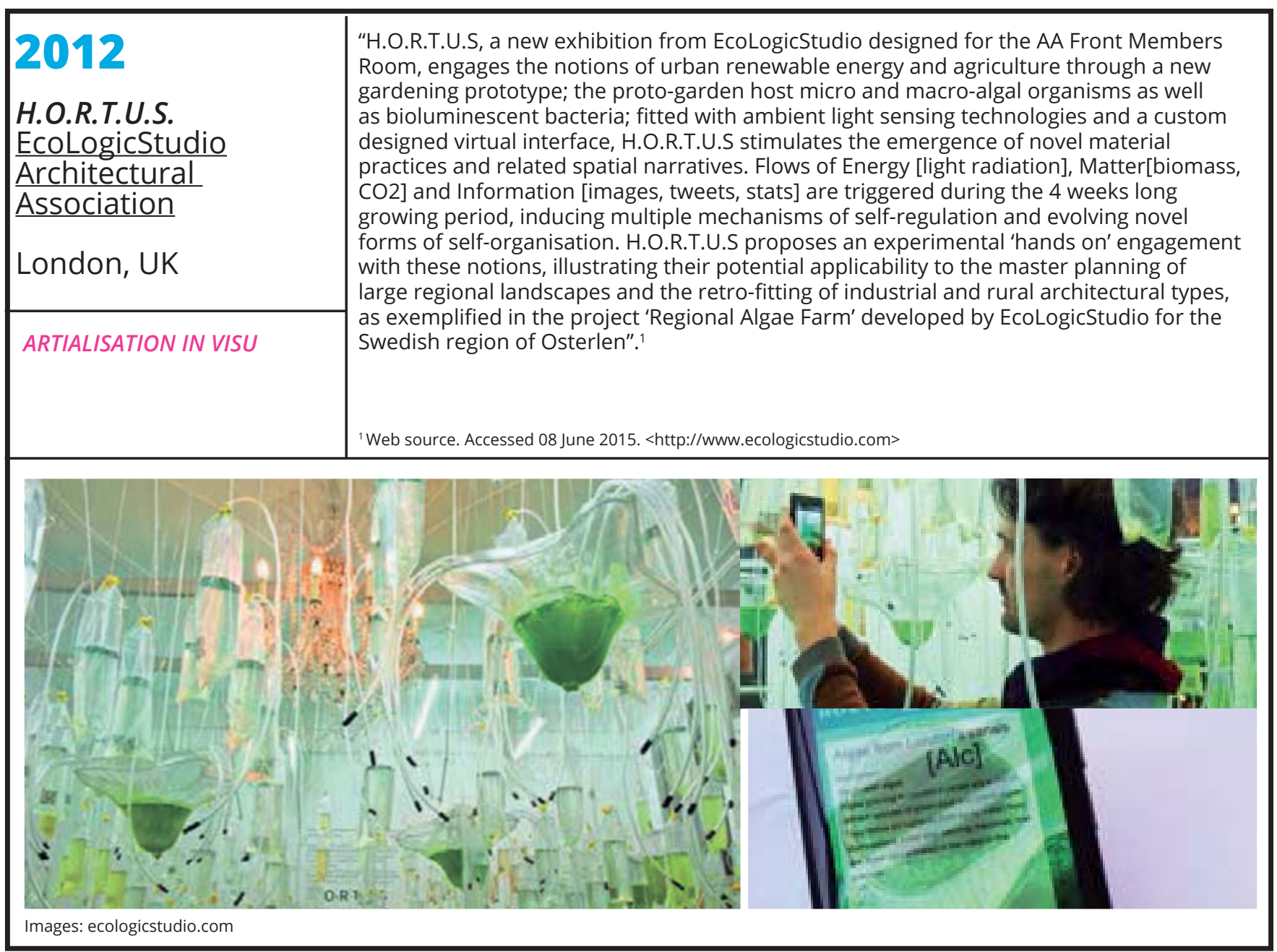




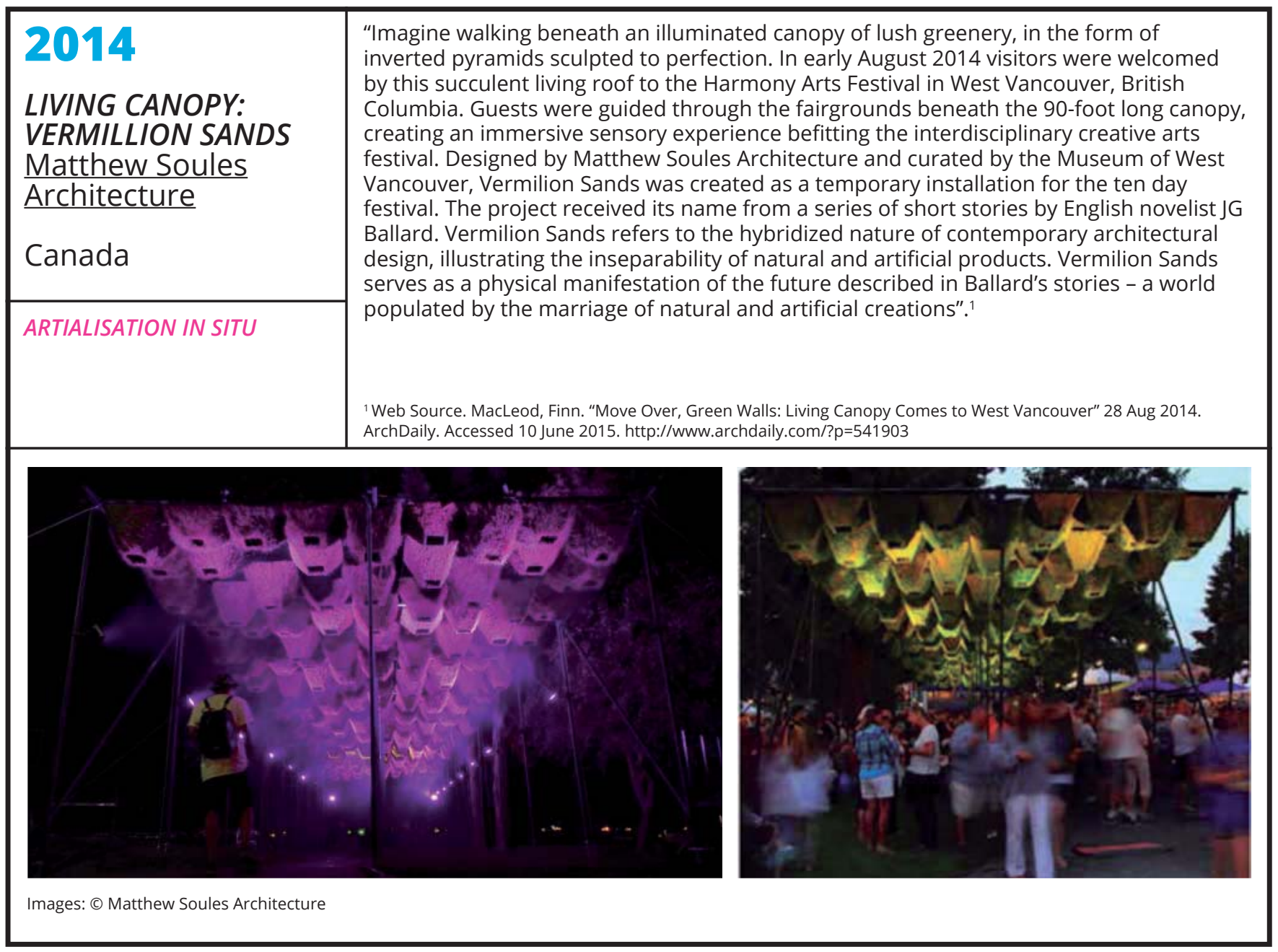

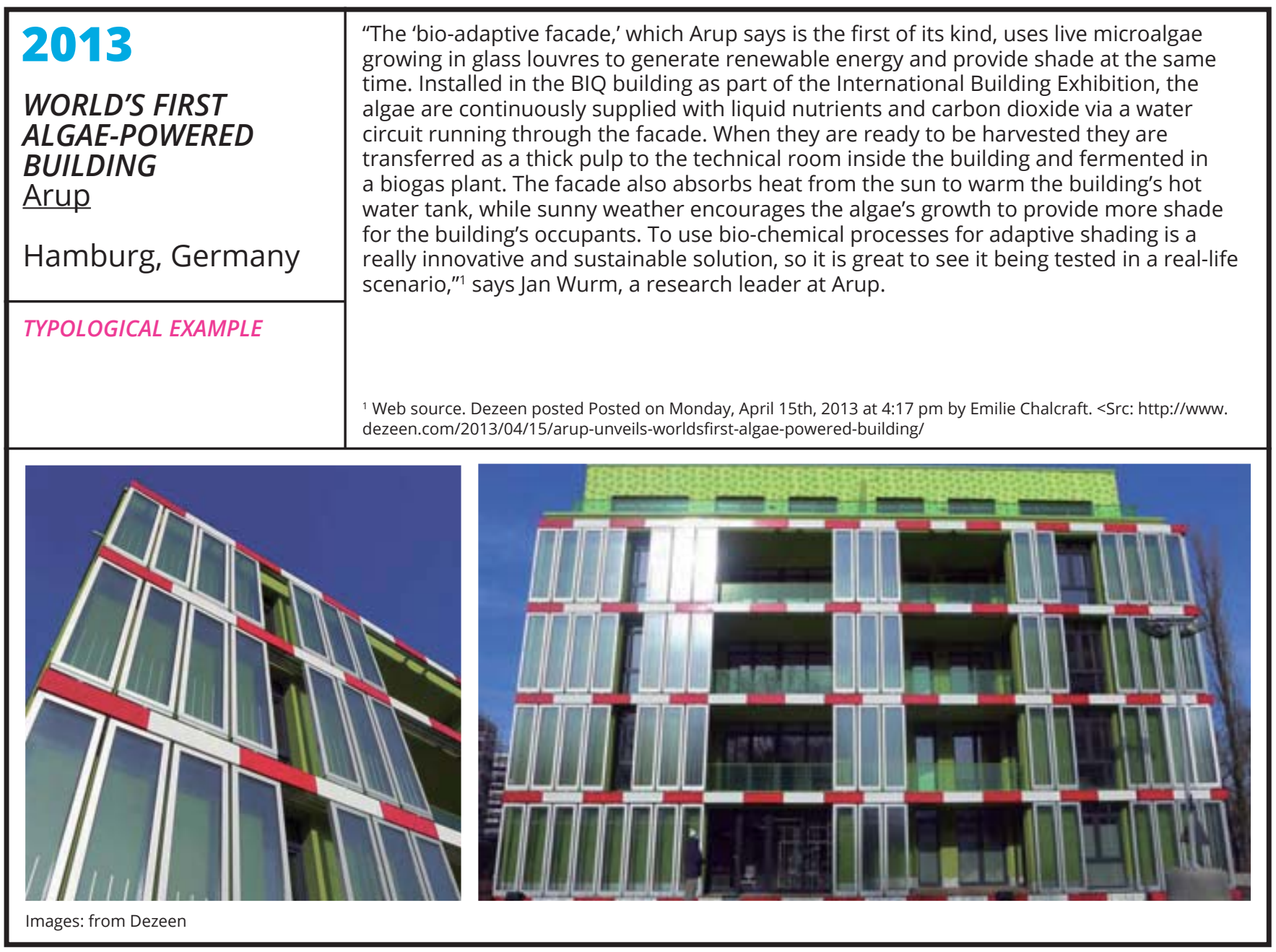




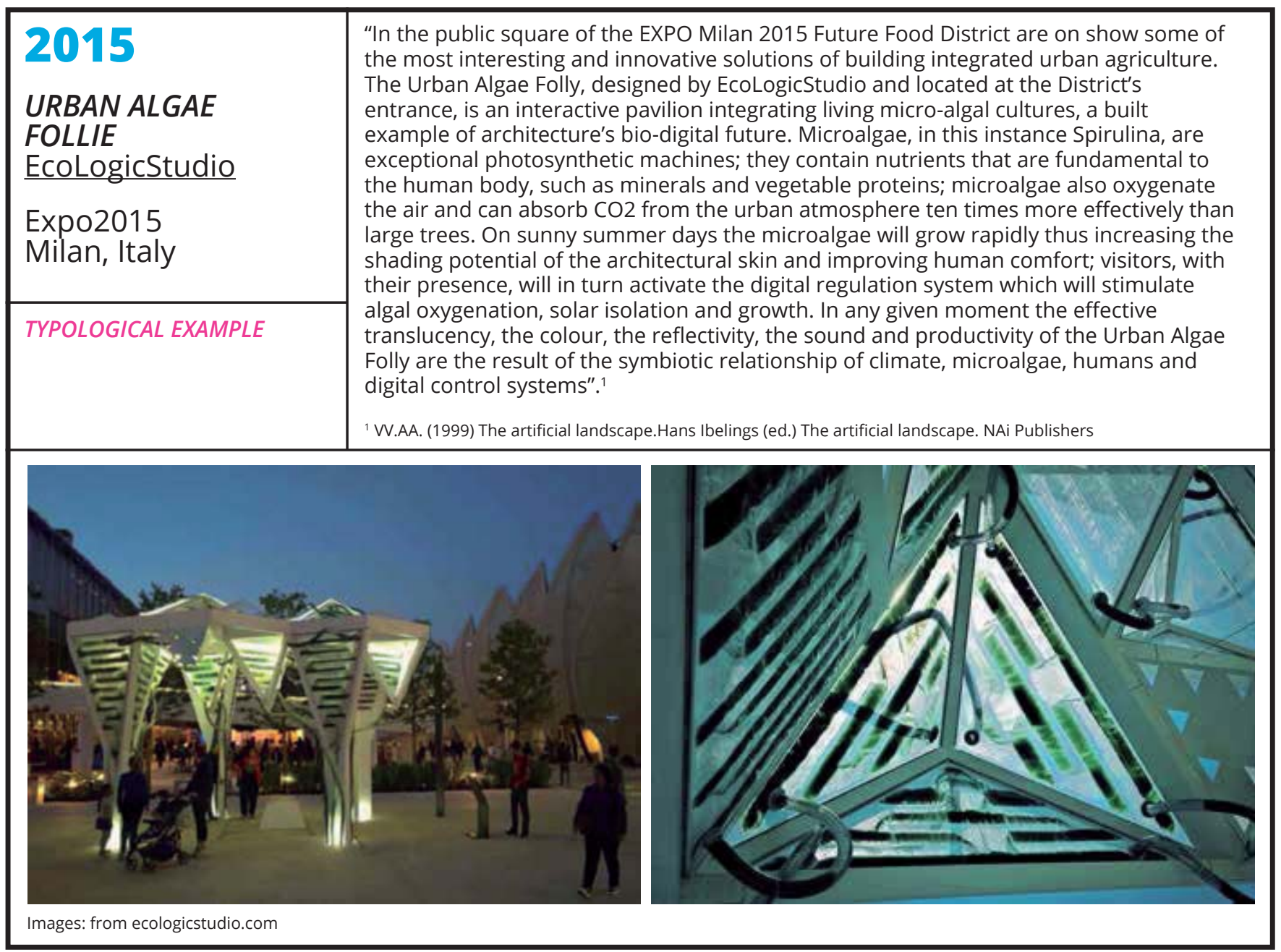

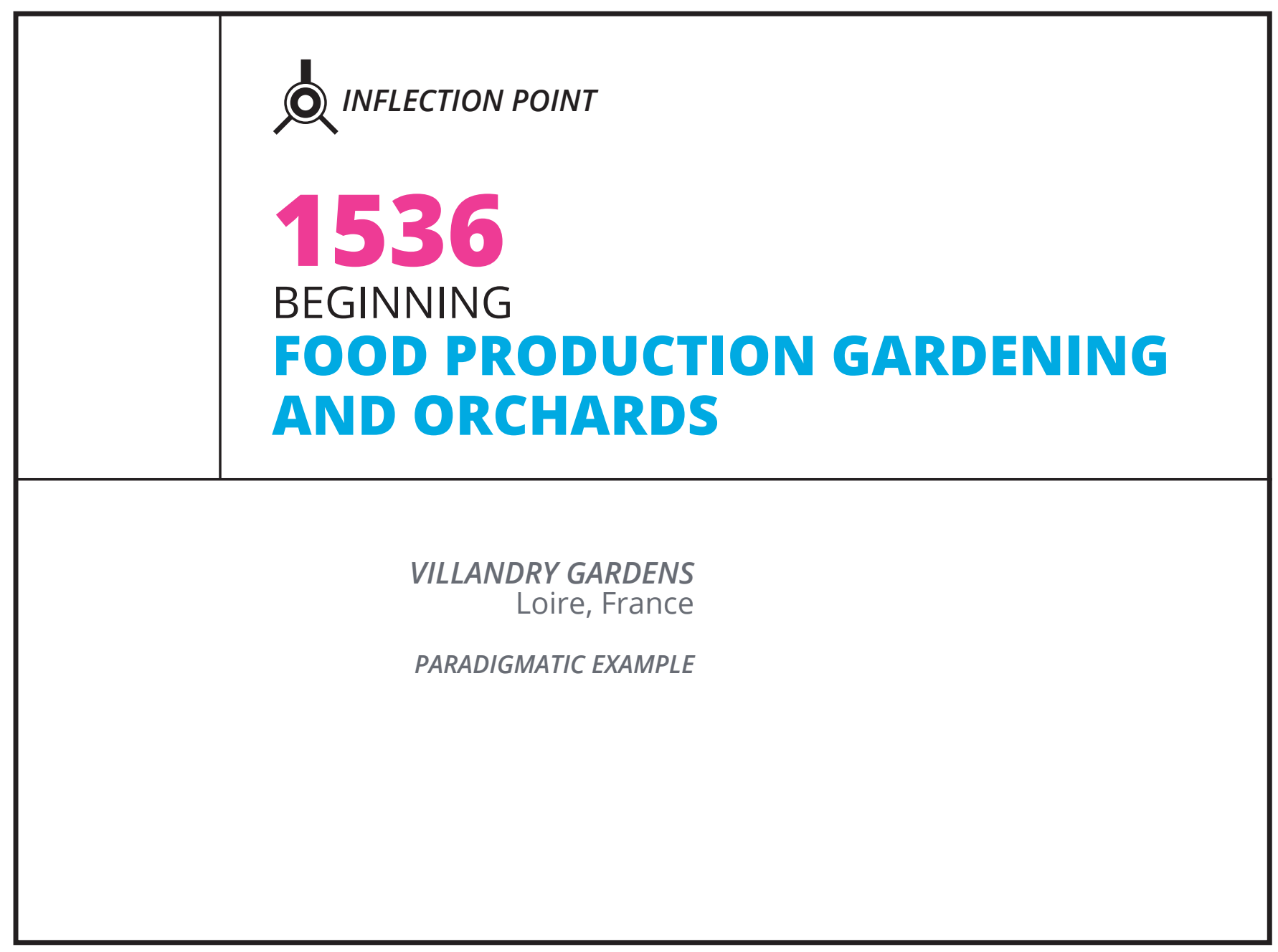




\begin{tabular}{|c|c|}
\hline $\begin{array}{l}1536 \\
\text { VILLANDRY } \\
\text { GARDENS } \\
\text { Loire, France }\end{array}$ & $\begin{array}{l}\text { "The Château de Villandry, one of the last large castles built along the Loire, is known } \\
\text { for its six gardens -a pleasure garden planted with tall box hedges, a 'classic'-style water } \\
\text { garden, etc- and its fabulous decorative vegetable garden which extends for nearly two } \\
\text { and a half acres. Villandry is best known, at least abroad, as France's archetypal potager, } \\
\text { a kitchen garden elevated to a regal plain and Frenchified to the maximum, with its } \\
\text { seemingly endless geometric parterres edged in immaculately clipped boxwood. This, at } \\
\text { least, is the impression I had of the garden before I visited. In fact, the potager forms only } \\
\text { part of what in fact is a painstaking and loving restoration of the gardens of a Renaissance } \\
\text { château, fraught with romantic symbolism and amenities -or agréments, as the French } \\
\text { would call them, features designed for pure pleasure"." }\end{array}$ \\
\hline PARADIGMATIC E & $\begin{array}{l}\text { 'Web source. Accessed } 29 \text { May 2015. <http://www.france.fr/en/art-and-culture/chateau-de-villandry.html><http:// } \\
\text { www.frenchgardening.com/visitez.html?pid=31106784011481 > }\end{array}$ \\
\hline 4. & 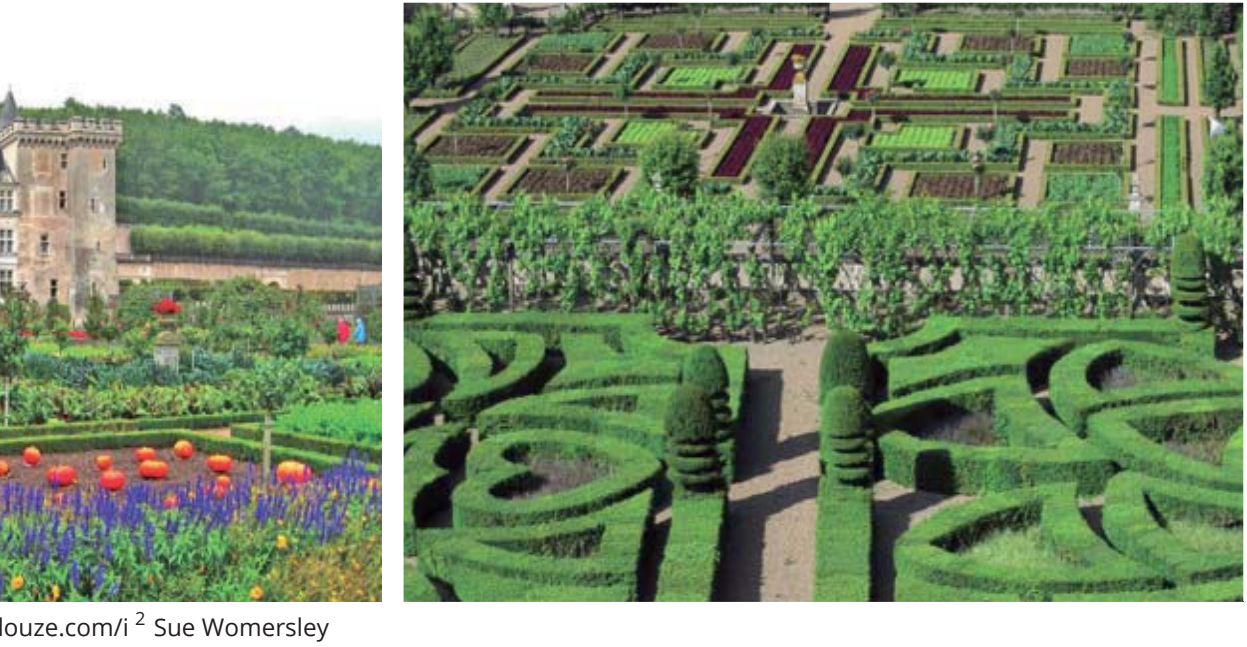 \\
\hline
\end{tabular}

2004

\section{SHENYANG \\ ARCHITECTURAL \\ UNIVERSITY}

Turenscape

Shenyang City, China

TYPOLOGICAL EXAMPLE
“This project demonstrates how agricultural landscape can become part of the urbanized environment and how cultural identity can be created through an ordinary productive landscape. The overwhelming urbanization of China is encroaching upon much arable land. With a population of 1.3 billion people and limited tillable land, food production and sustainable land use is a survival issue that landscape architects must address. In March of 2002, the Shenyang City in North China's Liaoning Province commissioned the designer to create a new, 80 hectares suburban campus for Shenyang Architectural University. Originally located downtown, the university was established in 1948 and played an important role in educating architects and civil engineers for the city of Shengyang and for the country as well. But due to a recent dramatic national surge in interest for architecture in China, the enrolment of the school ballooned, creating congestion and overcrowding in its downtown, urban location. After much deliberation, the school decided the best solution was to move the entire campus to the suburbs. The project submitted here is one portion of the campus at the southwest side of the campus, with an area of 3 hectares".
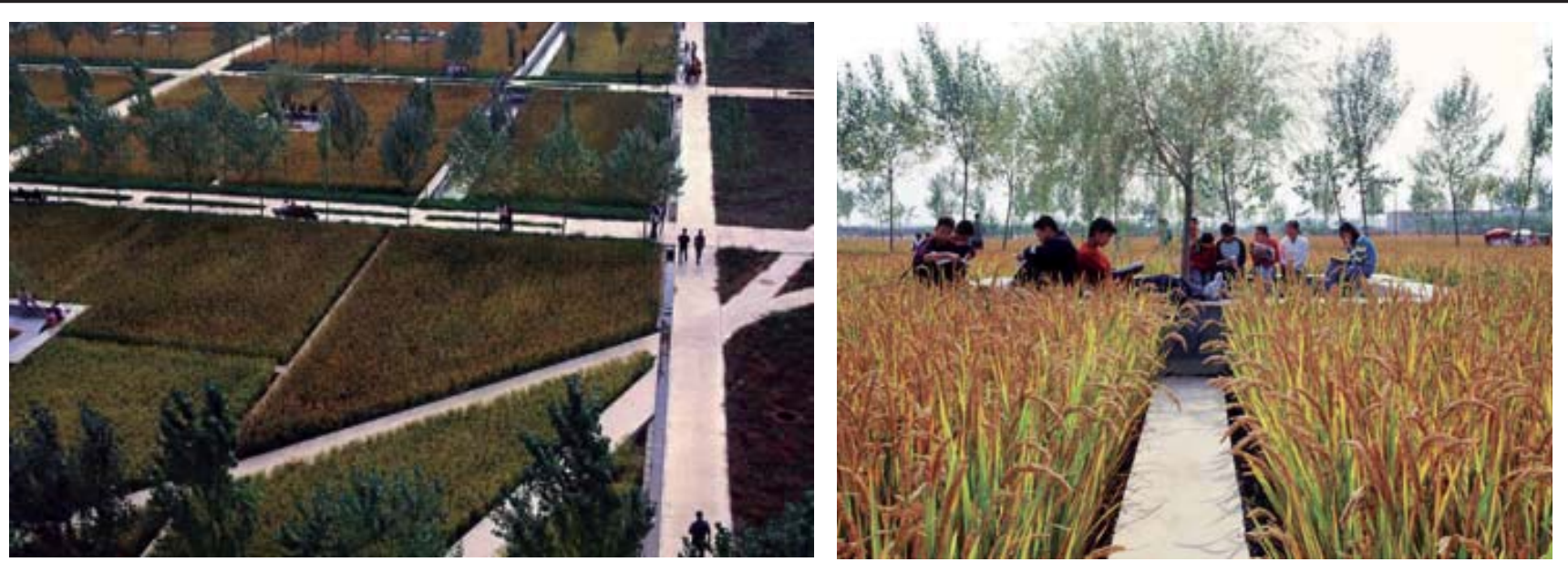

Images: (c) turenscape 


\begin{tabular}{|l|l|}
\hline 2004 & $\begin{array}{l}\text { "Astroculture is a suite of technologies used to produce and maintain a closed controlled } \\
\text { environment for plant growth. The two most recent missions supported growth of potato, } \\
\text { dwarf wheat, and mustard plants, and provided scientists with the first opportunity to }\end{array}$ \\
conduct true plant research in space. Light emitting diodes have particular usefulness \\
for plant growth lighting because they emit a much smaller amount of radiant heat than \\
do conventional lighting sources and because they have potential of directing a higher \\
percentage of the emitted light onto plants surfaces. Furthermore, the high output \\
LED's have emissions in the 600-700 nm waveband, which is of highest efficiency for \\
photosynthesis by plants"."
\end{tabular}

Images: NASA extracted from https://archive.org/details/MSFC-9804670

\begin{tabular}{|l|l|}
\hline 2010 & $\begin{array}{l}\text { "Eathouse by Architects de Stuurlui stedenbouw and Atelier GRAS!, is a house and garden } \\
\text { to eat, that you are able to touch, smell, taste, seed, weed, and harvest! EATHOUSE is a } \\
\text { house in a garden that attracts visitors with delicious vegetables, fruit, herbs and flowers. } \\
\text { They want to seduce people and make them taste the edible garden and the edible } \\
\text { house. EATHOUSE has a temporary character; it lasts a summer season. This is why all the } \\
\text { materials used in EATHOUSE can be re-used for a new season of EATHOUSE at a different } \\
\text { spot. EATHOUSE consists of a modular system of plain plastic crates, in combination with } \\
\text { a scaffold structure. These crates are used in the agricultural industry to harvest, transport } \\
\text { and exhibit fruit and vegetables in combination with a scaffold system. With this system } \\
\text { vertical green becomes accessible for everyone; you can make your own vegetable garden } \\
\text { on the wall of your balcony or on the roof of your garden shed!"1 }\end{array}$ \\
\hline $\begin{array}{l}\text { GokyO, Japan } \\
\text { ARTIALISATION IN SITU }\end{array}$ & $\begin{array}{l}\text { Web Source. Accessed 15 Jul 2015. posted in Design on 01 December 2011 by Begüm TARAKçI. } \\
<\text { http://www.architectureoflife.net/en/eathouse-by-atelier-gras-a-house-and-garden-to-eat/> }\end{array}$ \\
\hline Images: extracted from www.architectureoflifene &
\end{tabular}




\begin{tabular}{|l|l|}
2015 & $\begin{array}{l}\text { "When we quit our involvement in the further implementation and physical realization } \\
\text { of our masterplan for Expo Milan } 2015 \text { we would never have thought to come back to } \\
\text { that site with a real project. As much as we were convinced that our masterplan would } \\
\text { be a good platform for the radical re-invention of what a world exhibition could be in } \\
\text { the 21 } 1 \text { st century, we understood that the organizers would not undertake the necessary } \\
\text { steps to convince the participating nations to give up on their conventional indulging in } \\
\text { self-contemplation instead of focusing on their specific contribution to agriculture and } \\
\text { food production. We had indeed always seen that place, a triangular piece of land at the } \\
\text { very eastern end of the Expo's central boulevard, well-positioned to become one of the } \\
\text { main public forums within our masterplan concept. The pavilion should allow the visitors } \\
\text { to discover the significance of agricultural and food biodiversity, to explore the variety of } \\
\text { the products that are protagonists of biodiversity, and to become aware of the need of } \\
\text { adopting new consumption habits". }\end{array}$ \\
\hline DeMeurOn \\
Milan, Italy
\end{tabular}





\section{Escalas de la Agricultura y Territorio/}

\section{Rescaling Agriculture and Land}

\subsection{Introducción}

En los últimos años, los paisajes agrícolas han comenzado a reescalarse, acercándose y alejándose gradualmente a la jardinería productiva, ya tratada en el punto anterior; de hecho, en términos generales, ha dejado de existir una definición clara de escala en la agricultura. Las acciones humanas han transformado prácticamente la totalidad del planeta, de manera que nos encontramos inmersos en la propia productividad del paisaje. La visión general del territorio refleja una ausencia de límites definidos en cuanto a la escala del paisaje productivo, tendiendo hacia la globalidad. En cualquier caso, tras el camino recorrido a través de los muchos de los procesos de artealización del paisaje, existe una aceptación más o menos extendida del accidente, de los efectos de la naturaleza, de lo "natural" o del "medio físico" como bello; muy acorde o "próximo a las visiones propugnadas por la ecología" 86 .

Un ejemplo temprano de artealización in visu relacionado con el territorio agrícola, data del 2100 a.C. Se trata de la "Epopeya de Gilgamesh", a menudo considerado como el primer trabajo de literatura de la historia, en uno de cuyos pasajes el paisaje de viñedos es presentado con apariencia mágica. Esta característica será rescatada para crear todo un imaginario en torno a este tipo de territorio, que veremos más adelante proyectado en artealizaciones in situ recientes.

\subsection{Latifundios}

La gestión de este tipo de territorios productivos tiene su origen en los latifundios romanos -latifundium, latifundia-, que se encontraban especializados en el cultivo para la exportación, principalmente de ganado, grano, aceite o vino. "Tras la victoria de Augusto en el 27 a.C., se repartieron los territorios incautados entre los soldados romanos, así como los patricios urbanos se fueron haciendo, por medio nos siempre muy lícitos, con grandes extensiones de tierra, surgiendo así el término. Se aplicó a las grandes posesiones que eran trabajadas por esclavos y siervos al mando de los vilicus -mayorales encargados de su

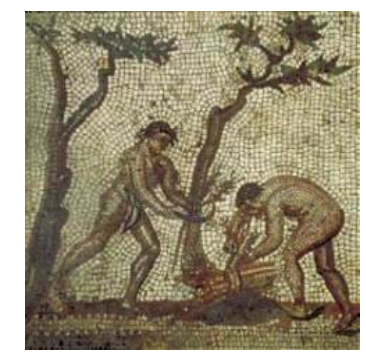

100 A.C. Latifundium..

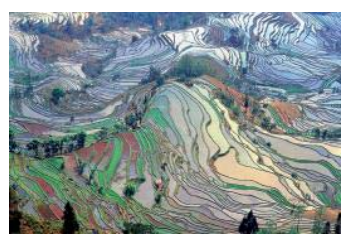

6000 B.C., Paddy Fields

${ }^{86}$ ÁBALOS, I. (2008) Atlas pintoresco. Vol. 2: Los Viajes. Gustavo Gili. Barcelona (pag 17). 


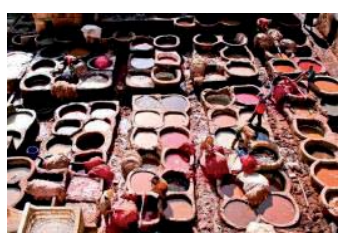

1200, Leather Tanning in Derb Chouwara

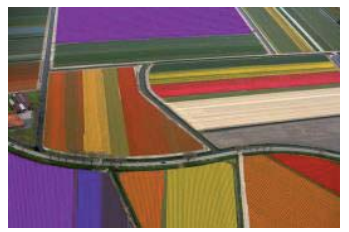

1637, Tulip Mania, Charles Mckay

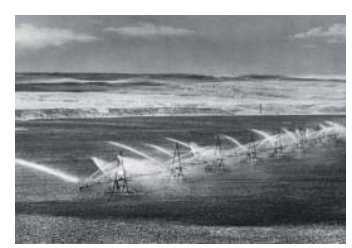

1940, Pivots Irrigation gestión.“ 87 Se considera como la aproximación más cercana a la agricultura industrial de hoy en día, y también su trazado, se convirtió en herencia en el territorio de las configuraciones posteriores. Los tamaños de las parcelas otorgadas a los terratenientes variaban desde los dos kilómetros cuadrados hasta terrenos que se escapaban a la vista, rondando los 1000 kilómetros cuadrados ${ }^{88}$; por lo que en ocasiones tenían que ser subdivididos en centurias. Así, tal y como Javier Maderuelo explica, "la colonización de los territorios conquistados, con sus divisiones territoriales en centurias, trabajados por siervos y esclavos, y la asignación de la propiedad en latifundios, con sus villas, como unidades de producción agrícola, constituyó la primera configuración consciente de unos "paisajes" de los que aún hoy, veinte siglos después, quedan vestigios reconocibles en Andalucía, donde se ha mantenido la explotación de grandes latifundios destinados a monocultivo, explotados por braceros y aparceros, y en los que la antigua villa romana se ha transformado en el actual cortijo.

La denominación de paisaje al territorio comienza con el momento que se populariza el género pictórico holandés landskip - landscape. Estas artealizaciones in visu, conformarán uno de los ejemplos más evidentes de posteriores artealizaciones in situ. Así las obras de Nicolas Poussin (1594-1665) o Claude Lorrain (1600-1682) se convirtieron en herramientas metodológicas para el diseño del paisaje. De hecho, éste último realizó la obra pictórica, Paisaje con Aeneas en Delos (1672), representando un tipo de paisaje que serviría de inspiración para Lord Burlington casi un siglo después, que lo materializaría en los jardines de Chiswick House (1724). Esta influencia es clara también en otros jardines ingleses del período, lo que daría lugar a una evolución en el paisaje, siendo uno de los factores que definiría la categoría estética de pintoresquismo ${ }^{89}$. Tal y como Iñaki Ábalos apunta, "lo pintoresco no restringe su campo de acción a la jardinería" ${ }^{90}$, sino que podría abarcar a todo lo que hasta entonces se había "expresado en un plano sentimental y lo traslada desde la naturaleza a todos los planos de la existencia humana (...). Lo pintoresco puede entenderse como una renovación de la mirada" ${ }^{91}$. Esta renovación de la mirada es la que producirá una transformación muy significante en la visión del territorio hasta el día de hoy.

${ }^{87}$ MADERUELO, J (2005): El Paisaje. Génesis de un concepto. Abada Editores. Madrid.

${ }^{88}$ GALE, T (2008): Latifundia. International Encyclopedia of the Social Sciences. Ver en: http://www.encyclopedia.com/topic/Latifundia.aspx (Consultado el 21 de Abril de 2016)

89 ÁBALOS, I. Op. Cit.

${ }^{90}$ ÁBALOS, I. Op. Cit

${ }^{91}$ ÁBALOS, 1 : Op Cit. 
De manera que cuando contemplamos un paisaje, puede tratarse de la artealización in situ intencionada de una in visu previa, -es decir, se encuentra diseñado buscando un ideal de belleza-; o bien, lecturas posteriores a su creación pueden haber encontrado un parecido con un ideal de belleza vigente en ese momento -artealización in visu-. Tenemos un ejemplo de esto en el momento en que corrientes como el expresionismo y expresionismo abstracto tuvieron su auge y sus artistas reflejaron sus particulares modos de representación. Tras su aparición, se establece un nuevo ideal estético en paisajes donde tenemos los colores y formas de la corriente; como la curtiduría al aire libre de Derb Chouwara en Fez (Marruecos) que ya había comenzado su funcionamiento cerca del año 1200 d.C.

Este espacio, que puede que fuera o no inspiración para la realización de obra de 1927 de Paul Klee, Flores en la Arena; lo que sí es muy probable es que esta última, fuera participante de la conformación del aparato estético que lo ha convertido en uno de los lugares más turísticos de Marruecos.

Lo mismo podríamos decir de la pintura Centro Blanco (1950), de Mark Rothko, y el paisaje de campos de tulipanes Holanda. La flor del tulipán es originariamente procedente de Turquía, pero en su cultivo en los Países Bajos, los bulbos se encontraban afectados por un parásito que producía que sus pétalos fueran multi-color. El éxito de estas nuevas flores provocó una oleada de especulación con ellas, causante de la quiebra de la economía holandesa en el año 1637. Aunque el tulipán en sí se considera una flor muy bella -en un pasado símbolo de riqueza y poder- el territorio inabarcable por la vista que estos campos generan, posee unas cualidades tonales que asemejan a ciertos cuadros del pintor, conformando impresionantes artealizaciones in situ.

Casi contemporáneos entre sí, vemos otro ejemplo de artealización in visu con su ejemplo paradigmático en el paisaje de los cultivos de regadío circulares con pivots, creados en 1940 en Kansas (USA). Tan sólo unos pocos años antes, el artista abstracto Robert Delaunay comenzó a pintar sus Discos Simultáneos, obra que, sorprendentemente, asemeja la misma apariencia vista en planta que un campo con cultivos con pivots. En la misma línea, también cabe destacar las relaciones entre el paisaje de salinas de San Francisco y las obras del artista español Pablo Palazuelo (ejemplo ilustrado en la portada de la Revista Derriere le Mirror No 184). Una vez más, el arte, aun el abstracto, consigue construir un aparato estético que nos hace percibir un territorio de lo pragmático como algo bello, sublime.

\subsection{Invernaderos}

El avance de la tecnología, que ha permitido obtener imágenes satélite de estos paisajes, ha provocado un cambio en nuestra percepción a través de estas nuevas formas 


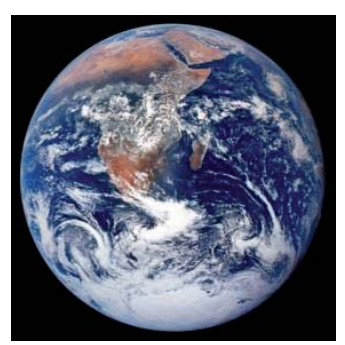

1972, "The Blue Marble. Apollo 17 de representación. Las primeras imágenes datarían de la carrera espacial, tras el lanzamiento del primer satélite en 1952 -Sputnik I-. Pero es “The Blue Marble" (la canica azul), tomada en 1972 por el Apollo 17, la que se convertiría en la fotografía más icónica de nuestro planeta, que conformando un ejemplo de artealización in visu del paisaje a una escala planetaria. La democratización de estas herramientas, como es el caso de Google Earth (2004) nos regala capturas de diversos paisajes sobre los que hasta entonces no habíamos podido considerar cargados de belleza.

Por ejemplo, las fotografías-satélite de los invernaderos del El Ejido, España (1970), muestran un dramático desarrollo de los cultivos bajo invernaderos o una suerte de Plasticultura. Curiosamente han llegado a ser consideradas como una artealización in visu, extendiendo la idea de que el mar continúa más allá de la costa a lo largo de 17000 hectáreas, como si la espuma de las olas al retirarse dejara un estampado blanco geométrico en el territorio -aunque ocasionalmente aún haya huecos-92.

La investigación de 2003 del arquitecto Juan Domingo Santos -Alojamientos Turísticos entre Invernaderos- en El Ejido, propone generar la rentabilidad máxima del territorio considerando lo existente, superponiendo la producción agrícola y la explotación turística, proponiendo así un paisaje más deseable y cambiante según la estación ${ }^{93}$. Este proyecto podría considerarse como una posible artealización in situ; combinando pragmática y poética en el mismo territorio.

\subsection{Canteras}

También ha sido muy frecuente a lo largo de la historia, la artealización posterior del propio paisaje por sus características inherentes de belleza e incomensurabilidad, tras haber sufrido agresivas intervenciones humanas. Este ha sido el caso de las canteras o las minas, que tras el agotamiento de su productividad inicial (que permite el acercamiento ocioso), generan impresionantes paisajes objeto de aprovechamiento para otro tipo de actividad, como cultural o turística. La deformidad que la acción humana produce en el territorio, lejos de ser tachada de fea, lleva a un proceso de negociación con lo bello; mediante un sentimiento de lo sublime referido a la inconmensurabilidad antes descrita, de lo pintoresco ${ }^{94}$ y de las artealización in visu que los reflejan. Él éxito total llegaría de la

\footnotetext{
92 (Traducida) LLUCH, V.A. (2000): Le Monde diplomatique. Ver en: https://mondediplo.com/2000/03/11spain (Consultada el 15 de Julio de 2015)
}

${ }^{93}$ DOMINGO SANTOS, J (2004): Alojamientos Turísticos entre Invernaderos. REVISTA EI CROQUIS, 119, Tomo I. Madrid.

${ }^{94}$ ÁBALOS, I. (2008) Atlas pintoresco. Vol. 2: Los Viajes. Gustavo Gili. Barcelona (pag 29). 
mano de Jean-Charles Adolphe Alphand que crearía entre 1865 y 1867 el parque público de Buttes-Chaumont a partir de la reutilización de los elementos de unas canteras -territorio, galerías, túneles, raíles...-95. Otros ejemplos, son las canteras de mármol de Carrara en Italia, usadas desde la Antigua Roma; o la Oreja de Dionisios, una cueva excavada a partir de una cantera de caliza en desuso -que también hizo las veces prisión- en Siracusa (1586).

A finales del siglo XIX son retratadas por artistas en sus viajes alrededor del mundo Grand Tour- como el pintor ruso Nikolai Ge -Loading Carrara Marble (1868) o Transportation of Marble at Carrara (1892)- y el pintor estadounidense John Singer Sargent en una serie de obras de la misma temática como "Carrara in a Quarry" (1911).

Otros ejemplos más recientes son la protección del Parque de las Minas de Rio Tinto en Huelva, España en 1992. Un paisaje que asemeja al lunar, debido a una serie de operaciones de extracción, con un cráter gigante rodeado por una serie de terrazas que parecen un inmenso anfiteatro. Además, posee pequeños flujos de agua roja, color que dio nombre al río, tinto. El crecimiento de las minas consumió no solo montañas y valles sino también pueblos enteros, que tuvieron que reconstruirse en las inmediaciones.

Precisamente ese es el tema de la artealización in visu que acompaña a este paraje, una novela y después película -The Heart Of The Earth de (2001)- que tiene aquí lugar. También en 1996 es protegida otra mina en desuso: Las Médulas, en el Bierzo, España. Las Médulas fue la mina de oro más importante del Imperio Romano, y siglos después, una vez que cesó su actividad, se reconvirtió en paisaje cultural y de investigación, en el cual todas las implicaciones de la minería romana se hacían visibles. Esto le valió su inclusión como paisaje catalogado por la UNESCO.

Un ejemplo con más intención de artealización contemporánea es el parque de Piedra Tosca. Su origen tiene lugar en el Bosque de Tosca, un lugar que se convirtió en una de tierra de nadie y de todos, donde cualquiera podía cultivar y hacerse propietario de los bloques de lava resultado de la geología del lugar. Estos bloques, localmente llamados Tussols, servían para construir vallas y refugios para los asentamientos y establecer límites en la agricultura. A principios del siglo XX, la imposibilidad de introducir la mecanización en el territorio hizo que fuera abandonándose para ser considerado un Parque Nacional. A partir de 1987, se contempla la reconsideración del futuro del Parque Nacional de Piedra Tosca, lo que deriva en la realización de un proyecto de gestión a través de pequeñas intervenciones a cargo de RCR Arquitectes en el año 2004.

Ese mismo año, se muestra al público la obra fotográfica y film de Edward Burtynsky Manufactured Landscapes, compuesta por imágenes aéreas de paisajes productivos o que

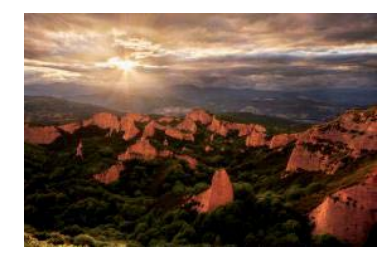

1996, Las Médulas de El Bierzo.

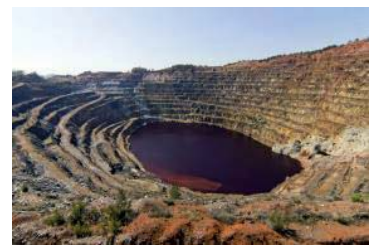

1992, Parque de las Minas del Rio Tinto en Huelva.

${ }^{95}$ IBID. 


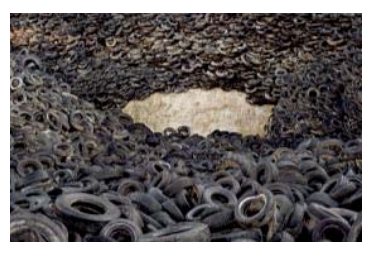

1997, Waste Landscape, Matthias Loebermann.

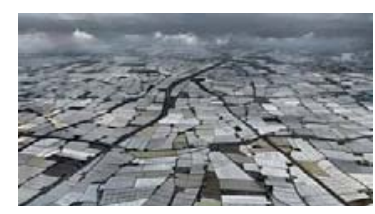

2006, El Ejido

"Manufacturated

Landscapes"

Edwuard Burtynsky.

en un pasado lo fueron -especialmente de Digestiones Pesadas, Escalas del territorio o la Gestión del Residuo-.

Esta artealización in visu es descrita por Jonathan Bordo en su ensayo sobre la obra, en el límite entre una belleza que alimenta la ansiedad ecológica y la premonición del desastre ${ }^{96}$.Bordo apunta que las fotografías han sido tomadas en su versión más literal, destacando su poética, y disminuyendo su significado político y cultural; es decir, los motivos representados prestan gran atención a zonas ecológicamente muertas, pero que siguen siendo paisajes, en su definición de la acumulación de las intervenciones humanas que en definitiva generan un lugar. La noción de paisaje se encuentra íntimamente ligada con lo local, aunque su escala es de alguna manera global y ubicua. Uno de los motivos por lo que las fotografías de Burtynsky son asociadas directamente con paisajes, es porque se nos aparecen como algo local, en el sentido de que parece un paisaje especial, no cualquier sitio ${ }^{97}$.

\subsection{Viñedos}

Al inicio de este Timeline encontramos una artealizacion in visu del paisaje de viñedos "Epopeya de Gilgamesh"- que en los siglos XX y XXI tomará singular importancia.

Progresivamente el vino y los viñedos se han popularizado y el imaginario que les

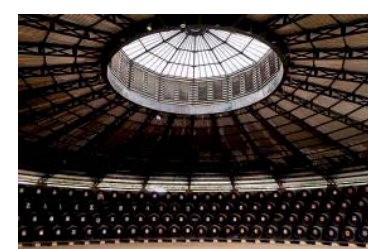

1869, Real Bodega de la Concha, Jerez. Gustave Eiffel.

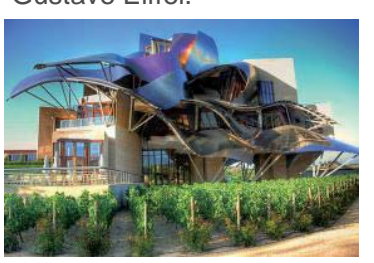

2007, Bodegas Marqués de Riscal,

Frank Gehry. dea se ha convertido en un símbolo de status. Comenzando con la Real Bodega de la Concha (1869) diseñada por el francés Gustave Eiffel, hasta llegar a las Bodegas Marqués de Riscal (2007) por Frank Gehry; arquitectos de renombre han estado desarrollando sus obras en lo que sería una ciudad del vino en territorio español. Con los años, el atractivo de los viñedos ha convertido especialmente la zona noroeste de España en un punto caliente para el turismo; influenciado también por otras artealizaciones in visu más contemporáneas como el film del director Alexander Payne, Sideways - Entre Copas (2004)-, galardonado con un Oscar.

El acercamiento gradual de la producción agrícola a la jardinería productiva en los últimos años le lleva a adquirir características comunes, especialmente en el campo de la producción de alimentos y en la consideración de la pequeña escala. Tanto es así que los cultivos y huertos -a caballo entre ambas líneas- se han vuelto muy populares gracias a la

${ }^{96}$ BORDO, J (2006): “An essay on Manufactured Landscapes. Yale University Press. 2004". Trent University (Consultado el 25 de Abril de 2016) Ver en https://journals.lib.unb.ca/index.php/mcr/article/view/18051/19355\#no21

97 IBID 
posibilidad de implantación en un espacio reducido urbano, además de una fuente de cultura y compromiso entre los usuarios. Sin embargo, tal y como se había apuntado con anterioridad, ha dejado de existir esa definición clara de escala y límites en la agricultura, encontrándonos completamente inmersos en la productividad del territorio. 


\section{RESCALING AGRICULTURE}

AND MINING

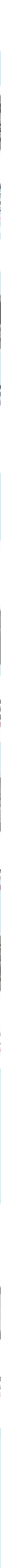




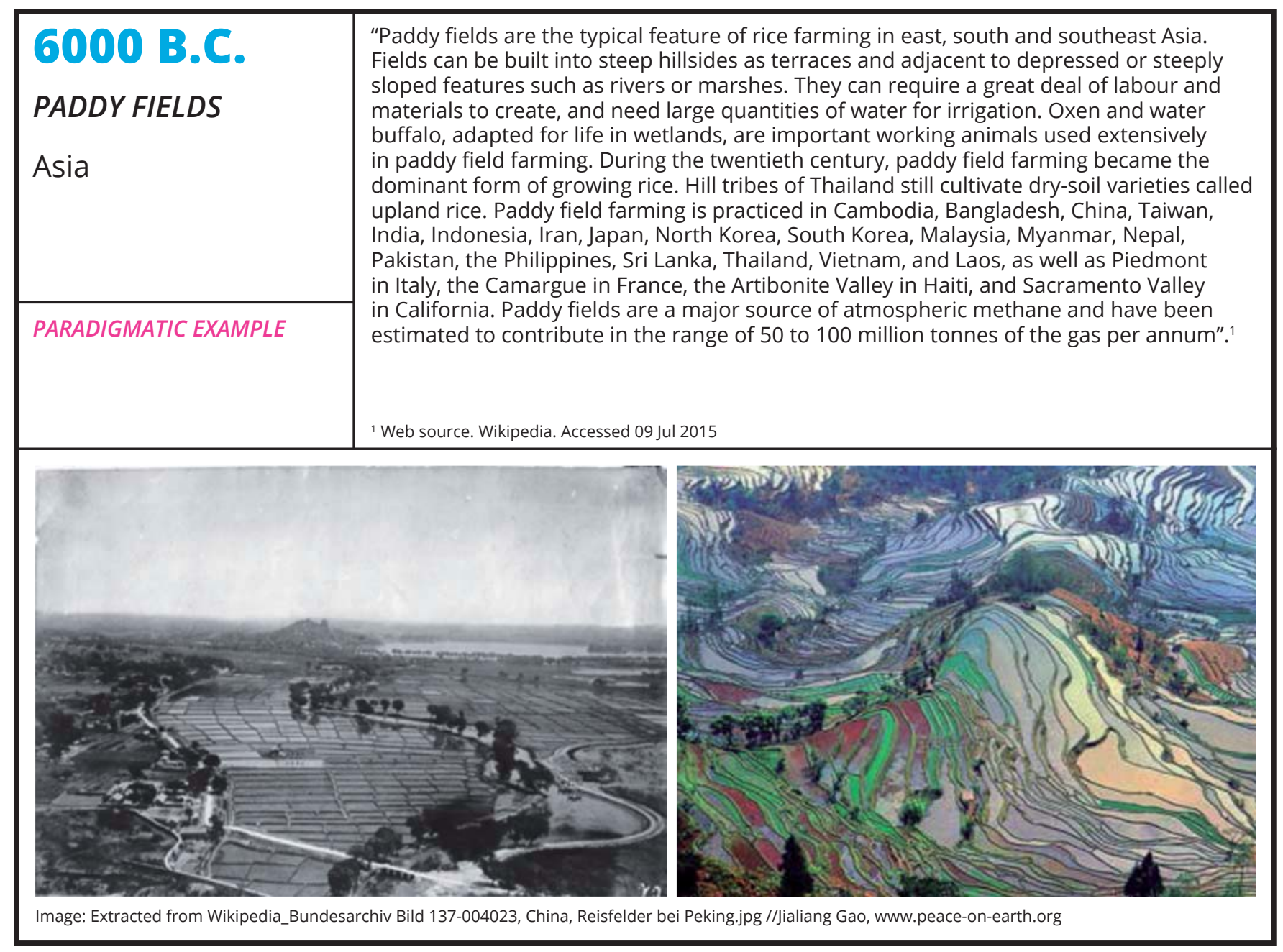

\begin{tabular}{|l|l|}
\hline 100 A.C. & $\begin{array}{l}\text { "A latifundium is a very extensive parcel of privately owned land. The latifundia } \\
\text { (Latin: latus, 'spacious' + fundus, farm, estate') of Roman history were great landed } \\
\text { estates, specializing in agriculture destined for export: grain, olive oil, or wine. They } \\
\text { were characteristic of Magna Graecia and Sicily, of Egypt and the North African } \\
\text { Maghreb and of Hispania Baetica in southern Spain. The latifundia were the closest } \\
\text { approximation to industrialized agriculture in Antiquity, and their economics } \\
\text { depended upon slave labour".' }\end{array}$ \\
$\begin{array}{l}\text { LANDED STATES } \\
\text { Roman Empire }\end{array}$ & \\
\hline &
\end{tabular}




$\begin{array}{ll}\text { LEATHER TANNING IN } & \begin{array}{l}\text { "Northeast of the Kairouine Mosque and Seffarine Square is Fez's most visited -and aromatic- } \\ \text { sight. A picture straight out of medieval times, the Chouwara Tannery is the largest and busiest } \\ \text { of the four traditional tanneries still operating in the medina. Sheep, goat, and cow skins are } \\ \text { cured stretched, scraped, and dyed in numerous honeycombed earthen pits in a process that } \\ \text { is still as manual as when it began in the 13th century upon the decline of Cordoba. The skins } \\ \text { are cured by a concoction that includes cow urine and pigeon guano and are then laid atop the } \\ \text { rooftops to dry. The final dying process involves the leather being mixed and soaked by hand } \\ \text { in the vats before being trimmed for the medina's leatherworkers. The vegetable dyes- poppy } \\ \text { (red), turmeric (yellow), mint (green), indigo (blue) -have been replaced by chemicals that, } \\ \text { along with the odd rinsing machine, are the only modern concessions to have infiltrated the } \\ \text { process. It's both a confronting and fascinating view at the same time, and strongly challenges } \\ \text { your sense of voyeuristic tourism. Perhaps the knowledge that the tanneries are still one of } \\ \text { the most important sources of income and trade for the city may temper any misgivings. The } \\ \text { Chouwara tanneries are best viewed in the morning, from the roof-terrace leatherware shops } \\ \text { along Derb Chouwara, where a well-placed sprig of mint will help those who find the smell } \\ \text { perhaps more confronting than the sight". }\end{array} \\ \text { Fez, } \\ \text { MorOcco }\end{array}$

\begin{tabular}{|l|l|}
\hline 2002 & $\begin{array}{l}\text { “These subterranean farms look like a conceptual factor from a sci-fi movie (remember } \\
\text { that oxygen garden from Danny Boyle's 2007 thiller Sunshine?), but they're actually being } \\
\text { cultivated right now in a former bank vault in Tokyo. Pasona O2 covers about a square } \\
\text { kilometer, growing vegetables and fruits like tomatoes, lettuce, and strawberries, as well } \\
\text { as flowers and herbs - even a rice paddy! Snazzy state-of-the-art technology controls } \\
\text { temperature and artificial sunlight levels. Deep below Tokyo's financial district, the } \\
\text { Pasona Group, an international employment agency, has flipped the switch on a stunning } \\
\text { experiment in urban agriculture. The company converted a bank vault in the sub-basement } \\
\text { of its headquarters into a series of super-sized greenhouses, all bathed in the glow of } \\
\text { computer-controlled grow lamps. Pasona O2, as the project is known, was launched } \\
\text { to pique interest in new methods of farming-and to generate future employment } \\
\text { opportunities in an island nation largely dependent on others for its food. For now the } \\
\text { subterranean gardens are still more a show-piece than a serious producer, since they yield } \\
\text { only 132 pounds of rice a year".' }\end{array}$ \\
TokyO, \\
Japan
\end{tabular}




\begin{tabular}{|l|l|}
\hline 1637 & $\begin{array}{l}\text { "Tulip mania or tulipomania was a period in the Dutch Golden Age during which contract } \\
\text { prices for bulbs of the recently introduced tulip reached extraordinarily high levels and } \\
\text { then suddenly collapsed. At the peak of tulip mania, in March 1637, some single tulip } \\
\text { bulbs sold for more than } 10 \text { times the annual income of a skilled craftsman. It is generally } \\
\text { considered the first recorded speculative bubble (or economic bubble), although some } \\
\text { researchers have noted that the Kipper- und Wipperzeit episode in 1619-22, a Europe- } \\
\text { wide chain of debasement of the metal content of coins to fund warfare, featured mania- } \\
\text { like similarities to a bubble. The term 'tulip mania' is now often used metaphorically to } \\
\text { refer to any large economic bubble (when asset prices deviate from intrinsic values). The } \\
1637 \text { event was popularized in } 1841 \text { by the book Extraordinary Popular Delusions and the } \\
\text { Madness of Crowds, written by British journalist Charles Mackay. According to Mackay, at } \\
\text { one point } 12 \text { acres (5 ha) of land were offered for a Semper augustus bulb. Mackay claims } \\
\text { that many such investors were ruined by the fall in prices, and Dutch commerce suffered } \\
\text { a severe shock".1 }\end{array}$ \\
\hline $\begin{array}{l}\text { Web source. Accessed 17 June 2015. Wikipedia; Mckay, Charles, Memoirs of Extraordinary Popular Delusions and } \\
\text { the Madness of Crowds, Second Edition, 1852.; https:/len.wikipedia.org'wiki/Tulip_mania }\end{array}$ \\
\hline Image: from: http://www.traveler.es/viajes/rankings/galerias/30-escapadas-naturales-para-semana-santa/444/image/21137 // Mark Rothko - White Center
\end{tabular}

\begin{tabular}{|c|c|}
\hline $\begin{array}{l}1940 \\
\text { CARRARA MARBLE } \\
\text { QUARRY } \\
\text { Kansas, } \\
\text { USA }\end{array}$ & $\begin{array}{l}\text { Centre pivot irrigation was invented by the farmer Frank Zybach. It was recognized as a } \\
\text { method to improve water distribution to fields. } \\
\text { "Centre pivot irrigation is a form of overhead sprinkler irrigation consisting of several } \\
\text { segments of pipe (usually galvanized steel or aluminium) joined together and supported } \\
\text { by trusses, mounted on wheeled towers with sprinklers positioned along its length. The } \\
\text { machine moves in a circular pattern and is fed with water from the pivot point at the } \\
\text { centre of the circle".1 }\end{array}$ \\
\hline PARADIGMATIC EXAMPLE & $\begin{array}{l}\text { 'Web source. Accessed } 17 \text { June 2015. Wikipedia. Morgan, Robert (1993). Water and the Land. Cathedral City, } \\
\text { CA: Adams Publishing Corp. pp. } 35-36 \text {. ISBN } 0935000026 \text { Alfred, Randy Uuly 22, 2008). "July 22, 1952: } \\
\text { Genuine Crop-Circle Maker Patented". Wired Magazine. Retrieved June 6, 2012 }\end{array}$ \\
\hline 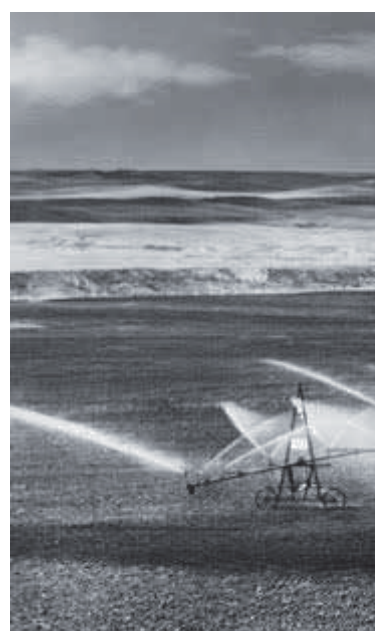 & innes 1 \\
\hline
\end{tabular}




\begin{tabular}{|l|l|}
\hline 1996 & $\begin{array}{l}\text { "Salt evaporation ponds are shallow man-made ponds designed to produce salt from } \\
\text { sea water. The seawater is fed into large ponds and water is drawn out through natural } \\
\text { evaporation which allows the salt to be subsequently harvested. The ponds also provide } \\
\text { a productive resting and feeding ground for more than } 70 \text { species of water birds, } \\
\text { including several endangered species. The ponds are commonly separated by levers. Due } \\
\text { to variable algal concentrations, vivid colours, from pale green to bright red, are created } \\
\text { in the evaporation ponds. The colour indicates the salinity of the ponds. Micro-organisms } \\
\text { change their hues as the salinity of the pond increases"." }\end{array}$ \\
$\begin{array}{l}\text { SALT EVAPORATION } \\
\text { PONDS }\end{array}$ & $\begin{array}{l}\text { San FrancisCO Bay, } \\
\text { USA }\end{array}$ \\
\hline ARTIALIZATION IN VISU & Web Source. Wikipedia. Accessed 14Jul 2015
\end{tabular}

\begin{tabular}{|c|c|}
\hline $\begin{array}{l}1970 \\
\text { EI EJIDO } \\
\text { GREENHOUSES. } \\
\text { PLASTICULTURE } \\
\text { Almeria, } \\
\text { Spain } \\
\text { TYPOLOGICAL EXAMPLE }\end{array}$ & $\begin{array}{l}\text { Satellite images show the dramatic development of crops under greenhouses or under } \\
\text { plastic in the desert of Almeria. "A sea that continues the horizon of the real sea and surfs } \\
\text { up towards the mountain to settle finally, in blue and white foam, against its flanks. Once } \\
\text { in a while, a lone Barbary fig-tree stands out. Very occasionally there are gaps, squared- } \\
\text { up but still empty and covered with scrubby bushes draped with thousands of scraps } \\
\text { of torn plastic. These are the greenhouses of El Ejido - } 17,000 \text { hectares of land covered } \\
\text { over with sheets of blue and white plastic. Above the walls of billowing plastic, there is a } \\
\text { sky with no horizon. And silence. Far away, as far as you can get from the made-up road, } \\
\text { washing hangs on lines. It is where the immigrant workers live, scattered, spread out } \\
\text { from each other, relegated to the middle of the labyrinth of greenhouses or banished to } \\
\text { the lower slopes of the mountain. They are pariahs, meant not to be seen or heard, and } \\
\text { certainly not to have any rights. They live inside the walls of an old building whose roof } \\
\text { has fallen in and been covered over with a sheet of plastic. Or in the shells of a couple } \\
\text { of old VW campers propped up side-by-side on their axles. Or in sheds, alongside the } \\
\text { pesticides and sacks of fertiliser".. } \\
\text { w web Source. Accessed } 15 \text { Jul } 2015 \text { <http://mondediplo.com/2000/03/11spain> }\end{array}$ \\
\hline ges: @ NASA/Visible Earth & 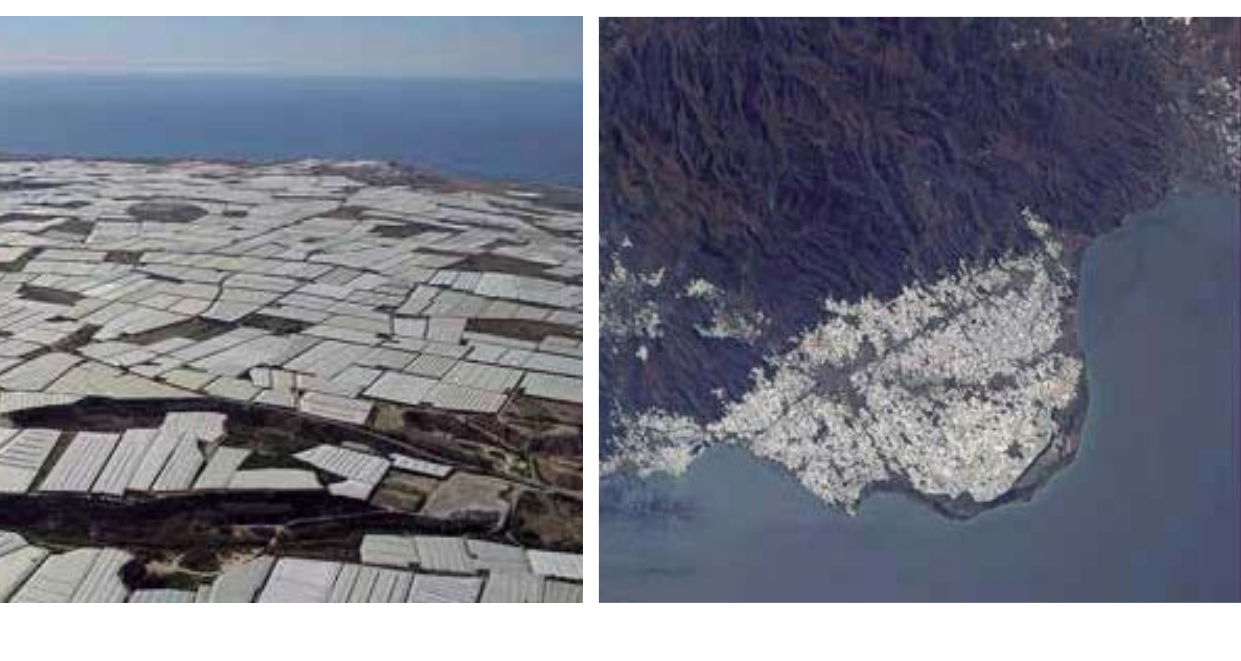 \\
\hline
\end{tabular}




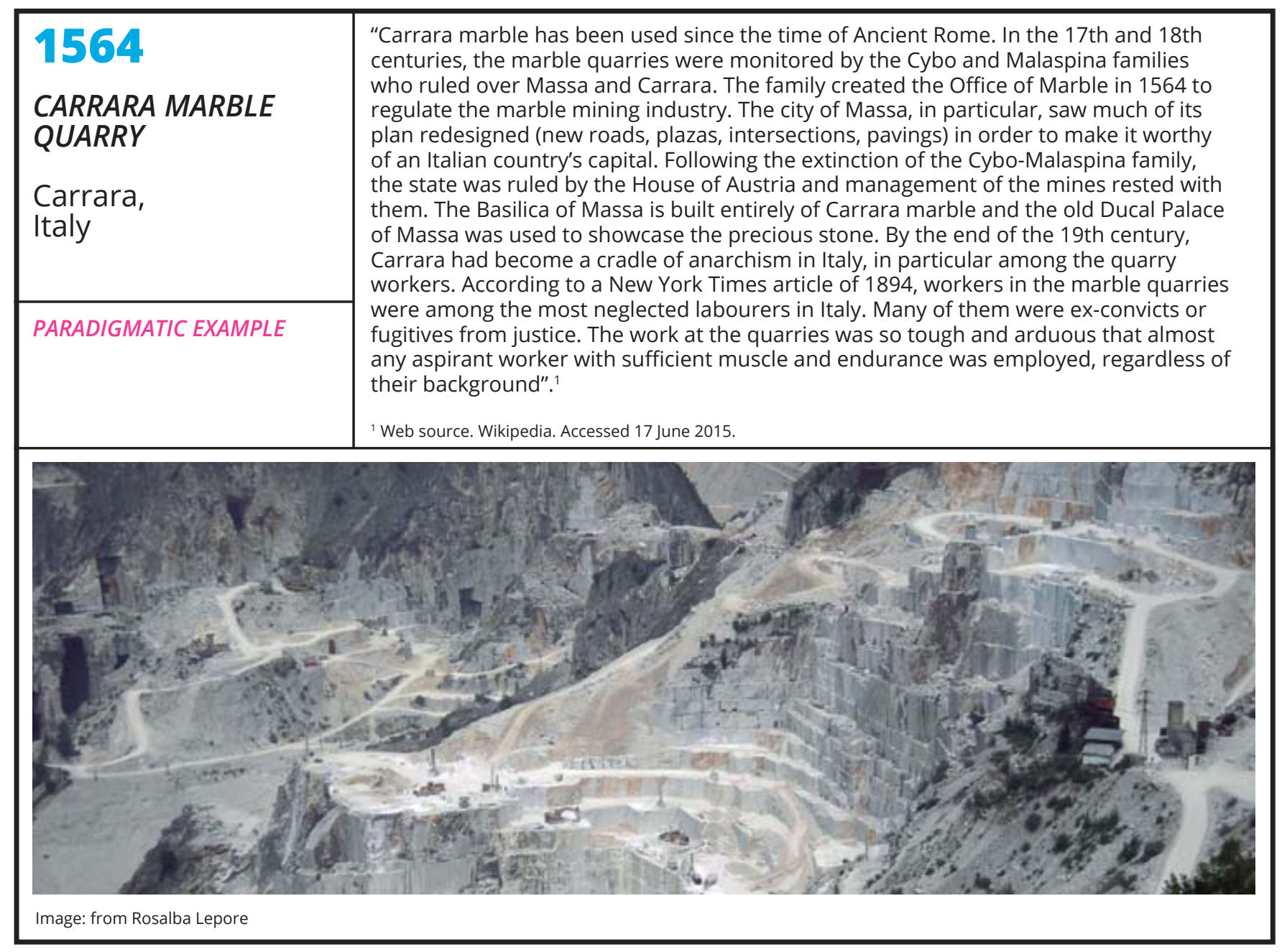

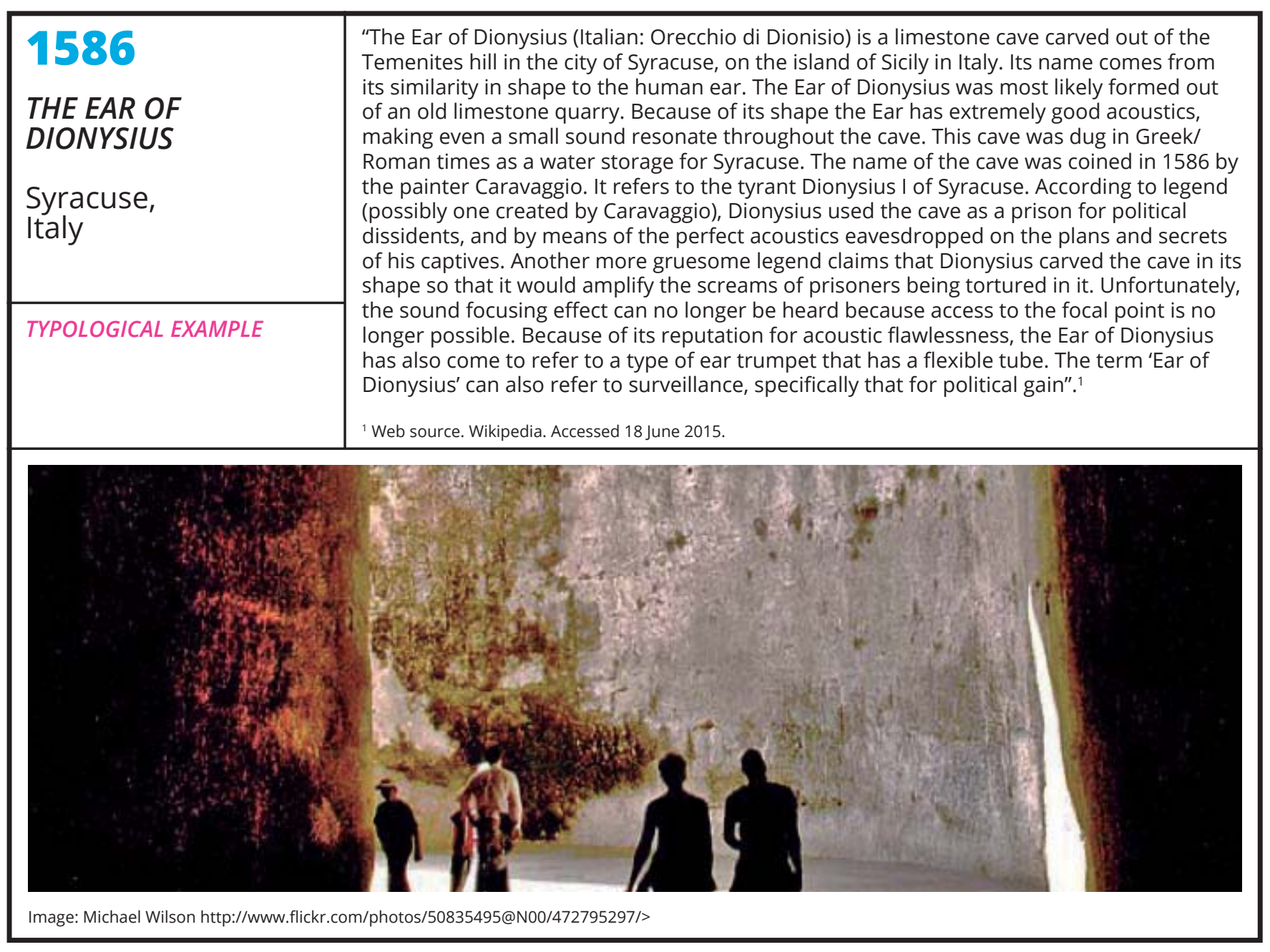




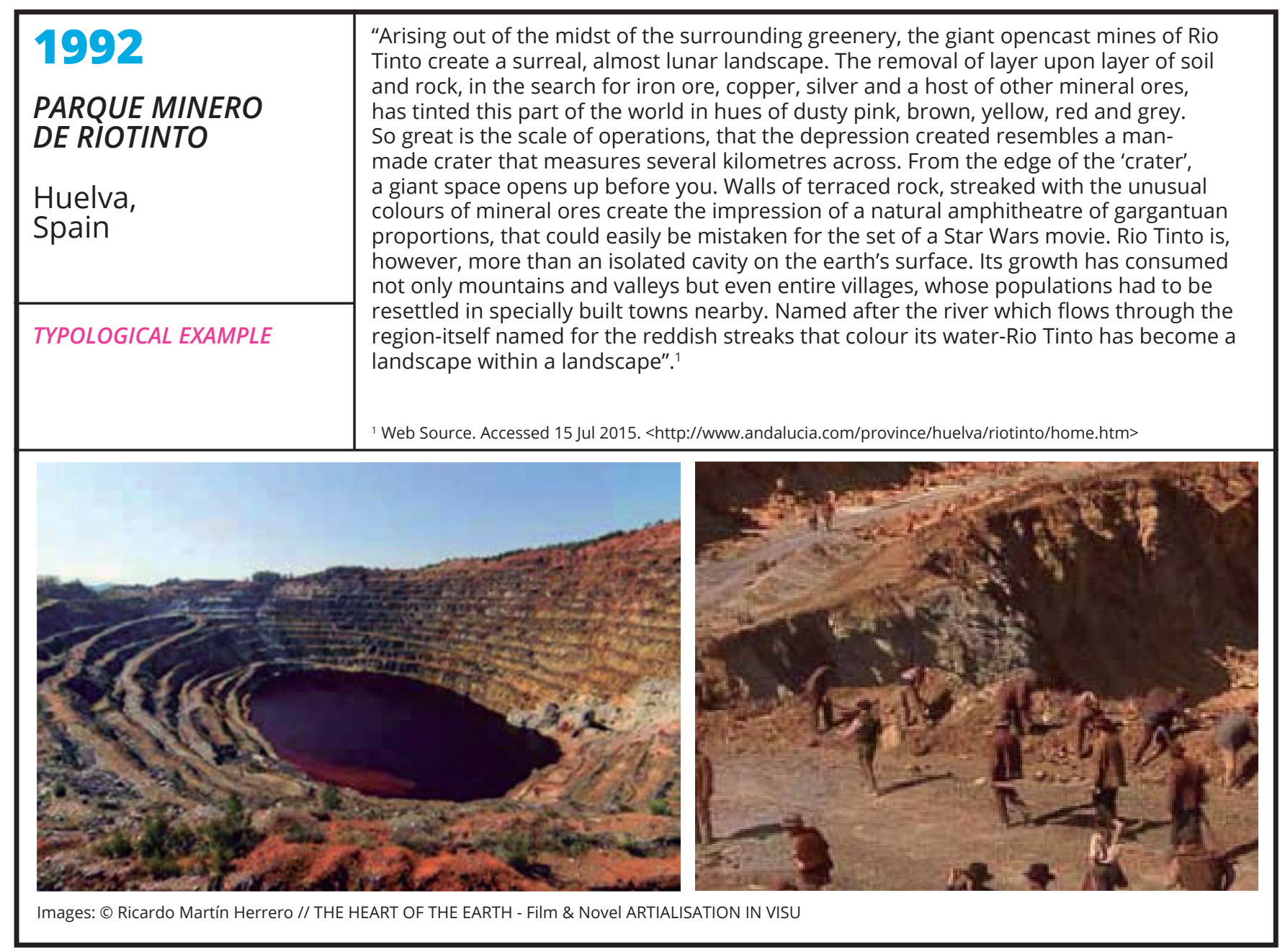

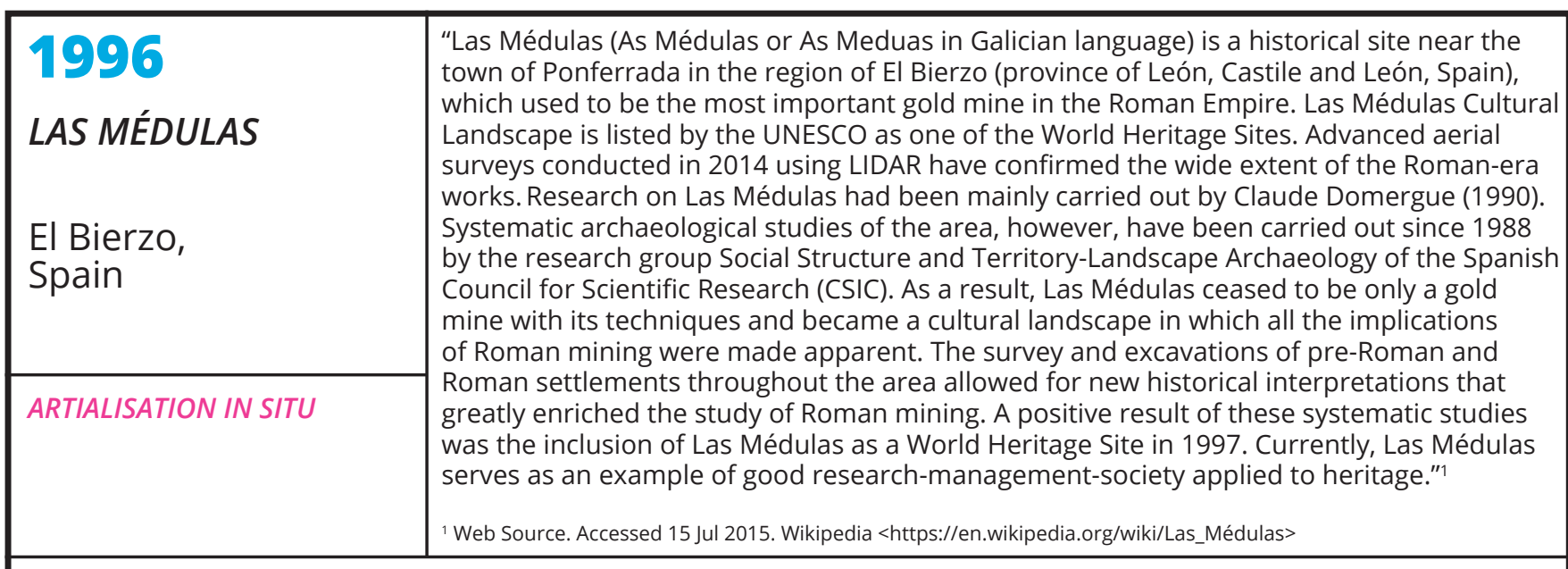

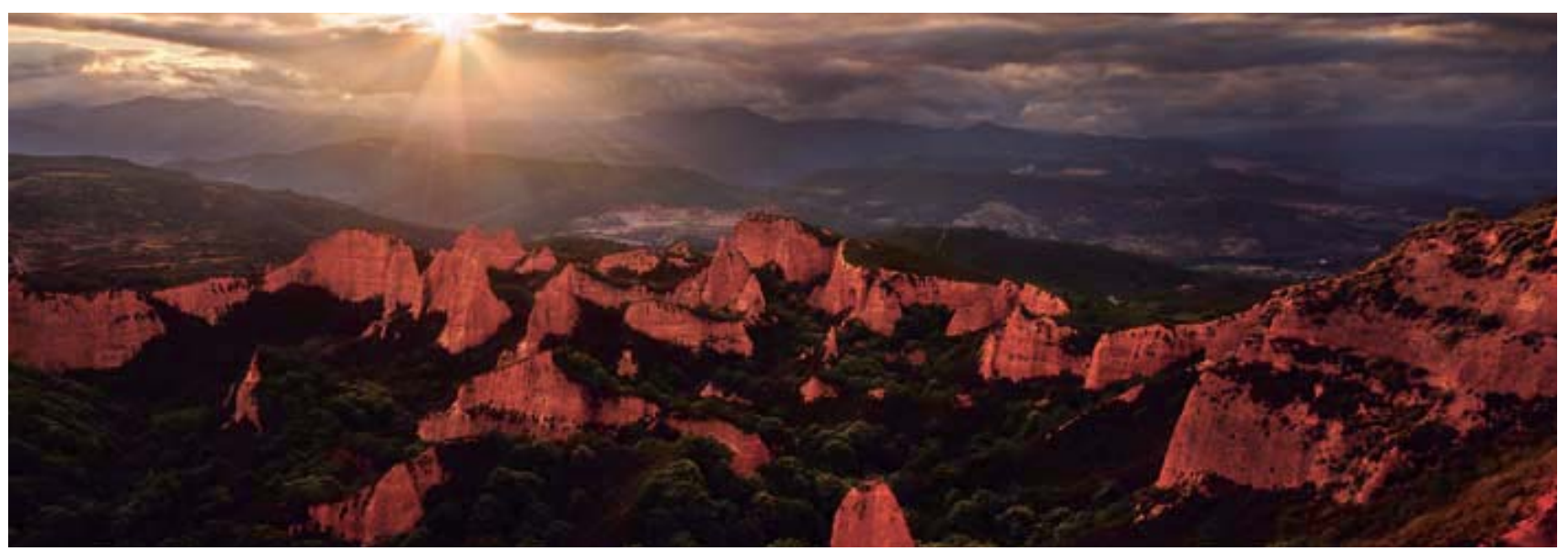

Images: @ Rubén Arroba 


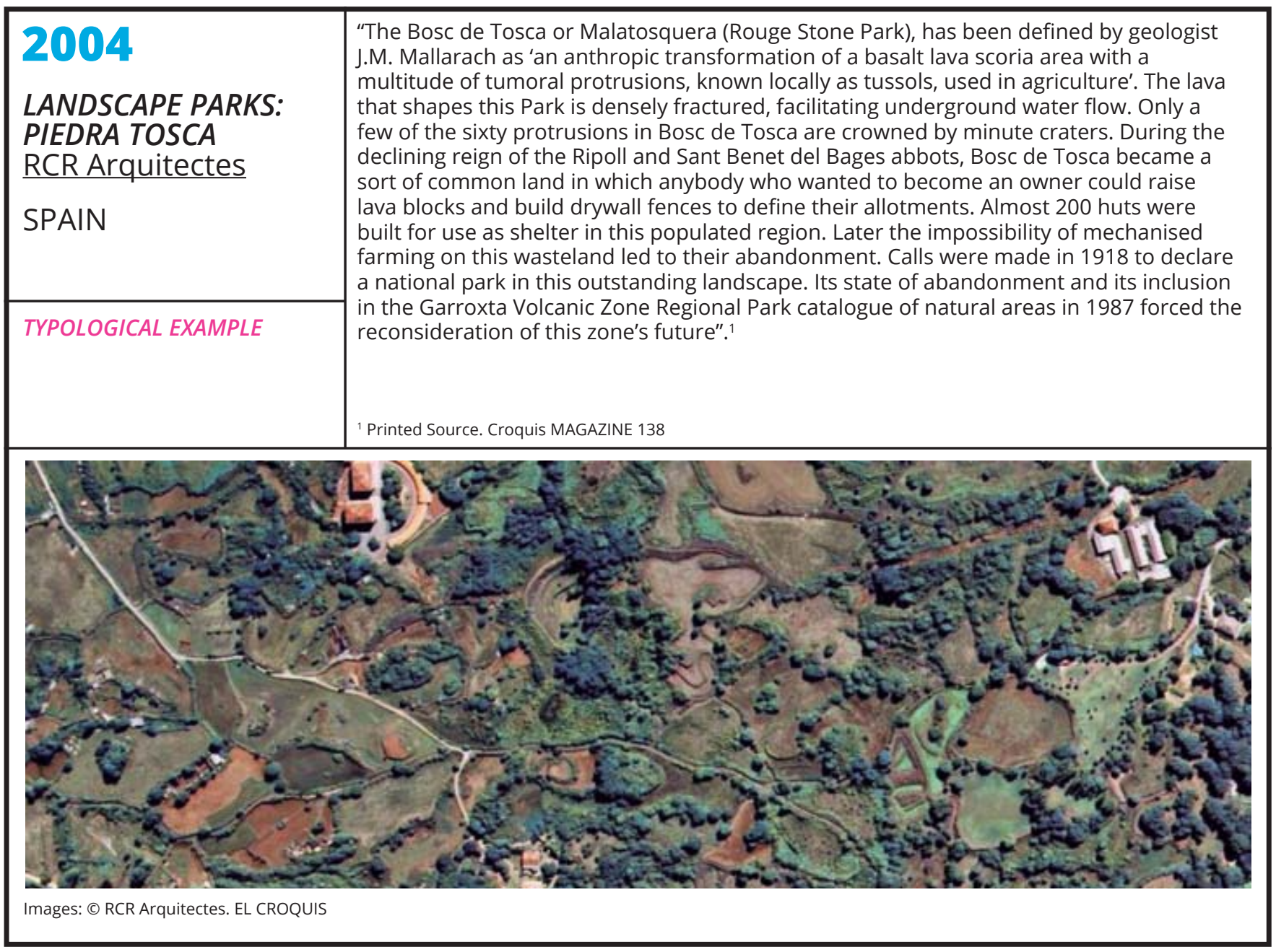

\begin{tabular}{|c|c|}
\hline $\begin{array}{l}1997 \\
\text { WASTE LANDSCAPE } \\
\text { MatthiaS } \\
\text { Loebermann } \\
\text { Oberstdorf, } \\
\text { Germany }\end{array}$ & $\begin{array}{l}\text { "Edward Burtynsky finds the eerie beauty in the man-made landscapes that dot our } \\
\text { Earth's surface. As a photographer who focuses on the relationship between humans and } \\
\text { nature, he travels to the hidden corners of the Earth to document the way people are } \\
\text { ravaging our planet. Below, } 13 \text { of his haunting images of altered nature. All images shown } \\
\text { courtesy of the photographer".1 }\end{array}$ \\
\hline ARTEALISATION IN VISU & $\begin{array}{l}\text { 'Posted by: Liz Jacobs October 31, } 2006 \text { at 10:48 am EDT } \\
\text { http://blog.ted.com/gallery-edward-burtynskys-extraordinary-images-of-manufactured-landscapes/ }\end{array}$ \\
\hline$\frac{5}{62}$ & (5) \\
\hline
\end{tabular}




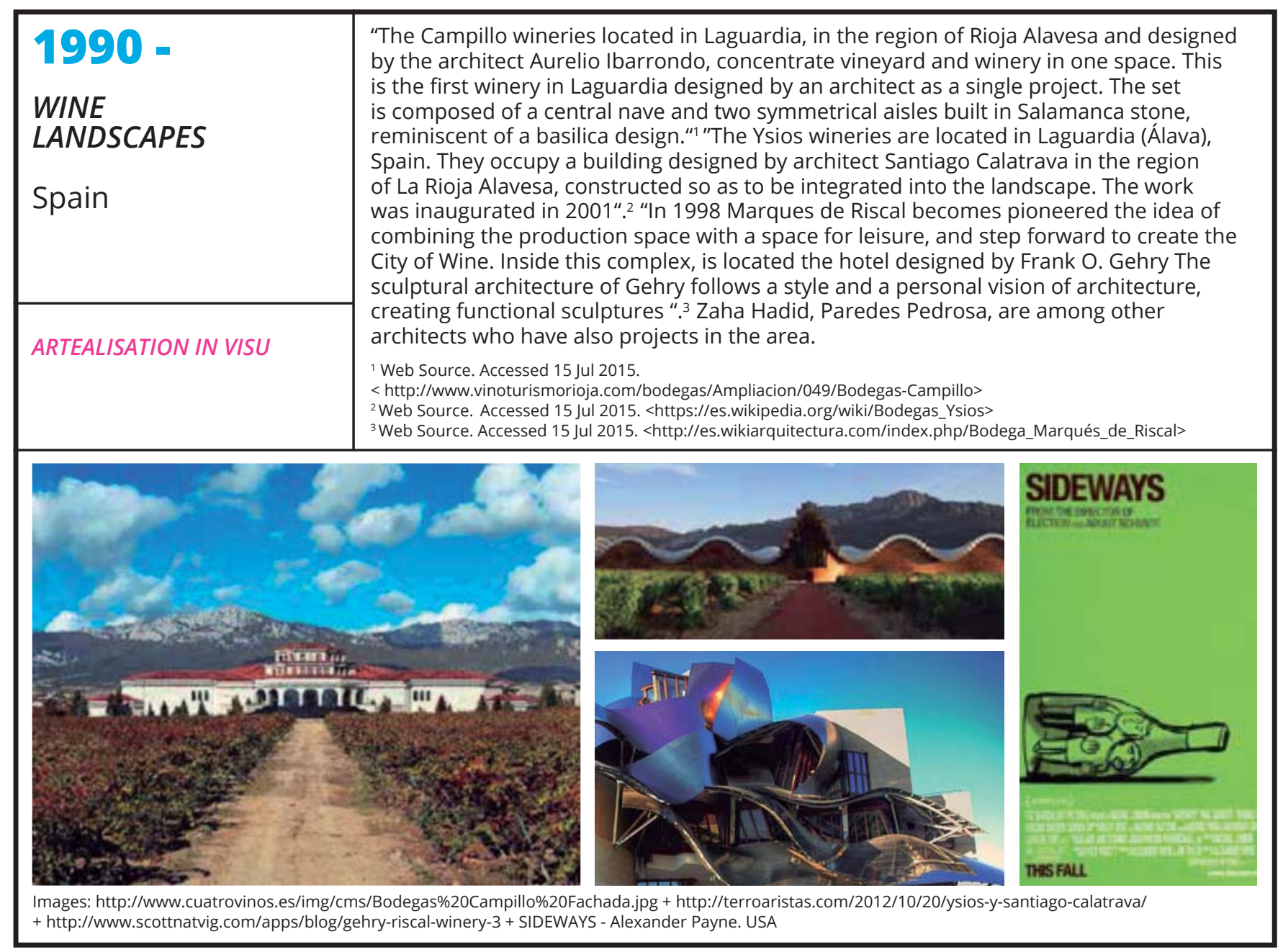





\section{Digestiones Pesadas / Heavy Digestions}

"After all, a devastated landscape is still a landscape. There is beauty in ruins" 98

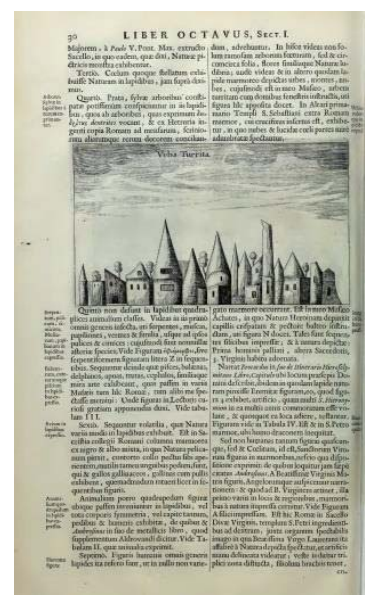

1667, Urbs Turrita. Mundus Subterraneus. Athanasius Kircher

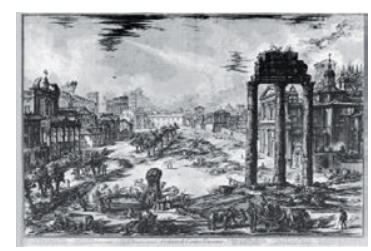

1745, "Vedute. Di Roma" G.B. Piranesi

\subsection{Introducción}

En la obra de 1677, Mundus Subterraneus, el estudioso Athanasius Kircher desarrolló un apartado de mineralogía ilustrado, donde describía minuciosamente las formas, e imágenes con las cuales la naturaleza mediante piedras se encontraba "señalada". Bajo el nombre de "Urbs Turrita", muestra la imagen de una ciudad con torres "achapiteladas". Kircher reprodujo lo que creía ver en una superficie de mármol. Esto fue el inicio de lo que se denominaría las piedras pictóricas, artealizaciones in visu que representaban el mundo conocido que se podía vislumbrar en minerales y otras rocas; sirviendo en sí mismas de soporte pictórico de ciudades, ruinas o paisajes de piedra. De esta manera, estos primeros ejemplos de chapiteles -más adelante desarrollados- son nacidos de supuestas representaciones de la propia naturaleza9; y así el trabajo de Kircher será inspiración de arquitectos posteriores de la "Tendenza" como es el caso de Aldo Rossi, que recuperarán la memoria y la historia.

\subsection{Paisajes recuperados}

En el siglo XVIII, el interés por el pasado llevó a entender las ruinas como "una mezcla de naturaleza y artificio" 100, el summum del paso del tiempo. Su popularización las convirtió en elementos cargados de gran poética y belleza. De esta manera, los grabados con motivos de construcciones pertenecientes a civilizaciones pasadas por artistas como Piranesi -Vedute (1745)-, se convertirían en artealizaciones in visu que representarían a la perfección este sentimiento. El efecto de estas obras artísticas tendría dos vertientes, en función del origen de la ruina; por un lado, la reconsideración de edificios que eran bellos per sé en un pasado, es decir la intencionalidad de su construcción tenía en un principio ánimo poético: véase monumentos, arcos del triunfo, templos...; y por otro, las ruinas de construcciones cuyo origen era fundamentalmente pragmático y funcional. En los primeros, su belleza inherente como ruina no sería considerada hasta lecturas posteriores, como sucederá en este momento, cuando son dotadas del atractivo de la memoria de un

\footnotetext{
${ }^{98}$ SONTAG, S. (2003) Regarding the pain of others. Farrar, Straus and Giroux. New York.

${ }^{99}$ KIRCHER, A (1667) Mundus Subterraneus. Urbs turrita. Amsterdam.

${ }^{100}$ ÁBALOS, I. (2008) Atlas pintoresco. Vol. 2: Los Viajes. Gustavo Gili. Barcelona (pag 29).
} 
pasado, remitiendo a nacionalismos y exotismo para los viajeros. En los segundos, el interés proviene de un sentimiento de admiración por lo conseguido; de la propia pragmática. En definitiva, ruinas antes bellas versus ruinas antes útiles.

Podríamos encontrar ejemplos de estos dos tipos diferentes de ruinas en la ciudad de Segovia. El acueducto, símbolo de la ciudad, realizado durante el imperio de Trajano en el siglo II, se trataría de una ruina antes útil. "Lo que nos asombraba y aún nos asombra del Acueducto es su audacia constructiva, es decir, la voluntad del hombre por superar barreras..."101; lo que denota que ese sentimiento de orgullo probablemente existiría también poco después de su construcción. Sin embargo, el sentimiento que brota al observar el Alcázar no es otro que la fantasía. Este fue precisamente lo que movió a los artistas extranjeros como el holandés Antón van den Wyngaerde a dibujarlo- recordemos que el hecho de dibujar ciudades, para un vernáculo estaba considerado casi espionaje ${ }^{102}$. En particular, el encargo para Wyngaerde fue establecido por Felipe II en 1562, y en estos dibujos tempranos se puede observar la primera silueta del castillo; usado más bien como fortaleza, con las torres rematadas por almenas y las techumbres con pendientes. Al trasladar la corte a Madrid, Felipe II decide convertirlo en base para crear un palacio, tal y como eran los deseos de su padre Carlos I. Para representar el estado moderno que era España, las torres fueron rematadas con chapiteles cónicos de pizarra, a imagen de otras construcciones europeas. En el siglo XIX, prácticamente olvidado por los sucesivos monarcas, la decadencia del castillo comenzó a despertar interés entre los viajeros ingleses y franceses. Así el acueducto, que gozaba de gran fama, actuó de señuelo para atraer a los visitantes a Segovia y también a su alcázar. Entre 1806 y 1820, es publicado “Voyage pittoresque et historique de l'Espagne", de Alexander Laborde, con ilustraciones de Liger ${ }^{103}$. Estas artealizaciones in visu llevarían a convertir el alcázar en un castillo icónico, que serviría de influencia para muchas otras, como el castillo de la película Blancanieves de Walt Disney (1937); o también para artealizaciones in situ como la restauración de la Ciudadela de Carcassone (1844) en Francia.

La ciudadela de Carcassone se encontraba en ruinas, a punto de ser demolida tras haber pasado por múltiples usos: fortaleza, palacio...siguiendo un proceso de abandono similar al alcázar de Segovia, que afectaría a toda la ciudad, quedando prácticamente deshabitada. Prosper Mérimée, entre otros, consiguió que se encargara la reconstrucción a Viollet Le-Duc. El arquitecto, remató las torres con chapiteles cónicos recubiertos de

\section{4, Fotograma de Le Miracle des Loups-} Carcassone

\footnotetext{
${ }^{101}$ RUIZ HERNANDO, A (1994) Iconografía del Alcázar de Segovia. Patronato del Alcázar de Segovia.

102 IBID.

103 IBID.
} 
pizarra, al estilo del alcázar de Segovia, en vez de terrazas y tejas ocres como era habitual en la región. La rehabilitación "estilística" 104 fue muy controvertida y criticada por sus coetáneos.

La discusión teórica sobre reusar como una forma de preservar monumentos históricos comienza en ese momento (S.XIX). La práctica de la restauración estaba situada entre dos doctrinas opuestas: el movimiento en pro de la restauración, dirigido por Eugène Emmanuel Viollet-le-Duc; y el movimiento de la anti-restauración, auspiciado por John Ruskin. Este último defendía la conservación del patrimonio desde una aproximación historicista, otorgándole la categoría de arte y su consecuente valor. Un valor documental, a partir de la originalidad con la que se ha construido, defendiendo únicamente una conservación que no altere la imagen con la que llegó a nuestro tiempo: “Se haya oído o no, no debo dejar de exponer la verdad, esto no es, una vez más, una cuestión de conveniencia o sensación de si hemos de conservar los edificios del pasado o no. En cualquier caso, no tenemos derecho a tocarlos. No son nuestros. Pertenecen en parte a aquellos que los construyeron y en parte a todas las generaciones de la humanidad que nos seguirán."105.

Mientras, Viollet-le-Duc, totalmente opuesto, proponía un tipo de restauración basada en la actualización del edificio, una combinación entre hechos históricos y nuevas modificaciones e invenciones. Con motivo de esto recibió duras críticas, ya que restituía a las obras -en sus propias palabras- su espíritu primitivo, y las transformaba en lo que, según él, deberían haber sido mediante la adición de nuevas piezas y la desaparición de otras. En definitiva, mejorándolas. Como resultado, encontramos las restauraciones de la Catedral de Notre Dame, Saint-Denis o la anteriormente descrita de Carcassone; así como otros muchos edificios desaparecidos que eran fundamentales para la sociedad europea del momento ${ }^{106}$. Este debate público fue el punto de partida para el desarrollo de una preocupación: qué hacer con los edificios y estructuras abandonadas; un debate que sigue vigente hoy en día. Es también el momento en el mundo se encontraba ya inmerso en la industrialización. Un proceso que había comenzado a partir de la segunda mitad del siglo XVIII y principios del siglo XIX.

${ }^{104}$ HERNANDEZ MARTINEZ, A (2007) La clonación arquitectónica. Ediciones Siruela.

${ }^{105}$ RUSKIN, J. 1849 (2012) Las siete lámparas de la arquitectura; La lámpara de la memoria. Coyoacan. ISBN: 9786079014599

${ }^{106}$ HERNANDEZ MARTINEZ, A. Op. Cit. 


\subsection{Paisajes industriales}

Reyner Banham en su ensayo La Atlántida de Hormigón (1986), cuenta cómo unas artealizaciones in visu; unas fotografías, llegan a manos de Walter Gropius, para ser después reproducidas por Le Corbusier en 1919 para la revista L'Espirit Nouveau. En ellas se podía observar instalaciones industriales americanas de principios de siglo XX, tales como silos de almacenamiento de grano ${ }^{107}$. La estética de estas construcciones nacidas del pragmatismo puro, llegaron a asombrar a los arquitectos de principios de siglo, estableciendo una relación directa posterior con los brutalistas de los años ‘50s -'70s, así como el triunfo del hormigón con respecto a otros materiales.

Uno de los principales testigos de este proceso fue el pintor inglés L.S. Lowry, que comenzó a pintar escenas industriales de la ciudad de Londres. El artista reflejaba la atmósfera de la ciudad de ese tiempo a través de sus pinturas, creando una suerte de artealizaciones in visu. Se mudó con su familia desde una parte residencial de Mánchester, a un suburbio dedicado a la minería y el carbón. Lowry comenzó a reflejar su entorno en forma de paisajes. Una de las pinturas más conocidas de Lowry es Paisaje Industrial Industrial Landscape (1955), que forma actualmente parte de la colección de la TATE Modern. El aire denso de humo desdibuja las chimeneas con sus penachos negros de vapores tóxicos, mientras alienados paseantes sobrellevan los rigores de invierno: no es un ambiente sano, y sin embargo, tras sucesivas retroalimentaciones, reconocemos en ellos una nobleza sencilla a la que los "collage" de arquitectura característicos de los últimos años parecen aspirar.

A partir de 1960, la pareja de artistas alemanes Bernd and Gilla Becher, calificados de "arqueólogos industriales" ${ }^{108}$, empezaron a tomar fotografías, casi obsesivamente, con una Gran Bretaña, Francia, Bélgica o USA, tomando así un carácter científico que examinaba sus similitudes y diferencias. Por otro lado, “Les intrigaba el hecho de que muchos de esos edificios fuesen construidos con gran atención hacia el diseño"109. Se podría decir que estas

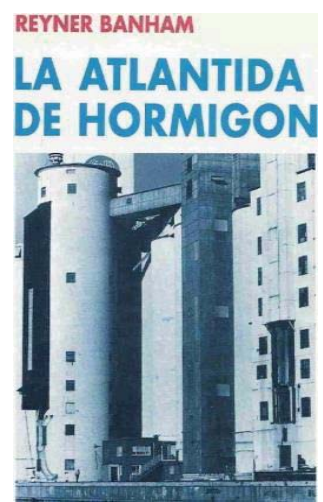

1986, La Atlantida de Hormigón - Reyner Banham
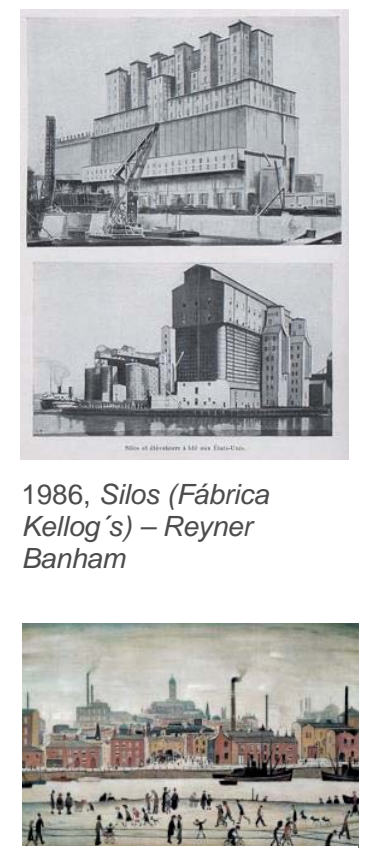

1955, Industrial Landscape, LS Lowry.

\footnotetext{
107 BANHAM, R. 1986 (1989) La Atlántida de hormigón: Edificios industriales de los Estados Unidos y arquitectura moderna europea, 1900-1925. Editorial Nerea.

108 (Traducida) ALLEY, R (2007): Catalogue of the Tate Gallery's Collection of Modern Art other than Works by British Artists, Tate Gallery and Sotheby Parke-Bernet, London 1981, p.38 en Tate, Bernd Becher and Hilla Becher 1931-2007, born 1934, Disponible en http://www.tate.org.uk/art/artists/bernd-becherand-hilla-becher-718 (Consultado 29 de Octubre de 2015).

109 (Traducida) Art \& Artists, Bernd \& Hilla Becher photography, Disponible en http://poulwebb.blogspot.mx/2011/01/bernd-and-hilla-becher-photography.html (Consultado el 29 de Octubre de 2015).
} 


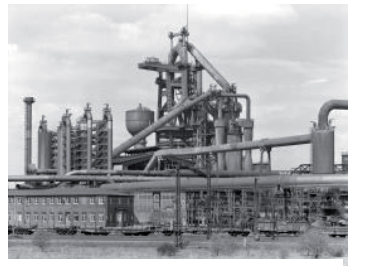

1965, Industrial Structures, Bernd and Hilla Becher.

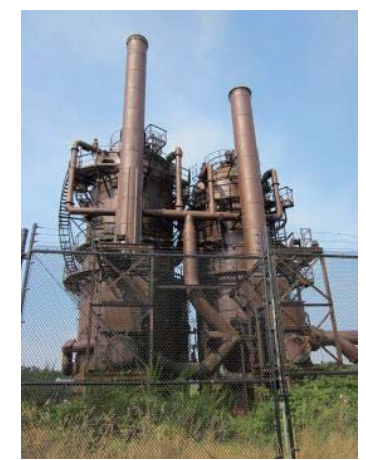

1975, Gas Work Park, Richard Haag.

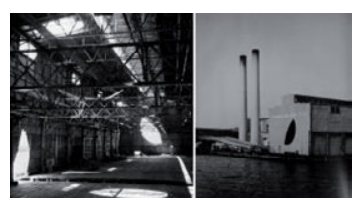

1975, Day's End Gordon Matta Clark. fotografías fueron también una artealización in visu de la infraestructura industrial que comenzaba a estar abandonada.

Es muy posible que esta fuera la razón por la cual la ciudad de Seattle compró una fábrica de carbón abandonada, para transformarla en uno de los principales parques de la localidad: The Gas Work Park (1975).

El arquitecto Richard Haag, fue el encargado de este proyecto y decidió mantener la antigua estructura industrial como nuevo símbolo de identidad del parque. Algunas partes permanecieron como ruinas; otras, pintadas y acondicionadas, se incorporaron a las estructuras de juego de los niños, así como a la zona de picnic. Todas son una forma más de preservar elementos de arqueología moderna y de incorporar a la ciudad actual el pasado industrial en desuso. Es un ejemplo paradigmático, que se añadió para su protección en 2013 al Registro de los Sitios Históricos Nacionales -el equivalente a Bien de Interés Cultural-, acompañando a otros proyectos como la Fallingwater House de Frank Lloyd Wright. Este fue el primer ejemplo de una serie de intervenciones que reúsan infraestructuras industriales.

Ese mismo año, en 1975, Gordon Matta-Clark realiza su obra Day's End (El dia final). Esta artealización in situ, consistió en una intervención que buscaba "recuperar un territorio abandonado y perdido en la ciudad para el disfrute y la creación colectiva" 110 . De la obra sólo se conservan fotografías y un cortometraje de lo que fue el proceso de deconstrucción de un edificio industrial decimonónico en desuso de la ciudad de Nueva York, en el que practicaría una apertura circular - "building cuts"-- El artista fue perseguido por la ley y la nave abandonada y posteriormente demolida. No obstante, su comparación con una basílica cristiana y su elevación a status de reliquia, lo convirtió en un ejemplo fundamental para considerar el paisaje industrial como deseable.

Landschaftpark Duisburg-Nord, también Ilamado LaPaDu, es un parque de la localidad alemana de Duisburg, resultado de la intervención de los arquitectos Peter y Anneliese Latz. El proyecto buscaba relacionarse con el pasado del lugar: por un lado, el abandono en 1985 de la fábrica de carbón y acero había dejado todas sus instalaciones en deterioro, y por otro, la recuperación del paisaje de cultivos que había sido antes del siglo XIX. Asociándose con ambos eventos, se propone la reconversión en un parque público que integra los artefactos industriales. La desmantelación de estos elementos resultaba

${ }^{110}$ HINOJOSA, L (2007): Day's End. Colección Museo Reina Sofía. Ver en: http://www.museoreinasofia.es/coleccion/obra/days-end-dia-final (Consultado el 21 de Abril de 2016). 
inviable y de un costo prohibitivo ${ }^{111}$, y los Latz sugirieron una combinación de naturaleza e industria ${ }^{112}$ como resultado de una experiencia que aludía a la memoria, y a una versión romántica de ruinas industriales, producto de artealizaciones in visu como las de Bernd y Hilla Becher décadas antes. De hecho, en una de las infraestructuras del propio parque, existe un friso formado por varias fotografías significativas de la pareja que decora la fachada de una de las naves; una acción que convierte estas obras a su vez en una artealización in situ, dentro de un ejemplo tipológico de proyecto de esta línea.

Otro ejemplo son los gasómetros abandonados de Viena. Son escenarios en la artealización in visu de la película de James Bond -The Living Daylights (1987). Pocos años antes, en 1978, son vaciados, solo conservando así, las fachadas exteriores de ladrillo, además de ser designados como espacio histórico protegido. En 2001 se convierten en un ejemplo tipológico de cómo se puede habitar la infraestructura industrial, cuando son reconvertidos físicamente para uso residencial y comercial por los arquitectos, Jean Nouvel, Coop Himmelblau, Manfred Wehdorn y Wilhem Holzbauer ${ }^{113}$. Se crea una comunidad muy activa formada por más de ochocientas viviendas, centro comercial, una sala de música, una sala de cine, archivo municipal...siendo otra ciudad, cercana a las dos mil personas, dentro de la ciudad de Viena. Pero es en el espacio virtual, donde se generan los verdaderos lazos entre los habitantes -en la llamada Gasometer Community- donde existen toda una serie de foros de discusión aún activos sobre aspectos físicos de la vida diaria, como fiestas, encuentros, política, cultura, deportes...así como activismos y empleo de la comunidad $^{114}$.

En esa misma época tiene lugar también la transformación de una vieja central de electricidad en Londres en el nuevo museo de arte contemporáneo de la ciudad (2000). Hablamos de la Tate Gallery de Londres, por los arquitectos Herzog \& DeMeuron. La London Bankside Power Station estuvo cerrada desde el año 1981, hasta que se abrió de nuevo al público como icono cultural, sin disminuir la presencia histórica del edificio. Los arquitectos proponían mínimas alteraciones exteriores, diluyendo la transición entre lo viejo y lo nuevo y evitando intervenciones que puedan competir con las obras de arte

${ }^{111}$ NICKERSON, Tim. Landschaftsoark Duisburg-Nord. Article published at Landscape Architecture Tour. Ver en: http://people.umass.edu/latour/Germany/tnickerson/ (Consultado el 10 de Diciembre de 2015).

112 LANGHORST, Joern. W. Rising from Ruins: Postindustrial Sites Between Abandoned and Engagment, Department of Landscape Architecture. Iowa State University.

${ }^{113}$ (Traducida) Gasometer City, en http://adaptivereuse.info/portfolio/gasometer-city/ (Consultado el 9 de Julio de 2015)

114 http://www.gasometer.cc/ (Consultado el 29 de Octubre de 2015) 


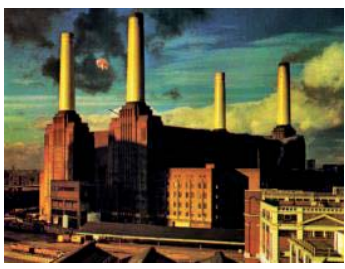

1977, Animal Cover, Pink Floyd

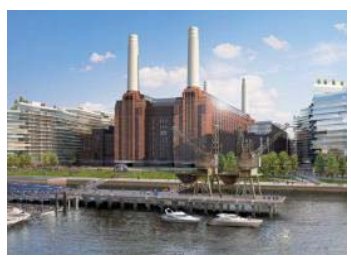

2020, Battersea Power Station, Rafael Viñoly expuestas. La Tate Modern, se configura como un ejemplo paradigmático en este tipo de readaptación de usos (Adaptive Reuse) ${ }^{115}$.

Un ejemplo tipológicamente parecido es el proyecto de 2011 propuesto por el arquitecto Rafael Viñoly para la Battersea Power Station, también en Londres. Su finalización se estima en el año 2020, y supone la renovación de todo un icono de la Revolución Industrial, que fracasó en sus posibles reconversiones en parque temático, o complejo hotelero. Se trata del edificio más grande de ladrillo en Europa en su momento (1939), que se hizo reconocible en 1965 como escenario de la película Help! de The Beatles. Su aparición en otras artealizaciones in visu como la portada del disco Animals de Pink Floyd, en un videoclip de la banda de rock Iron Maiden, así como numerosas series televisivas y videojuegos; convirtieron su silueta en un icono durante las últimas décadas. En desuso desde 1983, el proyecto de Viñoly busca reforzar la presencia de la Estación a través de un masterplan para toda la zona, formado por viviendas con terrazas abiertas y diferentes alineamientos de fachada ${ }^{116}$.

Recientemente y siendo partícipes del asentamiento de estas estéticas, como práctica habitual de actuación frente a las digestiones pesadas de la ciudad, podemos encontrar proyectos como el Caixa Forum (2008) de nuevo de Herzog \& DeMeuron en Madrid, la readaptación del aeropuerto de Tempelhof (2010) en Berlín, o el MediaLab Prado (2012) también en Madrid.

\subsection{Paisaje de raíles}

Con la industrialización, el progreso industrial en un principio no era considerado un

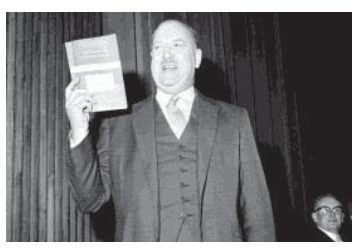

1963, Beeching Cuts Report, Richard Beeching tema cuando el tema central era la naturaleza, los viajes y lo exótico. No obstante, el ferrocarril produjo cierta fascinación en algunos pintores relevantes en su desarrollo a principios del siglo XIX. El ejemplo más notable de artealización in visu, es la pintura Rain, Steam, and Speed - The Great Western Railway (1844) de J.M.W. Turner. En esta obra la figura de la máquina se representa desdibujada por la velocidad y el humo, empleando un tratamiento similar de la luz de sus cuadros de marinas y paisajes. No hay una intención

115 JONES, Rennie. "AD Classics: The Tate Modern / Herzog \& de Meuron" 17 Sep 2013. ArchDaily. http://www.archdaily.com/429700/ad-classics-the-tate-modern-herzog-and-de-meuron/ (Consultado el 29 de octubre de 2015).

116 PORTILLA, Daniel. "Battersea Power Station Masterplan / Rafael Viñoly Architects" 27 feb 2010. Plataforma Arquitectura. http://www. plataformaarquitectura.cl/cl/02-37877/battersea-power-stationmasterplan-rafael-vinoly-architects (Consultado el 29 de octubre de 2015) 
explícita de homenajear al ferrocarril, ni a la revolución industrial, sino la de presentar un paisaje existente más, en su contemporaneidad.

En 1963 tiene lugar una reestructuración y reducción de la red de ferrocarriles en Gran Bretaña, para poner fin a las pérdidas de la industria producidas por el desarrollo del automóvil. Este importante evento, conocido por el Plan Beeching, produjo que mucha de la infraestructura de trenes existente quedara abandonada y obsoleta. Rápidamente se fue extendiendo por el resto de Europa, comenzando una tendencia al cierre de líneas que en ocasiones dejaban aisladas grandes regiones hasta la posterior estabilización de los años setenta ${ }^{117}$

Esta dinámica había llegado a Estados Unidos unos años antes, y tras la progresiva apertura de las autopistas interestatales a lo largo de la década de 1950, las consecuencias se vieron reflejadas en toda la nación con el cierre de las líneas de ferrocarril, como The High Line en Nueva York. Esta línea elevada que cruzaba toda la parte oeste de Manhattan fue gran parte demolida en 1960, y finalmente cerrada en 1980. Es en 2009 cuando por fin, tras una readaptación de usos, es abierta de nuevo.

El conocido proyecto de Diller y Scofidio transforma con éxito total, las vías abandonadas del tren en un jardín público elevado. Pero ¿cuándo se decidió que esta infraestructura industrial debería ser transformada en algo más para la ciudad? En 1979, aparece en el primer capítulo de la película Manhattan de Woody Allen. En 1984, la banda Art of Noise, grabó aquí el videoclip de Close (to the Edit). Pero la artealización definitiva de este lugar fue en el año 2000, cuando la Asociación de Vecinos de Chelsea, pidió al fotógrafo Joel Sternfeld que tomara fotografías de las vías abandonadas durante un año, para ver cómo la vegetación se volvía más salvaje y tupida.

La propuesta de Diller \& Scofidio, transformó estas imágenes en un jardín público real, desde esa artealización in visu hasta su conversión en un ejemplo paradigmático de parque público con diferentes eventos como gradas, lounge, solárium, fuentes...a lo largo de su recorrido sobre Manhattan, haciendo posible que las imágenes de Sternfeld convirtieran esta infraestructura en un valor real para la ciudad.

El proyecto neoyorquino se basa declaradamente en un ejemplo anterior, también resultado de la reducción de la red de ferrocarriles, pero en este caso en Europa, fue el parque de Coulée Verte René-Dumont en París. Se trata de un paseo plantado - la promenade plantée, que discurre a lo largo de un recorrido por las vías del tren que unían lo

117 KEENOR, Garry. «The Reshaping of British Railways - Part 1: Report» en http://www.railwaysarchive.co.uk/docsummary.php?doc/D=13. The Railways Archive. (Consultado el 29 de octubre de 2015).

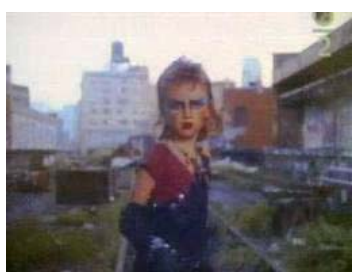

1984, CLOSE (to the Edit) Art of Noise directed by Zbigniew Rybczynski

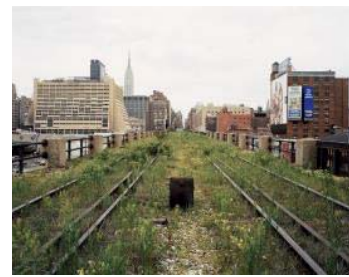

2000, Walking the High Line, Joel Sternfeld

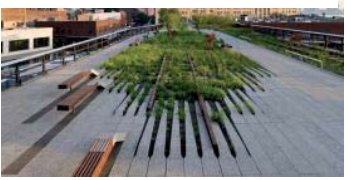

2009, HighLine, Diller \& Scofidio

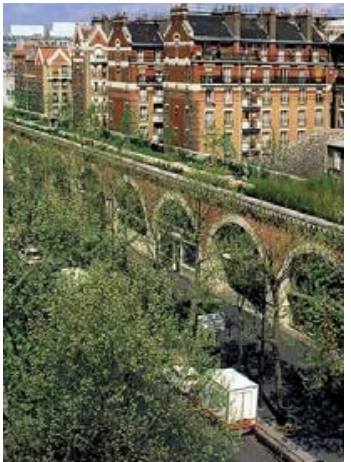

1993, Coulée Verte René-Dumont, Jacques Vergely and Philippe Mathieux 
que ahora es la ópera de la Bastilla con Verneuil-l'Étang. Parte de la línea fue incorporada a la red de cercanías de París, mientras que el resto fue abandonado. A finales de los años ochenta, el arquitecto Philippe Mathieux junto con Jacque Vergely, crean un parque público a lo largo de casi cinco kilómetros, aprovechando algunos jardines formados por la vegetación que había invadido los accesos a las estaciones ya existentes. En esta operación de integración -en parte elevada a diez metros de altura- aparecen, por tanto, ejemplos de paisajismo francés de un siglo atrás, y otros más modernos junto a eventos como el jardín de Reuilly formado por una gran explanada de césped, para concluir al nivel del suelo incorporándose en la avenida Vivaldi118.

${ }^{118}$ WIKIPEDIA, Coulée Verte René- Dumont. Ver en: https://es.wikipedia.org/wiki/Coul\%C3\%A9e verte Ren\%C3\%A9-Dumont (Consultado el 10 de diciembre de 2015) 


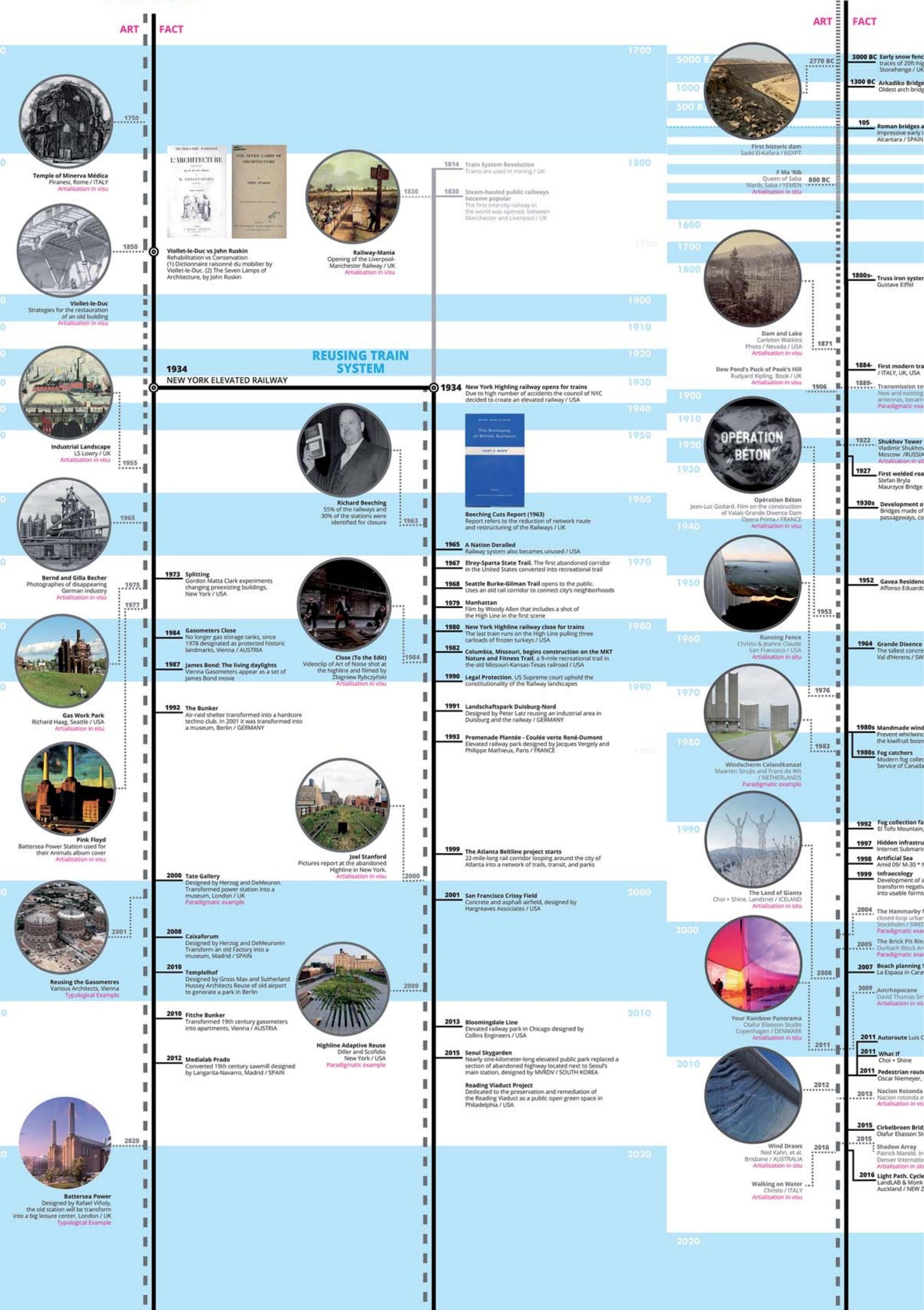




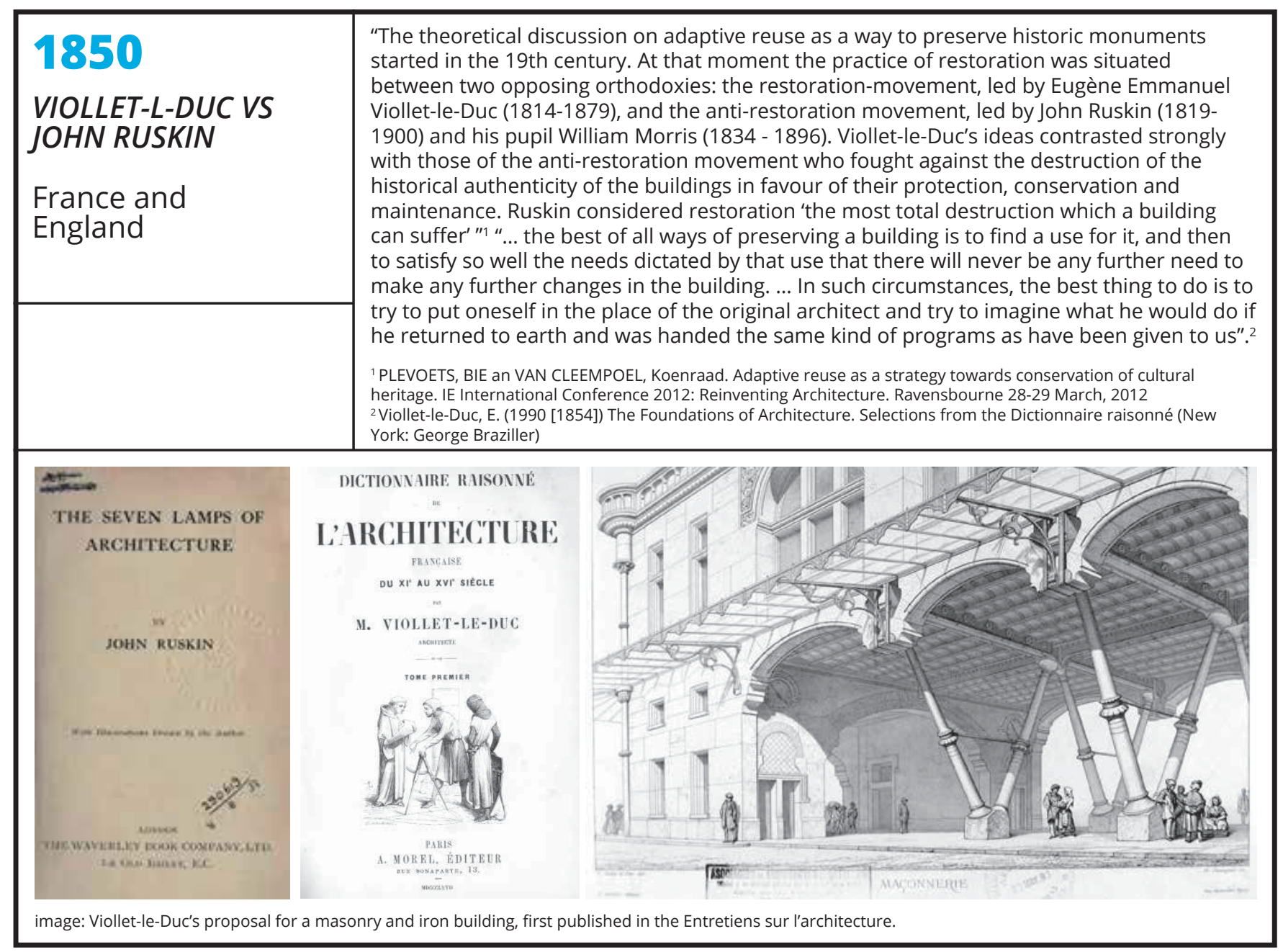

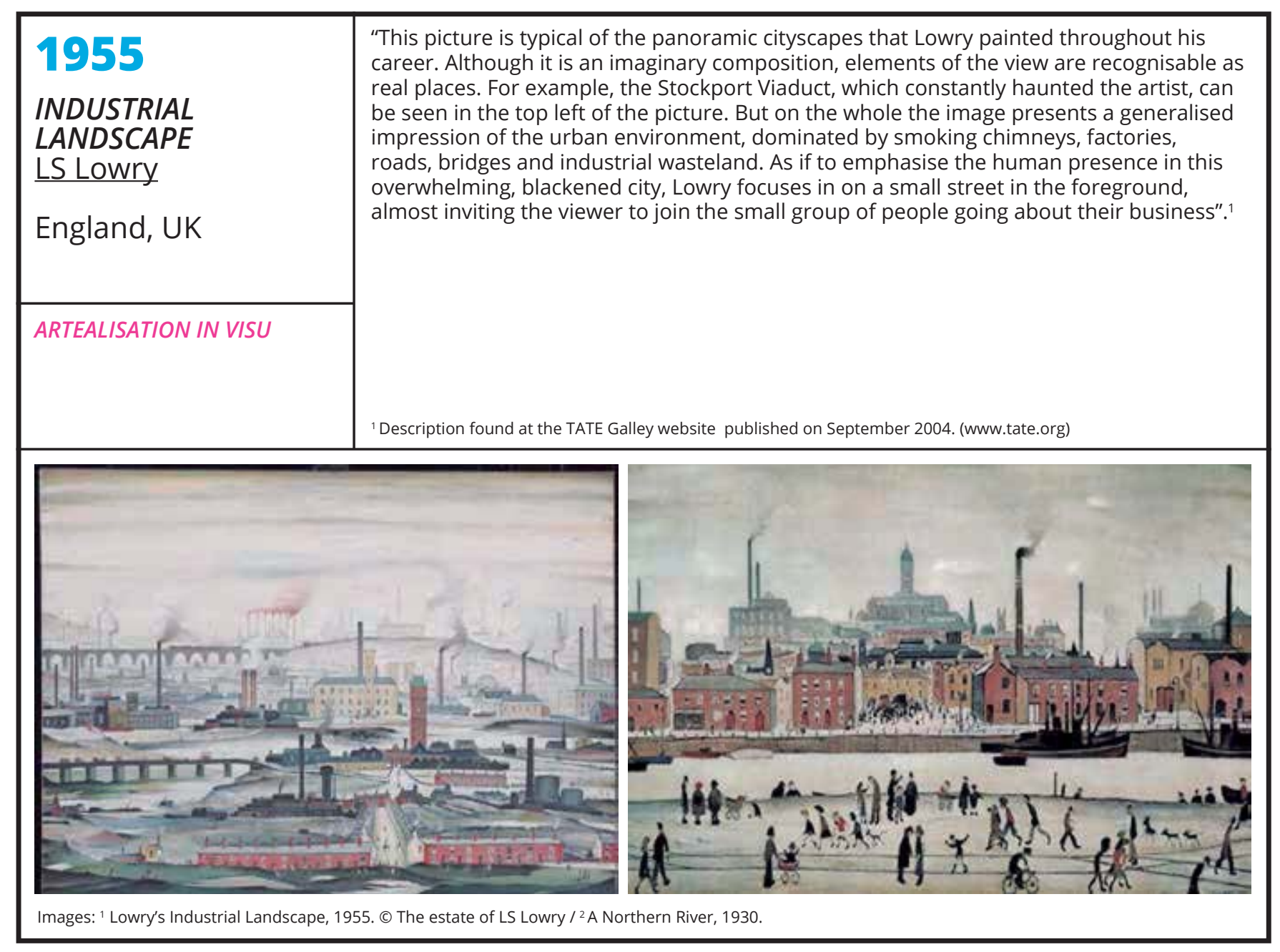




\begin{tabular}{|c|c|}
\hline $\begin{array}{l}1965 \\
\text { PICTURES } \\
\text { OF INDUSTRIAL } \\
\text { STRUCTURES } \\
\text { Bernd \& } \\
\text { Hilla Becher } \\
\text { Germany }\end{array}$ & $\begin{array}{l}\text { "For over } 40 \text { years, Bernd and Hilla Becher photographed the architecture of } \\
\text { industrialisation: water towers, coal bunkers, blast furnaces, gas tanks and factory } \\
\text { façades. They did so in an obsessively formalist way that defined a style, and made them } \\
\text { one of the most dominant influences in contemporary European photography and art. } \\
\text { Their approach soon became even more rigorous, with each structure being } \\
\text { photographed from a similar angle on a large-format plate camera. The grids were } \\
\text { arranged to highlight the formal similarities of each structure, which, as their images of } \\
\text { water towers in Detroit show, was constant around the world - but also their looming, } \\
\text { ominous presence"." }\end{array}$ \\
\hline ARTIALISATION IN VISU & $\begin{array}{l}\text { 'O' HAGAN, SEAN. Lost world: Bernd and Hilla Becher's legendary industrial photographs. Article published at The } \\
\text { Guardian. Wednesday } 3 \text { September 2014. (www.the guardian.com) }\end{array}$ \\
\hline $\begin{array}{l}1 \\
\text { Images: Bernd and Hilla Becher }\end{array}$ & prints, overall. The Museum of Modern Art. 0 2010 Hilla Becher \\
\hline
\end{tabular}

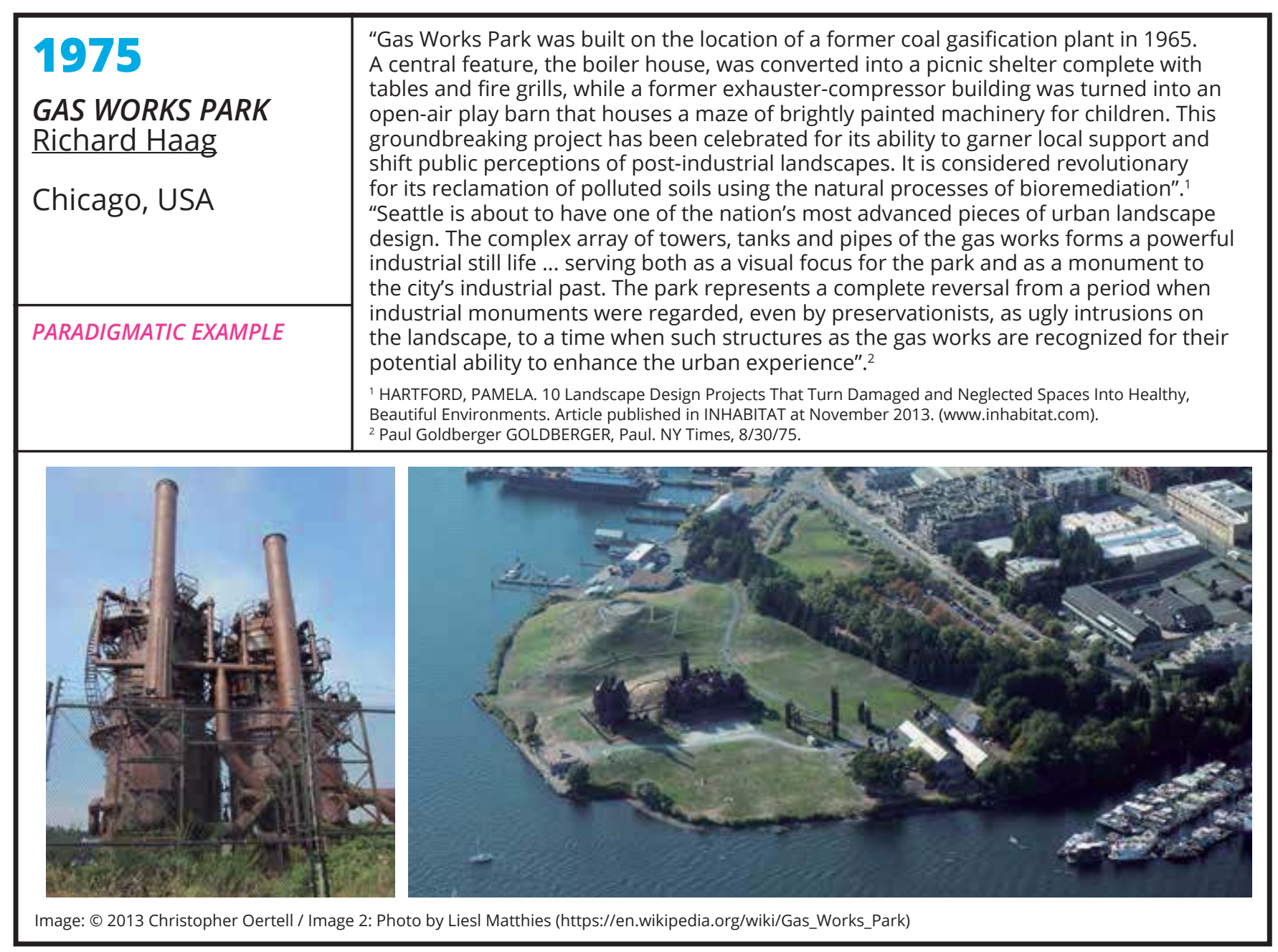




\begin{tabular}{|c|c|}
\hline $\begin{array}{l}2001 \\
\text { GASOMETERS } \\
\text { Various Architects } \\
\text { Vienna, } \\
\text { Austria }\end{array}$ & $\begin{array}{l}\text { "The Gasometers were built between } 1896 \text { and } 1899 \text { in the Simmering district of Vienna } \\
\text { near the Gaswerk Simmering gas works of the district. The containers were used to help } \\
\text { supply Vienna with town gas. At the time, the design was the largest in all of Europe. The } \\
\text { Gasometers were retired in } 1984 \text { due to new technologies in gasometer construction, } \\
\text { as well as the city's conversion from town gas and coal gas to natural gas. In 1978, they } \\
\text { were designated as protected historic landmarks. Each gasometer was divided into } \\
\text { several zones for living (apartments in the top), working (offices in the middle floors) and } \\
\text { entertainment and shopping (shopping malls in the ground floors). The shopping mall } \\
\text { levels in each gasometer are connected to the others by skybridges. The historic exterior } \\
\text { wall was conserved. The Gasometers have developed a village character all their own } \\
\text { and are a city within a city. A true sense of community has developed, and both a large } \\
\text { physical housing community (of tenants) as well as an active virtual internet community } \\
\text { (Gasometer Community) have formed"." }\end{array}$ \\
\hline PARADIGIMATI EХAVIPLE & $\begin{array}{l}\text { (Gasometer Community) have formed". } \\
\text { 'Article published at ADAPTIVE REUSE website. (www.adaptivereuse.info) }\end{array}$ \\
\hline (10) & 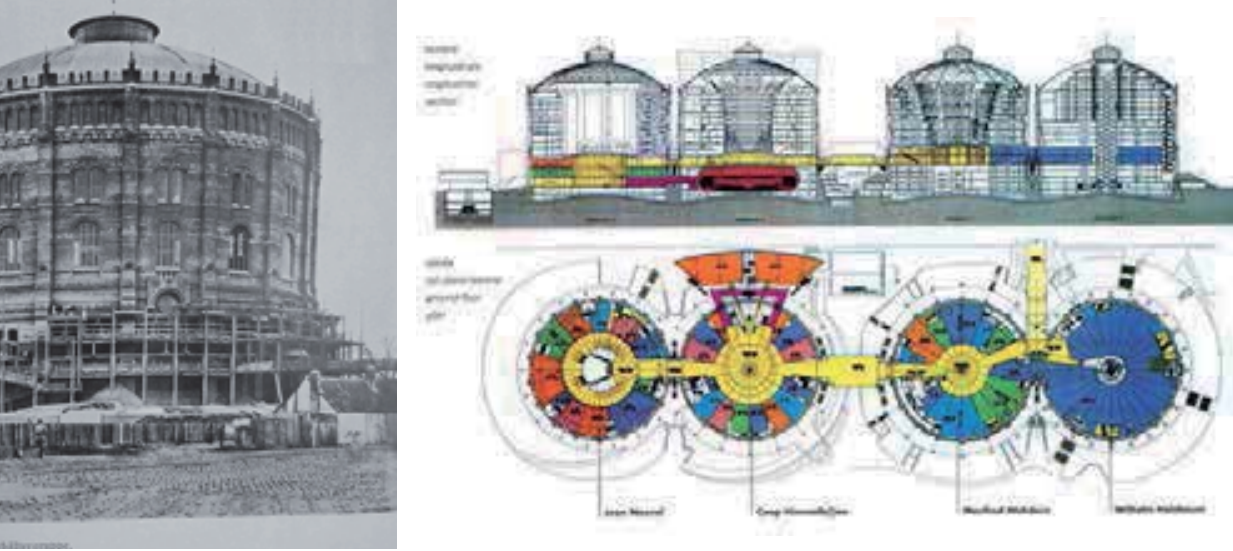 \\
\hline
\end{tabular}

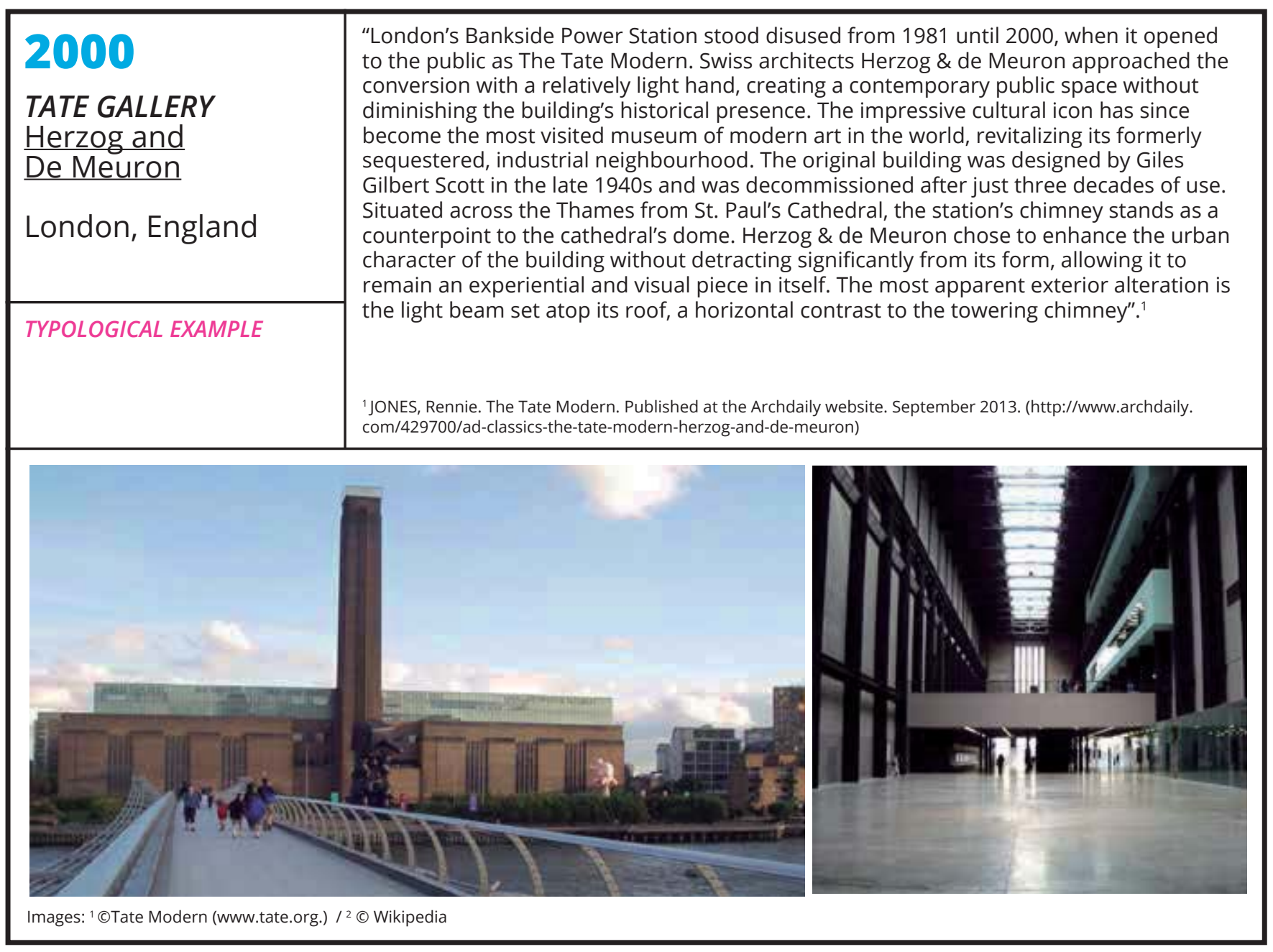




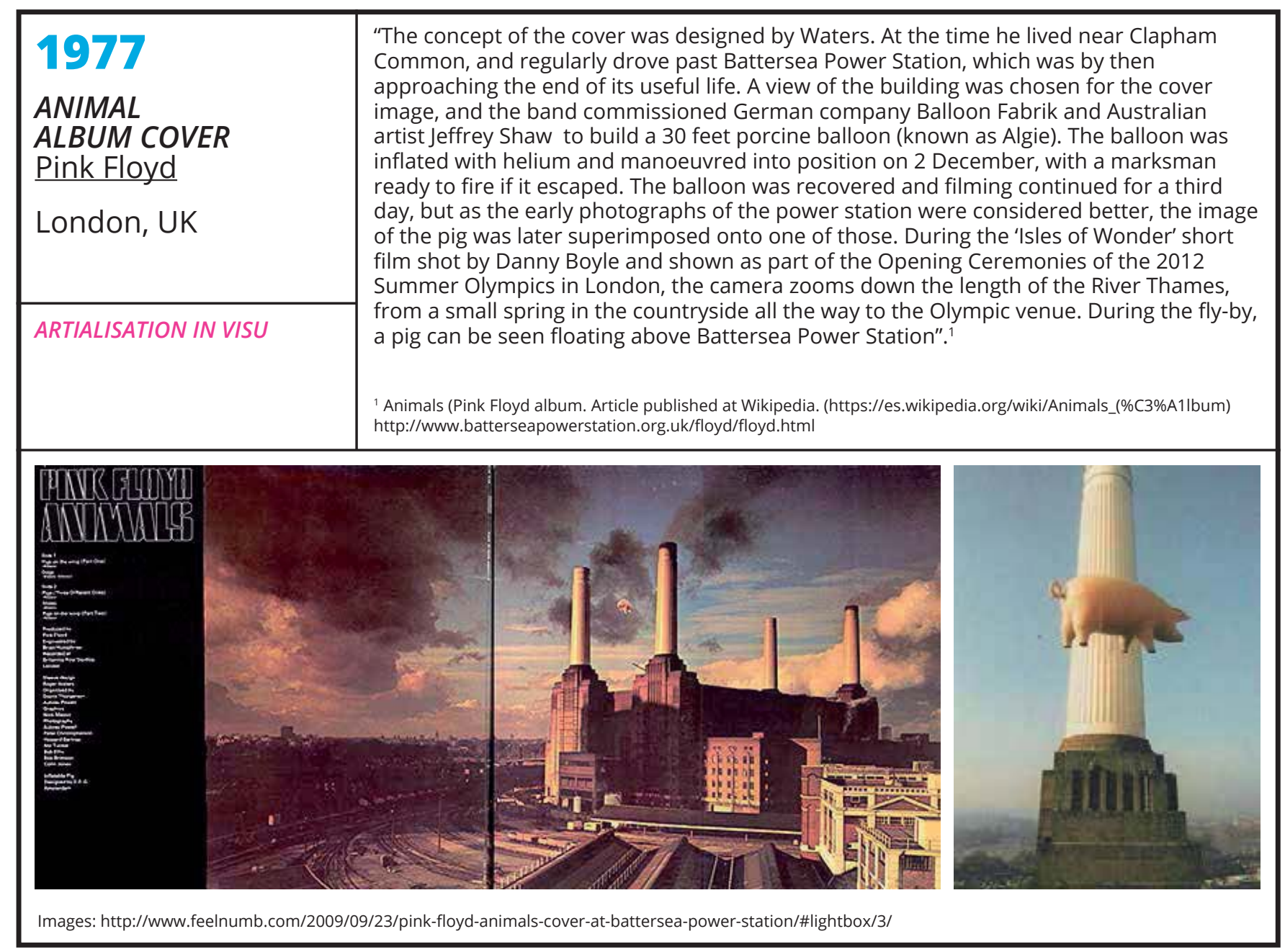

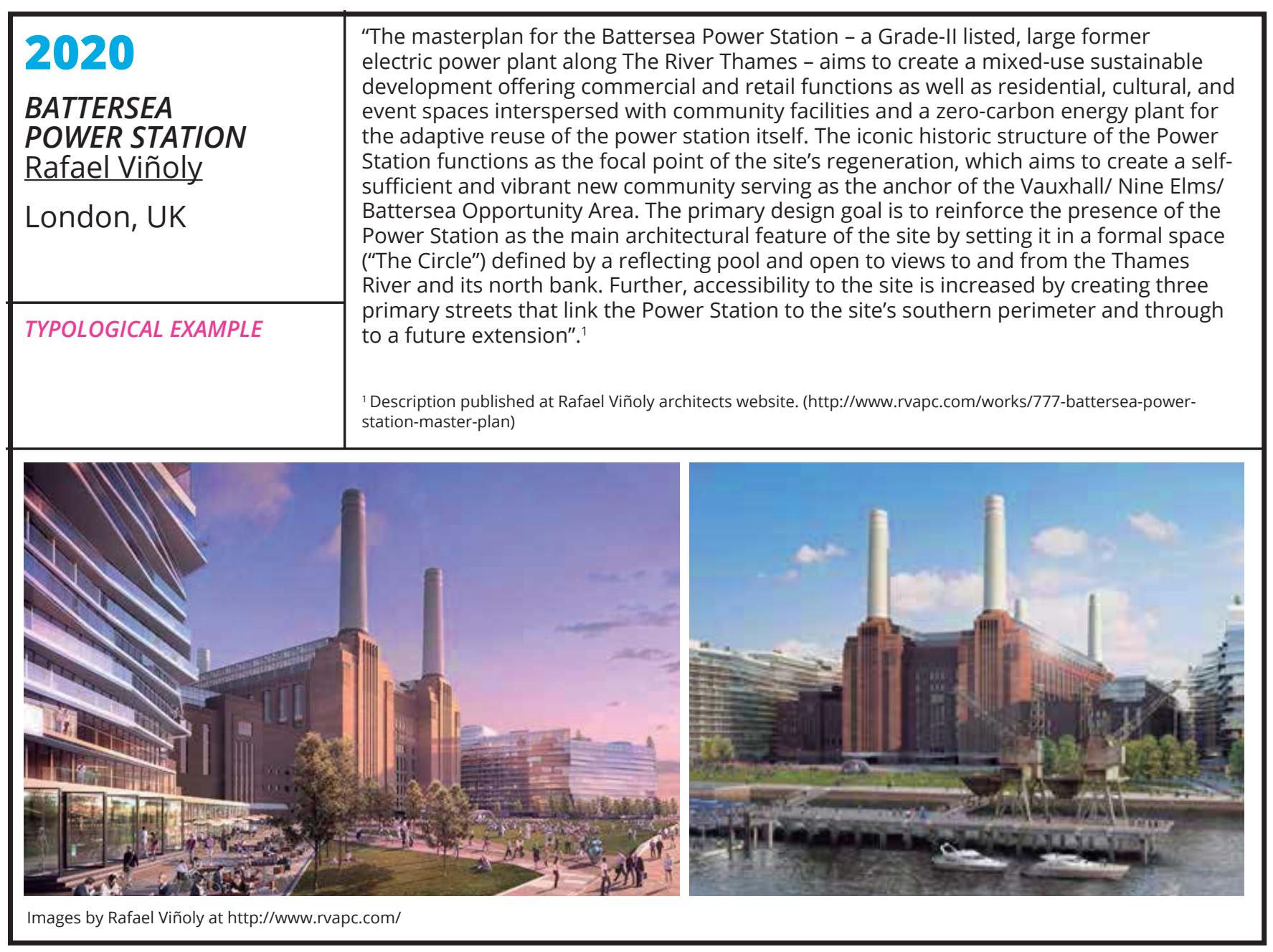




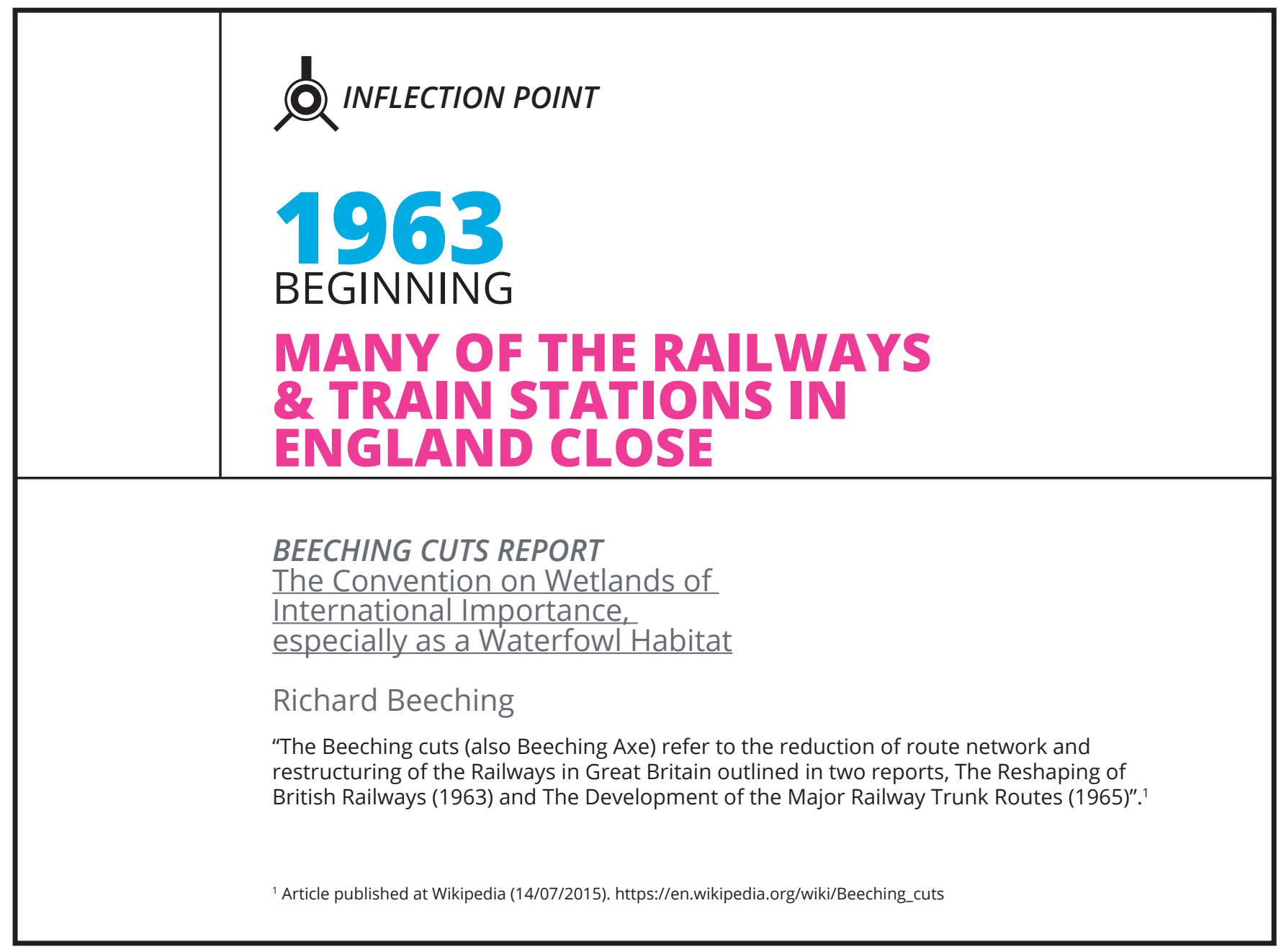

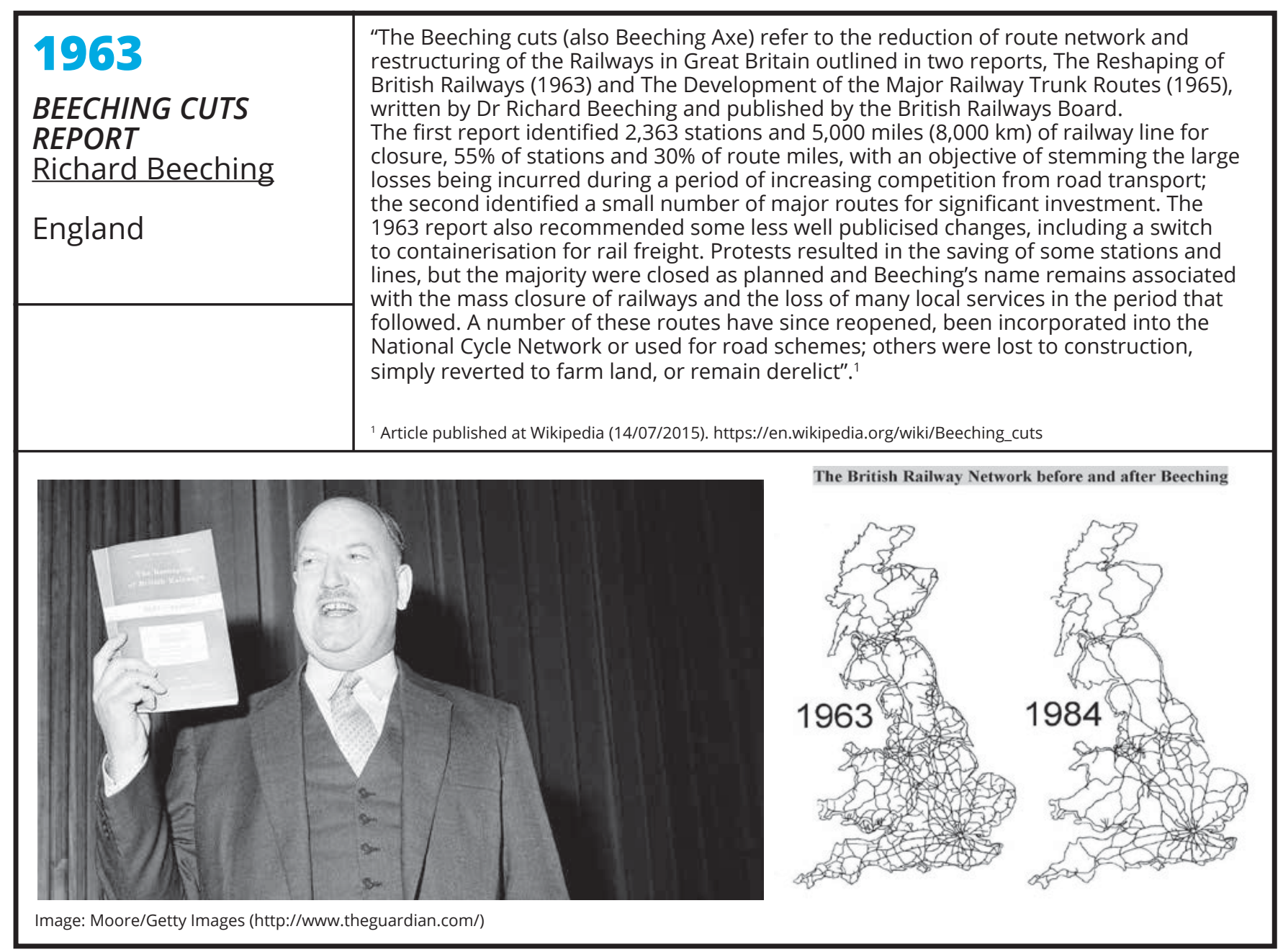




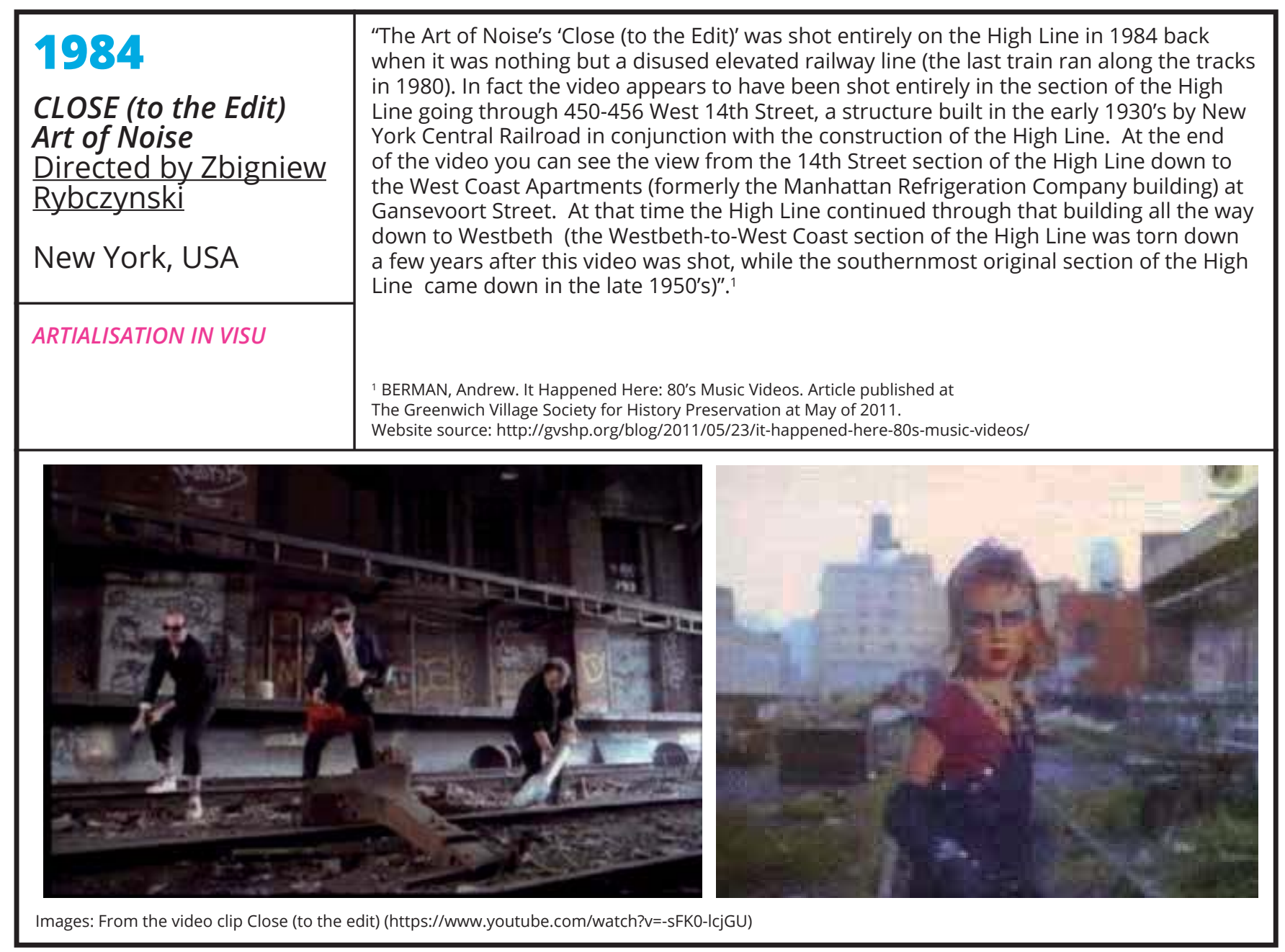

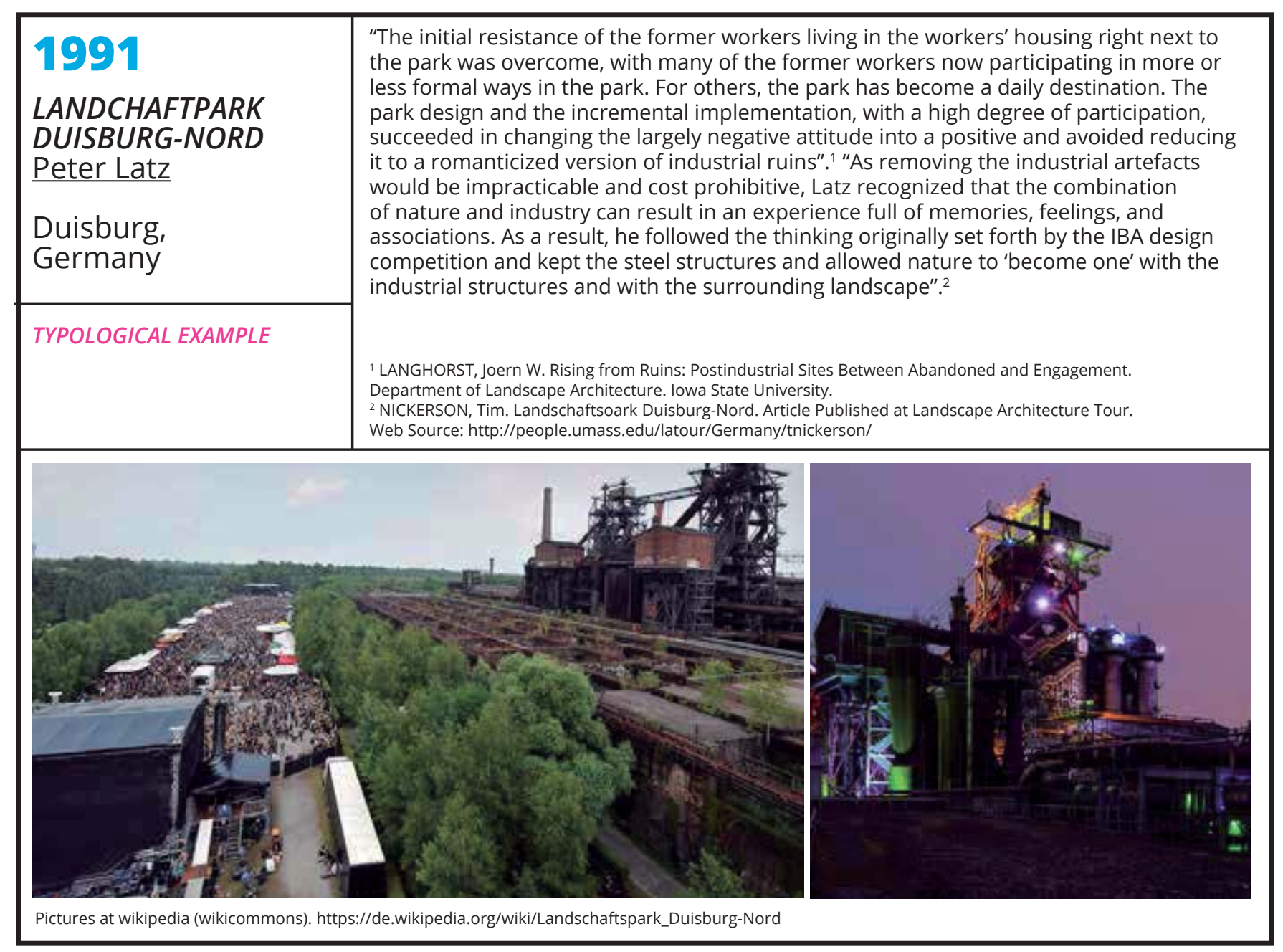




\begin{tabular}{|l|l|}
\hline 2000 & "Walking the High Line (2000-2001) examines landscape as an indicator of ecological and \\
social transformations from a new perspective. The High Line is an abandoned railroad \\
track in Manhattan, New York, a little over two kilometres long, which the photographer \\
describes as a motific contrast between apparently untouched nature and urban \\
development. While Sternfeld's earlier series visualize the colonization of nature by man, \\
the relationship is reverted here. Nature has reconquered an urban space, the only \\
sporadically visible rails hinting at the once busy traffic. In the case of Walking the High \\
Line, the socio-political dimension characteristic of all of Sternfeld's works has produced \\
concrete results: the disused track was transformed into a public park in 2009 not least \\
bHE HIGHLINE
\end{tabular}

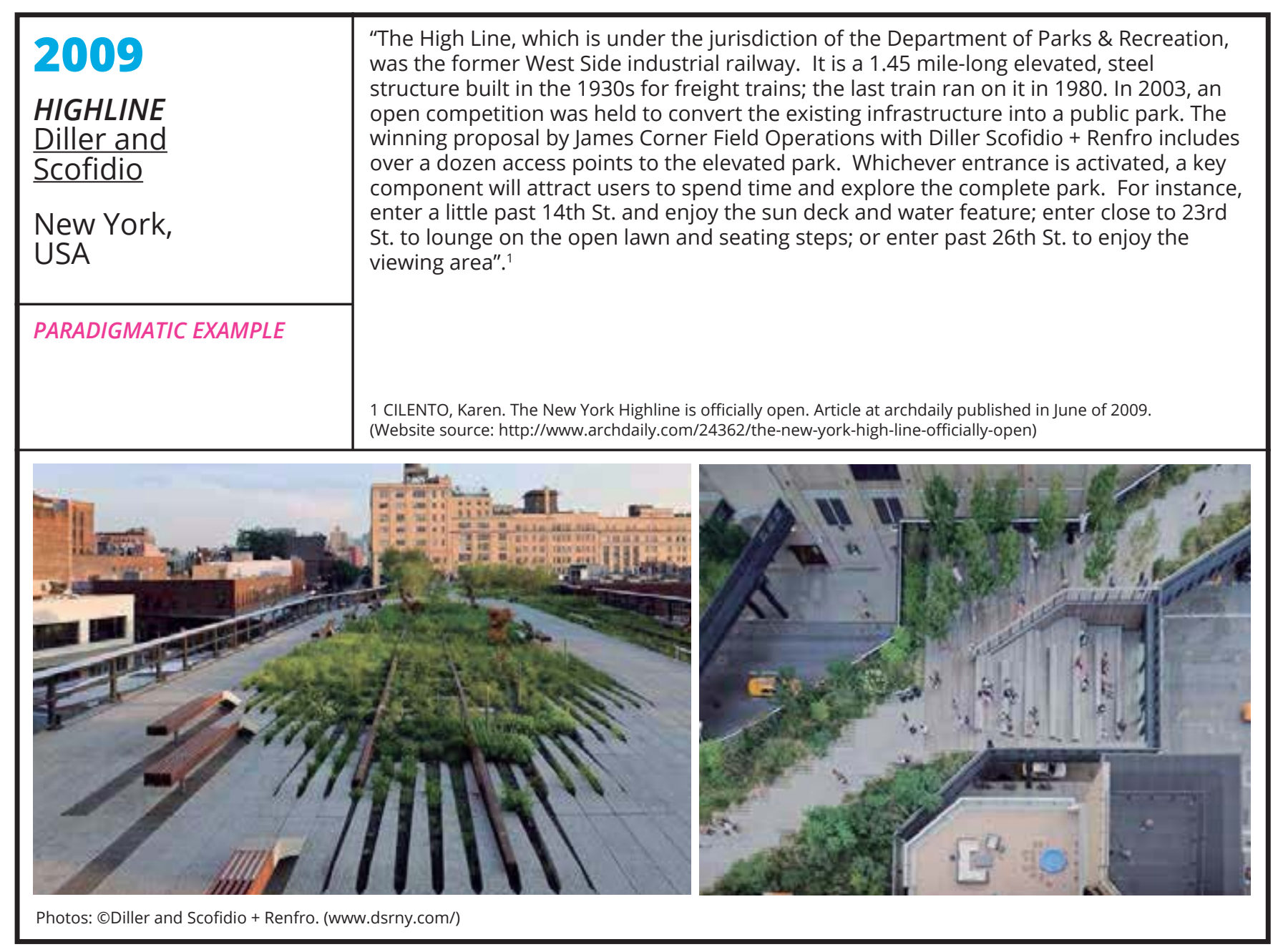




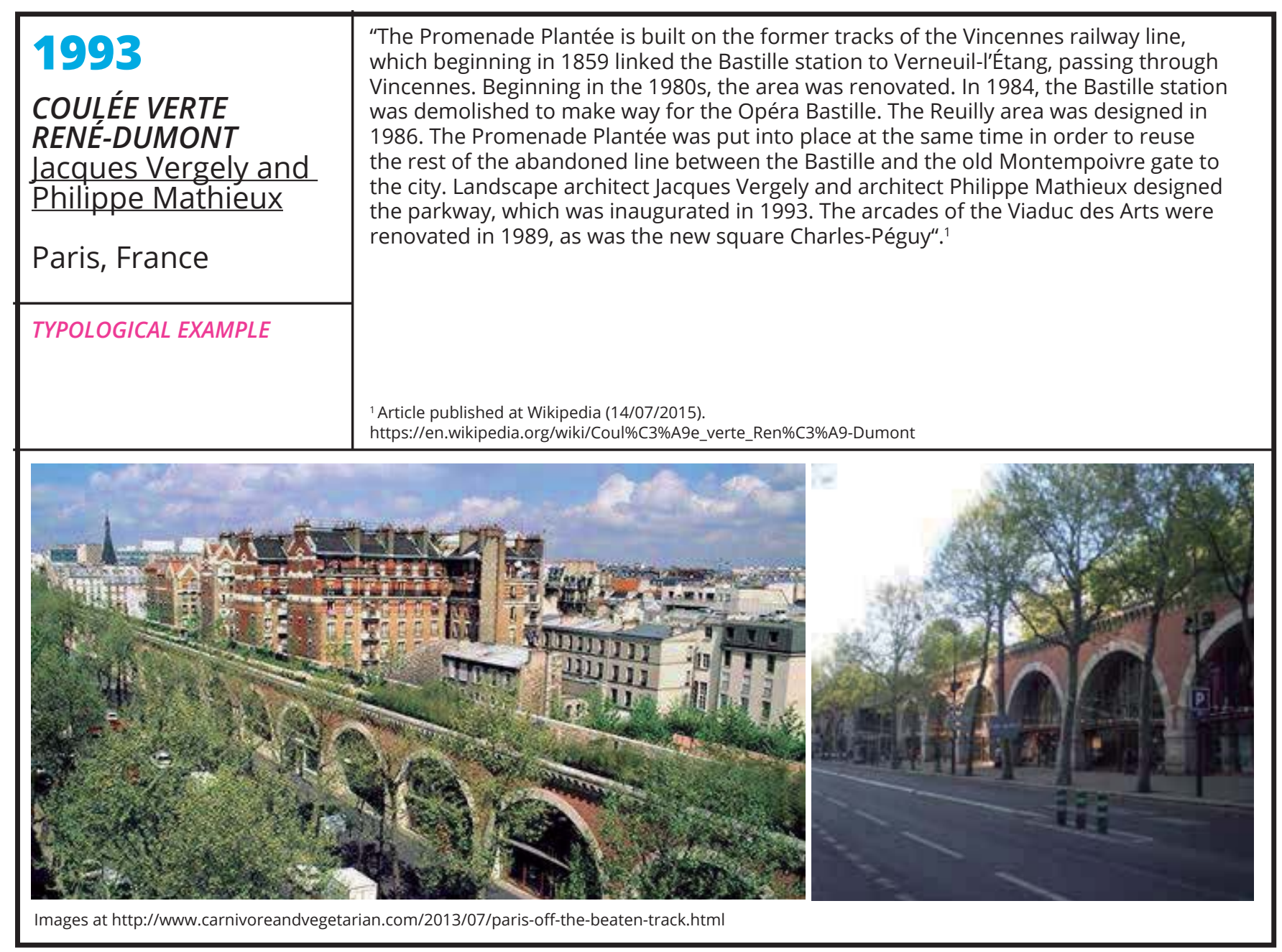


